\title{
Aplicação de catalisadores de Níquel e Cobalto preparados via precursores do tipo hidrotalcita nas Reações de Reforma a Vapor, Oxidação Parcial e Reforma Oxidativa do Metano.
}

\begin{abstract}
Tese apresentada ao Instituto de Química de São Carlos, da Universidade de São Paulo, para a obtenção do título de Doutor em Ciências - FísicoQuímica
\end{abstract}

Orientadora: Profa. Dra. Elisabete M. Assaf

São Carlos

2007 
Ao meu esposo Daniel, aos meus pais, Vivaldo e Ivani, e ao meu irmão Fábio. 


\section{Agradecimentos}

A Deus, que me deu meu bem maior, a vida.

À Profa. Dra. Elisabete M. Assaf, pela confiança depositada em mim, pela orientação no desenvolvimento deste trabalho e é claro, pela nossa amizade.

Ao meu querido Dani, que me acompanha por tantos anos e que sempre me dá forças e incentivo para continuar.

À minha família, principalmente meus queridos pais, meu irmãozinho e minha avó, pelo amor, carinho e incentivo durante toda a minha vida e também aos meus dois sobrinhos Gabriel e Léo, que me trazem muita alegria.

Ao Prof. Dr. Gregory Jerkiewicz por me acolher em seu laboratório e pela orientação com análises de XPS durante minha estadia na Queen's University.

Aos meus amigos de laboratório, Cecília, Luciene, Demetrius, Thaisa, Lidiane, Analine, Eurico (o mais animado do laboratório, acho que é o efeito do chocolate), o papai Jorge (o mago das vacâncias e também sempre aberto a uma boa conversa científica), Amanda, Ricardo, Camila e também ao pessoal que já passou por lá, mas que deixou muita saudade, Henrique, Letícia, Christofoletti, Marcelo, Boiadeiro e o papai Rudye.

Aos meus amigos do Canadá, Teresa, Jen Low, Bao Dong, Feng, Michael, Ed, Richard, Andrew e especialmente às minhas amigas, Aleks, que me acolheu tão bem em sua casa e a Maja que me ajudou muito durante toda minha estadia.

Aos técnicos do CAQI, das oficinas eletrônica, mecânica e da vidraria.

Aos colegas do LabCat da UFSCar pela amizade, em especial aos técnicos Rômulo e Espanhol pelo auxílio e realização das análises de RTP, ATG e BET e ao Prof. Dr. José Mansur Assaf pela orientação.

Às minhas grandes amigas, Cassandra (a mãe do Paulinho e do Pedrinho e que sempre arrumou um tempinho para cuidar de nós), Bibi, Bixona, Ari, Amandita, Rafinha, Amandinha e Maristela.

Aos meus amigos, Má, Ivan, Frank e em especial a três amigos que sempre me acompanharam nesta longa jornada de IQSC, Fabinho, Jackson e o paizão Bambi. 


\section{SUMÁRIO}

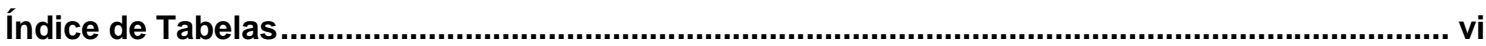

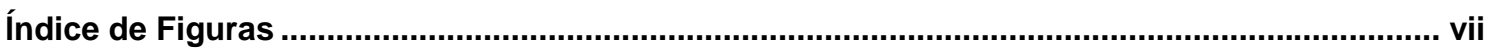

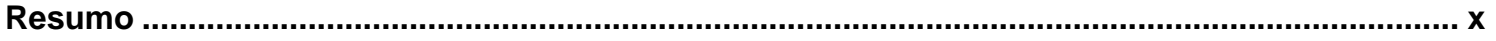

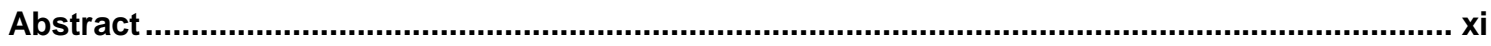

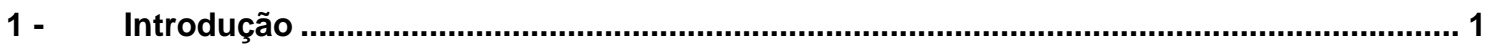

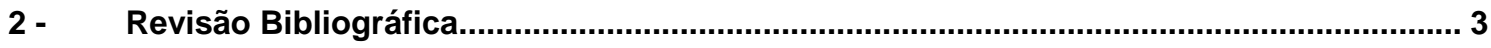

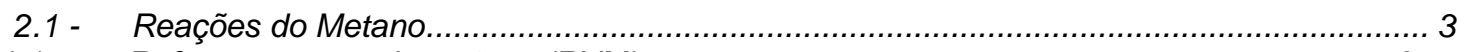

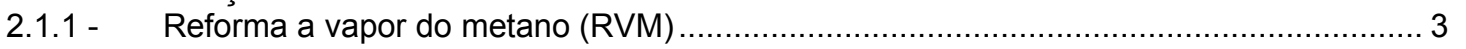

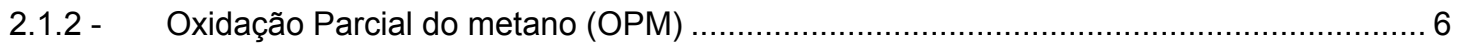

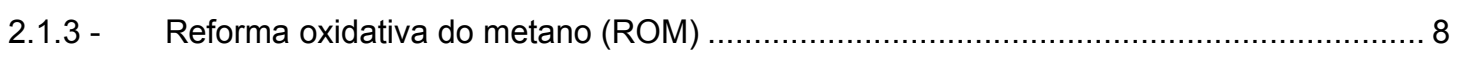

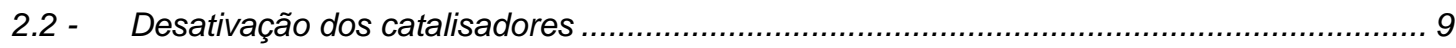

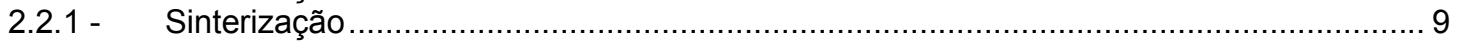

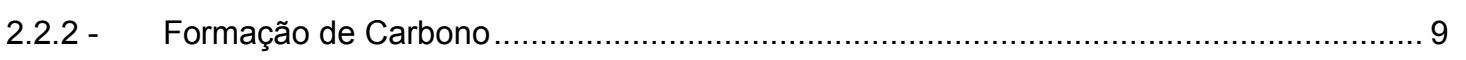

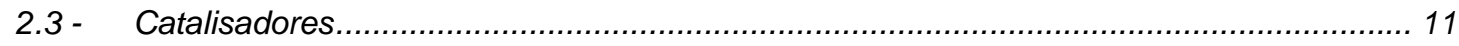

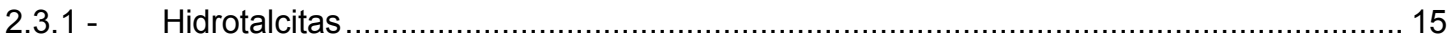

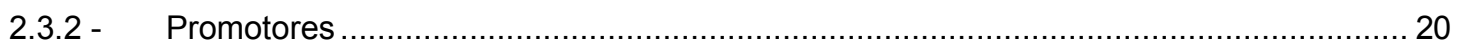

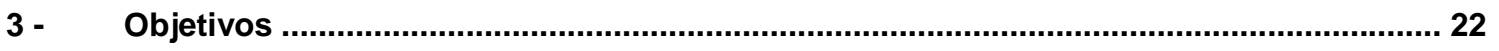

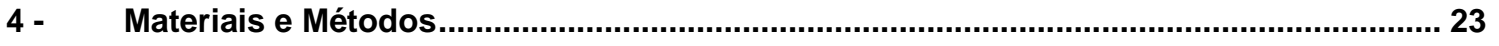

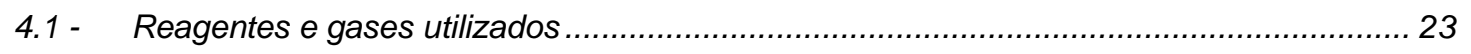

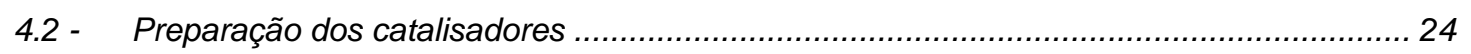

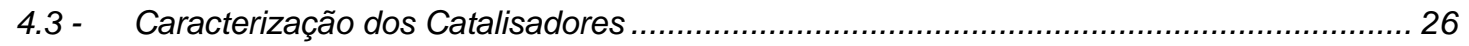

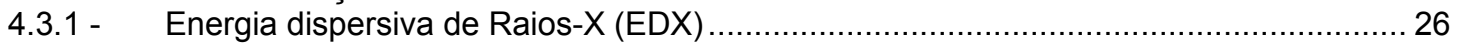

4.3.2 - Determinação da Área Superficial Específica Total, Raio Médio dos Poros e Volume Total dos Poros 26

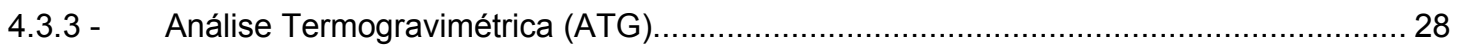

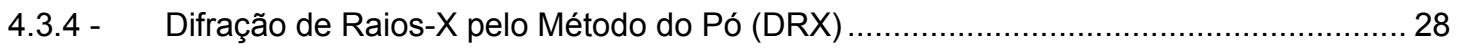

4.3.5 - Espectroscopia de Absorção na região do Infravermelho com transformada de Fourier (FTIR) $\quad 29$

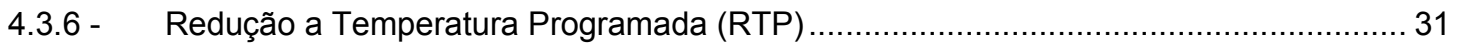

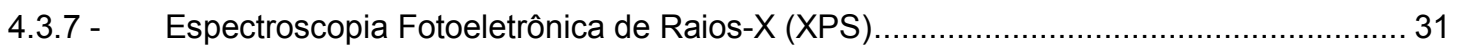

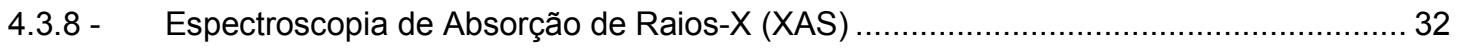

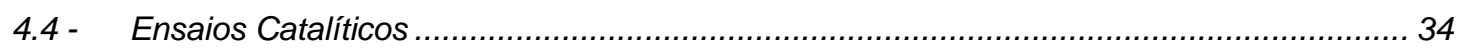




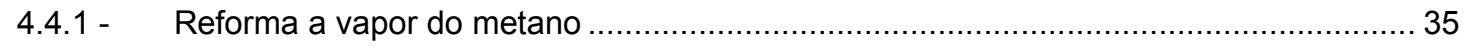

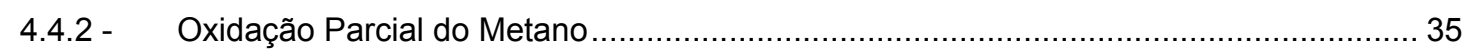

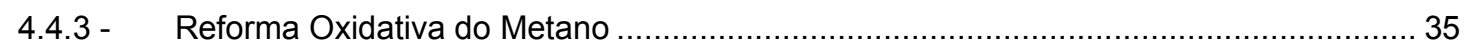

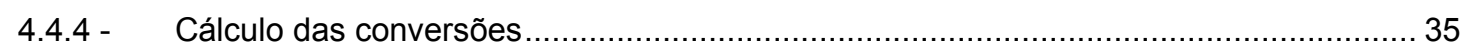

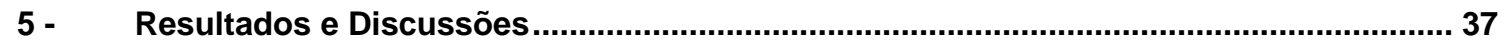

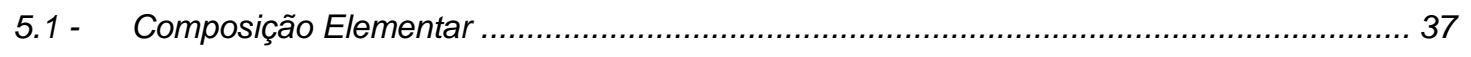

5.2 - Área Superficial Específica, Raio Médio e Volume Total de Poros ................................ 38

5.3 - Análise Termogravimétrica (ATG) ................................................................ 40

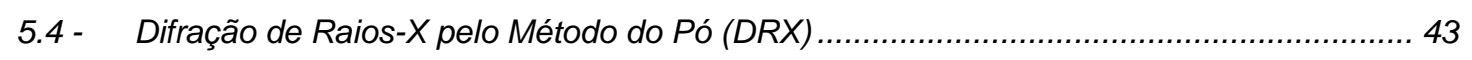

5.5 - Espectroscopia de infravermelho com Transformada de Fourier (FTIR).......................5 54

5.6 - Redução a temperatura programada (RTP).................................................. 58

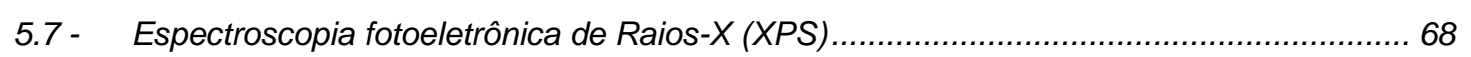

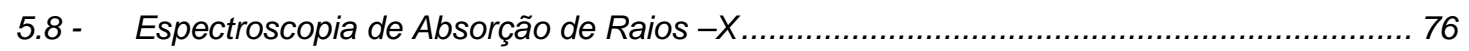

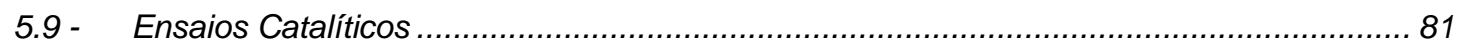

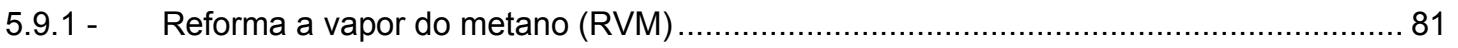

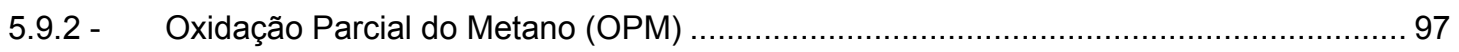

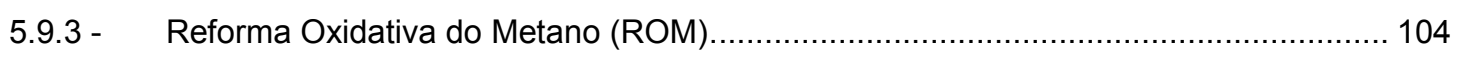

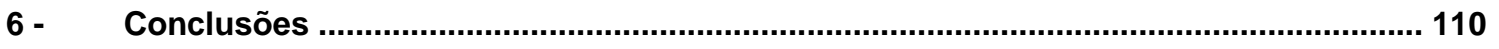

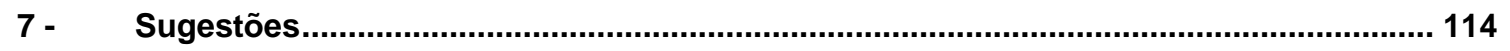

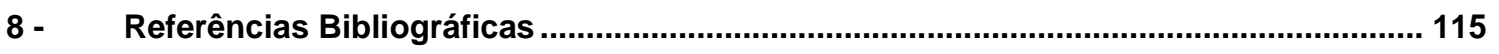

Apêndice A A.................................................................................................................. 121

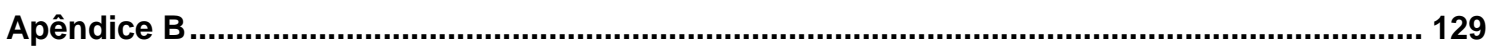




\section{Índice de Tabelas}

Tabela 1. Composição elementar na superfície obtida por análise de XPS e composição elementar do bulk obtida por EDX para as amostras de óxidos mistos de níquel. ..... 38

Tabela 2. Composição elementar na superfície obtida por análise de XPS e composição elementar do bulk obtida por EDX para as amostras de óxidos mistos de cobalto. ................................... 38

Tabela 3. Área Superficial Específica, Raio Médio e Volume Total de Poros para os catalisadores de níquel e cobalto.

Tabela 4. Parâmetros de rede a e $c$ dos precursores e tamanho de partícula calculado a partir da equação de Scherrer.

Tabela 5. Parâmetro de rede a (calculado com base nas distâncias do plano 220); tamanho de partícula calculado a partir da equação de Scherrer.

Tabela 6. Parâmetros de rede a (calculado com base nas distâncias do plano 110); c (calculado com base nas distâncias do plano (006)) dos precursores e tamanho de partícula calculado a partir da equação de Scherrer.

Tabela 7. Parâmetros de rede a (calculado com base nas distâncias do plano 220); tamanho de

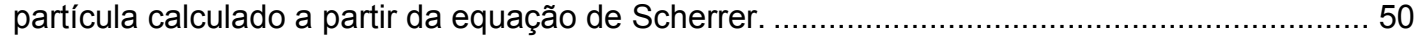

Tabela 8. Bandas de absorção dos precursores do tipo hidrotalcita de níquel. .............................56

Tabela 9. Bandas de absorção dos precursores do tipo hidrotalcita de cobalto..............................57

Tabela 10. Redutibilidade das amostras a $500^{\circ} \mathrm{C}(\%)$, tamanho de partícula $(\mathrm{nm})$ e parâmetro de rede a $(\mathrm{nm})$

Tabela 11. Resultados das energias de ligação (eV) obtidas na decomposição dos espectros do $\mathrm{Ni}_{2 p}$,

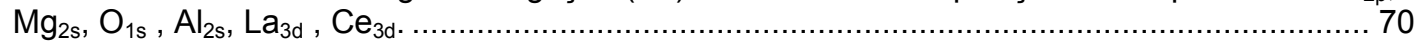

Tabela 12. Resultados das energias de ligação(eV) obtidas na decomposição dos espectros do $\mathrm{Co}_{2 p}$; magnitude do acoplamento spin-órbita $(\mathrm{eV})$.

Tabela 13. Resultados das energias de ligação (eV) para a decomposição dos espectros do $\mathrm{Mg}_{2 \mathrm{~s}}, \mathrm{O}_{1 \mathrm{~s}}$

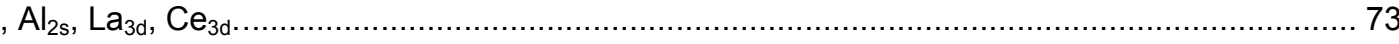

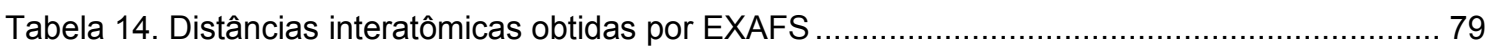

Tabela 15. Distâncias interatômicas obtidas por EXAFS ................................................... 81

Tabela 16. Valores médios de conversão do Metano (\%); mol produzido de $\mathrm{H}_{2} ; \mathrm{CO}$ e $\mathrm{CO}_{2} ; \mathrm{H}_{2}$ estequiométrico; Velocidade de formação de carbono $\left(\mathrm{mmolmin}^{-1}\right)$.

Tabela 17. Valores médios de conversão do Metano (\%); mol produzido de $\mathrm{H}_{2} ; \mathrm{CO}$ e $\mathrm{CO}_{2} ; \mathrm{H}_{2}$ estequiométrico; Velocidade de formação de carbono $\left(\mathrm{mmolmin}^{-1}\right)$.

Tabela 18. Valores médios de conversão do Metano (\%); mol produzido de $\mathrm{H}_{2} ; \mathrm{CO}$ e $\mathrm{CO}_{2} ; \mathrm{H}_{2}$ estequiométrico; Velocidade de formação de carbono ( $\left.\mathrm{mmolmin}^{-1}\right)$.

Tabela 19. Valores médios de conversão do Metano (\%); mol produzido de $\mathrm{H}_{2} ; \mathrm{CO}$ e $\mathrm{CO}_{2} ; \mathrm{H}_{2}$ estequiométrico; Velocidade de formação de carbono $\left(\mathrm{mmolmin}^{-1}\right)$.

Tabela 20. Valores médios de conversão do Metano (\%); mol produzido de $\mathrm{H}_{2} ; \mathrm{CO}$ e $\mathrm{CO}_{2} ; \mathrm{H}_{2}$ estequiométrico; Velocidade de formação de carbono $\left(\mathrm{mmolmin}^{-1}\right)$. 


\section{Índice de Figuras}

Figura 1. Estrutura de (a) Brucita $\mathrm{Mg}(\mathrm{OH})_{2}$, os cátions $\mathrm{Mg}^{+2}$ ocupam os centros dos octaedros, que compartilham arestas, cujos vértices são ocupados por ânions hidroxilas e (b) material do tipo hidrotalcita onde os centros dos octaedros são ocupados por cátions di e trivalentes, os vértices são ocupados por ânions hidroxilas e entre as camadas estão localizados os ânions

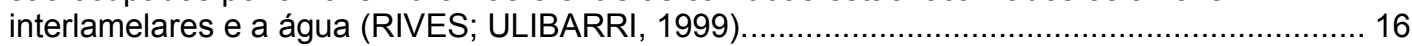

Figura 2. Perfis de ATG e DTG para os precursores de níquel e cobalto. ........................................ 42

Figura 3. Perfis de ATG/DTG para os precursores de níquel e cobalto promovidos com lantânio ou cério.

Figura 4. Difratogramas de Raios- $X$ dos precursores dos catalisadores preparados por diferentes métodos e promovidos $\left(\mathrm{H}=\right.$ hidrotalcita; $\left.{ }^{*}=\mathrm{Ce}(\mathrm{OH})_{3}\right)$.

Figura 5. Difratogramas de Raios-X: precursor preparado pelo método tradicional, Tr-Ni-LDH e da mistura de óxidos obtida por calcinação, Tr-Ni-Calc. (H=hidrotalcita; *=MgO e/ou NiO;

- $=\mathrm{MgAl}_{2} \mathrm{O}_{4}$ ou $\mathrm{NiAl}_{2} \mathrm{O}_{4}$ )....

Figura 6. Difratogramas de Raios-X: precursor preparado pelo método da co-precipitação, Cp-Ni-LDH e da mistura de óxidos obtida por calcinação, $\mathrm{Cp}-\mathrm{Ni}-\mathrm{Calc} .(\mathrm{H}=$ hidrotalcita; * $=\mathrm{MgO}$ e/ou NiO; - $=\mathrm{MgAl}_{2} \mathrm{O}_{4}$ ou $\mathrm{NiAl}_{2} \mathrm{O}_{4}$ ).

Figura 7. Difratogramas de Raios-X: precursor preparado pelo método da troca-aniônica, Ae-Ni-LDH e da mistura de óxidos obtida por calcinação, Ae-Ni-Calc. $\left(\mathrm{H}=\right.$ hidrotalcita; ${ }^{*}=\mathrm{MgO}$ e/ou NiO; - $=\mathrm{MgAl}_{2} \mathrm{O}_{4}$ ou $\mathrm{NiAl}_{2} \mathrm{O}_{4}$ ).

Figura 8. Difratogramas de Raios-X: precursor promovido com lantânio, Ae-La-Ni-LDH e da mistura de óxidos obtida por calcinação, Ae-La-Ni-Calc. (H=hidrotalcita; * $=\mathrm{MgO}$ e/ou NiO; $\bullet=\mathrm{MgAl}_{2} \mathrm{O}_{4}$ ou $\mathrm{NiAl}_{2} \mathrm{O}_{4}$ ).

Figura 9. Difratogramas de Raios-X: precursor promovido com cério, Ae-Ce-Ni-LDH e da mistura de óxidos obtida por calcinação, Ae-Ce-Ni-Calc. ( $\mathrm{H}=$ hidrotalcita; ${ }^{*}=\mathrm{MgO}$ ou $\mathrm{NiO} ; \bullet=\mathrm{MgAl}_{2} \mathrm{O}_{4}$ ou $\mathrm{NiAl}_{2} \mathrm{O}_{4} ; \mathrm{o}: \mathrm{CeO}_{2}$ )

Figura 10. Difratogramas de Raios- $X$ dos precursores dos catalisadores preparados por diferentes métodos e promovidos $\left(\mathrm{H}=\right.$ hidrotalcita; $\left.{ }^{*}=\mathrm{Ce}(\mathrm{OH})_{3}\right)$.

Figura 11. Difratogramas de Raios-X: precursor preparado pelo método tradicional, Tr-Co-LDH e da mistura de óxidos obtida por calcinação, Tr-Co-Calc. ${ }^{*}=\mathrm{MgO}, \mathrm{CoO} ; \bullet=\mathrm{Co}_{3} \mathrm{O}_{4}$ e/ou $\mathrm{MgAl}_{2} \mathrm{O}_{4}$ e/ou $\mathrm{Co}_{2} \mathrm{AlO}_{4}$ e/ou $\mathrm{CoAl}_{2} \mathrm{O}_{4}$ e/ou $\mathrm{MgCo}_{2} \mathrm{O}_{4}$ ).........

Figura 12. Difratogramas de Raios-X: precursor preparado pelo método da co-precipitação, $\mathrm{Cp}$-Co$\mathrm{LDH}$ e da mistura de óxidos obtida por calcinação, $\mathrm{Cp}$-Co-Calc. $\left({ }^{*}=\mathrm{MgO}, \mathrm{CoO} ; \bullet=\mathrm{Co}_{3} \mathrm{O}_{4}\right.$ e/ou $\mathrm{MgAl}_{2} \mathrm{O}_{4}$ e/ou $\mathrm{Co}_{2} \mathrm{AlO}_{4}$ e/ou $\mathrm{CoAl}_{2} \mathrm{O}_{4}$ e/ou $\mathrm{MgCo}_{2} \mathrm{O}_{4}$ )....

Figura 13. Difratogramas de Raios-X: precursor preparado pelo método da troca-aniônica, Ae-Co-LDH e da mistura de óxidos obtida por calcinação, Ae-Co-Calc. $\left({ }^{*}=\mathrm{MgO}, \mathrm{CoO} ; \bullet=\mathrm{Co}_{3} \mathrm{O}_{4}\right.$ e/ou $\mathrm{MgAl}_{2} \mathrm{O}_{4}$ e/ou $\mathrm{Co}_{2} \mathrm{AlO}_{4}$ e/ou $\mathrm{CoAl}_{2} \mathrm{O}_{4}$ e/ou $\mathrm{MgCo}_{2} \mathrm{O}_{4}$ ).....

Figura 14. Difratogramas de Raios-X: precursor promovido com lantânio, Ae-La-Co-LDH e da mistura de óxidos obtida por calcinação, Ae-La-Co-Calc. ${ }^{*}=\mathrm{MgO}, \mathrm{CoO} ; \bullet=\mathrm{Co}_{3} \mathrm{O}_{4}$ e/ou $\mathrm{MgAl}_{2} \mathrm{O}_{4}$ e/ou $\mathrm{Co}_{2} \mathrm{AlO}_{4}$ e/ou $\mathrm{CoAl}_{2} \mathrm{O}_{4}$ e/ou $\mathrm{MgCO}_{2} \mathrm{O}_{4}$ )......

Figura 15. Difratogramas de Raios-X : precursor promovido com cério, Ae-Ce-Co-LDH e da mistura de óxidos obtida por calcinação, Ae-Ce-Co-Calc. ( ${ }^{*}=\mathrm{MgO}, \mathrm{CoO} ; \bullet \cdot \mathrm{Co}_{3} \mathrm{O}_{4}$ e/ou $\mathrm{MgAl}_{2} \mathrm{O}_{4}$ e/ou $\mathrm{Co}_{2} \mathrm{AlO}_{4}$ e/ou $\mathrm{CoAl}_{2} \mathrm{O}_{4}$ e/ou $\mathrm{MgCo}_{2} \mathrm{O}_{4} ; \mathrm{o}=\mathrm{CeO}_{3}$ ).

Figura 16. Espectro de infravermelho para as hidrotalcitas precursoras de níquel. ........................... 54

Figura 17. Espectro de infravermelho para as hidrotalcitas precursoras de cobalto. .......................... 55

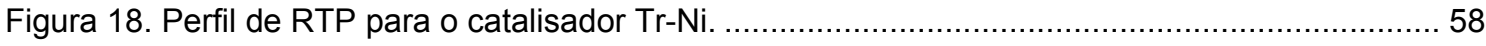

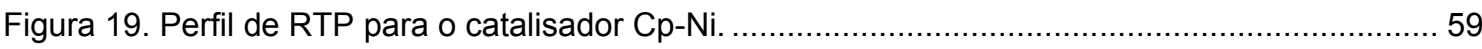


Figura 20. Perfil de RTP para o catalisador Ae-Ni. ....................................................... 59

Figura 21. Perfil de RTP para o catalisador Ae-La-Ni. ....................................................... 61

Figura 22. Perfil de RTP para o catalisador Ae-Ce-Ni................................................... 61

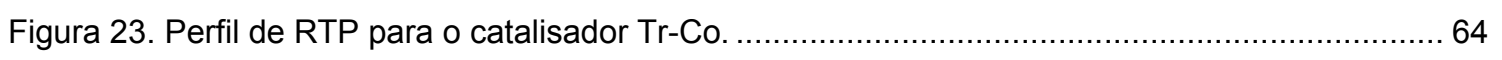

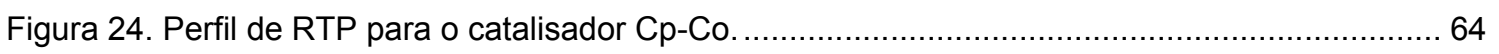

Figura 25. Perfil de RTP para o catalisador Ae-Co. ...................................................... 65

Figura 26. Perfil de RTP para o catalisador Ae-La-Co. ......................................................... 66

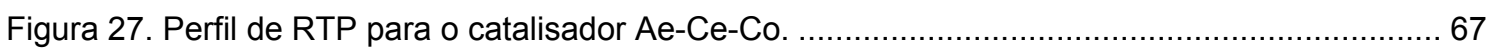

Figura 28. Espectros de XPS na região $\mathrm{Ni}_{2 p}$ das amostras óxidas. ....................................... 71

Figura 29. Espectros de XPS na região $\mathrm{Mg}_{2 \mathrm{~s}}$ das amostras óxidas. ...................................... 71

Figura 30. Espectros de XPS na região $\mathrm{O}_{1 \mathrm{~s}}$ das amostras óxidas. ..................................... 72

Figura 31. Espectros de XPS na região Co2p das amostras óxidas....................................... 74

Figura 32. Espectros de XPS na região Mg 2s das amostras óxidas....................................... 74

Figura 33. Espectros de XPS na região O1s das amostras óxidas......................................... 75

Figura 34. Espectros de XANES normalizados dos padrões e dos catalisadores de níquel. ............ 77

Figura 35. Magnitude da Transformada de Fourier do sinal de EXAFS da borda K do níquel para o

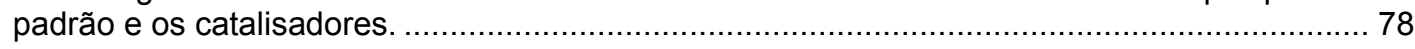

Figura 36. Espectros de XANES normalizados dos padrões e dos catalisadores.......................... 80

Figura 37. Magnitude da Transformada de Fourier do sinal de EXAFS da borda K do cobalto para o

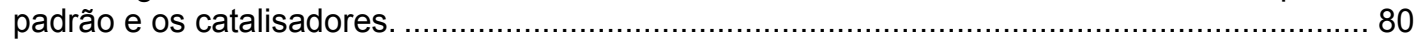

Figura 38. Conversão do Metano e Rendimento em Produtos para os catalisadores de níquel nãopromovidos na RVM com razão de alimentação $\mathrm{H}_{2} \mathrm{O}: \mathrm{CH}_{4}=4: 1$.

Figura 39. Conversão do Metano e Rendimento em Produtos para os catalisadores de níquel promovidos com Lantânio ou Cério na RVM com razão de alimentação $\mathrm{H}_{2} \mathrm{O}: \mathrm{CH}_{4}=4: 1$. ......... 84

Figura 40. Difratogramas de Raios-X do catalisador $\mathrm{Cp}$-Co após tratamento térmico e após a imediata desativação na RVM $\left(\left(^{*}=\mathrm{MgO}, \mathrm{CoO} ; \bullet=\mathrm{Co}_{3} \mathrm{O}_{4}\right.\right.$ e/ou $\mathrm{MgAl}_{2} \mathrm{O}_{4}$ e/ou $\mathrm{Co}_{2} \mathrm{AlO}_{4}$ e/ou $\mathrm{CoAl}_{2} \mathrm{O}_{4}$ e/ou $\left.\mathrm{MgCO}_{2} \mathrm{O}_{4}\right)$......

Figura 41. Conversão do Metano e Rendimento em Produtos para os catalisadores de níquel nãopromovidos na RVM com razão de alimentação $\mathrm{H}_{2} \mathrm{O}: \mathrm{CH}_{4}=2: 1$.

Figura 42. Conversão do Metano e Rendimento em Produtos para os catalisadores de níquel promovidos com Lantânio ou cério na RVM com razão de alimentação $\mathrm{H}_{2} \mathrm{O}: \mathrm{CH}_{4}=2: 1$.

Figura 43. Conversão do Metano e Rendimento em Produtos para os catalisadores de cobalto nãopromovidos na RVM com razão de alimentação $\mathrm{H}_{2} \mathrm{O}: \mathrm{CH}_{4}=2: 1$.

Figura 44. Conversão do Metano e Rendimento em Produtos para os catalisadores de cobalto promovidos com Lantânio ou cério na RVM com razão de alimentação $\mathrm{H}_{2} \mathrm{O}: \mathrm{CH}_{4}=2: 1$.

Figura 45. Conversão do Metano e Rendimento em Produtos para os catalisadores de níquel nãopromovidos na RVM com razão de alimentação $\mathrm{H}_{2} \mathrm{O}: \mathrm{CH}_{4}=0,5: 1$.

Figura 46. Conversão do Metano e Rendimento dos Produtos para os catalisadores de níquel promovidos na RVM com razão de alimentação $\mathrm{H}_{2} \mathrm{O}: \mathrm{CH}_{4}=0,5: 1$.

Figura 47. Conversão do Metano e Rendimento em Produtos para os catalisadores de cobalto nãopromovidos na RVM com razão de alimentação $\mathrm{H}_{2} \mathrm{O}: \mathrm{CH}_{4}=0,5: 1$.

Figura 48. Conversão do Metano e Rendimento em Produtos para os catalisadores de cobalto promovidos na RVM com razão de alimentação $\mathrm{H}_{2} \mathrm{O}: \mathrm{CH}_{4}=0,5: 1$.

Figura 49. Conversão do Metano e Rendimento em Produtos para os catalisadores de níquel nãopromovidos na OPM com razão de alimentação $\mathrm{CH}_{4}: \mathrm{O}_{2}=4: 1$ 
Figura 50. Conversão do Metano e Rendimento em Produtos para os catalisadores de níquel promovidos na OPM com razão de alimentação $\mathrm{CH}_{4}: \mathrm{O}_{2}=4: 1$

Figura 51. Difratograma de Raios-X do catalisador Ae-La-Ni na forma de precursor, óxido misto e após 6 horas de OPM ( $\mathrm{H}=$ hidrotalcita; $\mathrm{O}=\mathrm{NiO}$ e/ou $\mathrm{MgO} ;{ }^{*}=\mathrm{Ni}^{0} ; \mathrm{C}=$ grafite $)$.

Figura 52. Conversão do Metano e Rendimento em Produtos para os catalisadores de cobalto nãopromovidos na OPM com razão de alimentação $\mathrm{CH}_{4}: \mathrm{O}_{2}=4: 1$ 103

Figura 53. Conversão do Metano e Rendimento em Produtos para os catalisadores de cobalto promovidos na OPM com razão de alimentação $\mathrm{CH}_{4}: \mathrm{O}_{2}=4: 1$

Figura 54. Conversão do Metano e Rendimento em Produtos para os catalisadores de níquel nãopromovidos na ROM com razão de alimentação $\mathrm{CH}_{4}: \mathrm{H}_{2} \mathrm{O}: \mathrm{O}_{2}=4: 4: 1 \ldots$ 105

Figura 55. Conversão do Metano e Rendimento em Produtos para os catalisadores de níquel promovidos na $\mathrm{ROM}$ com razão de alimentação $\mathrm{CH}_{4}: \mathrm{H}_{2} \mathrm{O}: \mathrm{O}_{2}=4: 4: 1$

Figura 56. Conversão do Metano e Rendimento em Produtos para os catalisadores de cobalto nãopromovidos na ROM com razão de alimentação $\mathrm{CH}_{4}: \mathrm{H}_{2} \mathrm{O}: \mathrm{O}_{2}=4: 4: 1$.

Figura 57. Conversão do Metano e Rendimento em Produtos para os catalisadores de cobalto promovidos na $\mathrm{ROM}$ com razão de alimentação $\mathrm{CH}_{4}: \mathrm{H}_{2} \mathrm{O}: \mathrm{O}_{2}=4: 4: 1$. 


\section{Resumo}

Uma das principais aplicações do metano é a produção de gás de síntese, mistura de hidrogênio e monóxido de carbono. Três processos podem levar à formação de gás de síntese a partir do metano: reforma a vapor, reforma com $\mathrm{CO}_{2} \mathrm{e}$ oxidação parcial. Vários catalisadores de metais não-preciosos foram estudados para os processos de reforma, embora a deposição de carbono ou a sinterização do metal sempre esteja presente. Catalisadores obtidos de precursores do tipo hidrotalcita têm se mostrado resistentes à coqueificação nas reações de reforma a vapor do metano, podendo ser aplicados ao processo combinado de reforma e oxidação parcial de metano para obtenção de gás de síntese, com potencial para minimizar as dificuldades inerentes aos processos: altas temperaturas e desativação do catalisador.

Catalisadores de níquel e de cobalto, obtidos a partir de precursores do tipo hidrotalcita, com a adição de cério e de lantânio como promotores, foram preparados, caracterizados e aplicados em testes catalíticos nas reações de reforma a vapor, oxidação parcial e reforma oxidativa do metano, com o intuito de avaliar a atividade e estabilidade destes catalisadores e o efeito dos promotores.

Os catalisadores não-promovidos foram obtidos por três métodos: método tradicional, método da co-precipitação com quelato, e troca-ânionica. A adição de promotores foi feita por troca-aniônica.

Os compostos foram caracterizados por Energia dispersiva de Raios-X, Área Superficial Específica Total, Análise Termogravimétrica, Difração de Raios-X, Espectroscopia de Absorção na região do Infravermelho, Redução a Temperatura Programada, Espectroscopia Fotoeletrônica de Raios-X, Espectroscopia de Absorção de Raios-X e testes catalíticos com as reações de Reforma a vapor do metano, com razões molares de alimentação $\mathrm{H}_{2} \mathrm{O}: \mathrm{CH}_{4}=4: 1 ; 2: 1$ e 0,5:1, Oxidação Parcial do metano com razões molares de alimentação $\mathrm{CH}_{4}: \mathrm{O}_{2}=2: 1$ e 4:1 e Reforma oxidativa do metano com razão molar de alimentação $\mathrm{CH}_{4}: \mathrm{H}_{2} \mathrm{O}: \mathrm{O}_{2}=4: 4: 1$.

Os catalisadores mostraram-se ativos nas reações de reforma a vapor do metano, com exceção dos catalisadores de cobalto que não foram ativos para a razão de alimentação $\mathrm{H}_{2} \mathrm{O}: \mathrm{CH}_{4}=4: 1$. A adição de promotores favoreceu a reação de deslocamento gás-água. Nas reações de oxidação parcial do metano, os catalisadores foram ativos para a razão de alimentação $\mathrm{CH}_{4}: \mathrm{O}_{2}=4: 1$, com considerável redução na velocidade de formação de carbono para os catalisadores promovidos. Na reforma oxidativa do metano, o acoplamento levou a um favorecimento na seletividade para formação de $\mathrm{CO}_{2}$ e a uma maior velocidade de formação de carbono. 


\begin{abstract}
One of the most important applications of methane is the syngas production, a mixture of $\mathrm{H}_{2}$ and $\mathrm{CO}$. Three processes can lead to syngas formation from methane: steam reforming, $\mathrm{CO}_{2}$ reforming and partial oxidation. Various non-noble metal catalysts were studied in these processes, although the carbon deposition or the metal sinterization is always observed. Catalysts prepared from hydrotalcite precursors have presented resistance to carbon deposition, and considering this aspect they could be applied to the combined process of methane reforming with partial oxidation to produce syngas, with potential to minimize the difficulties of the process: high temperatures and catalyst deactivation.

In this work, nickel and cobalt catalysts, prepared from hydrotalcites and promoted with lanthanum and cerium, were prepared, characterized and tested in the reactions of steam reforming, partial oxidation and oxidative reforming of methane, with the goal of evaluating the activity and stability of these catalysts and the effect of promoter addition.

The un-promoted catalysts were prepared through three methods: the traditional method, the method of co-precipitation with chelate and the anion-exchange method. The promoter addition was made through the anion-exchange method.

The compounds were characterized by Energy Dispersive X-Ray Spectroscopy (EDX), Specific Surface Area, Thermo gravimetric Analysis, X-Ray Diffraction (XRD), Fourier Transformed Infrared Spectroscopy (FTIR), Temperature Programend Reduction (TPR), X-Ray Photoelectron Spectroscopy (XPS), X-Ray Absortion Spectroscopy (XAS) and catalytic tests using the folowing reactions of methane: steam reforming with molar ratio in feed of $\mathrm{H}_{2} \mathrm{O}: \mathrm{CH}_{4}=4: 1 ; 2: 1$ and $0,5: 1$, partial oxidation with molar ratio in feed of $\mathrm{CH}_{4}: \mathrm{O}_{2}=2: 1$ e $4: 1$ and oxidative reforming with molar ratio in feed of $\mathrm{CH}_{4}: \mathrm{H}_{2} \mathrm{O}: \mathrm{O}_{2}=4: 4: 1$.

All catalysts showed activity for methane steam reforming, except the cobalt catalysts, which did not present activity for the reaction with molar in feed of $\mathrm{H}_{2} \mathrm{O}: \mathrm{CH}_{4}=4: 1$. The promoters addition favored the shift reaction. For the partial oxidation reactions, the catalysts presented activity for molar ratio in feed of $\mathrm{CH}_{4}: \mathrm{O}_{2}=4: 1$, with pronounced reduction in the velocity of carbon formation for promoted catalysts. In the oxidative reforming, the coupling of the reactions lead to a favoring in the selectivity for $\mathrm{CO}_{2}$ but a higher velocity of carbon formation
\end{abstract}




\section{1 - Introdução}

Nos últimos anos a conversão de metano em produtos químicos de maior valor agregado e de maior aplicabilidade tem se tornado um dos mais importantes campos da catálise. Uma das principais aplicações do metano é a produção de gás de síntese, mistura de hidrogênio e monóxido de carbono. O gás de síntese é utilizado na fabricação de metanol, de amônia e também em processos de Fischer-Tropsch, para a produção de combustíveis líquidos, olefinas e compostos oxigenados (RUCKENSTEIN; HU, 1999). Três processos podem levar à formação de gás de síntese a partir do metano: reforma a vapor, reforma $\mathrm{com} \mathrm{CO}_{2}$ e oxidação parcial.

Segundo Ruckenstein e Hu (1997), a reforma a vapor, reação endotérmica, é o processo comercial dominante para geração de hidrogênio e de gás de síntese. Este processo apresenta baixa seletividade para $\mathrm{CO}$ e leva a uma alta razão $\mathrm{H}_{2}: \mathrm{CO}$ $(>4: 1)$. Na reforma a vapor, a razão $\mathrm{H}_{2} \mathrm{Ov} / \mathrm{C}$ na alimentação deve ficar entre 1,9 a 9,0, a fim de evitar a formação de coque, a qual destrói a estrutura do catalisador de níquel suportado, causando sua desativação (TWIGG, 1996).

A oxidação parcial do metano é uma reação com alta atividade, seletividade e velocidade, curto tempo de residência e conduz a uma relação $\mathrm{H}_{2}$ : $\mathrm{CO}$ próxima de 2:1, a qual é desejável para síntese de metanol e Fischer-Tropsch (razão requerida $=2,0)$. Esta reação é levemente exotérmica, porém um pequeno decréscimo na seletividade para $\mathrm{CO}$ pode levar à combustão completa do metano. Esta combustão é altamente exotérmica, resultando em grande aumento da temperatura de reação, o qual pode levar à formação de pontos quentes, com a conseqüente destruição do catalisador.

Estudos indicam que a combinação da reação de oxidação parcial com uma reação endotérmica (reforma a vapor ou com $\mathrm{CO}_{2}$ ) pode levar a uma solução deste 
problema, tendo em vista que a reação de reforma consumirá o calor gerado pela reação de oxidação parcial (RUCKENSTEIN et al., 1998).

Vários catalisadores foram estudados para os processos de reforma, embora a deposição de carbono ou a sinterização do metal sempre esteja presente. Em geral, catalisadores baseados em metais nobres podem ser utilizados com sucesso, originando baixa deposição de carbono, provavelmente devido à baixa solubilidade do carbono nos metais nobres (CHEN et al, 1996, 1999; WANG; RUCKENSTEIN, 2001). Entretanto, devido ao alto custo, é desejável empregá-los em baixas proporções ou substituí-los por metais não preciosos.

Assim, tendo em vista a necessidade de altas temperaturas e a indesejável desativação devido à formação de carbono que ocorrem nos processos de reforma a vapor, bem como as dificuldades para controlar a temperatura na reação de oxidação parcial do metano, é importante o contínuo estudo destas reações no sentido de desenvolver novos sistemas catalíticos, que apresentem alta atividade e estabilidade e metodologias reacionais que atinjam plenamente os objetivos e interesses do processo de obtenção de gás de síntese.

Catalisadores obtidos de precursores do tipo hidrotalcita têm se mostrado resistentes à coqueificação, podendo ser aplicados ao processo combinado de reforma e oxidação parcial de metano para obtenção de gás de síntese, com potencial para minimizar as dificuldades inerentes aos processos: altas temperaturas e desativação do catalisador.

Com base nestas considerações, o foco desta tese foi investigar o comportamento de catalisadores obtidos a partir de hidrotalcitas nas reações de conversão do metano. O restante desta tese apresenta em mais detalhes os objetivos e resultados deste trabalho. 


\section{2 - Revisão Bibliográfica}

A seguir será apresentada uma breve revisão sobre as reações do metano, reforma a vapor, oxidação parcial e reforma oxidativa do metano, bem como sobre a desativação dos catalisadores. Finalmente são apresentadas informações sobre catalisadores preparados via precursores do tipo hidrotalcita.

\section{1 - Reações do Metano}

\subsection{1 - Reforma a vapor do metano (RVM)}

A reforma a vapor do metano e de hidrocarbonetos leves é o principal processo para a produção de gás de síntese.

$\mathrm{O}$ gás de síntese, uma mistura de $\mathrm{H}_{2}$ e $\mathrm{CO}$, é amplamente utilizado como intermediário nas indústrias de processos químicos, tais como produção de amônia, metanol, olefinas, formaldeído, ácido acético e hidrogênio. Atualmente a capacidade diária de produção é de aproximadamente $120.000 .000 \mathrm{~m}^{3}$, uma energia equivalente a mais de 210.000 barris de petróleo por dia (SONG; GUO, 2005,14).

A reforma a vapor é uma reação química entre vapor de água e hidrocarbonetos para formar hidrogênio $\left(\mathrm{H}_{2}\right)$, monóxido $(\mathrm{CO})$ e dióxido de carbono $\left(\mathrm{CO}_{2}\right)$. O catalisador industrial normalmente utilizado é constituído de níquel suportado em material inerte, geralmente alumina, com ou sem adição de promotores (MALUF,2001).

As principais reações que ocorrem no processo são: conversão do metano em monóxido de carbono e hidrogênio (reação 1) e a reação de deslocamento ("shift") gás-água (reação 2). Em alguns casos $0 \mathrm{CO}_{2}$ pode substituir a $\mathrm{H}_{2} \mathrm{O}$ na reação e levar a uma diferente razão $\mathrm{H}_{2}: \mathrm{CO}$, via reforma seca do metano (reação 3). 


$$
\begin{aligned}
& \mathrm{CH}_{4}+\mathrm{H}_{2} \mathrm{O} \rightleftarrows \mathrm{CO}+3 \mathrm{H}_{2} \quad \Delta \mathrm{H}^{\circ}{ }_{298 \mathrm{~K}}=206 \mathrm{kJmol}^{-1} \\
& \Delta \mathrm{G}^{\circ}{ }_{298 \mathrm{~K}}=142 \mathrm{kJmol}^{-1} \\
& \mathrm{CO}+\mathrm{H}_{2} \mathrm{O} \rightleftarrows \mathrm{CO}_{2}+\mathrm{H}_{2} \quad \Delta \mathrm{H}^{\circ}{ }_{298 \mathrm{~K}}=-41,2 \mathrm{kJmol}^{-1} \\
& \Delta \mathrm{G}^{\circ}{ }_{298 \mathrm{~K}}=-28,5 \mathrm{kJmol}^{-1} \\
& \mathrm{CH}_{4}+\mathrm{CO}_{2} \rightleftarrows 2 \mathrm{CO}+2 \mathrm{H}_{2} \quad \Delta \mathrm{H}^{\circ}{ }_{298 \mathrm{~K}}=247,5 \mathrm{kJmol}-1 \\
& \Delta \mathrm{G}^{\circ}{ }_{298 \mathrm{~K}}=170,78 \mathrm{kJmol}^{-1}
\end{aligned}
$$

A reação 1, reação de reforma propriamente dita, é endotérmica, com expansão do número de moles, de modo que é favorecida por temperaturas elevadas $\left(700-800^{\circ} \mathrm{C}\right)$ e pressões reduzidas. Já a reação 2 é exotérmica e é favorecida por temperaturas mais baixas, porém as duas ocorrem simultaneamente no reator de reforma. A distribuição dos produtos é controlada pela termodinâmica, sendo a formação do $\mathrm{CH}_{4}$ favorecida em baixas temperaturas (abaixo de $650^{\circ} \mathrm{C}$ ) enquanto que a formação de $\mathrm{H}_{2}$ é favorecida em temperaturas da ordem de 700 $800^{\circ} \mathrm{C}$.

A necessidade de se operar em altas temperaturas leva a sérios problemas, como a estabilidade térmica do catalisador, favorecendo processos de sinterização do catalisador. Todavia, o maior problema consiste na desativação por formação de depósitos carbonáceos (TRIMM,1999).

O reator industrial é constituído por um feixe contendo de 30 a 40 tubos verticais, cada um medindo de 9 a $16 \mathrm{~cm}$ de diâmetro interno e de 6 a $12 \mathrm{~cm}$ de comprimento, recheados com catalisador e inseridos numa fornalha. A temperatura de alimentação está na faixa de $600^{\circ} \mathrm{C}$ e a pressão varia de 1,5 a $3,0 \mathrm{MPa}$. A temperatura de reação é estabelecida pelas limitações metalúrgicas dos tubos do reator (MALUF,2001).

Wei e Iglesia (2004 a;b) realizaram estudos sobre a cinética da reforma a

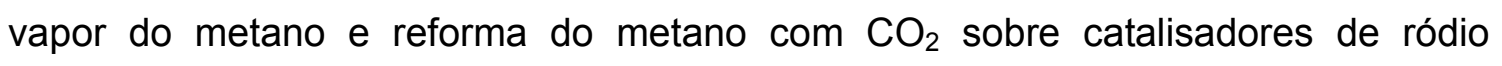
suportados em $\mathrm{Al}_{2} \mathrm{O}_{3}$ e $\mathrm{ZrO}_{2}$ e catalisadores de níquel suportados sobre $\mathrm{MgO}$, e 
encontraram resultados semelhantes para os catalisadores. Eles observaram que a velocidade de reação aumentava linearmente com o aumento da pressão parcial de metano na reação (5-450kPa), na faixa de temperatura de $823-1023 \mathrm{~K}$, todavia estas velocidades não foram influenciadas pelas pressões parciais de $\mathrm{H}_{2} \mathrm{O}$ ou $\mathrm{CO}_{2}$ (5450kPa). Também não foi observada influência devido às concentrações de CO ou $\mathrm{H}_{2}$. Assim, a etapa cineticamente relevante é a ativação inicial da ligação $\mathrm{C}-\mathrm{H}$ no $\mathrm{CH}_{4}$ catalisado por interações com a fase ativa. De acordo com seus resultados, Wei e Iglesia propuseram o mecanismo apresentado a seguir (reações 4 - 14) para as reações, onde as etapas de ativação da ligação C-H são seguidas pela remoção de $\mathrm{C}^{*}$ e de $\mathrm{H}^{*}$ via dessorção ou reação com $\mathrm{O}^{*}$ quimissorvido, derivado da $\mathrm{H}_{2} \mathrm{O}$ ou do $\mathrm{CO}_{2}$

De acordo com o mecanismo proposto por Wei e Iglesia (2004 a;b) o $\mathrm{CH}_{4}$ se decompõe em carbono quimissorvido $\left(C^{*}\right)$ via etapas seqüenciais de abstração de $H$, a qual se torna mais veloz à medida que átomos de $H$ são seqüencialmente removidos da molécula de $\mathrm{CH}_{4}$. Este processo leva a baixos recobrimentos de $\mathrm{CH}_{\mathrm{x}}{ }^{*}$ e $\mathrm{C}^{*}$ como o mais abundante intermediário reativo contendo carbono. O carbono quimissorvido é depois removido usando os co-reagentes $\mathrm{H}_{2} \mathrm{O}$ ou $\mathrm{CO}_{2}$.

Para o mecanismo são consideradas as seguintes notações:

$\rightarrow$ : etapa irreversível

1 : etapa de quase-equilíbrio

$\rightleftarrows$ : etapa reversível

$k_{i}$ : coeficiente de velocidade

$\mathrm{K}_{i}$ : constante de equilíbrio para a etapa $i$

* : sítio ativo 


$$
\begin{aligned}
& \mathrm{CH}_{4}+2^{*} \stackrel{k_{1}}{\rightarrow} \mathrm{CH}_{3}{ }^{*}+\mathrm{H}^{*} \\
& \mathrm{CH}_{3}{ }^{*}{ }^{*} \rightarrow \mathrm{CH}_{2}{ }^{*}+\mathrm{H}^{*} \\
& \mathrm{CH}_{2}{ }^{*} \rightarrow \mathrm{CH}^{*}+\mathrm{H}^{*} \\
& \mathrm{CH}^{*}+\mathrm{C}^{*}+\mathrm{H}^{*} \\
& \mathrm{CO}_{2}+2^{*} \quad \mathrm{CO}^{*}+\mathrm{O}^{*} \\
& \mathrm{C}^{*}+\mathrm{O}^{*} \\
& \mathrm{CO}^{*} \mathrm{CO}^{*}{ }^{*} \\
& \mathrm{H}^{*}+\mathrm{HO}^{*} \\
& \mathrm{H}^{*}+\mathrm{O}^{*} \mathrm{H}_{2}{ }^{*}{ }^{*} \\
& \mathrm{OH}^{*}+\mathrm{OH}^{*}{ }^{*} \\
& \mathrm{H}_{2} \mathrm{H}^{*} \mathrm{H}_{2} \mathrm{O}^{*}{ }^{*}
\end{aligned}
$$

\subsection{2 - Oxidação Parcial do metano (OPM)}

A oxidação parcial do metano (reação 15) é uma reação com alta atividade, seletividade e velocidade, curto tempo de residência e conduz a uma razão $\mathrm{H}_{2}: \mathrm{CO}=2: 1$. Esta reação é levemente exotérmica, porém um pequeno decréscimo na seletividade para $\mathrm{CO}$ pode levar à combustão completa do metano, reação altamente exotérmica, resultando num grande aumento da temperatura de reação, podendo chegar à formação de pontos quentes, com a conseqüente destruição do catalisador.

$$
\begin{array}{ll}
\mathrm{CH}_{4}+1 / 2 \mathrm{O}_{2} \rightarrow \mathrm{CO}+2 \mathrm{H}_{2} & \Delta \mathrm{H}^{0}{ }_{298 \mathrm{~K}}=-35,5 \mathrm{kJmol}^{-1} \\
& \Delta \mathrm{G}^{\circ}{ }_{298 \mathrm{~K}}=-86,5 \mathrm{kJmol}^{-1}
\end{array}
$$

Dois mecanismos de reação são propostos para a oxidação parcial do metano (RUCKENSTEIN; HU, 1999):

i) Combustão-reforma: onde ocorre a oxidação total do $\mathrm{CH}_{4}$ produzindo $\mathrm{H}_{2} \mathrm{O}$ e $\mathrm{CO}_{2}$ que vão reagir com $\mathrm{CH}_{4}$ por meio da reforma a vapor do metano (reação 1) e da 
reforma do metano $\mathrm{com} \mathrm{CO}_{2}$ (reação 3). Este mecanismo é favorecido em temperaturas acima de $850^{\circ} \mathrm{C}$.

$$
\begin{array}{ll}
\mathrm{CH}_{4}+2 \mathrm{O}_{2} \rightarrow \mathrm{CO}_{2}+2 \mathrm{H}_{2} \mathrm{O} & \Delta \mathrm{H}^{0}{ }_{298 \mathrm{~K}}=-801,7 \mathrm{kJmol}^{-1} \\
\Delta \mathrm{G}^{\circ}{ }_{298 \mathrm{~K}}=-801 \mathrm{kJmol}^{-1}
\end{array}
$$

ii) Pirólise: o carbono é oxidado a CO. A reação é favorecida em temperaturas abaixo de $800^{\circ} \mathrm{C}$.

$\mathrm{CH}_{4} \rightarrow \mathrm{C}+4 \mathrm{H}$

$\mathrm{C}+1 / 2 \mathrm{O}_{2} \rightarrow \mathrm{CO}$

Vários catalisadores têm se mostrado ativos para esta reação, entre eles catalisadores de metais nobres suportados, como $\mathrm{Rh}, \mathrm{Ru}, \mathrm{Pd}, \mathrm{Pt}$, catalisadores de níquel e cobalto suportados (WANG; RUCKENSTEIN, 2001).

De acordo com Zhang et al. (2005), o mecanismo das reações de oxidação pode ocorrer a partir das seguintes etapas:

i) Adsorção dissociativa do metano na superfície metálica (reações de 4 -7), ou a reação 19 , com as subseqüentes etapas de abstração de $H$.

$\mathrm{CH}_{4}+\mathrm{O}^{*} \rightarrow \mathrm{CH}_{3}{ }^{*}+\mathrm{OH}^{*}$

ii) Adsorção dissociativa do metano na superfície óxida

$\mathrm{CH}_{4}+2 \mathrm{O}^{*} \rightarrow \mathrm{O}^{*} \mathrm{CH}_{3}+\mathrm{OH}^{*}$

$O^{*}=$ nesta etapa é considerado como sendo um oxigênio da rede.

iii) Adsorção dissociativa do oxigênio

$\mathrm{O}_{2}+2^{*} \rightarrow 2 \mathrm{O}^{*}$

iv) Reações de superfície e dessorção de produtos

As reações de superfície e dessorção de produtos são apresentadas pela reação 22 e pelas reações 9 a 14, no mecanismo proposto por Wei e Iglesia (2004 a;b) para a reforma a vapor do metano. 
$\mathrm{OH}^{*}+\mathrm{OH}^{*} \rightarrow \mathrm{H}_{2} \mathrm{O}+\mathrm{O}^{*}$

A adsorção do metano em superfícies metálicas usualmente requer uma energia de ativação significante e é esperado que o metano seja capaz de competir com o oxigênio por sítios vacantes apenas quando a razão $\mathrm{CH}_{4}: \mathrm{O}_{2}$ for alta, podendo ocorrer a oxidação da fase metálica em altas concentrações de oxigênio.

\subsection{3 - Reforma oxidativa do metano (ROM)}

Estudos indicam que o acoplamento da reação de oxidação parcial com uma reação endotérmica, reforma a vapor ou com $\mathrm{CO}_{2}$, pode levar a benefícios para o processo (RUCKENSTEIN; HU, 1998).

Este processo, chamado de reforma autotérmica ou oxidativa do metano, é uma rota vantajosa para a produção de gás de síntese, por razões técnicas e econômicas. Esta reação possui baixos requerimentos de energia devido ao fato de a energia gerada pela reação exotérmica de oxidação parcial ser consumida pela reação endotérmica de reforma. O acoplamento destas reações pode melhorar o controle de temperatura no reator e reduzir a formação de pontos quentes, evitando a desativação do catalisador por sinterização ou deposição de carbono. Ainda, a reforma autotérmica do metano permite a produção de um gás de síntese com uma ampla escala de razão $\mathrm{H}_{2} / \mathrm{CO}$ devido à facilidade de manipular as concentrações relativas de $\mathrm{CO}_{2} / \mathrm{H}_{2} \mathrm{O}$ e $\mathrm{O}_{2}$ no fluxo alimentado (SOUZA et al., 2006).

Como a reforma autotérmica é a combinação dos processos de reforma a vapor do metano ou reforma do metano $\operatorname{com~} \mathrm{CO}_{2}$ com a oxidação parcial do metano, os catalisadores ativos para esta reação são os mesmos citados anteriormente. (DIAS; ASSAF, 2004) 


\section{2 - Desativação dos catalisadores}

\subsection{1 - Sinterização}

Os catalisadores podem sofrer modificações na sua estrutura durante a reação devido à participação de seus constituintes em reações químicas ou à sua sinterização.

A sinterização inclui processos dependentes da temperatura que conduzem ao crescimento das partículas dos catalisadores, levando a uma diminuição da área específica do catalisador. No controle da sinterização, além do método de preparação, a temperatura é uma variável muito importante (FIGUEIREDO, 1989).

O suporte também desempenha um papel importante na reforma a vapor do metano, promovendo uma maior estabilidade térmica, evitando processos de sinterização e ajudando na remoção de coque. Sabe-se que suportes básicos promovem a reação entre vapor e carbono (TRIMM, 1999).

\subsection{2 - Formação de Carbono}

Uma das principais causas de desativação do catalisador nas reações de reforma do metano é a formação de coque. Coque é uma descrição coletiva de vários tipos de depósitos carbonáceos formados no reator. Estes depósitos podem ter origem pirolítica ou catalítica (FIGUEIREDO, 1989).

O coque pirolítico se origina a partir da quebra térmica da molécula de metano em temperaturas acima de $600^{\circ} \mathrm{C}$. A origem destes compostos ocorre por meio da adsorção em superfícies não catalíticas dos precursores formados na fase gasosa (FIGUEIREDO, 1989). 
O coque promovido por catalisadores é mais complexo e difícil de minimizar. A formação de coque em superfícies de níquel é bem estudada, todavia nem todos os aspectos do processo são completamente claros. Acredita-se que hidrocarbonetos dissociem-se para produzir carbono $(\mathrm{C} \alpha)$ monoatômico altamente reativo. C $\alpha$ é facilmente gaseificado por reações como a reação (18), para formar monóxido de carbono. Todavia se um excesso de $\mathrm{C} \alpha$ é formado, ou se a gaseificação é lenta, ocorre um favorecimento da polimerização a $C \beta$. Testes mostram que $C \beta$ é muito menos reativo que $C \alpha$, e a gaseificação destas espécies é muito lenta. Como resultado, $\mathrm{C} \beta$ pode acumular na superfície ou difundir no níquel, precipitando na interface metal/suporte. Este processo contínuo leva à formação de filamentos de carbono, os quais deslocam o níquel da superfície do suporte, levando inicialmente a uma maior exposição do sítio ativo. Porém, o contínuo crescimento leva à fragmentação do filamento, com perda da fase ativa e entupimento do leito reacional (FIGUEIREDO, 1999).

Nem todo o coque formado na superfície se difunde através do níquel. Pelo menos algum carbono ainda permanece na superfície e encapsula o níquel. Ainda não está claro se carbonos encapsulantes envolvem apenas $C \beta$ ou se também incluem polímeros originados parcialmente na fase gasosa. Uma vez formado, os encapsulantes desativam o catalisador e são mais difíceis de gaseificar do que um $\mathrm{C} \alpha$. Portanto a formação de carbono sobre níquel é o resultado de um balanço entre a coqueificação e a gaseificação. A desativação catalítica pode resultar da encapsulação ou da formação de filamentos de carbono que não afetam a atividade, mas causam altas pressões no reator (TRIMM, 1999).

A deposição de carbono durante a reforma do metano pode ser originada tanto pela decomposição do metano (reação 23), favorável acima de $600^{\circ} \mathrm{C}$, quanto 
pelo desproporcionamento do $\mathrm{CO}$ segundo a reação de Boudouart (reação 24) favorável abaixo de $700^{\circ} \mathrm{C}$ (SOUZA et al., 2006).

O meio mais eficaz de evitar a formação de carbono é trabalhar com excesso de vapor de modo a favorecer a reação (25), a qual é favorável em temperaturas acima de $700^{\circ} \mathrm{C}$

$$
\begin{array}{ll}
\mathrm{CH}_{4} \rightleftarrows \mathrm{C}+2 \mathrm{H}_{2} & \Delta \mathrm{H}^{\circ}{ }_{298 \mathrm{~K}}=75 \mathrm{kJmol}^{-1} \\
& \Delta \mathrm{G}^{\circ}{ }_{298 \mathrm{~K}}=50,9 \mathrm{kJmol}^{-1} \\
2 \mathrm{CO} \rightleftarrows \mathrm{C}+\mathrm{CO}_{2} & \Delta \mathrm{H}^{\circ}{ }_{298 \mathrm{~K}}-172 \mathrm{kJmol}^{-1} \\
& \Delta \mathrm{G}^{\circ}{ }_{298 \mathrm{~K}}=-120 \mathrm{kJmol}^{-1} \\
\mathrm{C}+\mathrm{H}_{2} \mathrm{O} \rightleftarrows \mathrm{CO}+\mathrm{H}_{2} & \Delta \mathrm{H}^{\circ}{ }_{298 \mathrm{~K}}=131,3 \mathrm{kJmol}^{-1} \\
& \Delta \mathrm{G}^{\circ}{ }_{298 \mathrm{~K}}=91,4 \mathrm{kJmol}^{-1}
\end{array}
$$

Existem várias formas de minimizar a formação de coque. A primeira consiste no controle de tamanho de partícula, visto que a formação de coque é favorecida em partículas maiores do que aquelas requeridas para a reforma.

Outra forma de se minimizar a formação de coque consiste em acelerar a gaseificação das espécies carbonáceas. Estudos mostram que suportes básicos de terras raras provocam um aumento da reforma a vapor e um decréscimo significante na formação de carbono por meio de um favorecimento da gaseificação do coque. Céria, um suporte inativo para a reforma a vapor do metano, quando combinada com níquel, provoca uma melhora no controle de coque. Estudos indicam que parte deste efeito é devido a um aumento da adsorção da água no suporte de céria e do aumento da gaseificação de carbono (TRIMM, 1999).

\section{3 - Catalisadores}

O processo de reforma a vapor industrial é normalmente baseado em catalisadores de níquel suportado, porém nas altas temperaturas necessárias para esta reação, da ordem de $800^{\circ} \mathrm{C}$, ocorre a formação de carbono entre o domínio do 
cristal de níquel e a interface metal-suporte, liberando partículas de níquel da superfície do suporte e formando fibras de carbono, as quais destróem o catalisador (YAMAZAKI et al, 1996).

Vários catalisadores foram estudados para os processos de reforma, embora a deposição de carbono ou a sinterização do metal sempre esteja presente. Em geral, catalisadores baseados em metais nobres podem ser utilizados com sucesso, originando baixa deposição de carbono, provavelmente devido à menor solubilidade do carbono nos metais nobres, quando comparados ao níquel (CHEN et al, 1996, 1999; WANG; RUCKENSTEIN, 2001). Entretanto, devido ao alto custo, é desejável empregá-los em baixas proporções ou substituí-los por metais não preciosos.

Estudos da reação de reforma do $\mathrm{CH}_{4}$ com $\mathrm{CO}_{2}$ sobre $\mathrm{Ni}$ depositado em $\mathrm{Al}_{2} \mathrm{O}_{3}$ e em MgO mostram que ocorre uma grande formação de depósitos carbonáceos. Entretanto, Choudhary et al. $(1998,1999)$ verificaram que a reação combinada de reforma a vapor e com $\mathrm{CO}_{2}$ sobre catalisador $\mathrm{NiO}$ depositado num suporte coberto por $\mathrm{MgO}$ ocorreu sem desativação a $800^{\circ} \mathrm{C}$. Eles sugerem que o pré-recobrimento do suporte comercial macroporoso contendo alumina e sílica com MgO, antes da deposição do $\mathrm{NiO}$, cria uma camada protetora, $\mathrm{MgAl}_{2} \mathrm{O}_{4}$, na interface suporte-MgO, de alta estabilidade térmica, resultante da reação sólido-sólido entre o $\mathrm{MgO}$ e $\mathrm{Al}_{2} \mathrm{O}_{3}$. Esta camada evita a formação da espécie catalítica inativa, a fase $\mathrm{NiAl}_{2} \mathrm{O}_{4}$, minimizando o consumo do níquel, componente ativo do catalisador. Isto, juntamente com a formação da solução sólida de $\mathrm{NiO}-\mathrm{MgO}$, são os responsáveis pela alta atividade deste catalisador.

Choudhary e Mamman (2000) realizaram um estudo das reações de reforma a vapor de metano, reforma com $\mathrm{CO}_{2}$, da oxidação parcial e das reações simultâneas de reforma oxidativa sobre o catalisador NiO-MgO. Eles obtiveram 
resultados bastante interessantes, mostrando que a solução sólida NiO-MgO é muito ativa e seletiva para a produção de gás de síntese nas reações de acoplamento da reação endotérmica, reforma a vapor ou reforma com $\mathrm{CO}_{2}$, com a reação exotérmica, oxidação parcial do metano, tornando este processo energeticamente eficiente.

Ruckenstein e Wang (2001) estudaram catalisadores de cobalto em diferentes suportes $\left(\mathrm{MgO}, \mathrm{CaO}\right.$ e $\left.\mathrm{SiO}_{2}\right)$ para a reforma oxidativa de $\mathrm{CH}_{4}$ com $\mathrm{CO}_{2}$, onde $\mathrm{o}$ catalisador reduzido $\mathrm{Co} / \mathrm{MgO}$ apresentou alta eficiência e estabilidade, sem desativação em um período de 110 horas de reação. Porém, altas temperaturas de calcinação levaram à formação de solução sólida com fortes interações metalsuporte que apresentou difícil redutibilidade.

A grande vantagem da solução sólida é que ela confere estabilidade ao níquel frente aos processos de sinterização que ocorrem durante as reações oxidativas de metano para gás de síntese, em altas temperaturas. A forte interação entre o níquel dispersado na superfície e o magnésio inibe a sinterização do níquel. Como conseqüência, evita-se a formação de aglomerados ("clusters") de níquel, e conseqüentemente diminuem-se as reações de deposição de carbono (TOMISHIGE et al., 1999; RUCKENSTEIN; HU, 1998). Outra possibilidade para a redução das reações de formação de carbono é que o $\mathrm{MgO}$ inibe a reação de desproporcionamento do CO (reação de Boudouard) sobre o níquel (RUCKENSTEIN; HU, 1995):

Choudhary e Mamman (1998b) compararam o comportamento das soluçõessólidas $\mathrm{CoO}-\mathrm{MgO}$ e $\mathrm{NiO}-\mathrm{MgO}$ na OPM a $973 \mathrm{~K}$ e mostraram um pior desempenho catalítico dos catalisadores de cobalto, quando comparados aos de níquel na razão 
molar $\mathrm{CH}_{4}: \mathrm{O}_{2}=2: 1$ (90\% e $70 \%$ respectivamente), porém esta diferença diminuiu quando comparados na razão molar $\mathrm{CH}_{4}: \mathrm{O}_{2}=4: 1$ (38\% e 42\% respectivamente).

Shishido et al. (2001), em seus estudos de reforma de $\mathrm{CH}_{4} \operatorname{com~} \mathrm{CO}_{2}$, observaram que catalisadores de níquel preparados a partir de precursores do tipo hidrotalcita $\left(\mathrm{Mg}_{3} \mathrm{Al}-\mathrm{Ht}\right)$ apresentaram maior atividade e menor formação de coque por área superficial do que catalisadores preparados pelo método tradicional de impregnação como $\mathrm{Ni} / \propto \mathrm{Al}_{2} \mathrm{O}_{3}$ e Ni/MgO. Provavelmente devido a estes catalisadores conterem o metal distribuído homogeneamente no bulk e durante a redução in situ das espécies de níquel, uma parte substancial de níquel pode migrar da estrutura óxida para a superfície e formar partículas de metal altamente dispersas, resultando assim em uma maior atividade do catalisador.

Basile et al. (1998) estudaram catalisadores de Ni/Mg/Al, derivados de hidrotalcitas na OPM e observaram que o tratamento térmico a $1173 \mathrm{~K}$ levou a diferentes espécies de níquel na fase óxida distribuídas entre as fases $\mathrm{NiO}$, $(\mathrm{Ni}, \mathrm{Mg}) \mathrm{Al}_{2} \mathrm{O}_{3}$ e a estrutura $\mathrm{NiO}-\mathrm{MgO}$. Os resultados mostraram que catalisadores com alta quantidade de níquel $\left(\mathrm{Ni}_{61} \mathrm{Mg}_{10} \mathrm{Al}_{29}\right.$ e $\left.\mathrm{Ni}_{71} \mathrm{Al}_{29}\right)$ necessitaram de condições brandas de ativação, mas desativaram devido à formação de coque. Análises de difração de raios-X e redução a temperatura programada mostraram a presença das fases $\mathrm{NiO}$ e $(\mathrm{Ni}, \mathrm{Mg}) \mathrm{Al}_{2} \mathrm{O}_{3}$. Já os catalisadores com baixa quantidade de níquel $\left(\mathrm{Ni}_{10} \mathrm{Mg}_{61} \mathrm{Al}_{29}\right.$ e $\left.\mathrm{Ni}_{34} \mathrm{Mg}_{37} \mathrm{Al}_{29}\right)$ só foram ativos após severo tratamento de redução, mas apresentaram alta atividade na reação. Este comportamento se deve à formação da estrutura NiO-MgO de difícil redução.

Tsyganok et al. (2001) relataram um método para a incorporação de níquel na estrutura da hidrotalcita $\mathrm{Mg}-\mathrm{Al}$, baseado na habilidade do $\mathrm{Ni}^{2+}$ reagir com um agente quelato aniônico de $[E D T A]^{4-}$, formando espécies altamente estáveis de $[\mathrm{Ni}(\mathrm{EDTA})]^{2-}$, 
sugerindo assim a formação de uma estrutura Mg-Al LDH intercalada com $[\mathrm{Ni}(\mathrm{EDTA})]^{2-}$, obtendo desta forma o níquel mais disperso na estrutura, onde o catalisador correspondente apresentou alta atividade e estabilidade na reforma de metano com $\mathrm{CO}_{2}$ a $800^{\circ} \mathrm{C}$.

\subsection{1 - Hidrotalcitas}

As argilas podem ser divididas em dois grandes grupos: argilas catiônicas, amplamente encontradas na natureza e argilas aniônicas, que são mais raras na natureza, porém de fácil síntese. Entre as argilas aniônicas estão incluídas as hidrotalcitas.

Argilas aniônicas são hidróxidos lamelares mistos, naturais ou sintéticos, com os espaços interlamelares contendo ânions. Muitos nomes são utilizados em função da composição e da simetria destes minerais. Os termos gerais, compostos do tipohidrotalcita (HT) ou hidróxidos duplo lamelares (HDL's) são amplamente utilizados (VACCARI, 1998).

Entende-se por hidrotalcitas os hidroxicarbonatos hidratados de estrutura lamelar. A fórmula geral que descreve sua composição química é:

\section{$\left[\mathrm{M}_{1-x}{ }^{2+} \mathrm{M}_{x}{ }^{3+}(\mathrm{OH})_{2}\right]^{\mathrm{x}+}\left[\mathrm{A}_{x / \mathrm{n}}\right]^{\mathrm{n}-} \cdot \mathrm{mH}_{2} \mathrm{O}$}

onde

$\mathrm{M}^{2+}$ : cátion divalente

$\mathrm{M}^{3+}$ : cátion trivalente

$x$ ( razão molar): $\mathrm{M}^{3+} /\left(\mathrm{M}^{2+}+\mathrm{M}^{3+}\right)$

A : ânion de compensação de carga $n$

Hidrotalcitas possuem estrutura similar à da brucita $\mathrm{Mg}(\mathrm{OH})_{2}$, onde cada $\mathrm{Mg}^{2+}$ é coordenado octaedricamente com 6 íons $\mathrm{OH}^{-}$com unidades octaédricas 
compartilhando limites para formar infinitas camadas de carga neutra. No caso da substituição parcial de cátions $\mathrm{Mg}^{2+}$, ou qualquer outro metal $\mathrm{Me}^{+2}$ de raio iônico similar, como por exemplo, níquel ou cobalto, por cátions de maior carga, mas de raio similar, as camadas do tipo brucita tornam-se carregadas positivamente e esta carga é balanceada por ânions (geralmente carbonatos) e moléculas de água localizadas entre as camadas octaédricas, mantendo a neutralidade da molécula (CASENAVE et al. 2001). A Figura 1 apresenta as estruturas do tipo brucita e hidrotalcita.
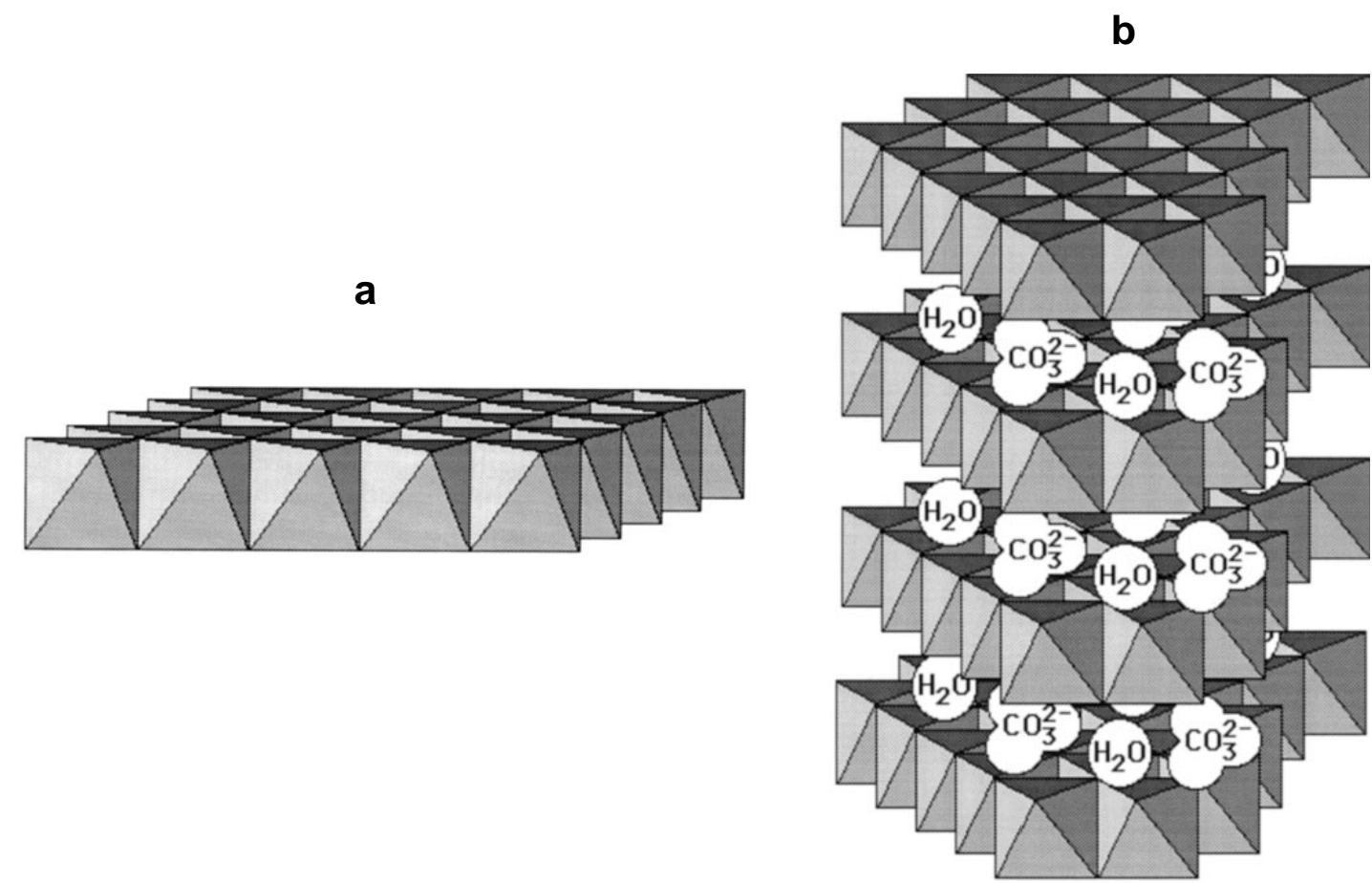

Figura 1. Estrutura de (a) Brucita $\mathrm{Mg}(\mathrm{OH})_{2}$, os cátions $\mathrm{Mg}^{+2}$ ocupam os centros dos octaedros, que compartilham arestas, cujos vértices são ocupados por ânions hidroxilas e (b) material do tipo hidrotalcita onde os centros dos octaedros são ocupados por cátions di e trivalentes, os vértices são ocupados por ânions hidroxilas e entre as camadas estão localizados os ânions interlamelares e a água (RIVES; ULIBARRI, 1999).

Um grande número de HDL's, contendo uma ampla variedade de cátions metálicos, tem sido sintetizado e estudado. Os cátions divalentes podem ser de: Mg, $\mathrm{Ni}, \mathrm{Fe}, \mathrm{Co}, \mathrm{Cu}, \mathrm{Zn}$, Ca e Mn; e os cátions trivalentes podem ser de: Al, Cr, Fe, Mn, 
$\mathrm{Ni}, \mathrm{Co}, \mathrm{Sc}$ e Ga. Para se formar a estrutura do tipo hidrotalcita, os cátions dos metais devem apresentar coordenação octaédrica, limitando os raios iônicos a valores entre 0,5 e $0,74 \AA$.

Para um composto ser um HDL não é uma condição necessária que este seja constituído apenas de dois cátions metálicos. Muitas argilas aniônicas naturais contêm misturas de cátions, tanto di como trivalentes em suas estruturas, geralmente com um deles em quantidade predominante e os outros em pequena proporção ou como traços (CREPALDI; VALIM, 1998).

A razão $\mathrm{M}^{+2} / \mathrm{M}^{+3}$, que equivale à quantidade de cátions $\mathrm{M}^{+2}$ substituídos por $\mathrm{M}^{+3}$ também é um fato importante na composição das camadas do tipo brucita. Quanto menor esta razão, maior a densidade de carga na lamela e conseqüentemente maior a quantidade de ânion intercalado. O número, o tamanho, a orientação dos ânions e a força das ligações entre os ânions e os grupos hidroxílicos das camadas do tipo brucita determinam a espessura das intercamadas.

Apesar de afirmações que compostos do tipo hidrotalcitas se formam para valores de $x$ entre 0,1 e 0,5 , existem muitas indicações de que as fases puras possam se formar apenas em uma estreita escala $(0,2<x<0,34)$. Estudos indicam que para valores altos, o aumento do número de $\mathrm{Al}^{+3}$ vizinhos leva à formação de $\mathrm{Al}(\mathrm{OH})_{3}$ e que, analogamente, baixos valores de $x$ levam à uma alta densidade de $\mathrm{Mg}^{+2}$ com segregação da fase $\mathrm{Mg}(\mathrm{OH})_{2}$ ( ARAÚJO, 2004).

As folhas de $\mathrm{OH}^{-}$podem exibir duas seqüências de empilhamento, romboédrica (chamada hidrotalcita) e hexagonal (chamada Manessita). As duas formas podem ser distinguidas apenas por análise de raios- $X$, já que os óxidos mistos obtidos por decomposição apresentam as mesmas propriedades físicas. Hidrotalcitas cristalizam com seqüência de empilhamento romboédrico $3 R$, sendo o 
parâmetro unitário de cela a e $c=3 c^{\prime}$ (onde $c$ 'é a espessura de uma camada consistindo de uma folha do tipo brucita e uma intercamada), enquanto que a manessita cristaliza com seqüência de empilhamento hexagonal $2 \mathrm{H}$, sendo $\mathrm{o}$ parâmetro unitário de cela a e $c=2 c^{\prime}$. Todavia, a forma normalmente obtida por síntese é a romboédrica (VACCARI, 1998).

Argilas aniônicas podem ser sintetizadas por várias técnicas, como por exemplo, co-precipitação (precipitação a pH constante), precipitação em pH variável, troca-aniônica, reconstrução estrutural, entre outros. O método mais utilizado para o preparo de altas quantidades de hidrotalcita é o da co-precipitação, onde todos os metais, $\mathrm{Me}^{+2}$ e $\mathrm{Me}^{+3}$, como por exemplo, $\mathrm{Mg}^{+2}, \mathrm{Ni}^{+2}$ e $\mathrm{Al}^{+3}$, são precipitados simultaneamente substituindo parte do $\mathrm{Me}^{+2}$ na folha de brucita, sendo o excesso de carga positiva compensado pelo ânion de compensação. A co-precipitação normalmente é realizada na faixa de $\mathrm{pH} 7-10$, em temperaturas entre $60-80^{\circ} \mathrm{C}$, baixa concentração de reagentes com baixo fluxo na alimentação. Normalmente são lavadas com água quente, e secas em temperaturas inferiores a $100^{\circ} \mathrm{C}$. Argilas aniônicas com outros ânions além de carbonatos podem ser preparadas por precipitação sob atmosfera inerte usando hidróxidos alcalinos. Todavia, pequenas quantidades de carbonatos estão sempre presentes.

A estrutura das argilas aniônicas apresenta boa capacidade de troca do ânion entre as camadas, podendo desta forma o espaço entre as camadas ser usado para aumentar a quantidade dos metais, para aumentar a dispersão destes metais, como por exemplo, níquel e cobalto, os quais podem ser introduzidos na forma aniônica (quelatos, cromatos, ferrocianetos, etc.), ou introduzir cátions que não são compatíveis com os sítios octaédricos das folhas do tipo brucita (por exemplo, cátions de maiores raios iônicos como o cério e lantânio) (VACCARI, 1998). 
Hidrotalcitas calcinadas podem ser utilizadas como catalisadores, devido às suas propriedades básicas, alta área superficial e estabilidade térmica. Vários cátions de metais de transição podem ser introduzidos nas camadas do tipo brucita alterando suas propriedades e conseqüentemente sua atividade (CHIMIELARZ et al, 2003).

A decomposição térmica das argilas aniônicas leva a uma mistura de óxidos de interesse industrial para a catálise e outras aplicações práticas e é geralmente caracterizada por duas transições endotérmicas. A primeira transição (370K - 570K) corresponde à perda da água entre as camadas, enquanto a segunda ocorre em temperaturas maiores devido à perda de grupos hidroxilas das camadas do tipo brucita e de ânions (PÉREZ-RAMIREZ et al., 2001). As mais importantes propriedades destes óxidos são as seguintes:

(A) Alta área superficial $\left(100-300 \mathrm{~m}^{2} / \mathrm{g}\right)$.

(B) Dispersão homogênea dos elementos termicamente estáveis também nas condições de redução, com formação de pequenos e estáveis cristalitos metálicos.

(C) Efeito de memória, no qual pode ocorrer a reconstrução da estrutura original pelo contato de solução contendo vários ânions (VACCARI, 1998).

De acordo com Takehira et al. (2005) a decomposição térmica da estrutura da hidrotalcita de $\mathrm{NiMgAl}$ em presença de ar a $650^{\circ} \mathrm{C}$ leva a uma mistura homogênea de óxidos, onde não apenas o $\mathrm{Ni}^{+2}$, mas também o $\mathrm{Al}^{+3}$, substitui os sítios da rede de MgO (Apêndice A, Figura $A 1$ ) em uma solução sólida (periclásio $\mathrm{Mg}(\mathrm{Al}) \mathrm{O}$ contendo níquel). Todavia, calcinações em temperatura da ordem de $750^{\circ} \mathrm{C}$ levam à formação da fase espinélio $\mathrm{MgAl}_{2} \mathrm{O}_{4}$ (Apêndice $\mathrm{A}$, Figura $\mathrm{A} 2$ ) contendo níquel. Estes resultados estão de acordo com Gazzano et al. (1997), que por estudos de difração de neutrôns in situ da hidrotalcita Ni/Mg/Al, verificaram que a decomposição da 
hidroatalcita ocorre acima de $327^{\circ} \mathrm{C}$, e que entre $427^{\circ} \mathrm{C}$ e $727^{\circ} \mathrm{C}$, ocorre a presença da fase óxida cúbica $\mathrm{Mg}(\mathrm{Al}) \mathrm{O}$ a qual é convertida parcialmente na fase espinélio entre $827^{\circ} \mathrm{C}$ e $977^{\circ} \mathrm{C}$.

\subsection{2 - Promotores}

Promotor é um composto que possui baixa ou nenhuma atividade catalítica, mas que quando adicionado em pequenas porções ao catalisador acarreta em uma melhor atividade, estabilidade ou seletividade para a reação desejada. De acordo com Borowiecki et al. (1997), os promotores podem ser classificados como: texturais, os quais agem por um efeito físico, estabilizando ou provocando uma melhor dispersão do agente ativo, ou estruturais, que agem por um efeito químico, mudando a composição química do catalisador.

O promotor pode agir catalisando a formação de um intermediário, pode provocar defeitos estruturais ou pode agir mudando a estrutura eletrônica do catalisador, facilitando, assim, a adição ou remoção de elétrons a partir de um metal e mudando, assim, a força da quimissorção (SATTERFIELD,1993).

A adição de pequenas quantidades de metais terras raras, os quais possuem propriedades extremamente básicas, pode alterar as características das hidrotalcitas após tratamento térmico, aumentando sua basicidade (ANGELESCU et al., 2004). Sabe-se que suportes básicos de terras raras provocam um aumento da reforma a vapor e um significante decréscimo na formação de carbono por meio de um favorecimento da gaseificação do coque (TRIMM, 1999).

Alguns trabalhos reportam a aplicação de cério e lantânio como promotores do catalisador $\mathrm{Ni} / \mathrm{Al}_{2} \mathrm{O}_{3}$ na reforma seca do metano, aumentando a estabilidade térmica, resistência à formação de coque e atividade catalítica (ZNAK et al., 2005). 
A capacidade do cério apresentar mais de um estado de oxidação é de grande importância para sua participação em catalisadores heterogêneos. Sabe-se que uma pequena fração de íons $\mathrm{Ce}^{+4}$ é sempre reduzida a $\mathrm{Ce}^{+3}$, sendo assim acompanhada pelo surgimento de vacâncias de oxigênio, afetando desta forma tanto as estruturas do bulk como da superfície (GOTTE et al., 2004). A presença do cério também estabiliza a dispersão metálica e promove a atividade catalítica para reações de reforma, devido à melhora na adsorção e dissociação de moléculas de água associadas à $\mathrm{CeO}_{2}$ (NAVARRO et al., 2006).

Martinez et al. (2004) estudaram a adição de lantânio em catalisadores coprecipitados $\mathrm{Ni}$-Al aplicados na reforma seca do metano e observaram que a adição de pequenas quantidades de promotores levou a uma melhora na dispersão metálica, a maiores níveis de conversão e a um decréscimo na formação de depósitos carbonáceos. 


\section{3 - Objetivos}

A partir das considerações acima, e no sentido de contribuir para o entendimento do processo de obtenção de gás de síntese, sobre catalisadores obtidos de precursores do tipo hidrotalcita, a partir de reações com metano, pode-se apresentar os objetivos deste trabalho como sendo:

Desenvolvimento, caracterização e aplicação de catalisadores de níquel e cobalto obtidos via precursores do tipo hidrotalcita, para a conversão de $\mathrm{CH}_{4}$ em gás de síntese.

Adição dos promotores cério e lantânio, visando estudar o efeito dos mesmos na estrutura do catalisador, bem como seu efeito na distribuição dos produtos reacionais. 


\section{4 - Materiais e Métodos}

\section{1 - Reagentes e gases utilizados}

Os reagentes utilizados na obtenção e caracterização dos precursores, óxidos e catalisadores e também nos testes catalíticos foram:
$\mathrm{Ni}\left(\mathrm{NO}_{3}\right)_{2} \cdot 6 \mathrm{H}_{2} \mathrm{O}-\mathrm{Nitrato}$ de níquel
(Aldrich)
$\mathrm{Co}\left(\mathrm{NO}_{3}\right)_{2} \cdot 6 \mathrm{H}_{2} \mathrm{O}-\mathrm{Nitrato}$ de cobalto
(Alfa Aesar)
$\mathrm{Mg}\left(\mathrm{NO}_{3}\right)_{2} \cdot 6 \mathrm{H}_{2} \mathrm{O}-$ Nitrato de magnésio
(Mallinckrodt)
$\mathrm{Al}\left(\mathrm{NO}_{3}\right)_{3} \cdot 9 \mathrm{H}_{2} \mathrm{O}-\mathrm{Nitrato}$ de alumínio
(Carlo Erba)
$\mathrm{La}\left(\mathrm{NO}_{3}\right)_{3} \cdot 6 \mathrm{H}_{2} \mathrm{O}-$ Nitrato de lantânio
(VETEC)
$\mathrm{Ce}\left(\mathrm{NO}_{3}\right)_{3} \cdot 9 \mathrm{H}_{2} \mathrm{O}-\mathrm{Nitrato}$ de cério
(Alfa-Aesar)
$\mathrm{Na}_{2} \mathrm{CO}_{3}$ anidro- Carbonato de sódio
(Synth)
$\mathrm{NaOH}$ - Hidróxido de sódio
(Synth)
$\mathrm{C}_{10} \mathrm{H}_{16} \mathrm{O}_{8} \mathrm{Na}_{4} .3 \mathrm{H}_{2} \mathrm{O}$-EDTA tetrassódico
(Synth)
Ar Sintético
Mistura $\mathrm{H}_{2} / \mathrm{N}_{2}(94,4 \%)$
$\mathrm{H}_{2}(99,995 \%)$
(AGA)
$\mathrm{N}_{2}(99,997 \%)$
(AGA)
$\mathrm{He}(99,995 \%)$
(AGA)
$\mathrm{CH}_{4}(99,95 \%)$
(AGA) 


\section{2 - Preparação dos catalisadores}

As condições utilizadas nas precipitações foram temperatura de $65^{\circ} \mathrm{C}$ e pH 10 controlado pela adição de solução de $\mathrm{NaOH} 1 \mathrm{M}$.

\section{Método tradicional: $\operatorname{tr}-\mathrm{Ni}(\mathrm{Co}) \mathrm{MgAl}-\mathrm{CO}_{3}$}

A formação de hidróxidos de dupla camada foi feita a partir da precipitação simultânea de uma solução de sais de nitratos $\mathrm{Ni} / \mathrm{Co}(\mathrm{II}), \mathrm{Mg}(\mathrm{II})$ e $\mathrm{Al}(\mathrm{III})(5,25$ e 10 mmol, respectivamente) com solução de $\mathrm{Na}_{2} \mathrm{CO}_{3}(30 \mathrm{mmol})$ sob agitação constante. A suspensão obtida foi mantida em agitação por $1 \mathrm{~h}$ e depois sem agitação por 18h, na mesma temperatura. O precipitado obtido foi separado por filtração e lavado com água destilada. Depois foi seco em estufa por $24 \mathrm{~h}$ a $80^{\circ} \mathrm{C}$ e reservado.

\section{Preparo do complexo do tipo quelato (MeY)}

Para a co-precipitação e troca-aniônica foi utilizado um complexo de quelato de metal $[\mathrm{Ni}(\mathrm{II}), \mathrm{Co}(\mathrm{II}), \mathrm{La}(\mathrm{III})$ ou $\mathrm{Ce}(\mathrm{III})]$ o qual foi preparado pela adição de solução de nitrato do metal (50 mmol) a uma solução de sal tetrassódico de EDTA (50 mmol) a $65^{\circ} \mathrm{C}$ e $\mathrm{pH} 10$, sendo denominado $(\mathrm{MeY})^{-2}$ no caso do níquel e cobalto e $(\mathrm{MeY})^{-}$ para o lantânio e cério.

\section{Método de co-precipitação do quelato - cp- MgAl-Ni(Co)Y}

A formação dos hidróxidos de dupla camada foi feita a partir da precipitação de uma solução aquosa de sais de nitrato de $\mathrm{Mg}(\mathrm{II})$ e $\mathrm{Al}(\mathrm{III})(30 \mathrm{mmol}$ e $10 \mathrm{mmol})$ à solução de (Ni/CoY $)^{-2}$ sob agitação. A suspensão recebeu o mesmo tratamento feito para o método tradicional. 


\section{Método de troca aniônica - ae- MgAl-Ni(Co)Y}

Para a troca aniônica primeiramente foi obtida a hidrotalcita MgAl-LDH, a partir da precipitação de uma solução aquosa dos nitratos de $\mathrm{Mg}(\mathrm{II})$ e $\mathrm{Al}(\mathrm{III})$ (30 mmol e $10 \mathrm{mmol}$, respectivamente) $\mathrm{com} \mathrm{NaOH} 1 \mathrm{M}$ sob agitação. A suspensão foi agitada por uma hora e mantida a $65^{\circ} \mathrm{C}$ por $18 \mathrm{~h}$. Para a troca aniônica adicionou-se a essa suspensão, lentamente sob agitação, a solução (Ni/CoY $)^{-2}$ em temperatura ambiente. A suspensão obtida foi agitada por $24 \mathrm{~h}$ à temperatura ambiente, sendo que o precipitado recebeu o mesmo tratamento que o método tradicional e coprecipitação.

\section{Método da troca-aniônica, adição de promotores - ae - Ni(Co)MgAl-La(Ce)Y}

A introdução dos promotores foi feita pela troca-aniônica devido ao alto valor de raio iônico do lantânio e cério, quando comparados ao do magnésio (VACCARI, 1998). Para a síntese do precursor primeiramente foi obtida a hidrotalcita $\mathrm{Ni}(\mathrm{Co}) \mathrm{MgAl}-\mathrm{LDH}$, a partir da precipitação de uma solução aquosa dos nitratos de $\mathrm{Ni} / \mathrm{Co}(\mathrm{II}), \mathrm{Mg}(\mathrm{II})$ e $\mathrm{Al}(\mathrm{III})(5,25 \mathrm{mmol}$ e $10 \mathrm{mmol}$, respectivamente) com $\mathrm{NaOH} 1 \mathrm{M}$ sob agitação. A suspensão foi agitada por uma hora e mantida a $65^{\circ} \mathrm{C}$ por $18 \mathrm{~h}$. Para a troca aniônica adicionou-se a essa suspensão, lentamente sob agitação, a solução $(\mathrm{La} / \mathrm{CeY})^{-3}$ em temperatura ambiente. A suspensão obtida foi agitada por $24 \mathrm{~h}$ à temperatura ambiente, sendo que o precipitado recebeu o mesmo tratamento que o método tradicional e co-precipitação.

\section{Formação dos óxidos mistos}

A mistura de óxidos foi obtida pela calcinação de todas as amostras a $500^{\circ} \mathrm{C}$, com taxa de aquecimento de $10^{\circ} \mathrm{Cmin}^{-1}$ e fluxo de ar sintético de $30 \mathrm{mlmin}^{-1}$ por $15 \mathrm{~h}$. 


\section{3 - Caracterização dos Catalisadores}

\subsection{1 - Energia dispersiva de Raios-X (EDX)}

A técnica de Espectroscopia Dispersiva de Raios-X (EDX) é utilizada na análise qualitativa e semiquantitativa e é baseada na observação de dois parâmetros: a energia específica dos picos de raios-x característicos para cada elemento e o conceito de família de picos de raios-x. Tais parâmetros são vitais para a identificação de elementos, caracterizada pelo aparecimento das famílias de linhas K, L e M.

A quantificação da composição do bulk foi determinada usando um microscópio eletrônico de varredura LEO 440 com filamento de tungstênio acoplado a um detector de energia dispersiva de Raios-X. As amostras foram preparadas na forma de pastilhas e recobertas com camada de ouro para evitar o carregamento que ocorre para amostras não condutoras.

\subsection{2 - Determinação da Área Superficial Específica Total, Raio Médio dos Poros e Volume Total dos Poros}

Para a determinação da Área Superficial Específica total utilizou-se o método elaborado por Brunauer, Emmett e Teller (B.E.T) em 1938, o qual baseia-se na determinação do volume de nitrogênio adsorvido $(V)$, através de adsorções e dessorções, a diversas pressões relativas $P / P_{0}$ na temperatura do nitrogênio líquido. Uma vez encontrado $V_{m}$, volume de nitrogênio adsorvido necessário para a formação da monocamada, a área superficial específica, Sg, pode ser calculada pela equação 1: 


$$
\mathrm{S}_{\mathrm{g}}=\mathrm{n} \cdot \sigma \cdot \mathrm{V}_{\mathrm{m}} / \mathrm{M}_{\mathrm{a}}
$$

Onde:

$\mathrm{n}=6,023 \times 10^{23}$ moléculas. $\mathrm{cm}^{3}$

$M_{a}=$ massa da amostra em gramas

$\sigma=$ área da cobertura de uma molécula de $N_{2}$ adsorvido $\left(16 \AA^{2}\right)$

Esse processo é conhecido como Fisissorção de $\mathrm{N}_{2}$ (CARDOSO, 1987;CIOLA, 1981).

A determinação do volume de poros e distribuição do raio dos poros foi feita pelo método de adsorção de um gás, chamado Barrett-Joyner-Halenda (BJH).

O volume total dos poros é obtido quando se aplica um valor de pressão $(P)$ igual ao valor de saturação do $N_{2}\left(P_{0}\right)$, pois nesta situação tem-se nitrogênio passando sobre a amostra na forma líquida e preenchendo todos os poros presentes. Então a partir da equação de Kevin (equação 2) determina-se r para cada valor de $P / P_{0}$ e determina-se uma isoterma experimental ( $V$ em função de $r$ ), da qual pode-se obter o volume de gás necessário para preencher os poros de raio $r$ e a partir da derivada desta isoterma $(\mathrm{dV} / \mathrm{dr})$ em função de $r$, obtém-se a curva de distribuição dos raios dos poros do catalisador (CARDOSO, 1987;CIOLA, 1981).

$$
\ln \left(P / P_{0}\right)=2 \sigma V / r R T
$$

Onde:

$r=$ raio do poro

$\mathrm{P} / \mathrm{P}_{0}=$ pressão relativa de vapor do líquido no poro pela pressão de vapor saturado $\sigma=$ tensão superficial $V=$ volume molar do gás adsorvido na fase líquida e na temperatura $T$ $\mathrm{R}=$ constante dos gases 
As análises de Área Superficial Específica, Raio Médio de Poro e volume total de poro foram realizadas por adsorção de $\mathrm{N}_{2}$, utilizando um equipamento Nova Data Analysis Package Ver. 2.00.

\subsection{3 - Análise Termogravimétrica (ATG)}

Na análise termogravimétrica é feito o controle da variação da massa de uma amostra, em uma atmosfera controlada, em função da temperatura ou do tempo à medida que a temperatura da amostra aumenta (SKOOG, 2002).

Para as análises de ATG utilizou-se um ATG-Therma Analyst 2100, (TA Instruments) operando sob fluxo de $\mathrm{N}_{2}$ de $25-1000^{\circ} \mathrm{C}$ com velocidade de aquecimento de $10^{\circ} \mathrm{Cmin}^{-1}$.

\subsection{4 - Difração de Raios-X pelo Método do Pó (DRX)}

Na difração de Raios-X pelo método do pó a amostra a ser analisada é reduzida a um pó fino e submetida a um feixe de Raios-X monocromático. A radiação refletida é registrada e o registro é conhecido como difratograma, o qual é um gráfico de intensidade de reflexão versus ângulo de Bragg (20). Nele, uma série de picos aparece, os quais constituem uma característica própria da substância estudada, possibilitando sua identificação (WEST, 1985).

Os dados foram coletados à temperatura ambiente em um Difratômetro URD6 Carl Zeiss com fonte de radiação Cu Ka $(\lambda=1,54056 \AA)$. Os difratogramas foram varridos na faixa de $2 \theta=3^{\circ}$ a $80^{\circ}$ na velocidade de $2^{\circ} \cdot \min ^{-1}$.

A identificação dos compostos foi feita por meio da lei de Bragg e por comparação com dados da literatura (JCPDS, 1994).

Os parâmetros de rede (comprimento dos lados da célula unitária) a e c para o precursor do tipo hidrotalcita, de simetria romboédrica (Apêndice A, Tabela A1), 
foram calculados de acordo com as equações simplificadas, 3 e 4, (Apêndice A, Tabela A2) abaixo:

$a=2^{*} \mathrm{~d}(110)$, referente ao plano (110) da hidrotalcita

$c=3^{*} \mathrm{~d}(003)$, referente ao plano $(003)$ da hidrotalcita

O parâmetro de rede $a$ das amostras óxidas foi calculado a partir do pico de maior intensidade utilizando a equação 5 , considerando o sistema cristalino cúbico (Apêndice A, Tabela A1) para os óxidos (Apêndice A, Tabela A2):

$1 / \mathrm{d}^{2}=\left(\mathrm{h}^{2}+\mathrm{k}^{2}+\mathrm{l}^{2}\right) / a^{2}$

Onde:

$\mathrm{d}=\lambda / 2 \operatorname{sen} \theta($ Lei de Bragg)

O tamanho de partícula foi calculado de acordo com a equação de Scherrer (equação 7):

$D=K^{*} \lambda / \beta^{*} \cos (\theta)$

onde:

$D=$ diâmetro da partícula

$\theta=$ ângulo de Bragg considerado

$\beta=$ largura da meia altura do pico considerado

$\mathrm{K}=0,9$ (considerando a partícula como uma esfera)

$\lambda=1.5406 \AA$

\subsection{5 - Espectroscopia de Absorção na região do Infravermelho com transformada de Fourier (FTIR)}

A espectroscopia no infravermelho se baseia no fato de que as ligações químicas das substâncias possuem freqüências de vibração específicas, as quais correspondem a níveis vibracionais. Tais freqüências dependem da forma da 
superfície de energia potencial da molécula, da geometria molecular, das massas dos átomos e eventualmente do acoplamento vibrônico.

Para absorver radiação infravermelha, uma molécula precisa sofrer uma variação no momento de dipolo como conseqüência do movimento vibracional ou rotacional. Apenas nestas circunstâncias o campo elétrico alternado da radiação pode interagir com a molécula e causar variações na amplitude de um de seus movimentos. O momento dipolar é determinado pela magnitude da diferença de carga e da distância entre dois centros de carga. Se a freqüência de radiação coincidir exatamente com a freqüência vibracional natural da molécula, ocorre uma transferência de energia efetiva e resulta em uma variação da amplitude da vibração molecular, tendo como conseqüência a absorção da radiação. Do mesmo modo, a rotação das moléculas assimétricas em torno dos seus centros de massa resulta em uma variação periódica do dipolo que pode interagir com a radiação. As freqüências de vibrações podem, em uma primeira aproximação, serem relacionadas ao comprimento da ligação e à massa dos átomos em cada ponta da ligação.

As vibrações caem nas categorias de estiramentos, que envolvem uma variação contínua na distância interatômica ao longo do eixo da ligação entre dois átomos, e de deformações angulares que são caracterizadas pela variação do ângulo entre duas ligações (SKOOG, 2002)

As análises foram realizadas em um equipamento de FTIR Bomem, modelo MB-series utilizando detector DTGS e resolução de $4 \mathrm{~cm}^{-1}$. Para as análises as amostras foram prensadas em pastilhas com $\mathrm{KBr}$ e para cada análise foram realizadas 16 varreduras. 


\subsection{6 - Redução a Temperatura Programada (RTP)}

A técnica consiste basicamente na redução de um óxido metálico através da passagem de uma mistura gasosa contendo gás redutor e um diluente sobre a amostra, enquanto a temperatura do sistema é variada com uma velocidade de aquecimento constante. Acoplado ao equipamento está um detector de condutividade térmica que mede a variação da concentração do gás redutor na corrente. Por meio da integração das curvas geradas, consumo de gás redutor por temperatura, chega-se a um valor de área que pode ser transformado em número de mols de $\mathrm{H}_{2}$ consumido para a redução dos óxidos metálicos.

Para a análise introduziu-se a amostra em um reator tubular de quartzo, o qual foi colocado em um forno com módulos de programação de rampas e de aquecimento e de controle de temperatura.

As análises foram realizadas em um equipamento Micromerits Chemissorb 2705 utilizando $50 \mathrm{mg}$ de catalisador e uma rampa de temperatura de 25 a $1000^{\circ} \mathrm{C}$ a uma velocidade de aquecimento de $10^{\circ} \mathrm{C}$, e um fluxo de $30 \mathrm{mLmin}^{-1}$ da mistura padrão $5 \% \mathrm{H}_{2} / \mathrm{N}_{2}$.

\subsection{7 - Espectroscopia Fotoeletrônica de Raios-X (XPS)}

É uma técnica que envolve as primeiras camadas da superfície catalítica, sendo desta forma muito importante para a catálise, já que a partir dela é possível se obter informações sobre a composição elementar da superfície bem como informação sobre os estados de oxidação dos elementos.

O princípio básico da técnica de XPS é o efeito fotoemissão, ou seja, a ejeção de um elétron das camadas mais internas do átomo por um fóton de raios- $X$ de energia $h v$. A energia dos elétrons emitidos é então analisada por um espectrômetro e os dados são apresentados como um gráfico de intensidade pela energia do 
elétron. A energia cinética do elétron é experimentalmente medida no espectrômetro, mas é dependente da fonte de raios-X empregada, não sendo desta forma uma propriedade intrínseca do material. Geralmente são utilizadas fontes de raios- $X$ de alumínio ou magnésio.

Em XPS mede-se a intensidade de fotoelétrons como função das suas energias cinéticas $\left(E_{k}\right)$, porém os espectros de XPS são normalmente apresentados em função da energia de ligação $\left(E_{b}\right)$ (WATTS, 1990, RIBEIRO, 2003).

Os elementos presentes na superfície da amostra são caracterizados diretamente pela determinação das energias de ligação dos picos fotoelétricos. Informações sobre a composição superficial da amostra são obtidas pela área integrada do pico, que é proporcional ao número de átomos no volume detectado.

As energias de ligação não são somente específicas para cada elemento, como também contêm informações químicas, pois os níveis de energia dos elétrons de caroço dependem do estado químico do átomo.

As análises foram realizadas em um instrumento Thermo VG MICROLAB 310F. Os dados foram coletados com fonte de Raios-X MgKa e 50eV de energia de passagem. As amostras foram preparadas na forma de pastilhas e fixadas em suporte de cobre por fita de cobre. Os efeitos de carga foram corrigidos usando o pico do $\mathrm{C}_{1 \mathrm{~s}}$. Os espectros foram analisados pelo programa Avantage Data Spectrum Processing.

\subsection{8 - Espectroscopia de Absorção de Raios-X (XAS)}

A espectroscopia de absorção de raios-X apresenta seletividade atômica, visto que a energia de ligação dos elétrons mais internos é característica de cada 
elemento químico, permitindo assim o estudo do ambiente químico ao redor do átomo de interesse do material investigado.

A borda de absorção refere-se à emissão fotoelétrica de um elétron contido em um nível de energia interno do átomo absorvedor, resultante da transferência de energia do fóton de raios- $X$ absorvido para o elétron. As informações estruturais e eletrônicas contidas nos espectros de absorção de raios-X podem ser encontradas na região XANES (que se estende até $\sim 50 \mathrm{eV}$ acima da borda de absorção), que contem informações estéreo-químicas, podendo-se obter informações sobre o estado de oxidação, e a região EXAFS (compreende a faixa de energia de 50 a 1000eV acima da borda de absorção), a partir da qual distâncias atômicas precisas e número de coordenação do átomo absorvedor podem ser obtidos (SOUZA, 2006; RIBEIRO, 2003).

Os experimentos foram realizados no Laboratório Nacional de Luz Síncrotron (LNLS) na linha de absorção de Raios-X no modo de transmissão utilizando um monocromador de $\mathrm{Si}(111)$.

O preparo das amostras para a obtenção dos espectros consistiu na prensagem de uma mistura contendo $150 \mathrm{mg}$ de amostra e $40 \mathrm{mg}$ de carbono teflonado formando uma pastilha de $2,5 \mathrm{~cm}^{2}$. Para os experimentos nas bordas de absorção do Ni e Co, o monocromador foi calibrado utilizando-se folhas metálicas dos respectivos elementos.

O sistema de aquisição de dados para o XAS foi composto por três detectores de ionização (incidência Io, transmitido It, referência $\mathrm{Ir}_{\mathrm{r}}$ ). O canal de referência foi empregado primeiramente para a calibração interna da posição da borda usando uma folha do metal puro. Nitrogênio foi usado nas câmaras lo, It e Ir. A análise dos dados de XAS foi feita utilizando o pacote WinXAS (RESSLER, 1997). 


\section{4 - Ensaios Catalíticos}

A atividade catalítica foi testada em micro-reatores tubulares de leito fixo a fim de analisar a conversão do metano e a atividade dos catalisadores para a produção de $\mathrm{H}_{2}, \mathrm{CO}$ e $\mathrm{CO}_{2}$ e a formação de carbono em função do tempo de reação. Os testes catalíticos foram realizados utilizando uma linha de reação consistindo de controladores de fluxo, a unidade do reator e o sistema analítico. O sistema de fluxo consiste de um conjunto de controladores de massa (Allborg, quatro canais) a fim de se controlar os gases alimentados no reator $\left(\mathrm{H}_{2}, \mathrm{CH}_{4}, \mathrm{~N}_{2}, \mathrm{O}_{2}\right)$. Os catalisadores foram depositados em um leito de lã de quartzo dentro de um micro-reator de fluxo contínuo (13 mm de diâmetro). A temperatura de operação foi controlada por um termopar dentro do forno e próximo ao leito catalítico. Antes das reações, $100 \mathrm{mg}$ de catalisador foram introduzidos dentro do reator e reduzidos in situ sob fluxo de $\mathrm{H}_{2}$ $\left(50 \mathrm{mLmin}^{-1}\right)$ a $550^{\circ} \mathrm{C}$ (taxa de aquecimento de $10^{\circ} \mathrm{Cmin}^{-1}$ ) por $1 \mathrm{~h}$. Em seguida a temperatura foi elevada a $750^{\circ} \mathrm{C}$, temperatura utilizada em todas as reações, sob fluxo de $\mathrm{N}_{2}$. Para as reações utilizou-se fluxo de $\mathrm{CH}_{4}$ de $40 \mathrm{mLmin}^{-1}$.

As análises dos reagentes e produtos gasosos foram realizadas em linha por cromatografia gasosa (equipamento Varian, modelo 3800) com dois detectores de condutividade térmica. O fluxo gasoso de produtos foi dividido em duas alíquotas por uma válvula de injeção automática. Uma destas alíquotas foi utilizada para analisar o $\mathrm{H}_{2}$ e $\mathrm{CH}_{4}$, os quais foram separados em uma coluna empacotada do tipo peneira molecular $13 \mathrm{X}$ usando $\mathrm{N}_{2}$ como gás de arraste. A segunda alíquota foi utilizada para analisar $\mathrm{CO}_{2}, \mathrm{CH}_{4}, \mathrm{CO}$ e $\mathrm{N}_{2}$. Hélio foi utilizado como gás de arraste, a separação foi feita por colunas empacotadas em seqüência, uma peneira molecular 13X e Porapak N. 
Ao final de $6 \mathrm{~h}$ de testes parou-se o fluxo de reagentes e o catalisador foi resfriado em atmosfera de $\mathrm{N}_{2}$ e reservado para análises posteriores.

\subsection{1 - Reforma a vapor do metano}

Para a reforma a vapor do metano a água foi bombeada até o vaporizador, onde foi aquecida a $180^{\circ} \mathrm{C}$. As razões molares testadas foram $\mathrm{H}_{2} \mathrm{O}_{\mathrm{v}}: \mathrm{CH}_{4}=4: 1 \mathrm{e}$ $\mathrm{H}_{2} \mathrm{O}_{\mathrm{v}}: \mathrm{CH}_{4}=2: 1$ para avaliar a conversão do metano e distribuição dos produtos e $\mathrm{H}_{2} \mathrm{O}_{\mathrm{v}}: \mathrm{CH}_{4}=0,5: 1$ para avaliar a estabilidade do catalisador frente a um excesso de $\mathrm{CH}_{4}$.

\subsection{2 - Oxidação Parcial do Metano}

Para a oxidação parcial do metano utilizou-se como reagente ar sintético, sendo que foi considerada a seguinte composição: $21 \% \mathrm{O}_{2}$ e $79 \%$ de $\mathrm{N}_{2}$. As razões molares utilizadas foram $\mathrm{CH}_{4}: \mathrm{O}_{2}=2: 1 \mathrm{e} \mathrm{CH}_{4}: \mathrm{O}_{2}=4: 1$.

\subsection{3 - Reforma Oxidativa do Metano}

Na reação combinada de reforma a vapor com oxidação parcial do metano utilizou-se a seguinte razão molar de alimentação $4 \mathrm{CH}_{4}: 4 \mathrm{H}_{2} \mathrm{O}: 1 \mathrm{O}_{2}$.

\subsection{4 - Cálculo das conversões}

Para o cálculo das conversões e dos rendimentos em produtos foram utilizadas as equações 8 e 9, apresentadas a seguir.

Conversão do Metano:

$$
\mathrm{X}_{\mathrm{CH} 4}=\frac{\text { Mols de } \mathrm{CH}_{4} \text { reagido }}{\text { Mols de } \mathrm{CH}_{4} \text { alimentado }}=\frac{\mathrm{F}_{\mathrm{CH} 4}^{0}-\mathrm{F}_{\mathrm{CH} 4}}{\mathrm{~F}_{\mathrm{CH} 4}^{0}}
$$


Rendimento em produtos:

$$
\mathrm{Mol}_{\text {prod }} / \mathrm{Mol}_{\mathrm{CH} 4 \text { conv }}=\frac{\text { Mols de i sa ída }}{\text { Mols de } \mathrm{CH}_{4} \text { convertido }}=\frac{\mathrm{F}_{\mathrm{i}}}{\mathrm{F}_{\mathrm{CH} 4 \mathrm{conv}}}
$$

Onde:

$\mathrm{F}_{\mathrm{CH} 4}^{0}=$ Fluxo Molar de $\mathrm{CH}_{4}$ na alimentação

$\mathbf{F}_{\mathrm{CH} 4}=$ Fluxo Molar de $\mathrm{CH}_{4}$ na saída

$\mathrm{F}_{\mathrm{i}}=$ Fluxo molar do componente $\mathrm{i}$

$\mathbf{X}_{\mathrm{CH}_{4}}=$ Conversão de Metano em produtos

$\mathrm{Mol}_{\text {prod } \mathrm{i}} / \mathrm{Mol}_{\mathrm{CH} 4 \text { conv }}=$ Rendimento i $/ \mathrm{mol}$ de $\mathrm{CH}_{4}$ convertido 


\section{5 - Resultados e Discussões}

\section{1 - Composição Elementar}

Nas Tabelas 1 e 2 encontram-se as relações molares dos metais para os óxidos mistos. As composições superficiais foram obtidas por XPS e as composições do bulk foram obtidas por EDX. A relação molar de partida nas sínteses das amostras $\operatorname{Tr}-\mathrm{Ni}(\mathrm{Co}), \mathrm{Ae}-\mathrm{La}(\mathrm{Ce})-\mathrm{Ni}(\mathrm{Co})$ foi $\mathrm{Ni}: \mathrm{Mg}: \mathrm{Al}=0,2: 1$ :0,4 sendo a relação $\mathrm{M}^{+3} / \mathrm{M}^{+2}=0,33$.; Para as amostras $\mathrm{Cp}-\mathrm{Ni}(\mathrm{Co})$ e $\mathrm{Ae}-\mathrm{Ni}(\mathrm{Co})$ utilizou-se a seguinte relação molar Mg:Al=1:0,33.

Os resultados obtidos por EDX mostram que as amostras não promovidas apresentaram uma perda de níquel e cobalto, obtendo-se desta forma valores menores do que os nominais e mostrando que a incorporação dos metais não foi completa. No método da co-precipitação e da troca-aniônica isto pode ser explicado pela competição entre os ânions do tipo quelato com o carbonato proveniente do ar e grupos hidroxilas (TSYGANOK; SAYARI, 2006).

Para as amostras promovidas observou-se uma perda em alumínio sugerindo a formação de complexos solúveis do tipo tetrahidroxialuminato (reação 26) os quais têm sua formação favorecida no pH utilizado nas sínteses (VOGEL, 1981):

$\mathrm{Al}(\mathrm{OH})_{3}+\mathrm{OH}^{-} \rightleftarrows\left[\mathrm{Al}(\mathrm{OH})_{4}\right]^{-}$

Comparando-se os resultados do bulk e da superfície é possível observar uma considerável diferença entre os valores de lantânio e cério, para os catalisadores promovidos. Estes resultados podem sugerir que apenas parte dos complexos foi introduzida entre as camadas da hidrotalcita e que parte destes complexos depositou-se na superfície do precursor. Uma outra hipótese pode ser devido ao tratamento térmico ter favorecido a migração dos promotores de maior raio iônico 
para a superfície. O mesmo comportamento foi observado para catalisadores de cobalto. Os catalisadores de níquel não apresentaram grandes variações entre as concentrações de bulk e de superfície.

Tabela 1. Composição elementar na superfície obtida por análise de XPS e composição elementar do bulk obtida por EDX para as amostras de óxidos mistos de níquel.

\begin{tabular}{|c|c|c|c|c|}
\hline Amostra & $\begin{array}{l}\text { Composição (XPS) } \\
\mathrm{Ni} / \mathrm{Mg} / \mathrm{Al} / \mathrm{La} / \mathrm{Ce}\end{array}$ & $\mathrm{M}^{+3} / \mathrm{M}^{+2}$ & $\begin{array}{l}\text { Composição (EDX) } \\
\mathrm{Ni} \text { Mg Al La Ce }\end{array}$ & $\mathrm{M}^{+3} / \mathrm{M}^{+2}$ \\
\hline $\mathrm{Tr}-\mathrm{Ni}$ & $0,11 / 1 / 0,34 /-/$ - & 0,31 & $0,11 / 1 / 0,40 /-/-$ & 0,36 \\
\hline $\mathrm{Cp}-\mathrm{Ni}$ & $0,09 / 1 / 0,38 /-/-$ & 0,35 & $0,10 / 1 / 0,35 /-/-$ & 0,32 \\
\hline $\mathrm{Ae}-\mathrm{Ni}$ & $0,07 / 1 / 0,30 /-/$ - & 0,28 & $0,08 / 1 / 0,34 /-/$ - & 0,32 \\
\hline Ae-La-Ni & $0,11 / 1 / 0,22 / 0,04 /-$ & 0,23 & $0,11 / 1 / 0,20 / 0,01 /$ - & 0,19 \\
\hline $\mathrm{Ae}-\mathrm{Ce}-\mathrm{Ni}$ & $0,09 / 1 / 0,28 /-/ 0,05$ & 0,30 & $0,10 / 1 / 0,23 /-/ 0,02$ & 0,22 \\
\hline
\end{tabular}

Tabela 2. Composição elementar na superfície obtida por análise de XPS e composição elementar do bulk obtida por EDX para as amostras de óxidos mistos de cobalto.

\begin{tabular}{|l|l|c|l|c|}
\hline Amostra & $\begin{array}{l}\text { Composição (XPS) } \\
\text { Co Mg Al La Ce }\end{array}$ & $\mathrm{M}^{+3} / \mathrm{M}^{+2}$ & $\begin{array}{l}\text { Composição (EDX) } \\
\text { Co Mg Al La Ce }\end{array}$ & $\mathrm{M}^{+3} / \mathrm{M}^{+2}$ \\
\hline Tr-Co & $0,16 / 1 / 0,32 /-/-$ & 0,31 & $0,10 / 1 / 0,40 /-/$ - & 0,36 \\
\hline Cp-Co & $0,31 / 1 / 0,40 /-/-$ & 0,35 & $0,13 / 1 / 0,40 /-/$ - & 0,35 \\
\hline Ae-Co & $0,31 / 1 / 0,40 /-/-$ & 0,28 & $0,13 / 1 / 0,40 /-/-$ & 0,35 \\
\hline Ae-La-Co & $0,25 / 1 / 0,18 / 0,06 /-$ & 0,23 & $0,11 / 1 / 0,20 / 0,01 /-$ & 0,19 \\
\hline Ae-Ce-Co & $0,29 / 1 / 0,32 /-/ 0,06$ & 0,30 & $0,11 / 1 / 0,20 /-/ 0,03$ & 0,21 \\
\hline
\end{tabular}

\section{2 - Área Superficial Específica, Raio Médio e Volume Total de Poros}

Na Tabela 3 estão apresentados os resultados de análise textural dos catalisadores. 
Tabela 3. Área Superficial Específica, Raio Médio e Volume Total de Poros para os catalisadores de níquel e cobalto.

\begin{tabular}{|c|c|c|c|}
\hline Amostra & $\begin{array}{c}\text { Área } \\
\left(\mathrm{m}^{2} \mathrm{~g}^{-1}\right)\end{array}$ & $\begin{array}{c}\text { Raio médio } \\
(\AA)\end{array}$ & $\begin{array}{c}\text { Volume total de } \\
\text { poros }\left(\mathrm{cm}^{3} \mathrm{~g}^{-1}\right)\end{array}$ \\
\hline $\mathrm{Tr}-\mathrm{Ni}$ & 129 & 13,7 & 0,09 \\
\hline $\mathrm{Cp}-\mathrm{Ni}$ & 167 & 22,3 & 0,19 \\
\hline $\mathrm{Ae}-\mathrm{Ni}$ & 200 & 29,6 & 0,30 \\
\hline Ae-La-Ni & 150 & 51,5 & 0,38 \\
\hline Ae-Ce-Ni & 162 & 29,5 & 0,24 \\
\hline Tr-Co & 132 & 31,4 & 0,15 \\
\hline Cp-Co & 184 & 32,1 & 0,29 \\
\hline Ae-Co & 206 & 52,8 & 0,30 \\
\hline Ae-La-Co & 116 & 37,1 & 0,31 \\
\hline Ae-Ce-Co & 133 & & \\
\hline
\end{tabular}

Os resultados mostram um aumento das áreas superficiais específicas para as amostras preparadas por complexos do tipo quelatos. Esta observação é válida para todos os catalisadores exceto para o catalisador de cobalto promovido com lantânio. Também se observa o aumento do raio médio e do volume total dos poros para as amostras preparadas por estes métodos.

De acordo com a literatura tem-se que para hidrotalcitas de magnésio e alumínio precipitadas com carbonato, quanto maior a quantidade de alumínio na estrutura maior será a quantidade de ânions na intercamada para compensar a carga formada na folha de brucita. Esta maior quantidade de ânions de compensação acarreta, com o tratamento térmico, uma maior evolução de $\mathrm{H}_{2} \mathrm{O}$ e $\mathrm{CO}_{2}$ e conseqüentemente um aumento na área superficial e no aparecimento de 
poros na faixa de 20-40A (CANTRELL et al., 2005; CIOLA, 1981; CHMIERLARZ et al., 2003).

As amostras preparadas por meio de complexos do tipo quelatos apresentaram maiores áreas, raio médio de poros e volume de poros do que as preparadas pelo método tradicional com precipitação de carbonato, apesar de a quantidade de alumínio nestas amostras terem sido menores do que as do método tradicional, isto ocorre, possivelmente, devido à liberação de $\mathrm{CO}_{2}$ oriundo da decomposição dos grupos carboxílicos presentes nos complexos de EDTA intercalados na estrutura (TSYGANOK; SAYARI, 2006).

\section{3 - Análise Termogravimétrica (ATG)}

A decomposição térmica de amostras do tipo hidrotalcita apresenta um perfil típico, geralmente caracterizado por duas transições endotérmicas. A primeira transição $\left(90-297^{\circ} \mathrm{C}\right)$ corresponde à perda da água da intercamada e a segunda, em maiores temperaturas, corresponde a desidroxilação das camadas de brucita e à decomposição de ânions de compensação (VACCARI, 1998), o que está de acordo com os perfis apresentados nas Figuras 2 e 3.

De acordo com Chmielarz et al. (2003) hidrotalcitas de Mg-Al decompõem-se com perda total de massa da ordem de $45 \%$, enquanto que a perda total de massa para hidrotalcitas contendo metais de transição é geralmente de 2 a 3\% menor.

No presente trabalho, hidrotalcitas preparadas pelo método tradicional apresentaram a decomposição térmica em duas etapas, sendo a etapa 1 entre 40 $240^{\circ} \mathrm{C}$ e a etapa 2 entre $250-900^{\circ} \mathrm{C}$. Com relação à perda de massa, pôde-se observar 3 picos, onde a temperatura de $80^{\circ} \mathrm{C}$ foi suficiente para remover a água e $\mathrm{CO}_{2}$ fisissorvidos. A temperatura de $200^{\circ} \mathrm{C}$ foi necessária para a dessorção de água estrutural e o terceiro pico em $380^{\circ} \mathrm{C}$ pode ser relacionado à perda simultânea de 
moléculas de água oriundas da decomposição de hidroxilas das folhas de brucita e da dessorção de $\mathrm{CO}_{2}$ da intercamada (PÉREZ-RAMIREZ et al., 2001). A perda total de massa para os precursores de níquel e cobalto foi de aproximadamente $42 \%$.

Considerando os precursores obtidos a partir de complexos do tipo quelatos, as amostras também apresentaram a decomposição térmica em duas etapas. Com relação à perda de massa também se pôde observar 3 picos para as amostras Cp$\mathrm{Ni}(\mathrm{Co})-\mathrm{LDH}$ e Ae-Ni-LDH. Assim como para as amostras preparadas pelo método tradicional, os dois primeiros picos, em temperaturas da ordem de $80^{\circ} \mathrm{C}$ e $200^{\circ} \mathrm{C}$, sendo referentes à água e $\mathrm{CO}_{2}$ fissisorvidos e dessorção da água estrutural, respectivamente. O terceiro pico, posicionado por volta de $400^{\circ} \mathrm{C}$, pode ser considerado como sendo resultante da perda simultânea de água, decomposição de grupos hidroxila e da decomposição de ânions da intercamada. Neste caso pôde-se observar, na Figura 2 uma pronunciada diferença entre as perdas de massa da etapa 1 para a etapa 2, o que não foi observado para as amostras preparadas pelo método tradicional. Esta diferença ocorre devido à liberação de $\mathrm{CO}_{2}$ oriundo da decomposição dos grupos carboxílicos presentes nos complexos de EDTA intercalados na estrutura (TSYGANOK; SAYARI, 2006). A perda total de massa para estes precursores foi de aproximadamente $44 \%$.

Para os precursores de níquel e cobalto promovidos (Figura 3), bem como para o precursor Ae-Co-LDH observa-se mais do que 3 picos para a perda de massa, esta diferença ocorre provavelmente devido à evolução de $\mathrm{H}_{2} \mathrm{O}, \mathrm{CO}_{2}$ e $\mathrm{NO}$ oriundos de diferentes ambientes na estrutura, visto a complexidade da molécula de EDTA. As amostras também apresentaram por volta de $44 \%$ de perda total de massa, exceto as amostras promovidas com cério que apresentaram $42 \%$. 

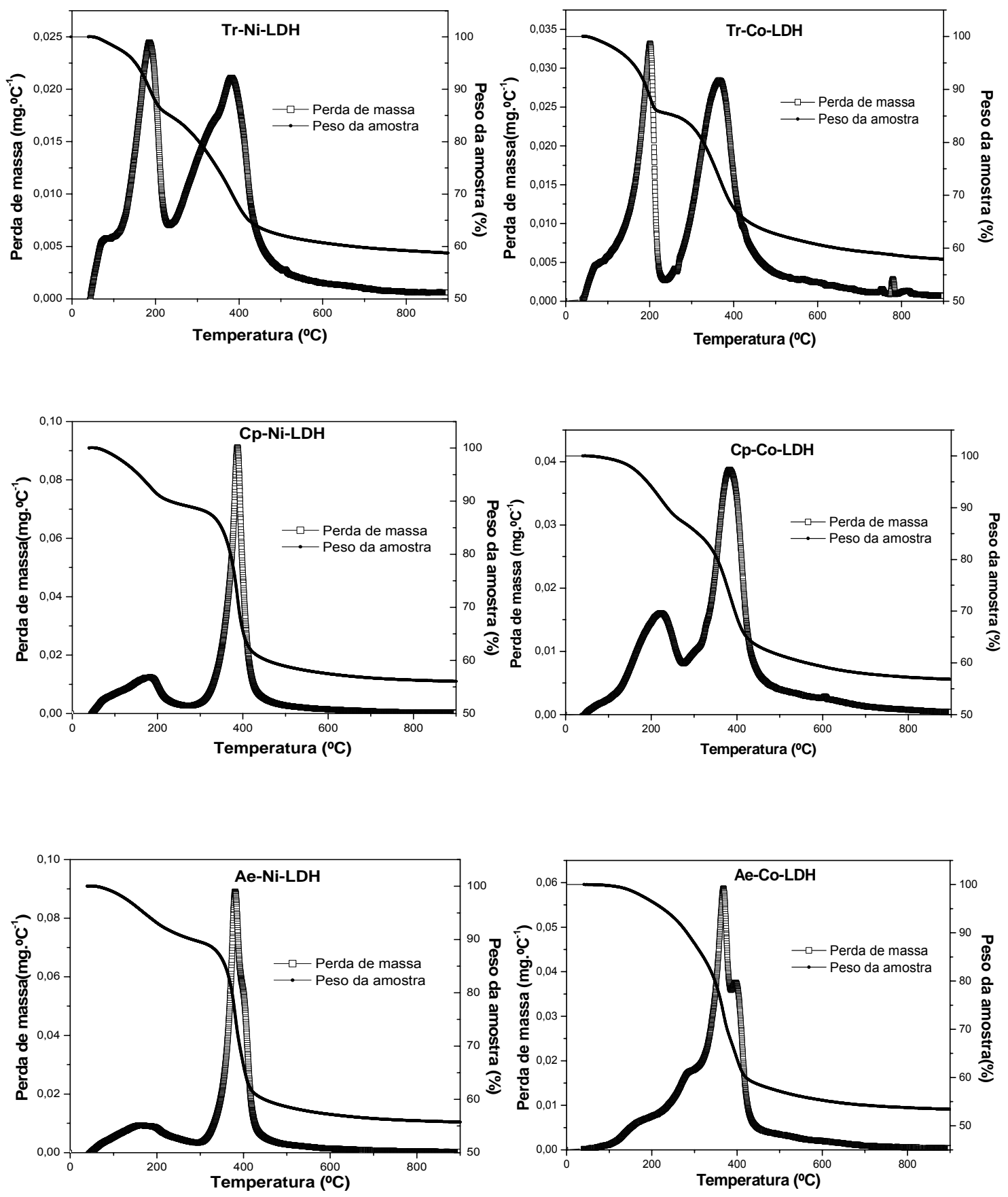

Figura 2. Perfis de ATG e DTG para os precursores de níquel e cobalto. 

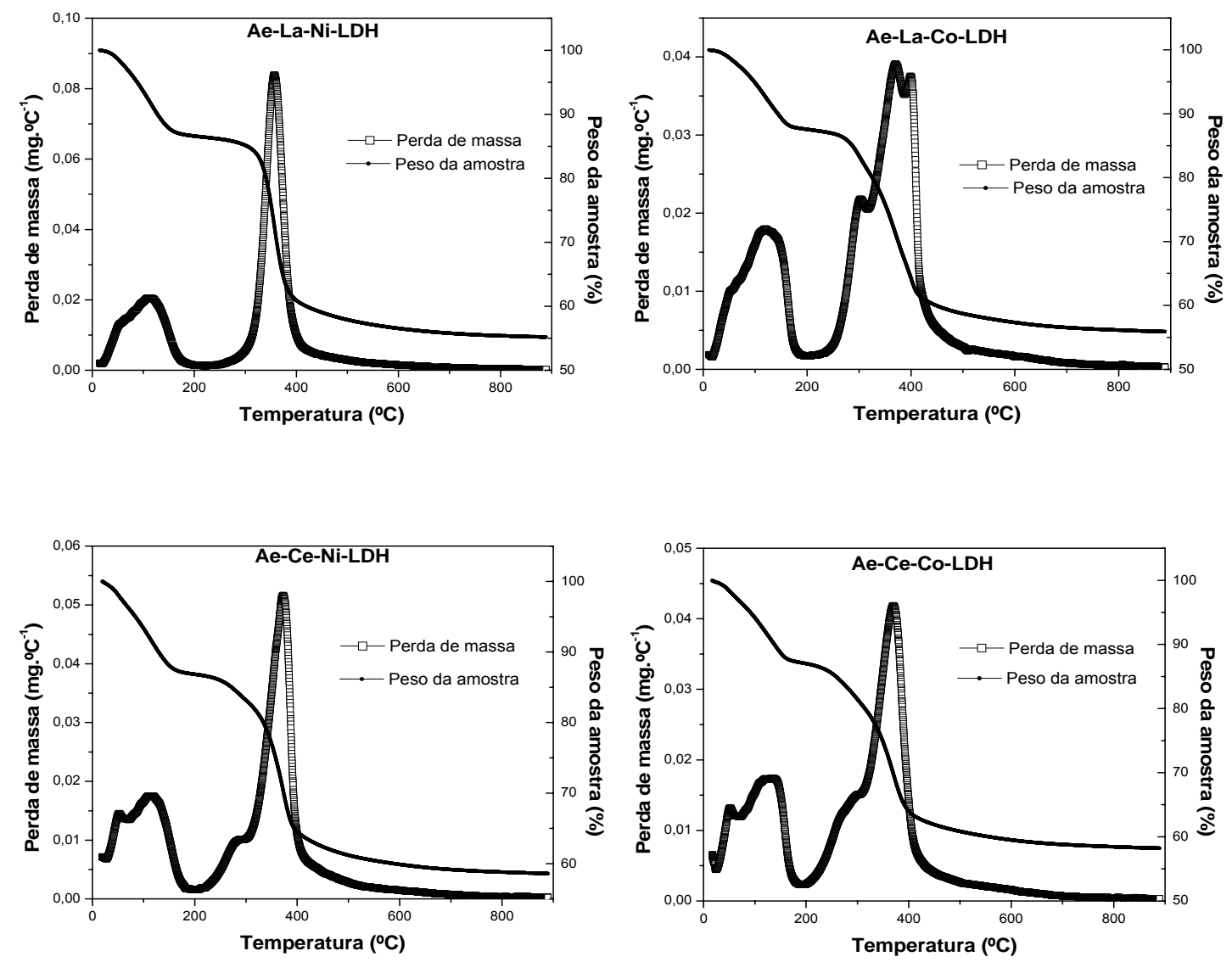

Figura 3. Perfis de ATG/DTG para os precursores de níquel e cobalto promovidos com lantânio ou cério.

\section{4 - Difração de Raios-X pelo Método do Pó (DRX)}

Na Figura 4 estão apresentados os difratogramas dos precursores de níquel. Para todos os precursores observa-se que houve a formação da fase hidrotalcita. Para as amostras não-promovidas e para a amostra promovida com lantânio não foi observada nenhuma fase adicional a hidrotalcita, enquanto que para a amostra promovida com cério observam-se linhas de difração adicionais indicando um excesso de cério, na forma de $\mathrm{Ce}(\mathrm{OH})_{3}$, o qual não foi não incorporado na estrutura. Os difratogramas da fase hidrotalcita exibem reflexões finas e simétricas para os planos (003), (006), (110) e (113) e reflexões amplas e assimétricas para os planos 
(102), (105) e (108), característicos de compostos lamelares cristalinos de simetria romboédrica (CASENAVE et al., 2001; PÉREZ-RAMIREZ et al., 2001).

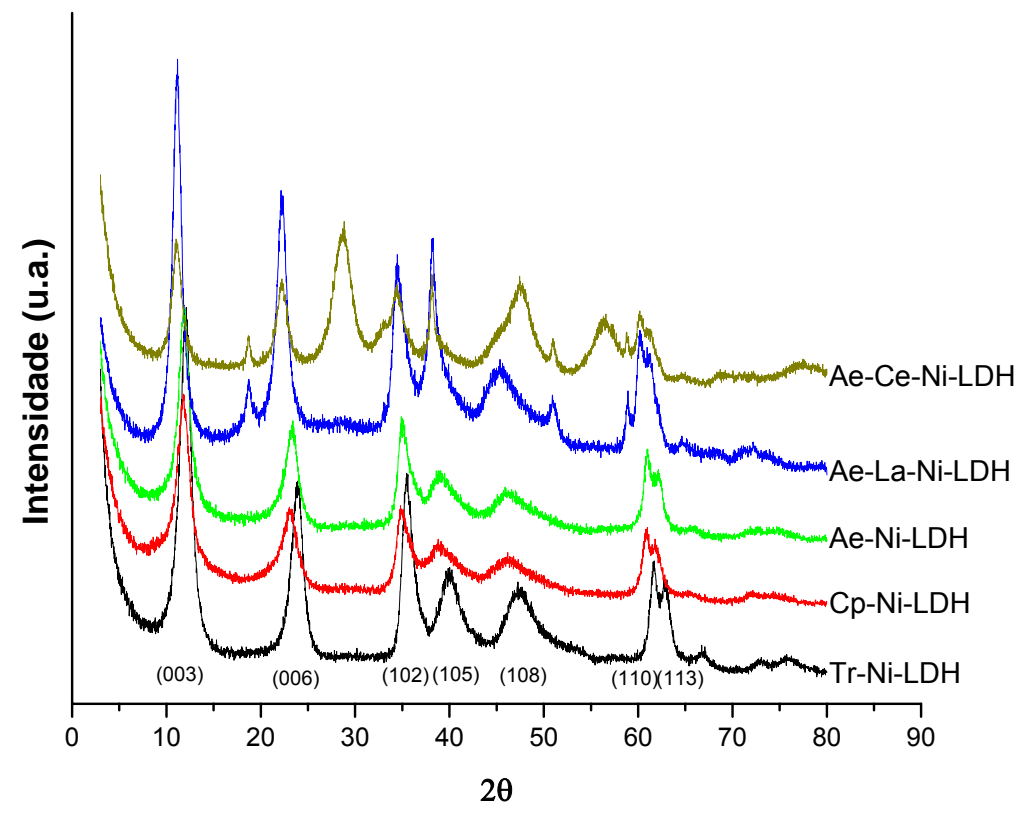

Figura 4. Difratogramas de Raios- $X$ dos precursores dos catalisadores preparados por diferentes métodos e promovidos $\left(\mathrm{H}=\right.$ hidrotalcita; $\left.{ }^{*}=\mathrm{Ce}(\mathrm{OH})_{3}\right)$.

$\mathrm{Na}$ Tabela 4 estão indicados os valores dos parâmetros de rede $a$ e o parâmetro c para os precursores.

Tabela 4. Parâmetros de rede $a$ e $c$ dos precursores e tamanho de partícula calculado a partir da equação de Scherrer.

\begin{tabular}{|c|c|c|c|c|}
\hline Amostra & $\begin{array}{c}\text { Razão } \\
\mathbf{M}^{\mathbf{+ 3}} / \mathbf{M}^{\mathbf{+ 2}}\end{array}$ & $\begin{array}{c}\text { Parâmetro } \boldsymbol{a} \\
\mathbf{( n m})\end{array}$ & $\begin{array}{c}\text { Parâmetro } \mathbf{c} \\
\mathbf{( n m})\end{array}$ & $\begin{array}{c}\text { Tamanho da } \\
\text { Partícula (nm) }\end{array}$ \\
\hline Tr-Ni-LDH & 0,36 & 0,301 & 2,219 & 5,2 \\
\hline Cp-Ni-LDH & 0,32 & 0,304 & 2,277 & 4,5 \\
\hline Ae-Ni-LDH & 0,32 & 0,304 & 2,275 & 6,3 \\
\hline Ae-La-Ni-LDH & 0,19 & 0,306 & 2,390 & 7,4 \\
\hline Ae-Ce-Ni-LDH & 0,22 & 0,306 & 2,389 & 7,3 \\
\hline
\end{tabular}


Pode-se observar que os precursores preparados via quelatos não apresentaram grande variação nos valores de $a$ (correspondente à distância cátioncátion na folha octaédrica de brucita), indicando que não houve a incorporação do complexo nas folhas de brucita e nem dos promotores cério ou lantânio, que apresentam um alto valor de raio iônico e que levariam ao aumento do valor deste parâmetro. Para os valores do parâmetro $c$ (referente a três vezes o tamanho da folha de brucita mais a intercamada), observa-se um pequeno aumento no valor deste parâmetro com a introdução dos quelatos, porém menor do que o valor reportado por Li et al. (2004), que apresenta valores da ordem de $4 \mathrm{~nm}$ para a hidrotalcita $\mathrm{Mg}_{2} \mathrm{Al}-\mathrm{EuY}$.

Nas Figura 5 a 9 são apresentados os difratogramas dos precursores de níquel e dos óxidos mistos obtidos por calcinação.

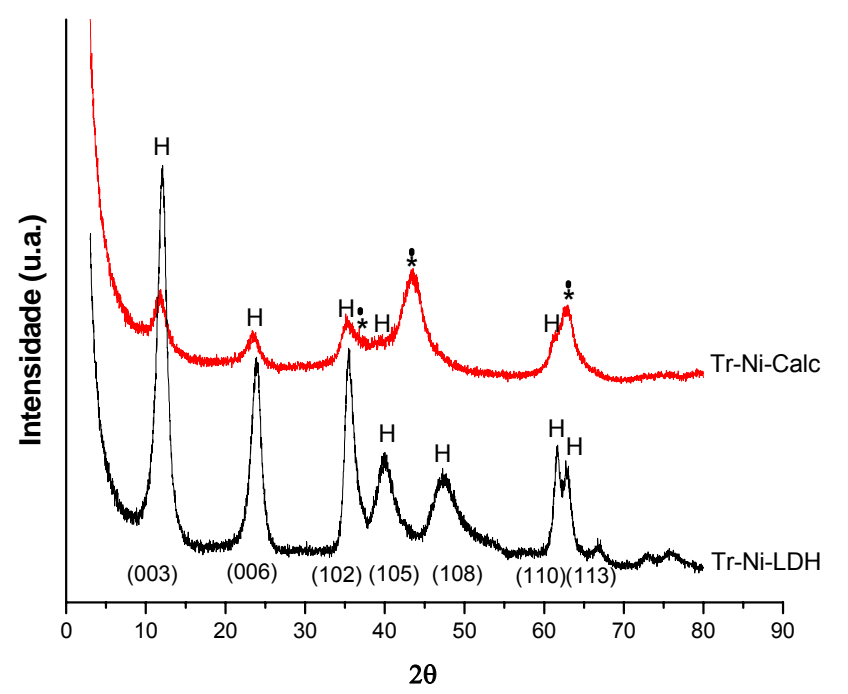

Figura 5. Difratogramas de Raios-X: precursor preparado pelo método tradicional, Tr-Ni-LDH e da mistura de óxidos obtida por calcinação, Tr-Ni-Calc. ( $\mathrm{H}=$ hidrotalcita; ${ }^{*}=\mathrm{MgO}$ e/ou $\mathrm{NiO} ; \bullet=\mathrm{MgAl}_{2} \mathrm{O}_{4}$ ou $\mathrm{NiAl}_{2} \mathrm{O}_{4}$ ) 


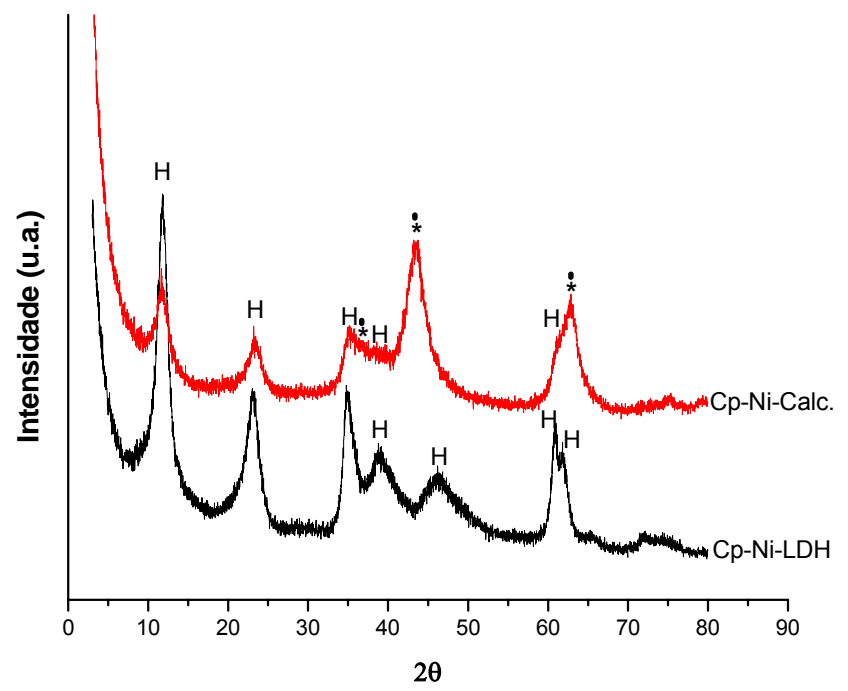

Figura 6. Difratogramas de Raios-X: precursor preparado pelo método da co-precipitação, Cp-Ni-LDH e da mistura de óxidos obtida por calcinação, $\mathrm{Cp}-\mathrm{Ni}-\mathrm{Calc}$. $\left(\mathrm{H}=\right.$ hidrotalcita; ${ }^{*}=\mathrm{MgO}$ e/ou NiO; $\cdot=\mathrm{MgAl}_{2} \mathrm{O}_{4}$ ou $\mathrm{NiAl}_{2} \mathrm{O}_{4}$ )

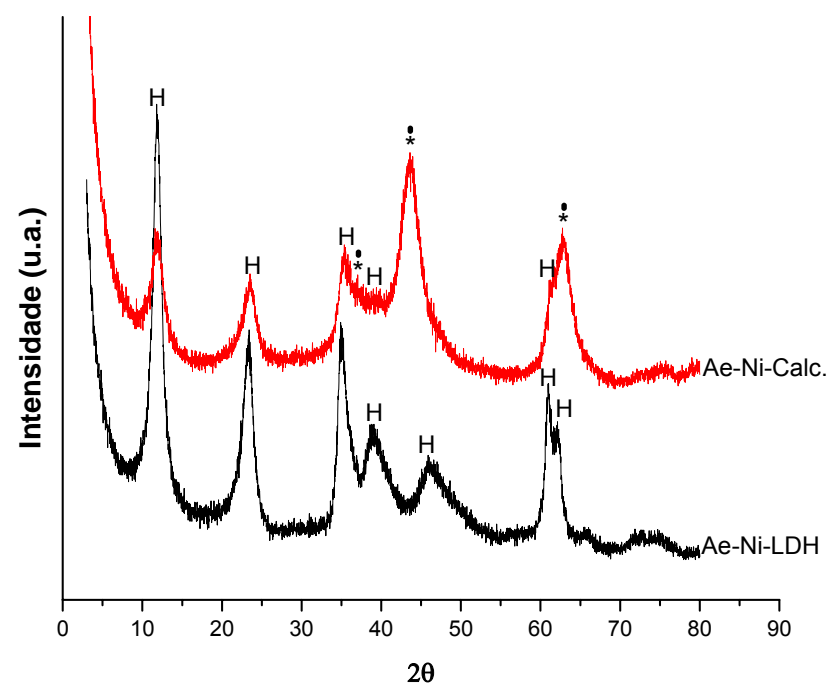

Figura 7. Difratogramas de Raios-X: precursor preparado pelo método da troca-aniônica, Ae-Ni-LDH e da mistura de óxidos obtida por calcinação, Ae-Ni-Calc. ( $\mathrm{H}=$ hidrotalcita; ${ }^{*}=\mathrm{MgO}$ e/ou NiO;

$\cdot=\mathrm{MgAl}_{2} \mathrm{O}_{4}$ ou $\mathrm{NiAl}_{2} \mathrm{O}_{4}$ ) 


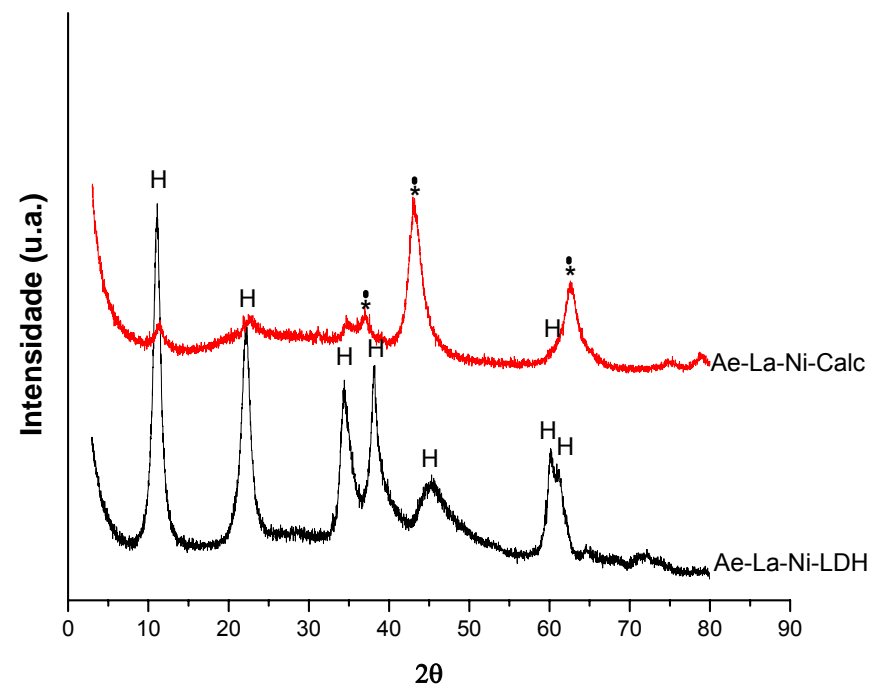

Figura 8. Difratogramas de Raios-X: precursor promovido com lantânio, Ae-La-Ni-LDH e da mistura de óxidos obtida por calcinação, Ae-La-Ni-Calc. (H=hidrotalcita; * $=\mathrm{MgO}$ e/ou NiO; $\bullet=\mathrm{MgAl}_{2} \mathrm{O}_{4}$ ou $\mathrm{NiAl}_{2} \mathrm{O}_{4}$ )

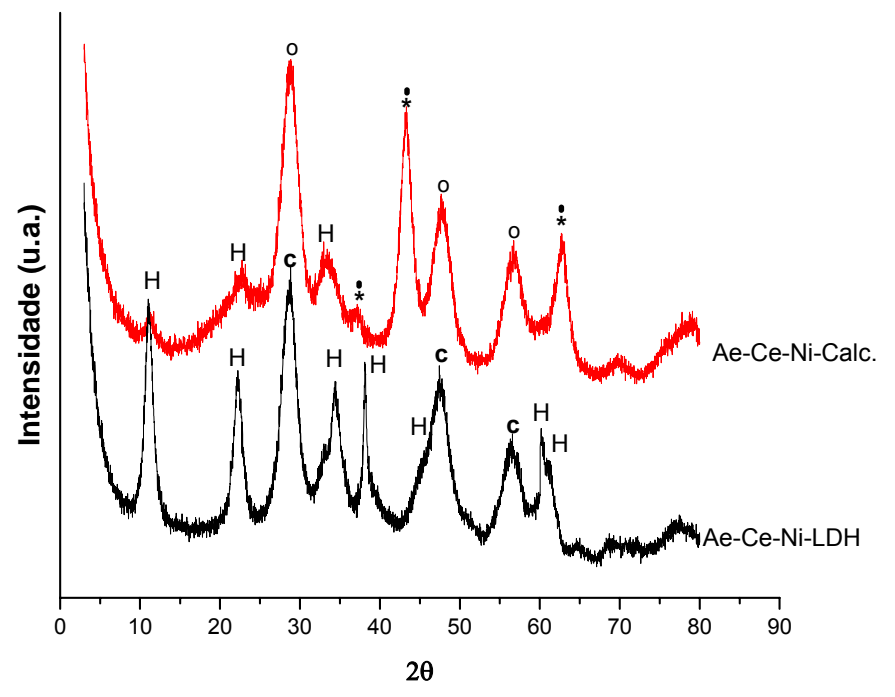

Figura 9. Difratogramas de Raios-X: precursor promovido com cério, $\mathrm{Ae}-\mathrm{Ce}-\mathrm{Ni}-\mathrm{LDH}$ e da mistura de óxidos obtida por calcinação, Ae-Ce-Ni-Calc. ( $\mathrm{H}=$ hidrotalcita; * $=\mathrm{MgO}$ ou $\mathrm{NiO} ; \bullet=\mathrm{MgAl}_{2} \mathrm{O}_{4}$ ou $\mathrm{NiAl}_{2} \mathrm{O}_{4}$; o: $\left.\mathrm{CeO}_{2}\right)$

A calcinação levou ao desaparecimento da fase hidrotalcita e ao aparecimento de novos picos, com parâmetros de rede intermediários entre as fases $\mathrm{NiO}$ e MgO, como pode ser visto na Tabela 5, e possível sobreposição de picos 
destas fases com as fases $\mathrm{NiAl}_{2} \mathrm{O}_{4}$ e $\mathrm{MgAl}_{2} \mathrm{O}_{4}$ (Apêndice A, Figuras entre A3 e A5 ). Estes resultados estão de acordo com dados reportados na literatura por vários autores (TAKEHIRA et al., 2005; REBOURS et al., 1994; GAZZANO et al., 1997), onde devido à alta homogeneidade dos óxidos na mistura, que ocorre devido ao método de preparação, não somente as espécies $\mathrm{Ni}^{+2}$, mas também espécies $\mathrm{Al}^{+3}$ substituem o $\mathrm{Mg}^{+2}$ formando a solução sólida, ou seja, ocorre a formação da estrutura do tipo periclásio $\mathrm{Mg}(\mathrm{Al}) \mathrm{O}$ contendo $\mathrm{Ni}$, no processo de calcinação da hidrotalcita $\mathrm{Mg}(\mathrm{Ni})-\mathrm{Al}$.

Portanto, pode-se considerar que os óxidos mistos preparados a partir do tratamento térmico dos precursores do tipo hidrotalcita a $500^{\circ} \mathrm{C}(773 \mathrm{~K})$, neste trabalho, constituem do periclásio $\mathrm{Mg}(\mathrm{Al}, \mathrm{Ni}) \mathrm{O}$ podendo haver a coexistência da estrutura espinélica $(\mathrm{Mg}, \mathrm{Ni}) \mathrm{Al}_{2} \mathrm{O}_{4}$.

Pode-se observar nas Tabelas 4 e 5 que a adição de promotores levou a um aumento do tamanho de partícula.

Tabela 5. Parâmetro de rede $a$ (calculado com base nas distâncias do plano 220); tamanho de partícula calculado a partir da equação de Scherrer.

\begin{tabular}{|c|c|c|}
\hline Amostra & $\begin{array}{c}\text { Parâmetro a } \\
\text { (nm) }\end{array}$ & $\begin{array}{c}\text { Tamanho da Partícula } \\
\text { (nm) }\end{array}$ \\
\hline Tr-Ni-Calc. & 0,416 & 2,8 \\
\hline Cp-Ni-Calc. & 0,416 & 2,9 \\
\hline Ae-Ni-Calc. & 0,415 & 4,7 \\
\hline Ae-La-Ni-Calc. & 0,418 & 4,5 \\
\hline Ae-Ce-Ni-Calc. & 0,418 & - \\
\hline $\mathrm{MgO}^{*}$ & 0,421 & - \\
\hline $\mathrm{NiO}^{*}$ & 0,418 & \\
\hline
\end{tabular}

*(JCPDS, 1994) 
$\mathrm{Na}$ Figura 10 estão apresentados os difratogramas dos precursores de cobalto. Os resultados são semelhantes aos dos precursores de níquel, onde se pode observar a formação da estrutura do tipo hidrotalcita, sem formação de fases adicionais, com exceção da amostra promovida com cério.

As mesmas observações feitas para os parâmetros de rede $a$ e $c$ dos catalisadores de níquel são feitas os catalisadores de cobalto que seguiram o mesmo comportamento das amostras de níquel, como pode ser visto na Tabela 6,

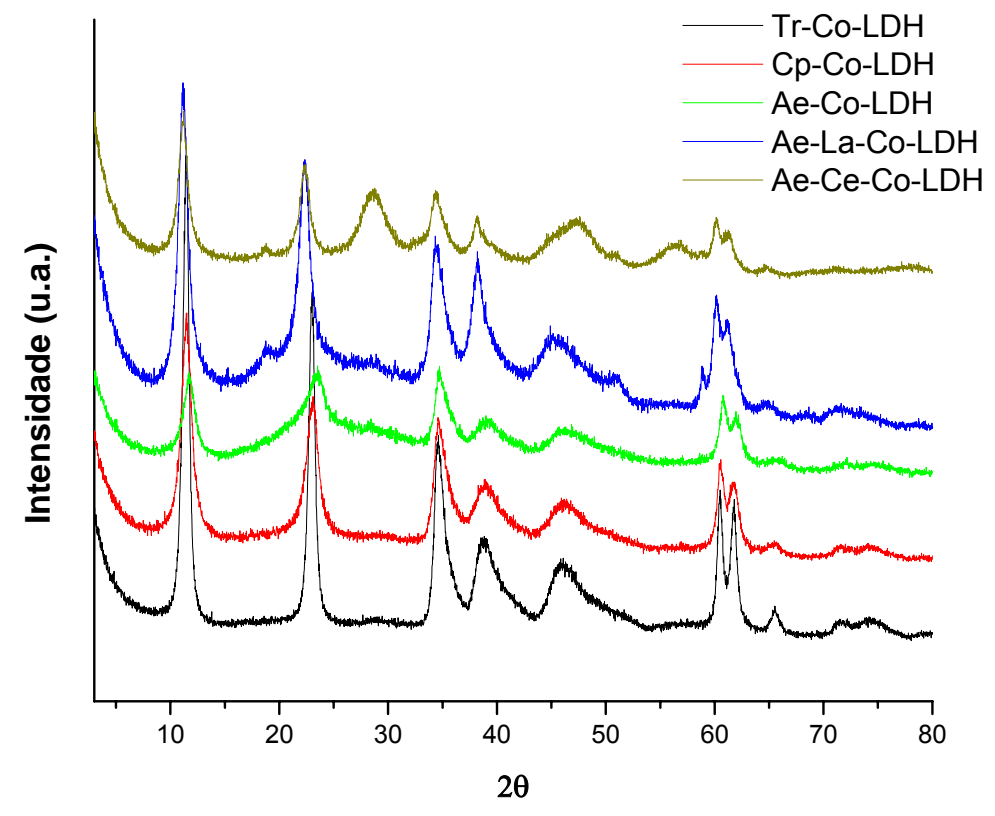

Figura 10. Difratogramas de Raios- $X$ dos precursores dos catalisadores preparados por diferentes métodos e promovidos $\left(\mathrm{H}=\right.$ hidrotalcita; $\left.{ }^{*}=\mathrm{Ce}(\mathrm{OH})_{3}\right)$. 
Tabela 6. Parâmetros de rede $a$ (calculado com base nas distâncias do plano 110); c (calculado com base nas distâncias do plano (006)) dos precursores e tamanho de partícula calculado a partir da equação de Scherrer.

\begin{tabular}{|c|c|c|c|c|}
\hline Amostra & $\begin{array}{l}\text { Razão } \\
\mathrm{M}^{+3} / \mathrm{M}^{+2}\end{array}$ & $\begin{array}{c}\text { Parâmetro } a \\
\text { (nm) }\end{array}$ & $\begin{array}{c}\text { Parâmetro c } \\
\text { (nm) }\end{array}$ & $\begin{array}{c}\text { Tamanho da } \\
\text { Partícula (nm) }\end{array}$ \\
\hline Tr-Co-LDH & 0,36 & 0,305 & 2,264 & 9,7 \\
\hline Cp-Co-LDH & 0,35 & 0,306 & 2,306 & 6,2 \\
\hline Ae-Co-LDH & 0,35 & 0,305 & 2,282 & 6,2 \\
\hline Ae-La-Co-LDH & 0,19 & 0,307 & 2,382 & 7,4 \\
\hline Ae-Ce-Co-LDH & 0,21 & 0,307 & 2,391 & 7,4 \\
\hline
\end{tabular}

Tabela 7. Parâmetros de rede $a$ (calculado com base nas distâncias do plano 220); tamanho de partícula calculado a partir da equação de Scherrer.

\begin{tabular}{|c|c|c|}
\hline Amostra & $\begin{array}{c}\text { Parâmetro a } \\
\mathbf{( n m})\end{array}$ & $\begin{array}{c}\text { Tamanho da Partícula } \\
\text { (nm) }\end{array}$ \\
\hline Tr-Co-Calc. & 0,415 & 3,4 \\
\hline Cp-Co-Calc. & 0,414 & 3,5 \\
\hline Ae-Co-Calc. & 0,414 & 4,5 \\
\hline Ae-Co-Calc. & 0,419 & 6,3 \\
\hline Ae-Co-Calc. & 0,418 & - \\
\hline MgO $^{*}$ & 0,421 & - \\
\hline CoO $^{*}$ & 0,426 & \\
\hline
\end{tabular}

* JCPDS (1994)

Nas Figura 11 a 15 estão apresentados os difratogramas dos precursores de cobalto e dos óxidos mistos obtidos por calcinação.

Os resultados dos parâmetros de rede a (Tabela 7) para as amostras calcinadas de cobalto seguem o mesmo comportamento dos catalisadores de níquel, o que indica que os precursores do tipo hidrotalcita levaram a uma dispersão 
homogênea dos cátions na mistura oxida, sugerindo que os óxidos mistos estão principalmente na forma do periclásio $\mathrm{Mg}(\mathrm{Co}, \mathrm{Al}) \mathrm{O}$ juntamente com o espinélio $\mathrm{Co}_{3} \mathrm{O}_{4}$ podendo haver a coexistência da estrutura espinélica $(\mathrm{Mg}, \mathrm{Co}) \mathrm{Al}_{2} \mathrm{O}_{4}$.

Assim como os catalisadores de níquel, os catalisadores de cobalto também apresentaram um aumento no tamanho de partícula com a adição de promotores.

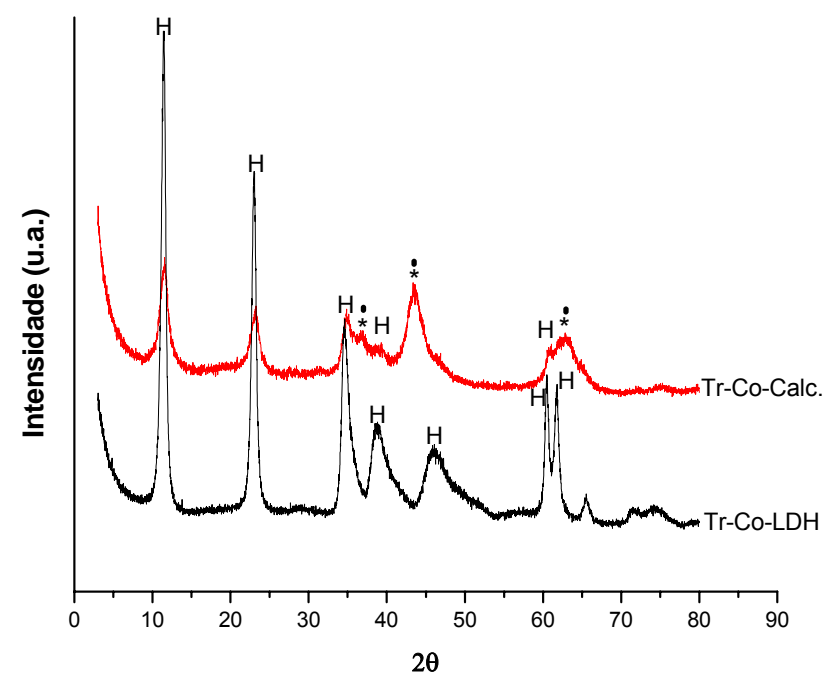

Figura 11. Difratogramas de Raios-X: precursor preparado pelo método tradicional, Tr-Co-LDH e da mistura de óxidos obtida por calcinação, Tr-Co-Calc. ${ }^{*}=\mathrm{MgO}, \mathrm{CoO} ; \bullet \cdot \mathrm{Co}_{3} \mathrm{O}_{4}$ e/ou $\mathrm{MgAl}_{2} \mathrm{O}_{4}$ e/ou $\mathrm{Co}_{2} \mathrm{AlO}_{4}$ e/ou $\mathrm{CoAl}_{2} \mathrm{O}_{4}$ e/ou $\mathrm{MgCO}_{2} \mathrm{O}_{4}$ ) 


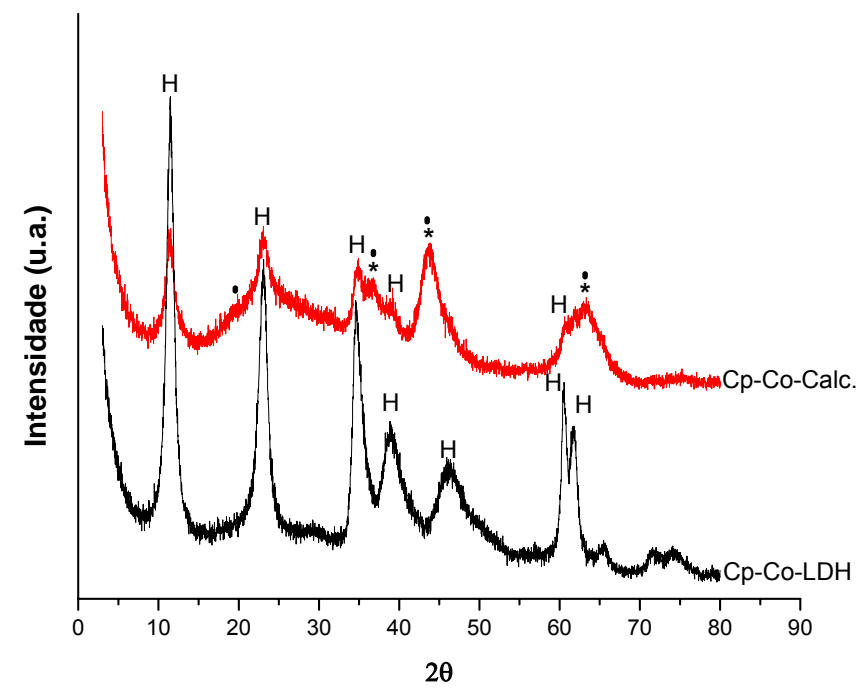

Figura 12. Difratogramas de Raios- $X$ : precursor preparado pelo método da co-precipitação, $\mathrm{Cp}$-Co$\mathrm{LDH}$ e da mistura de óxidos obtida por calcinação, $\mathrm{Cp}$-Co-Calc. ${ }^{*}=\mathrm{MgO}, \mathrm{CoO} ; \bullet=\mathrm{Co}_{3} \mathrm{O}_{4} \mathrm{e} / \mathrm{ou}$ $\mathrm{MgAl}_{2} \mathrm{O}_{4}$ e/ou $\mathrm{Co}_{2} \mathrm{AlO}_{4}$ e/ou $\mathrm{CoAl}_{2} \mathrm{O}_{4}$ e/ou $\mathrm{MgCo}_{2} \mathrm{O}_{4}$ )

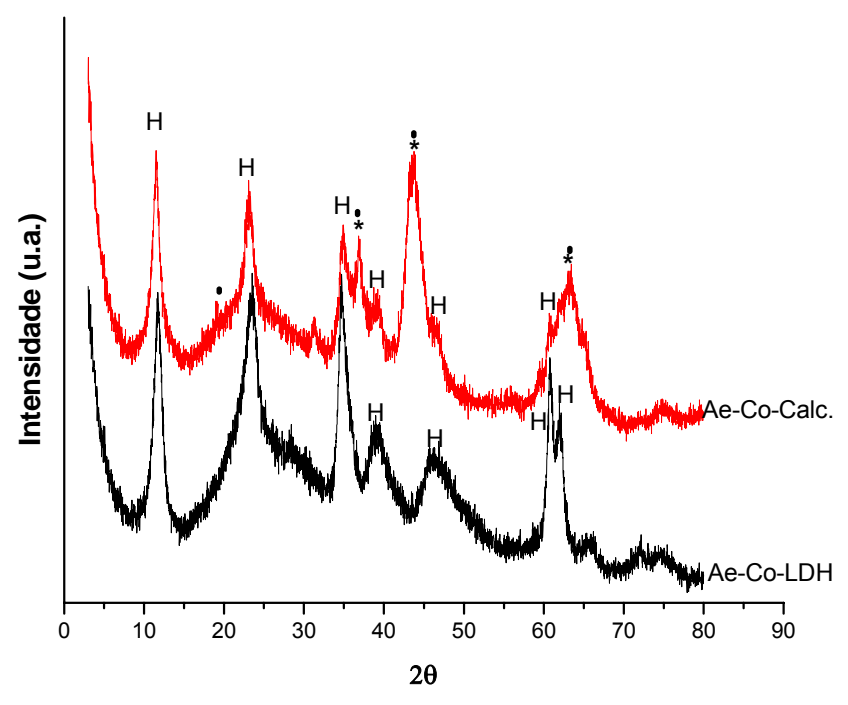

Figura 13. Difratogramas de Raios-X: precursor preparado pelo método da troca-aniônica, Ae-Co$\mathrm{LDH}$ e da mistura de óxidos obtida por calcinação, Ae-Co-Calc. $\left({ }^{*}=\mathrm{MgO}, \mathrm{CoO} ; \bullet=\mathrm{Co}_{3} \mathrm{O}_{4}\right.$ e/ou $\mathrm{MgAl}_{2} \mathrm{O}_{4}$ e/ou $\mathrm{Co}_{2} \mathrm{AlO}_{4}$ e/ou $\mathrm{CoAl}_{2} \mathrm{O}_{4}$ e/ou $\mathrm{MgCo}_{2} \mathrm{O}_{4}$ ) 


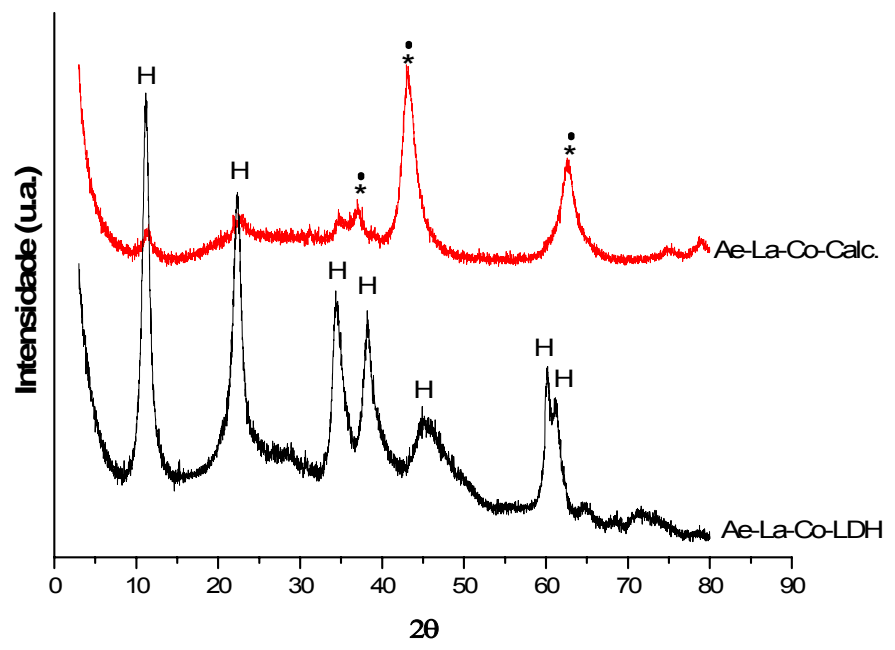

Figura 14. Difratogramas de Raios-X: precursor promovido com lantânio, Ae-La-Co-LDH e da mistura de óxidos obtida por calcinação, Ae-La-Co-Calc. ${ }^{*}=\mathrm{MgO}, \mathrm{CoO} ; \bullet=\mathrm{Co}_{3} \mathrm{O}_{4}$ e/ou $\mathrm{MgAl}_{2} \mathrm{O}_{4}$ e/ou $\mathrm{Co}_{2} \mathrm{AlO}_{4}$ e/ou $\mathrm{CoAl}_{2} \mathrm{O}_{4}$ e/ou $\mathrm{MgCo}_{2} \mathrm{O}_{4}$ )

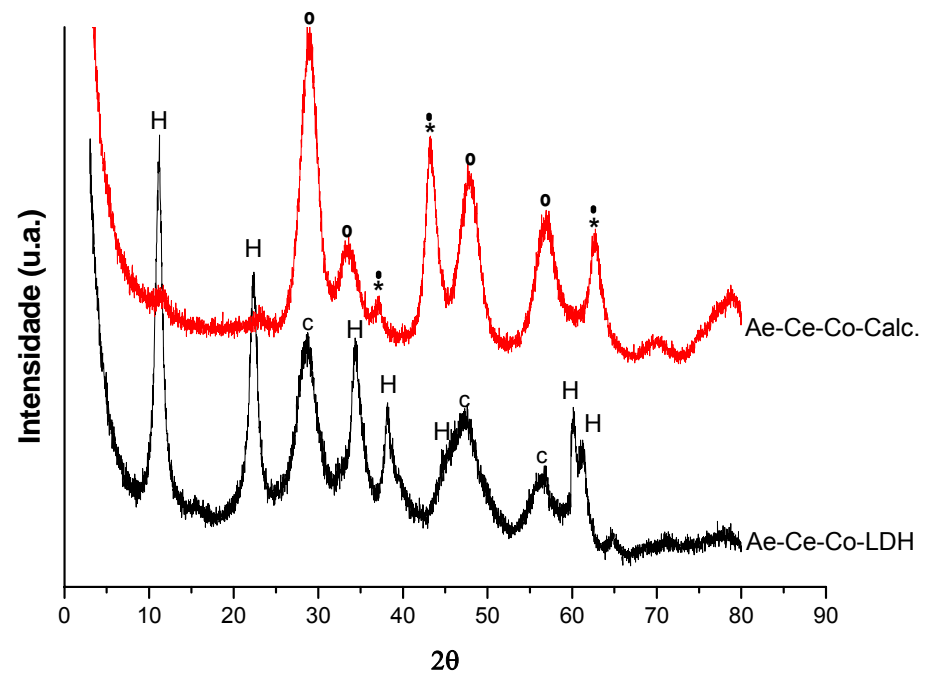

Figura 15. Difratogramas de Raios- $X$ : precursor promovido com cério, Ae-Ce-Co-LDH e da mistura de óxidos obtida por calcinação, Ae-Ce-Co-Calc. ${ }^{*}=\mathrm{MgO}, \mathrm{CoO} ; \bullet=\mathrm{Co}_{3} \mathrm{O}_{4}$ e/ou $\mathrm{MgAl}_{2} \mathrm{O}_{4}$ e/ou $\mathrm{Co}_{2} \mathrm{AlO}_{4}$ e/ou $\mathrm{CoAl}_{2} \mathrm{O}_{4}$ e/ou $\mathrm{MgCo}_{2} \mathrm{O}_{4} ; \mathrm{o}=\mathrm{CeO}_{3}$ ) 


\section{5 - Espectroscopia de infravermelho com Transformada de Fourier (FTIR)}

A análise de infravermelho foi utilizada para verificar a ocorrência ou não da introdução de espécies de complexos do tipo quelatos $[\mathrm{MeY}]^{-\mathrm{x}}$ nas intercamadas da hidrotalcita. As amostras de níquel e cobalto, promovidas ou não, preparadas por quelatos foram comparadas com as preparadas pelo método tradicional de precipitação com carbonatos e os resultados estão apresentados nas Figura 16 e Figura 17 e os valores das bandas de absorção obtidas para cada catalisador estão mostrados nas Tabelas 8 e 9. As Figuras são apresentadas na região de 1000 a $2000 \mathrm{~cm}^{-1}$ e 2500 a $4000 \mathrm{~cm}^{-1}$ de modo a facilitar a visualização das bandas observadas. A região abaixo de $1000 \mathrm{~cm}^{-1}$ se deve principalmente a vibrações da rede estrutural, porém a análise por infravermelho nesta região se torna difícil devido ao alto nível de ruído (KLOPROGGE; FROST, 1999).

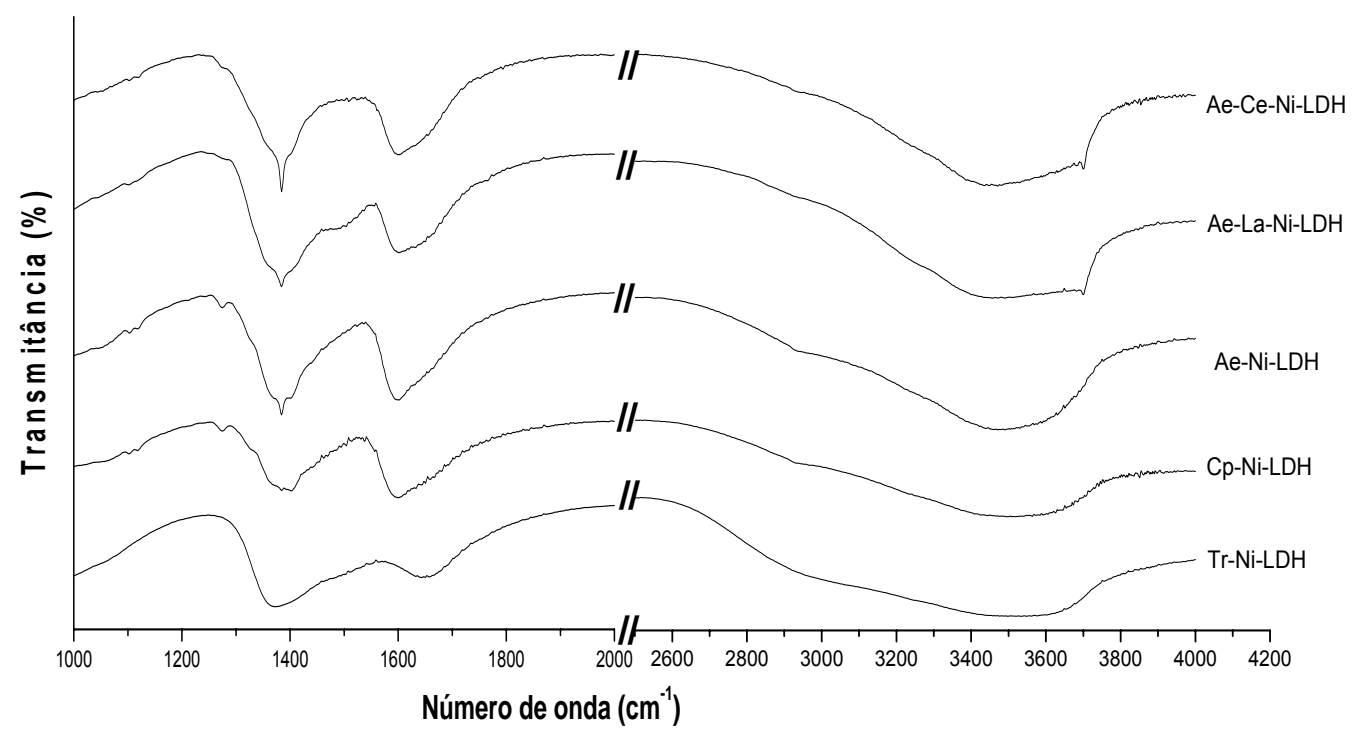

Figura 16. Espectro de infravermelho para as hidrotalcitas precursoras de níquel. 


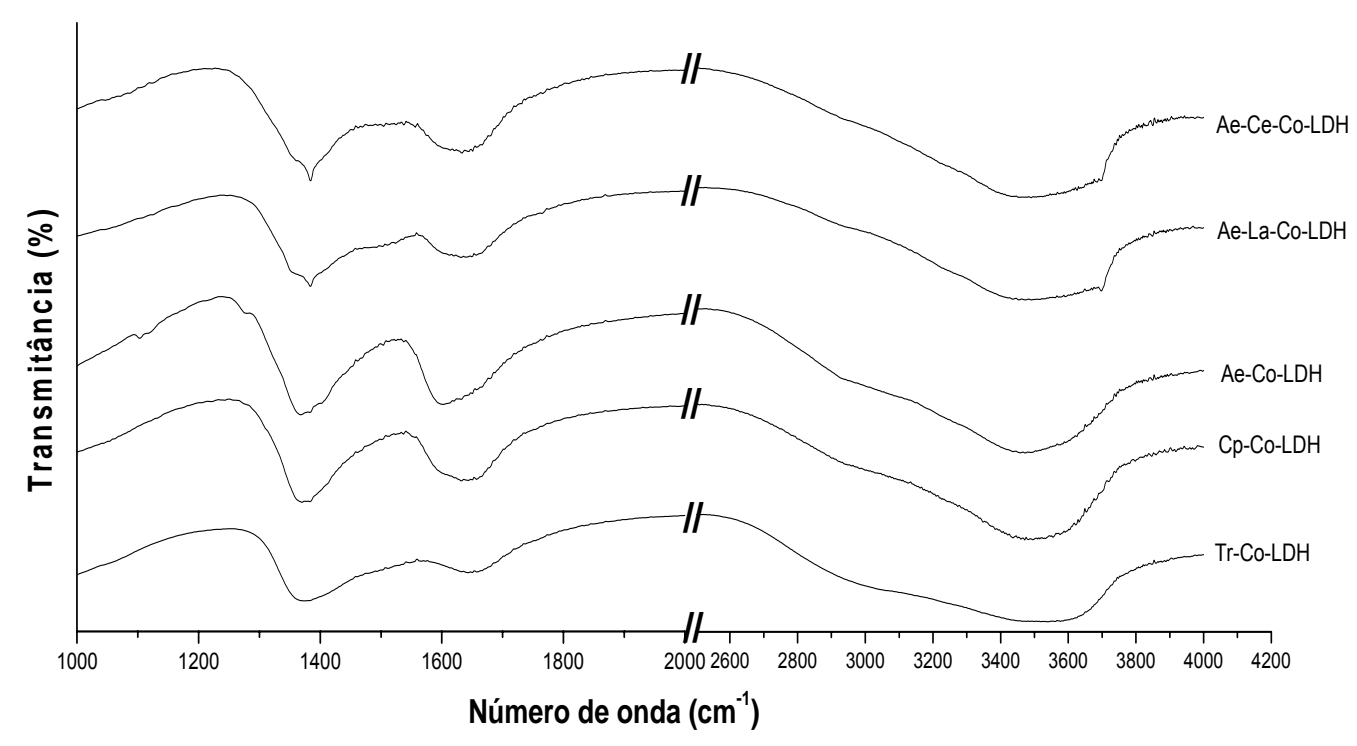

Figura 17. Espectro de infravermelho para as hidrotalcitas precursoras de cobalto.

Os espectros obtidos para as hidrotalcitas são similares aos apresentados na literatura, sendo que as amostras preparadas pelo método tradicional apresentam uma intensa banda de absorção na região de $1360 \mathrm{~cm}^{-1}$, referente ao estiramento de modo assimétrico dos ânions nitrato e carbonato da intercamada da hidrotalcita (KLOPROGGE; FROST, 1999; TSYGANOK; SAYARI, 2006; LI et al., 2004). O amplo pico de média intensidade na região de $1620-1640 \mathrm{~cm}^{-1}$ é referenciado a modos de vibração do tipo deformação angular das moléculas de água presente nos materiais. Também se observa uma ampla banda de absorção centrada na faixa de 2900 a $3500 \mathrm{~cm}^{-1}$, que segundo Kroprogge e Frost (1999) corresponde à sobreposição de 3 picos na região de 3000,3300 e $3470 \mathrm{~cm}^{-1}$, sendo a banda na região de $3000 \mathrm{~cm}^{-1}$ referente a uma forte interação entre os hidrogênios de moléculas de água e o íon carbonato na intercamada $\mathrm{CO}_{3}^{-2}-\mathrm{H}_{2} \mathrm{O}$, a segunda banda por volta de $3300 \mathrm{~cm}^{-1}$ seria referente às interações hidrogênio entre as moléculas de água da intercamada e a última seria referente a diferentes modos de estiramento da ligação $\mathrm{Me}-\mathrm{OH}$. 
Os espectros dos precursores obtidos por quelatos apresentam algumas diferenças em relação ao método tradicional, com o aparecimento de novas bandas de absorção. A intensa banda na região de $1500-1600 \mathrm{~cm}^{-1}$ é atribuída ao modo de vibração do tipo estiramento assimétrico do grupo $-\mathrm{COO}^{-}$coordenado ao metal, enquanto que o ombro na faixa de 1630-1660 poderia ser devido ao modo de vibração do tipo estiramento assimétrico do grupo -COO` não coordenado ao metal, como também aos modos de vibração do tipo deformação angular de moléculas de água presente nos materiais (LI et a., 2004, TSYGANOK; SAYARI, 2006).

Tabela 8. Bandas de absorção dos precursores do tipo hidrotalcita de níquel.

\begin{tabular}{|c|c|c|}
\hline Amostra & $\begin{array}{l}\text { Bandas de } \\
\text { Absorção }\left(\mathrm{cm}^{-1}\right)\end{array}$ & Atribuição das bandas \\
\hline $\begin{array}{l}\mathrm{Tr}-\mathrm{Ni} \\
\mathrm{NiMgAl}-\mathrm{CO}_{3}\end{array}$ & $\begin{array}{l}1366,1448 \\
1640 \\
3511\end{array}$ & $\begin{array}{l}\mathrm{CO}_{3}^{-} \text {e } \mathrm{NO}_{3}^{-} \text {na intercamada } \\
\mathrm{H}_{2} \mathrm{O} \text { : Deformação angular } \\
\text { Estiramento referentes à ligação }-\mathrm{OH} \text { e } \mathrm{H}_{2} \mathrm{O} \text { : }\end{array}$ \\
\hline $\begin{array}{l}\text { Cp-Ni } \\
\text { Cp-MgAl-(NiY) }\end{array}$ & $\begin{array}{l}1275 \\
1379,1437 \\
1600,1670 \\
2922 \\
3508 \\
\end{array}$ & $\begin{array}{l}\text { Estiramento } \mathrm{C}-\mathrm{C}\left(\mathrm{CH}_{2}-\mathrm{COO} \text { do quelato }\right) \\
\mathrm{CO}_{3}^{-} \text {e } \mathrm{NO}_{3}^{-} \text {na intercamada e estiramento } \\
\text { simétrico da ligação } \mathrm{COO}^{-} \\
\text {Estiramento assimétrico da ligação } \mathrm{COO}^{-} \\
\text {Estiramento } \mathrm{C}-\mathrm{H}\left(\mathrm{CH}_{2} \text { do quelato }\right) \\
\text { Estiramentos referentes à ligação }-\mathrm{OH} \text { e } \mathrm{H}_{2} \mathrm{O}\end{array}$ \\
\hline $\begin{array}{l}\mathrm{Ae}-\mathrm{Ni} \\
\mathrm{Ae}-\mathrm{MgAl}-(\mathrm{NiY})^{-2}\end{array}$ & $\begin{array}{l}1274 \\
1384,1417 \\
1597,1646 \\
2936 \\
3485\end{array}$ & $\begin{array}{l}\text { Estiramento } \mathrm{C}-\mathrm{C} \\
\mathrm{CO}_{3}^{-} \text {e } \mathrm{NO}_{3}^{-} \text {na intercamada e estiramento } \\
\text { simétrico da ligação } \mathrm{COO}^{-} \\
\text {Estiramento assimétrico da ligação } \mathrm{COO}^{-} \\
\text {Estiramento } \mathrm{C}-\mathrm{H} \\
\text { Estiramento } \mathrm{OH} \text { e } \mathrm{H}_{2} \mathrm{O}\end{array}$ \\
\hline $\begin{array}{l}\text { Ae-La-Ni } \\
\text { Ae-NiMgAl-(LaY) }\end{array}$ & $\begin{array}{l}1275 \\
1384,1486 \\
1601,1648 \\
2928 \\
3470,3690 \\
\end{array}$ & $\begin{array}{l}\text { Estiramento } \mathrm{C}-\mathrm{C} \\
\mathrm{CO}_{3}^{-} \text {e } \mathrm{NO}_{3}^{-} \text {na intercamada e estiramento } \\
\text { simétrico da ligação } \mathrm{COO} \\
\text { Estiramento assimétrico da ligação COO- } \\
\text { Estiramento } \mathrm{C}-\mathrm{H} \\
\text { Estiramento } \mathrm{OH} \text { e } \mathrm{H}_{2} \mathrm{O}\end{array}$ \\
\hline $\begin{array}{l}\text { Ae-Ce-Ni } \\
\text { Ae-NiMgAl-)CeY) }\end{array}$ & $\begin{array}{l}1275 \\
1383,1459 \\
1601,1640 \\
2930 \\
3475,3690 \\
\end{array}$ & $\begin{array}{l}\text { Estiramento } \mathrm{C}-\mathrm{C} \\
\mathrm{CO}_{3}^{-} \text {e } \mathrm{NO}_{3}^{-} \text {na intercamada e estiramento } \\
\text { simétrico da ligação COO- } \\
\text { Estiramento assimétrico da ligação COO- } \\
\text { Estiramento } \mathrm{C}-\mathrm{H} \\
\text { Estiramento } \mathrm{OH} \text { e } \mathrm{H}_{2} \mathrm{O}\end{array}$ \\
\hline
\end{tabular}

Segundo Li et al. (2004), as bandas por volta de $1400 \mathrm{~cm}^{-1}$ seriam devido a modos de vibração simétricos de grupos - $\mathrm{COO}^{-}$coordenados ao metal e também 
referente ao estiramento de modo assimétrico dos ânions nitrato e carbonato da intercamada da hidrotalcita . Ainda observa-se o aparecimento de bandas de fraca intensidade na região de $2900 \mathrm{~cm}^{-1}$, devido ao estiramento das ligações $\mathrm{C}-\mathrm{H}$, do grupo $\mathrm{CH}_{2}$ do quelato, e também um fraco pico na região de $1270-1275 \mathrm{~cm}^{-1}$, que ocorre devido ao estiramento da ligação $\mathrm{C}-\mathrm{C}$ do grupo $\mathrm{CH}_{2}-\mathrm{COO}^{-}$do quelato (TSYGANOK; SAYARI, 2006). Os precursores preparados com lantânio e cério ainda apresentam uma banda adicional na região de $3680-3690 \mathrm{~cm}^{-1}$, que segundo a literatura se deve a ligação $\mathrm{Me}-\mathrm{OH}$. Neste caso, o maior número observado de onda é devido à alta massa molecular destes metais (KROPROGGE; FROST, 1999).

Tabela 9. Bandas de absorção dos precursores do tipo hidrotalcita de cobalto.

\begin{tabular}{|c|c|c|}
\hline Amostra & $\begin{array}{l}\text { Bandas de } \\
\text { Absorção }\left(\mathrm{cm}^{-1}\right)\end{array}$ & Atribuição das bandas \\
\hline $\begin{array}{l}\text { Tr-Co } \\
\text { CoMgAl-CO }\end{array}$ & $\begin{array}{l}1368,1418 \\
1630,1650 \\
3100,3511\end{array}$ & $\begin{array}{l}\mathrm{CO}_{3}^{-} \text {e } \mathrm{NO}_{3}^{-} \text {na intercamada } \\
\mathrm{H}_{2} \mathrm{O} \text { : Deformação angular } \\
\mathrm{OH} \text { e } \mathrm{H}_{2} \mathrm{O} \text { : estiramento }\end{array}$ \\
\hline $\begin{array}{l}\text { Cp-Co } \\
\text { Cp-MgAl-(CoY)-2 }\end{array}$ & $\begin{array}{l}1368,1423 \\
1603,1650 \\
2940 \\
3100,3508 \\
\end{array}$ & $\begin{array}{l}\mathrm{CO}_{3}^{-} \text {e } \mathrm{NO}_{3}^{-} \text {na intercamada e estiramento } \\
\text { simétrico da ligação } \mathrm{COO} \text { - } \\
\text { Estiramento assimétrico da ligação COO- } \\
\text { Estiramento } \mathrm{C}-\mathrm{H}\left(\mathrm{CH}_{2} \text { do quelato) }\right. \\
\text { Estiramento } \mathrm{OH} \text { e } \mathrm{H}_{2} \mathrm{O}\end{array}$ \\
\hline $\begin{array}{l}\mathrm{Ae}-\mathrm{Co} \\
\mathrm{Ae}-\mathrm{MgAl}-(\mathrm{CoY})^{-2}\end{array}$ & $\begin{array}{l}1274 \\
1370,1437 \\
1600,1650 \\
2935 \\
3485\end{array}$ & $\begin{array}{l}\text { Estiramento } \mathrm{C}-\mathrm{C}\left(\mathrm{CH}_{2}-\mathrm{COO} \text { do quelato) }\right. \\
\mathrm{CO}_{3}^{-} \text {e } \mathrm{NO}_{3}^{-} \text {na intercamada e estiramento } \\
\text { simétrico da ligação } \mathrm{COO}- \\
\text { Estiramento assimétrico da ligação } \mathrm{COO}- \\
\text { Estiramento } \mathrm{C}-\mathrm{H}\left(\mathrm{CH}_{2} \text { do quelato }\right) \\
\text { Estiramento } \mathrm{OH} \text { e } \mathrm{H}_{2} \mathrm{O}\end{array}$ \\
\hline $\begin{array}{l}\text { Ae-La-Co } \\
\text { Ae-CoMgAl-(LaY) }\end{array}$ & $\begin{array}{l}1275 \\
1374,1497 \\
1608,1631 \\
2947 \\
3490,3690 \\
\end{array}$ & $\begin{array}{l}\text { Estiramento } \mathrm{C}-\mathrm{C}\left(\mathrm{CH}_{2}-\mathrm{COO} \text { do quelato }\right) \\
\mathrm{CO}_{3}^{-} \text {e } \mathrm{NO}_{3}^{-} \text {na intercamada e estiramento } \\
\text { simétrico da ligação } \mathrm{COO}- \\
\text { Estiramento assimétrico da ligação } \mathrm{COO}- \\
\text { Estiramento } \mathrm{C}-\mathrm{H}\left(\mathrm{CH}_{2} \text { do quelato }\right) \\
\text { Estiramento } \mathrm{OH} \mathrm{e} \mathrm{H}_{2} \mathrm{O}\end{array}$ \\
\hline $\begin{array}{l}\mathrm{Ae}-\mathrm{Ce}-\mathrm{Co} \\
\mathrm{Ae}-\mathrm{CoMgAl}-\mathrm{CeY})^{-1}\end{array}$ & $\begin{array}{l}1275 \\
1385,1500 \\
1601,1640 \\
2935 \\
3480,3680\end{array}$ & $\begin{array}{l}\text { Estiramento } \mathrm{C}-\mathrm{C}\left(\mathrm{CH}_{2}-\mathrm{COO} \text { do quelato }\right) \\
\mathrm{CO}_{3}^{-} \text {e } \mathrm{NO}_{3}^{-} \text {na intercamada e estiramento } \\
\text { simétrico da ligação } \mathrm{COO}- \\
\text { Estiramento assimétrico da ligação } \mathrm{COO}- \\
\text { Estiramento } \mathrm{C}-\mathrm{H}\left(\mathrm{CH}_{2} \text { do quelato }\right) \\
\text { Estiramento } \mathrm{OH} \mathrm{e} \mathrm{H}_{2} \mathrm{O}\end{array}$ \\
\hline
\end{tabular}




\section{6 - Redução a temperatura programada (RTP)}

Os ensaios de RTP para os catalisadores de níquel estão representados pelas Figuras 18 a 22.

Nas Figuras 18, 19 e 20 estão apresentados os perfis de RTP dos catalisadores de níquel não promovidos.

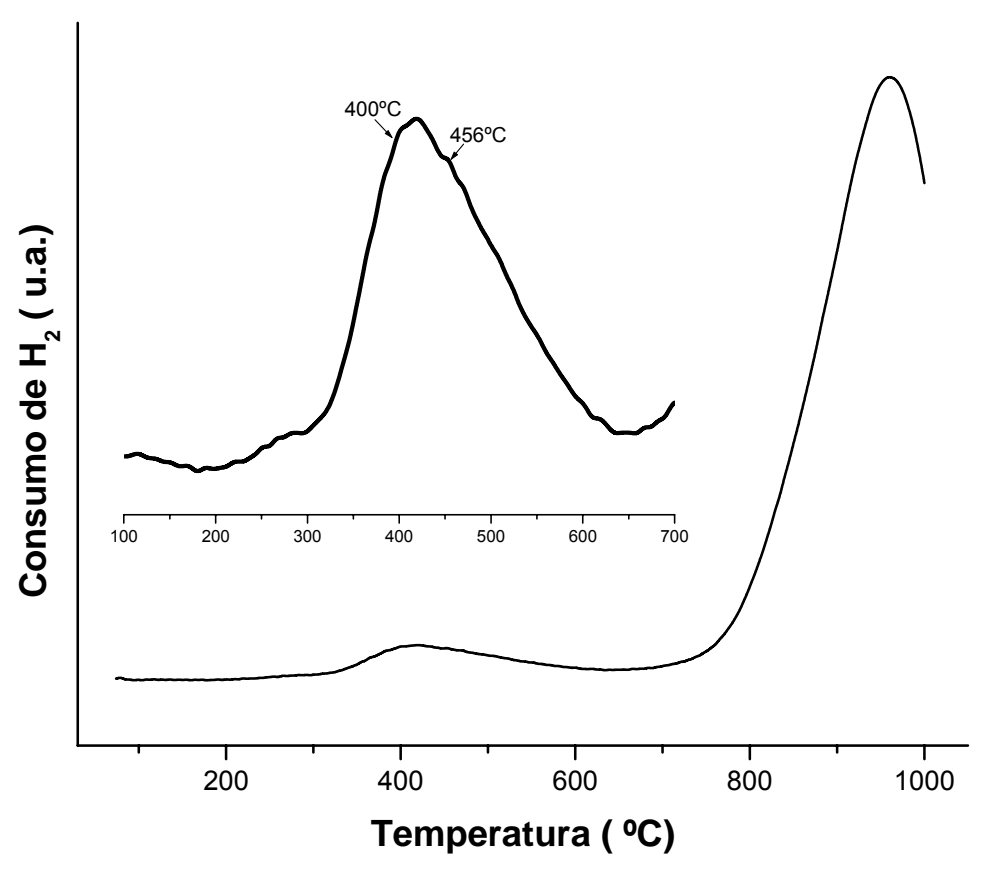

Figura 18. Perfil de RTP para o catalisador Tr-Ni. 


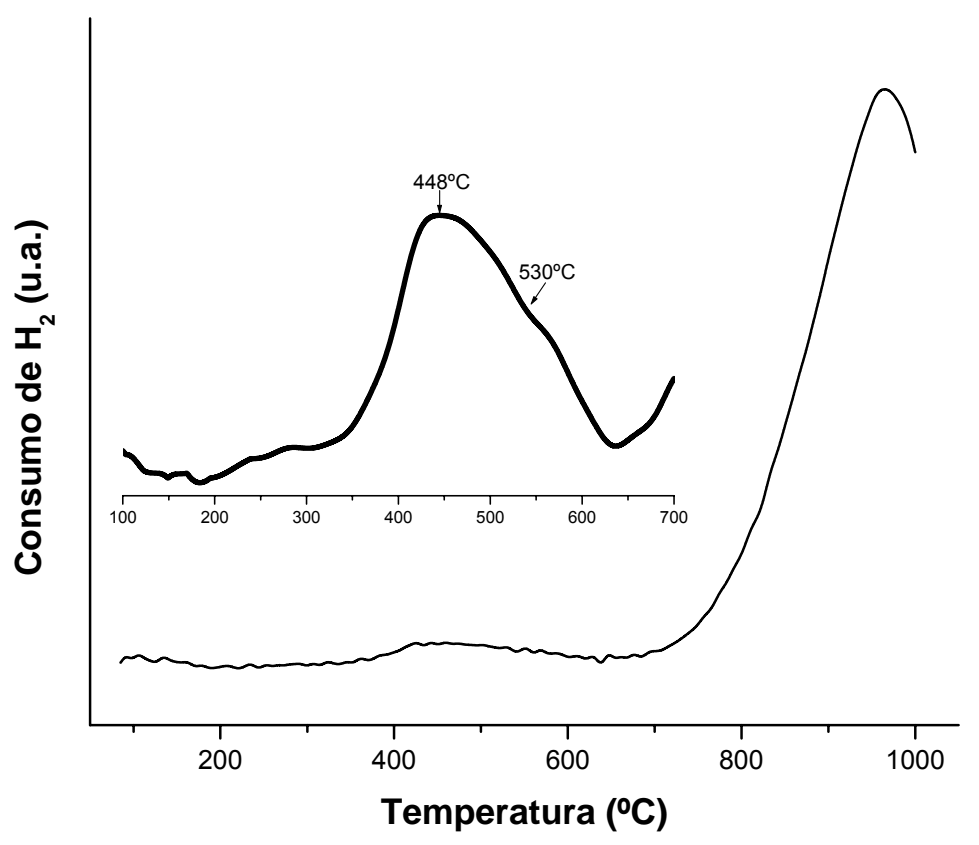

Figura 19. Perfil de RTP para o catalisador $\mathrm{Cp}-\mathrm{Ni}$.

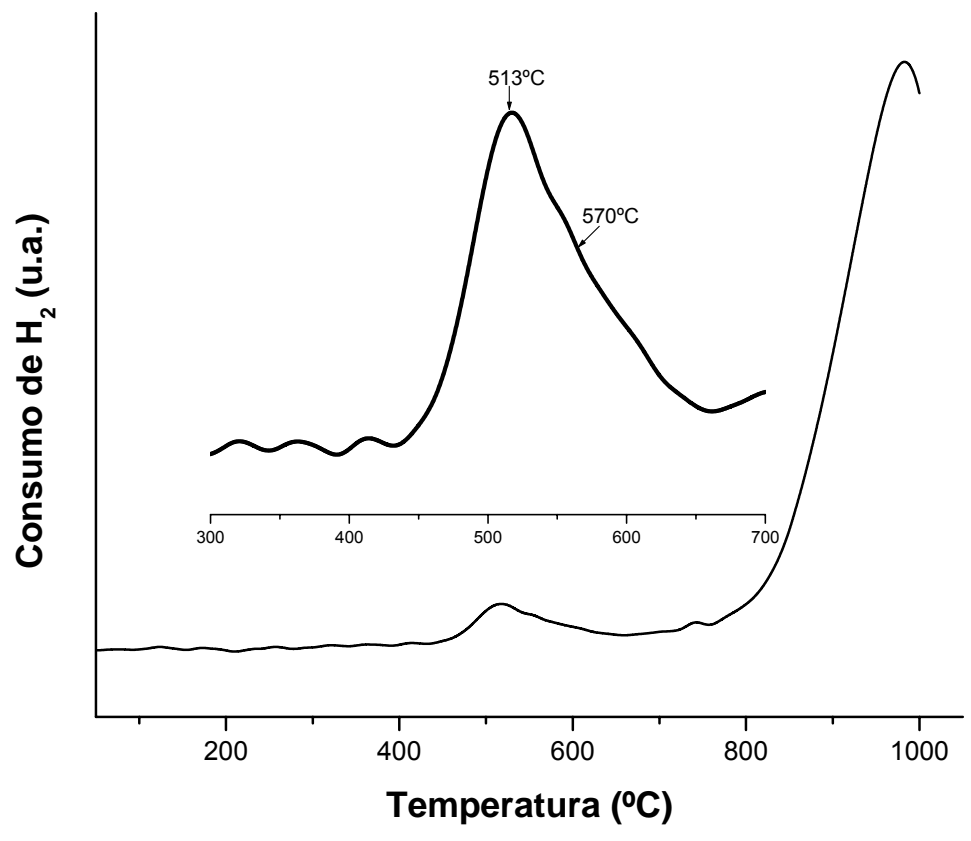

Figura 20. Perfil de RTP para o catalisador Ae-Ni. 
Como se pode observar, os três perfis apresentam basicamente duas zonas de redução, uma em temperaturas da ordem de $500^{\circ} \mathrm{C}$ e outra acima de $800^{\circ} \mathrm{C}$. Na primeira zona de redução são observados dois picos principais, um por volta de $400^{\circ} \mathrm{C}$ (mais precisamente: $\operatorname{Tr}: 400^{\circ} \mathrm{C}$; $\mathrm{Cp}: 448^{\circ} \mathrm{C}$, Ae: $513^{\circ} \mathrm{C}$ ) referente à redução de espécies de $\mathrm{Ni}^{+2}$ na fase $\mathrm{NiO}$ livre e outro por volta de $500^{\circ} \mathrm{C}$ ( $\mathrm{Tr}: 456{ }^{\circ} \mathrm{C}$; $\mathrm{Cp}$ : 530 ${ }^{\circ} \mathrm{C} ; \mathrm{Ae}: 570^{\circ} \mathrm{C}$ ) referente à interação não estequiométrica de óxido de níquel com o magnésio e alumínio do suporte (CHMIELARZ et al., 2003). O intenso pico acima de $800^{\circ} \mathrm{C}$, que aparece para todos os catalisadores de níquel pode ser atribuído a uma forte interação do óxido de níquel com o suporte, possivelmente devido à formação de fases termicamente estáveis, como a estrutura do tipo espinélio $(\mathrm{Ni}, \mathrm{Mg}) \mathrm{Al}_{2} \mathrm{O}_{4}$ e a estrutura do tipo periclásio ( $\mathrm{Ni}, \mathrm{Al}) \mathrm{MgO}$. Estas estruturas necessitam de temperaturas de redução superiores a $800^{\circ} \mathrm{C}$, devido à transferência eletrônica do $\mathrm{NiO}$ para o $\mathrm{MgO}$ que envolve fortes interações entre $\mathrm{NiO}$ e $\mathrm{MgO}$ inibindo desta forma a redução do NiO (BASILE et al., 1998; SERRA et al., 2000). A presença destas fases é resultante de reações no estado sólido que ocorrem durante o processo de calcinação. Isto ocorre devido à maior proximidade dos óxidos ocasionada pelo método de preparação do precursor. Estes resultados estão de acordo com os resultados obtidos por DRX.

De acordo com as temperaturas de redução, observa-se que os precursores preparados a partir de quelatos levaram a óxidos mais estáveis termicamente. Isto é um indicativo de uma maior dispersão da fase ativa níquel no óxido misto quando o níquel é introduzido entre as camadas da estrutura do precursor.

Nas Figuras 21 e 22 estão apresentados os perfis de redução dos catalisadores de níquel promovidos com lantânio e cério. 


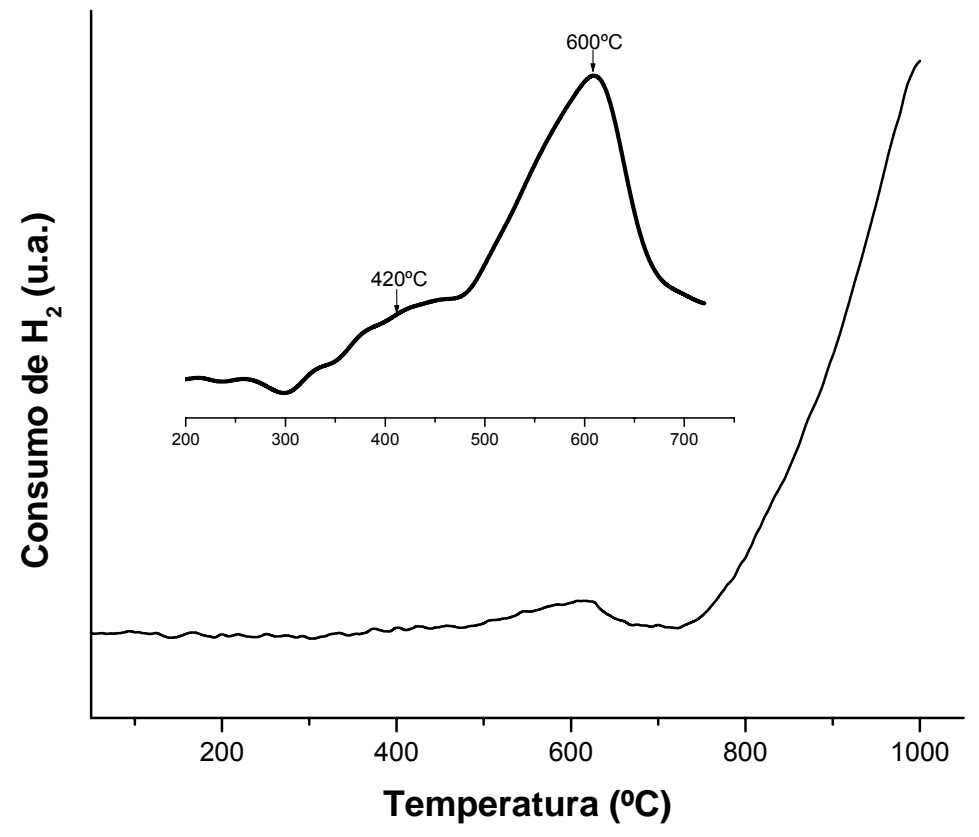

Figura 21. Perfil de RTP para o catalisador Ae-La-Ni.

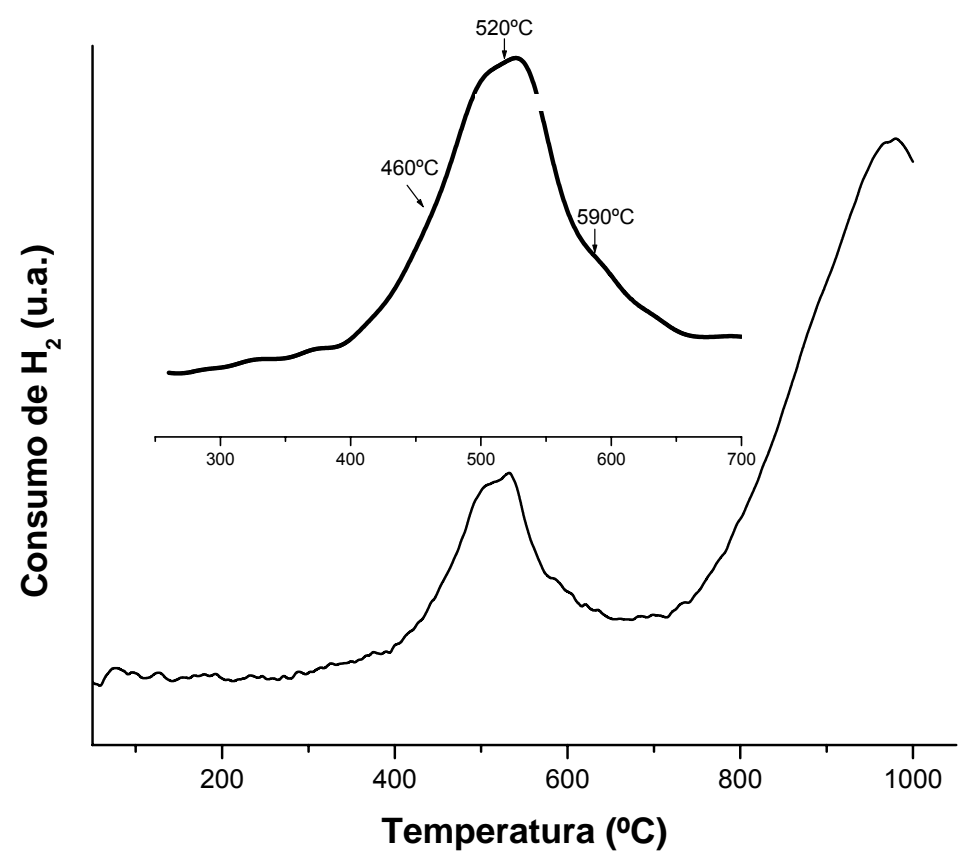

Figura 22. Perfil de RTP para o catalisador Ae-Ce-Ni. 
Os catalisadores promovidos apresentam comportamento semelhante aos catalisadores não promovidos com duas zonas de redução, uma em temperaturas da ordem de $500^{\circ} \mathrm{C}$ e outra acima de $800^{\circ} \mathrm{C}$. Na zona de $500^{\circ} \mathrm{C}$, pode-se observar dois picos principais para a amostra contendo lantânio $\left(T=420^{\circ} \mathrm{C}\right.$ e $\left.600^{\circ} \mathrm{C}\right)$ e três picos para a amostra contendo cério $\left(\mathrm{T}=460^{\circ} \mathrm{C} ; \mathrm{T}^{\circ} \mathrm{C} 520^{\circ} \mathrm{C} ; \mathrm{T}=590^{\circ} \mathrm{C}\right)$, onde os picos em $420^{\circ} \mathrm{C}$ e $460^{\circ} \mathrm{C}$ podem ser atribuídos à redução de espécies de $\mathrm{Ni}^{+2}$ na fase $\mathrm{NiO}$ livre e os picos em torno de $590^{\circ} \mathrm{C}$ são referentes à interação não estequiométrica de óxido de níquel com o suporte magnésio, alumínio e lantânio/ou cério do suporte (CHMIELARZ et al., 2003; ZNAK et al., 2005). O pico adicional observado para o cério, em $520^{\circ} \mathrm{C}$, é atribuído à redução do $\mathrm{CeO}_{2}$ a $\mathrm{Ce}_{2} \mathrm{O}_{3}$ na superfície. O pico presente acima de $800^{\circ} \mathrm{C}$ pode ser novamente atribuído a uma forte interação do óxido de níquel com o suporte, possivelmente devido à formação de fases do tipo espinélio $(\mathrm{Ni}, \mathrm{Mg}) \mathrm{Al}_{2} \mathrm{O}_{4}$ e do tipo periclásio ( $\left.\mathrm{NiAl}\right) \mathrm{MgO}$ e também da redução do $\mathrm{CeO}_{2}$ estrutural. A adição dos promotores levou a um aumento na temperatura de redução do pico atribuído à interação não estequiométrica do níquel com o suporte. Isto é um indicativo de uma maior interação do níquel com o suporte, sugerindo, desta forma, que a adição de promotores levou a uma melhor dispersão das espécies de níquel (ZNAK et al., 2005).

Na Tabela 10 estão apresentados os valores de redutibilidade das amostras. De acordo com esta tabela pode-se observar que todas as amostras de níquel apresentaram uma baixa redutibilidade, que ocorre devido à alta interação do níquel com o suporte, indicando a alta dispersão do níquel na mistura de óxidos. 
Tabela 10. Redutibilidade das amostras a $500^{\circ} \mathrm{C}(\%)$, tamanho de partícula $(\mathrm{nm})$ e parâmetro de rede $a(\mathrm{~nm})$.

\begin{tabular}{|c|c|c|c|}
\hline Amostra & Redutibilidade a & Tamanho da & Parâmetro a \\
& $\mathbf{5 0 0 ^ { \circ } \mathbf { C }} \mathbf{( \% ) ^ { * }}$ & partícula $\mathbf{( n m )}$ & (nm) \\
\hline Tr-Ni-Calc. & 7 & 2,8 & 0,416 \\
\hline Cp-Ni-Calc. & 5 & 2,9 & 0,416 \\
\hline Ae-Ni-Calc. & 7 & 2,9 & 0,415 \\
\hline Ae-La-Ni-Calc. & 8 & 4,7 & 0,418 \\
\hline Ae-Ce-Ni-Calc. & 6 & 4,5 & 0,418 \\
\hline Tr-Co-Calc. & 43 & 3,4 & 0,414 \\
\hline Cp-Co-Calc. & 37 & 3,5 & 0,414 \\
\hline Ae-Co-Calc. & 49 & 2,9 & 0,419 \\
\hline Ae-La-Co-Calc. & 29 & 4,5 & 0,418 \\
\hline Ae-Ce-Co-Calc. & 14 & 6,3 & \\
\hline
\end{tabular}

${ }^{*}$ Cálculo feito com base nos dados apresentados no Apêndice B.

Os ensaios de RTP para os catalisadores de cobalto estão representados pelas Figuras de 23 a 27.

Nas Figuras 23, 24 e 25 estão apresentados os perfis dos catalisadores de cobalto não promovidos. 


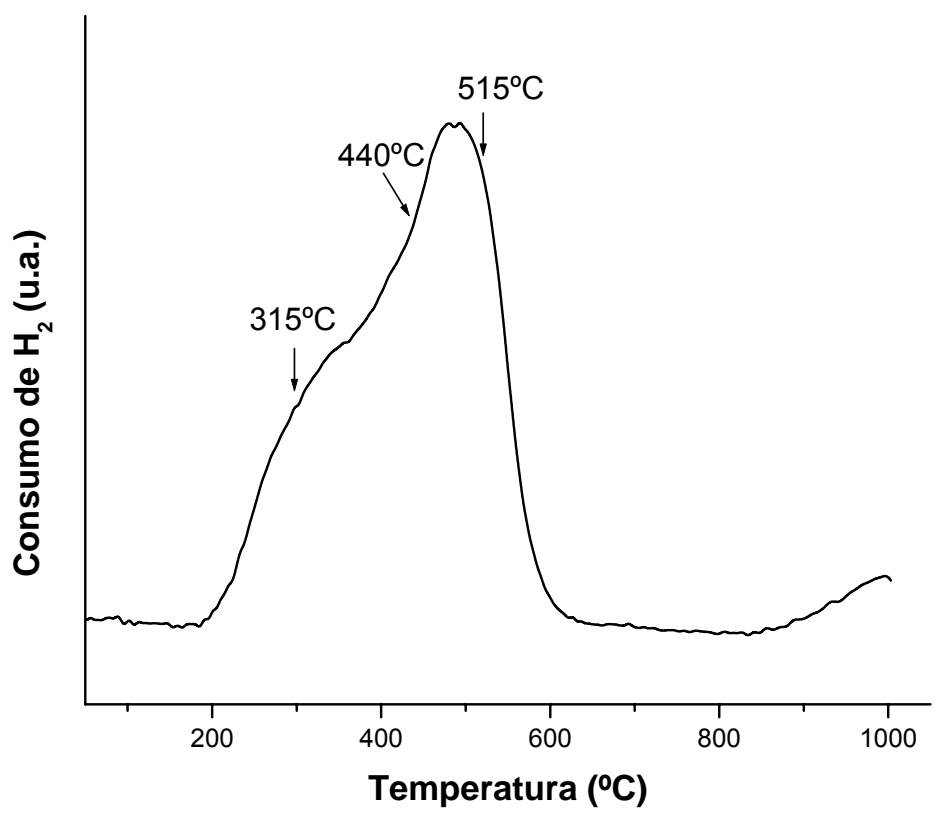

Figura 23. Perfil de RTP para o catalisador Tr-Co.

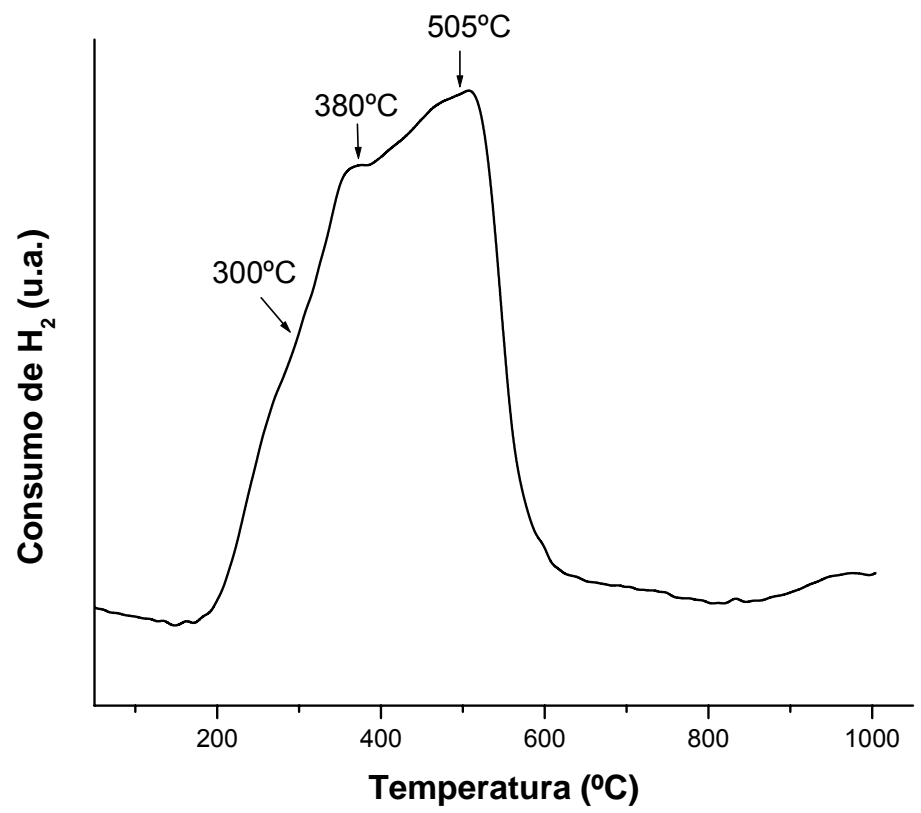

Figura 24. Perfil de RTP para o catalisador Cp-Co. 


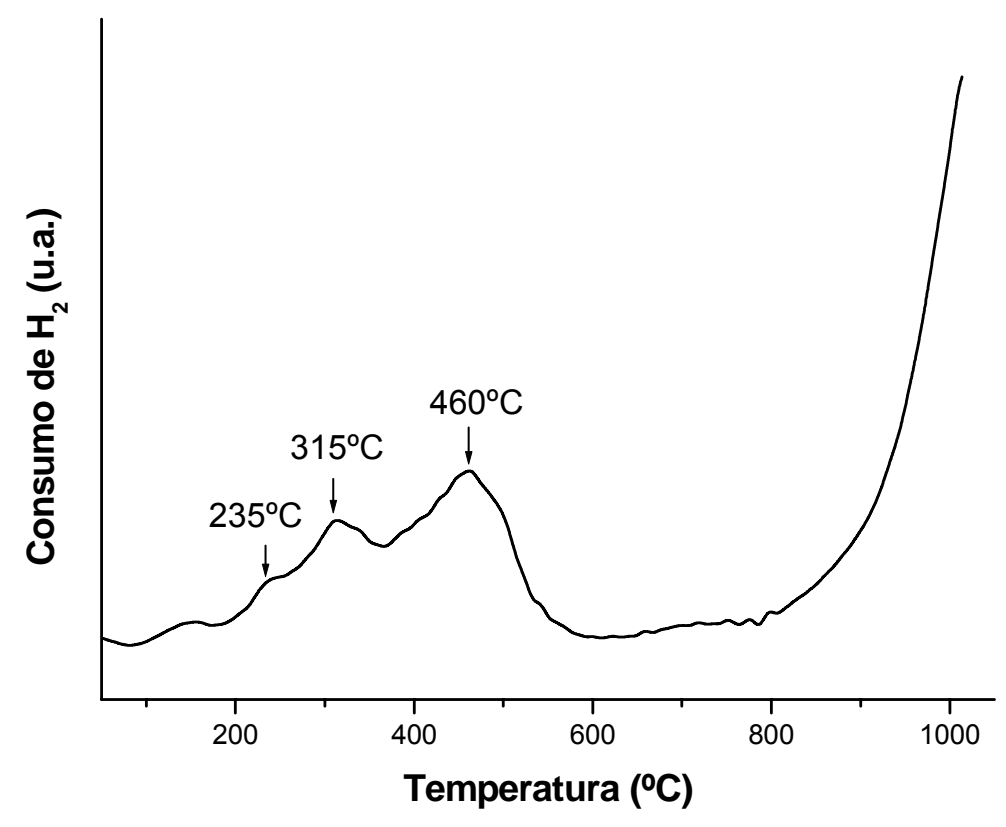

Figura 25. Perfil de RTP para o catalisador Ae-Co.

Os perfis de RTP do cobalto apresentam basicamente 3 regiões de redução. As duas primeiras por volta de $240^{\circ} \mathrm{C}$ e $350^{\circ} \mathrm{C}\left(\operatorname{Tr}: 315\right.$ e $440^{\circ} \mathrm{C}$; Cp: 300 e $380^{\circ} \mathrm{C}$; Ae: 235 e $315^{\circ} \mathrm{C}$ ) que segundo Khassin et al. (2001) é referente à redução do $\mathrm{Co}_{3} \mathrm{O}_{4}$, a qual pode ocorrer em duas etapas, nas temperaturas de 250 e $350^{\circ} \mathrm{C}$, formando $\mathrm{CoO}$ e $\mathrm{Co}^{0}$, respectivamente. Como se pode observar, os catalisadores preparados via quelatos apresentaram menor temperatura de redução, sendo este efeito mais pronunciado no catalisador preparado pela troca-aniônica. Os catalisadores apresentaram um outro pico por volta de $510^{\circ} \mathrm{C}\left(\operatorname{Tr}: 510^{\circ} \mathrm{C} ; \mathrm{Cp}: 505^{\circ} \mathrm{C}\right.$; Ae: $\left.460^{\circ} \mathrm{C}\right)$ atribuídos à redução de $\mathrm{Co}^{+2 /+3}$ interagidos de forma não estequiométrica com o suporte de magnésio e alumínio (CHMIELARZ et al., 2001). O catalisador preparado pela troca-aniônica ainda apresentou um pico adicional acima de $800^{\circ} \mathrm{C}$ referente a uma forte interação do óxido de cobalto com o suporte, possivelmente devido à formação das fases termicamente estáveis, estrutura do tipo espinélio (Co,Mg) $\mathrm{Al}_{2} \mathrm{O}_{4}$ e a estrutura do tipo periclásio (Co, Al)MgO (RUCKENTEIN; WANG, 2001a; MAKOA 
et al., 1999). Este pico não foi observado para as amostras preparadas pelo método tradicional e co-precipitação, possivelmente devido a uma maior interação metalsuporte que leva a maior temperatura de redução destas fases.

Nas Figuras 26 e 27 estão apresentados os perfis de RTP dos catalisadores de cobalto promovidos com cério e lantânio.

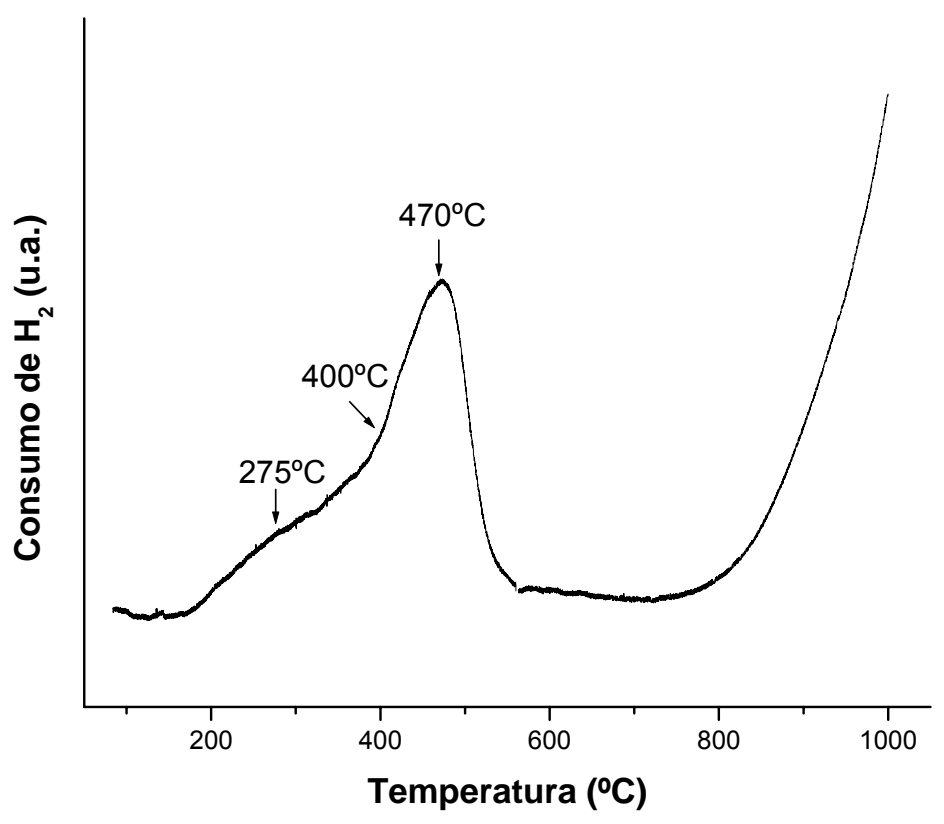

Figura 26. Perfil de RTP para o catalisador Ae-La-Co. 


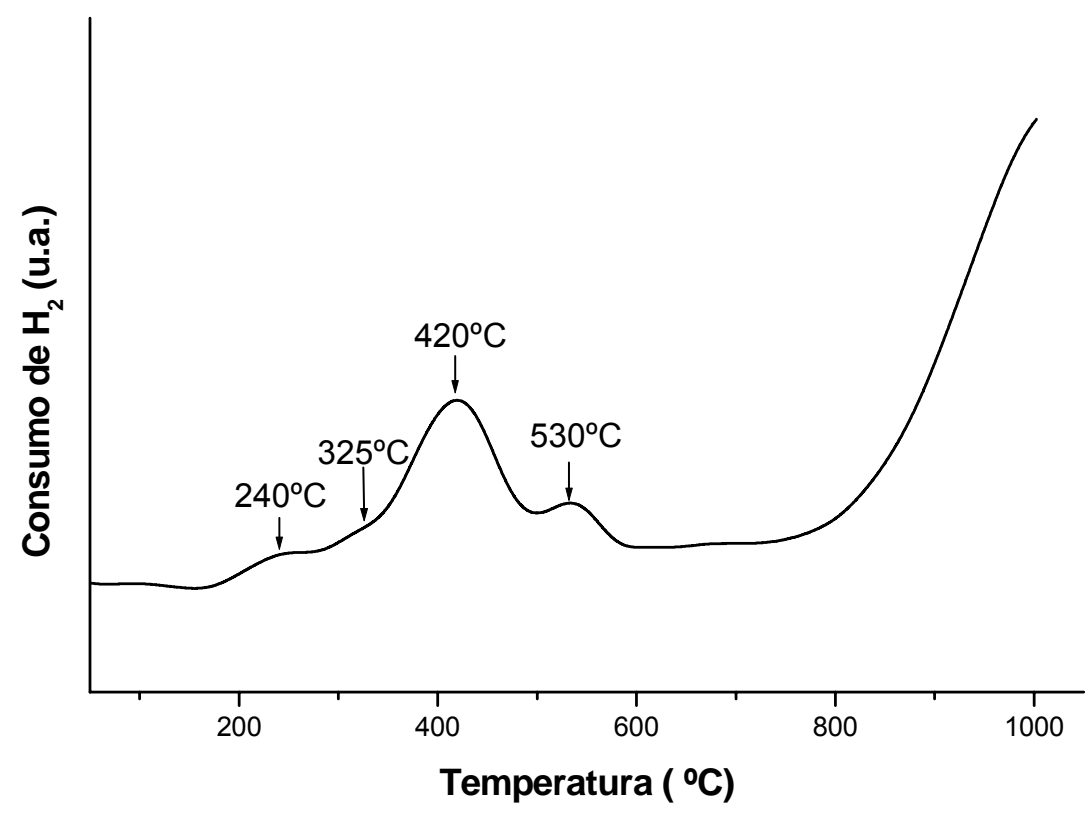

Figura 27. Perfil de RTP para o catalisador Ae-Ce-Co.

Todos os catalisadores apresentaram picos em $240^{\circ} \mathrm{C}$ e $312^{\circ} \mathrm{C}$, atribuídos à redução das fases $\mathrm{Co}_{3} \mathrm{O}_{4}$ e $\mathrm{CoO}$. Também pode ser observado um pico acima de $420^{\circ} \mathrm{C}$, referente à redução de cátions $\mathrm{Co}^{+3} / \mathrm{Co}^{+2}$ fracamente interagidos com o suporte (CHMIELARZ et al., 2002). A adição de promotores nos catalisadores de cobalto provocou um efeito contrário ao apresentado para os catalisadores de níquel, levando a uma diminuição na temperatura de redução das fases, provavelmente devido a uma menor interação metal-suporte.

O catalisador promovido com cério ainda apresentou a redução de uma fase em $530^{\circ} \mathrm{C}$, referente à redução superficial de $\mathrm{CeO}_{2}$ a $\mathrm{Ce}_{2} \mathrm{O}_{3}$ (ZNAK et al., 2005).

De acordo com os dados apresentados na Tabela 10, os catalisadores de cobalto apresentaram um maior redutibilidade quando comparados aos catalisadores de níquel. Estes dados estão de acordo com os resultados da composição da 
superfície, obtida por XPS, que mostram uma alta concentração de cobalto na superfície.

\section{7 - Espectroscopia fotoeletrônica de Raios-X (XPS)}

As energias de ligação obtidas para as amostras de níquel nas regiões $\mathrm{Ni}_{2 p}$, $\mathrm{Mg}_{2 \mathrm{~s}}, \mathrm{O}_{1 \mathrm{~s}}$ e $\mathrm{Al}_{1 \mathrm{~s}}$ estão apresentadas na Tabela 11. Os espectros das regiões do $\mathrm{Ni}_{2 \mathrm{p}}$, $\mathrm{Mg}_{2 \mathrm{~s}}$ e $\mathrm{O}_{1 \mathrm{~s}}$ estão apresentados nas Figuras 28, 29 e 30, respectivamente.

O nível $2 p$ do níquel é caracterizado por dois componentes $2 p_{3 / 2}$ e $2 p_{1 / 2}$, que aparecem devido a uma separação spin-órbita. Um elétron com momento angular orbital $\mathrm{L}$ e momento angular de spin $\mathrm{S}$ tem um momento angular orbital total $\mathrm{J}=\mathrm{L}+\mathrm{S}$. Cada nível com $\mathrm{J} \geq 1$ tem dois subníveis, pois $S= \pm 1 / 2$ então, considerando $L=1, J=$ $1 \pm 1 / 2$; o que resulta em dois picos de fotoemissão em $\mathrm{J}=1 / 2$ e $\mathrm{J}=\frac{3}{2}$ (KHASSIN et al., 2001; RIBEIRO et al., 2003). A mesma separação pode ser observada para o cobalto.

Os resultados das amostras óxidas dos catalisadores para a região do $\mathrm{Ni}_{2 p}$, Figura 28, mostram um pico amplo na região do $\mathrm{Ni}_{2 p 3 / 2}$, o qual pôde ser deconvoluído em dois picos, nas regiões aproximadas de $855,5 \mathrm{eV}$ e $856,5 \mathrm{eV}$. Estes dois picos correspondem a duas fases distintas de níquel, que de acordo com a literatura, a fase na região de $855,5 \mathrm{eV}$ corresponde à fase $\mathrm{NiO}$ interagida com o magnésio, que se encontra em maiores valores do que o do $\mathrm{NiO}$ puro $(854,5 \mathrm{eV})$. Esta diferença ocorre devido a uma transferência de elétrons do níquel para o magnésio na solução sólida, resultando em uma maior energia de ligação (RUCKENSTEIN; HU, 1999). O pico na região de $856,5 \mathrm{eV}$ seria referente à interação do $\mathrm{NiO}$ com o alumínio, o que está de acordo com os valores de referência para espécies do tipo $\mathrm{NiAl}_{2} \mathrm{O}_{4}(856 \mathrm{eV})$. 
Para as regiões do $\mathrm{Mg}_{2 \mathrm{~s}}$, Figura 29, também são observados amplos picos que correspondem a diferentes formas de interação do magnésio. O primeiro pico na região de $87 \mathrm{eV}$ pode ser relacionado a uma interação do magnésio com o níquel, que devido à transferência de elétrons do níquel para o magnésio aparece em menor energia de ligação do que o $\mathrm{MgO}$ puro $(88,1 \mathrm{eV})$. Já o pico em $88,4 \mathrm{eV}$ seria devido à interação do $\mathrm{MgO}$ com o $\mathrm{Al}^{+3}$, que é deficiente em elétrons, o que provoca um aumento na energia de ligação.

$\mathrm{Na}$ região do $\mathrm{O}_{1 \mathrm{~s}}$, Figura 30 , observam-se dois picos, um na região de $529,6 \mathrm{eV}$ e outro na região de $531,1 \mathrm{eV}$. O primeiro pico pode ser relacionado ao oxigênio da fase $(\mathrm{Ni}, \mathrm{Mg}) \mathrm{O}$, onde a interação leva a valores intermediários entre os reportados para os óxidos puros $(\mathrm{NiO}=529,5$ e $\mathrm{MgO}=530)$. O pico em maiores valores se deve ao oxigênio da fase (Ni.Mg)O interagida com alumínio, que normalmente apresentam picos em maiores energias de ligação. 
Tabela 11. Resultados das energias de ligação $(\mathrm{eV})$ obtidas na decomposição dos espectros do $\mathrm{Ni}_{2 \mathrm{p}}$, $\mathrm{Mg}_{2 \mathrm{~s}}, \mathrm{O}_{1 \mathrm{~s}}, \mathrm{Al}_{2 \mathrm{~s}}, \mathrm{La}_{3 \mathrm{~d}}, \mathrm{Ce}_{3 \mathrm{~d}}$.

\begin{tabular}{|l|l|l|l|l|l|l|}
\hline Amostra & $\mathrm{Ni}_{2 p 3 / 2}$ & $\mathrm{Ni}_{2 p 3 / 2 s a t}$ & $\mathrm{Mg}_{2 \mathrm{~s}}$ & $\mathrm{O}_{1 \mathrm{~s}}$ & $\mathrm{Al}_{2 \mathrm{~s}}$ & $\mathrm{La} / \mathrm{Ce}_{3 \mathrm{~d}}$ \\
\hline Tr-Ni-oxi & $855,4-856,4$ & 861,4 & $87,4-88,3$ & $529,6-$ & 118,2 & - \\
& & & & 530,8 & & \\
\hline $\mathrm{Cp}-\mathrm{Ni}-\mathrm{oxi}$ & $855,3-856,7$ & 861,6 & $87,8-88,2$ & $529,9-$ & 118,0 & - \\
& & & & 531,7 & & \\
\hline $\mathrm{Ae}-\mathrm{Ni}-\mathrm{oxi}$ & $855,2-856,4$ & 861,4 & $87,3-88,1$ & $529,5-$ & 117,8 & - \\
\hline $\begin{array}{l}\mathrm{Ae}-\mathrm{La}-\mathrm{Ni}- \\
\text { oxi }\end{array}$ & $855-856,01$ & 861,8 & $87,7-88,6$ & $529,9-$ & 118,4 & 835,7 \\
\hline $\mathrm{Ae}-\mathrm{Ce}-$ & $855,4-857$ & 861,7 & $87,4-88,4$ & $529,9-$ & 118,1 & $882,2 / 885,1$ \\
$\mathrm{Ni}_{-}{ }^{\circ}$ & & & & 532,0 & & \\
\hline $\mathrm{NiO}^{*}$ & 854,5 & 856 & - & 529,5 & - & - \\
\hline $\mathrm{Ni}_{2} \mathrm{O}_{3}{ }^{*}$ & 856 & - & - & 531,7 & - & - \\
\hline $\mathrm{NiAl}_{2} \mathrm{O}_{4}{ }^{*}$ & 856 & - & - & 531 & 119,1 & - \\
\hline $\mathrm{MgO}^{*}$ & - & - & 88,1 & 530 & - & - \\
\hline $\mathrm{MgAl}_{2} \mathrm{O}_{4}{ }^{*}$ & - & - & 89,3 & 531 & 119,4 & - \\
\hline $\mathrm{Al}_{2} \mathrm{O}_{3}{ }^{*}$ & - & - & - & 531 & 119 & - \\
\hline $\mathrm{La}_{2} \mathrm{O}_{3}{ }^{*}$ & - & - & - & 529 & - & 833 \\
\hline $\mathrm{Ce}_{2} \mathrm{O}_{3}{ }^{*}$ & - & - & - & 530 & - & 885 \\
\hline $\mathrm{CeO}_{2}{ }^{*}$ & - & - & - & 529,2 & - & 882 \\
\hline
\end{tabular}

* (NIST X-ray Photoelectron Spectroscopy Database, 2002) 


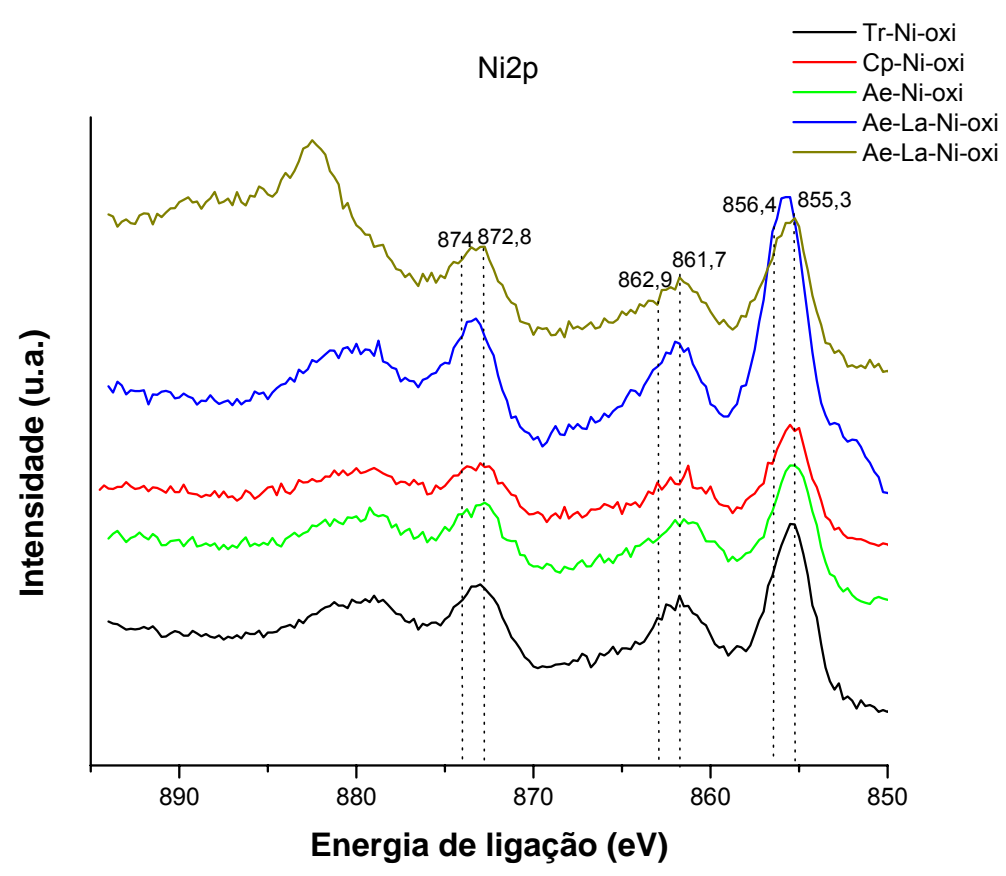

Figura 28. Espectros de XPS na região $\mathrm{Ni}_{2 p}$ das amostras óxidas.

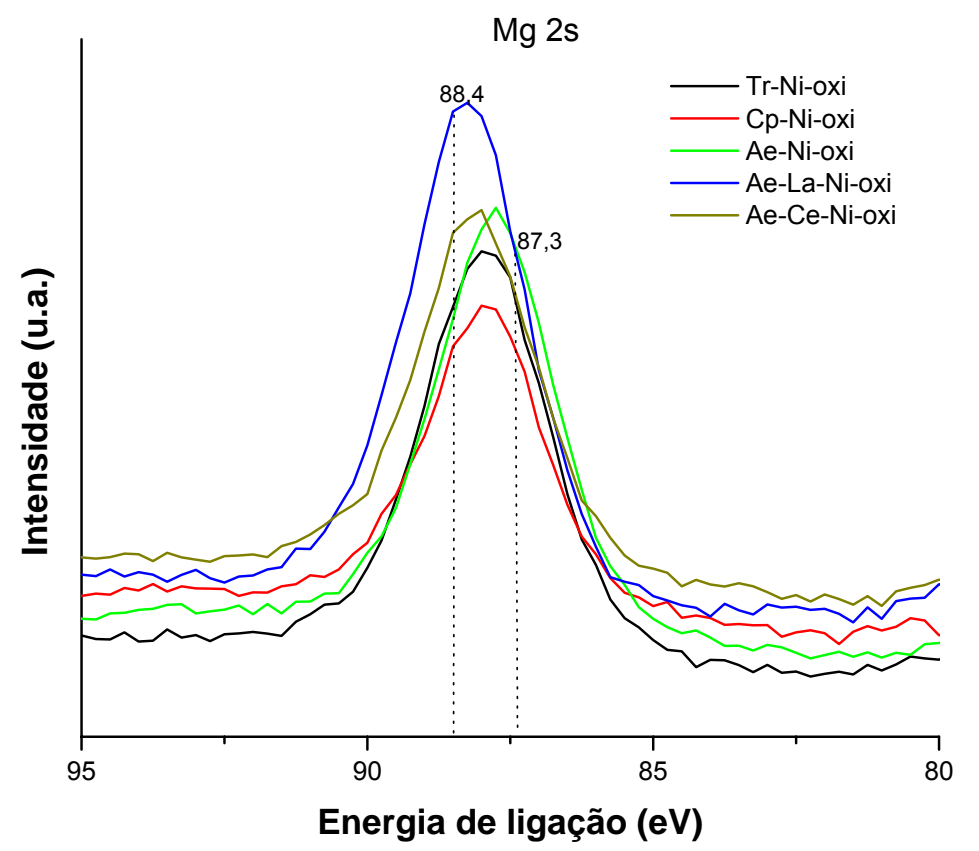

Figura 29. Espectros de XPS na região $\mathrm{Mg}_{2 s}$ das amostras óxidas. 


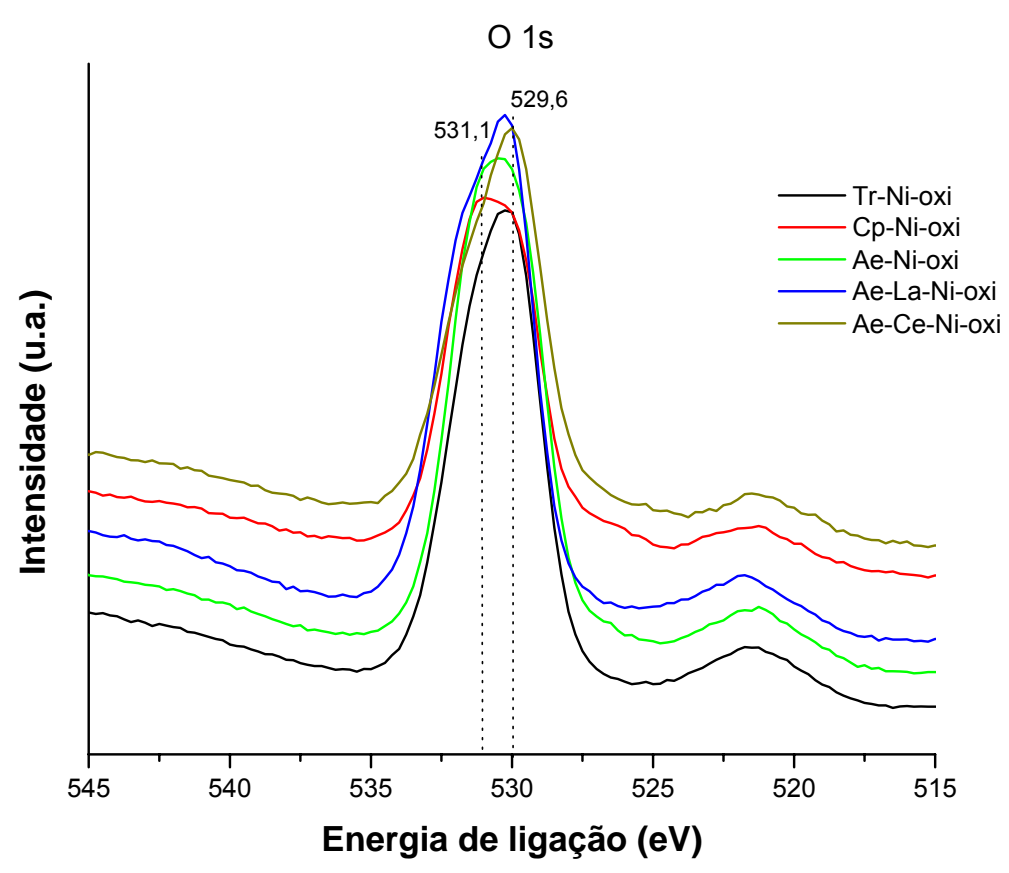

Figura 30. Espectros de XPS na região $O_{1 \mathrm{~s}}$ das amostras óxidas.

As energias de ligação e magnitude do acoplamento spin-órbita obtidos para as amostras de cobalto na região do $\mathrm{Co}_{2 p}$ estão apresentados na Tabela 12. As energias de ligação obtidas para as amostras de cobalto na região do $\mathrm{Mg}_{2 \mathrm{~s}}, \mathrm{O}_{1 \mathrm{~s}} \mathrm{e}$ $\mathrm{Al}_{2 \mathrm{~s}}$ estão apresentadas na Tabela 13. Os espectros das regiões do $\mathrm{Co}_{2 \mathrm{p}}, \mathrm{Mg}_{2 \mathrm{~s}}$ e $\mathrm{O}_{1 \mathrm{~s}}$ estão apresentados nas Figuras 31, 32 e 33, respectivamente.

$\mathrm{O}$ espectro do nível $\mathrm{Co}_{2 p}$ apresenta dois componentes devido à separação spin-órbita e satélites do tipo shake up. Estes componentes são muito importantes na análise das fases de cobalto, já que a energia de separação entre as linhas $\mathrm{Co}_{2 \mathrm{p} 3 / 2}$ e $\mathrm{Co}_{2 \mathrm{p} 1 / 2}$ e seus respectivos satélites, bem como a energia da separação spin-órbita, são dependentes do estado químico do cobalto (KHASSIN et al., 2001). 
Tabela 12. Resultados das energias de ligação(eV) obtidas na decomposição dos espectros do $\mathrm{Co}_{2 p}$; magnitude do acoplamento spin-órbita $(\mathrm{eV})$.

\begin{tabular}{|l|l|l|l|l|}
\hline Amostra & $\mathrm{Co}_{2 \mathrm{p} 3 / 2}$ & $\mathrm{Co}_{2 \mathrm{p} 3 / 2 \mathrm{sat}}$ & $\mathrm{Co}_{2 \mathrm{p} 1 / 2}$ & $\mathrm{Co}_{2 \mathrm{p} 3 / 2 \mathrm{sat}}-\mathrm{Co}_{2 \mathrm{p} 3 / 2}$ \\
\hline Tr-Co-oxi & 780,44 & 786,30 & 795,95 & 15,51 \\
\hline $\mathrm{Cp-Co-oxi}$ & 779,83 & 785,56 & 795,53 & 15,7 \\
\hline Ae-Co-oxi & 780,61 & 786,32 & 796,19 & 15,6 \\
\hline Ae-Co-La-oxi & 780,11 & 785,94 & 795,66 & 15,5 \\
\hline Ae-Ce-Co-oxi & 780,54 & 786,40 & 796,11 & 15,6 \\
\hline $\mathrm{CôO}{ }^{*}$ & 780 & 789,1 & 796,5 & 15,5 \\
\hline $\mathrm{Co}_{2} \mathrm{O}_{3}{ }^{*}$ & 780 & 787,6 & 797,1 & - \\
\hline $\mathrm{Co}_{3} \mathrm{O}_{4}{ }^{*}$ & 779,6 & 788,2 & 795 & 15 \\
\hline $\mathrm{CoAl}_{2} \mathrm{O}_{4}{ }^{*}$ & 781 & - & - & 15,5 \\
\hline
\end{tabular}

(NIST X-ray Photoelectron Spectroscopy Database, 2002)

Tabela 13. Resultados das energias de ligação (eV) para a decomposição dos espectros do $\mathrm{Mg}_{2 \mathrm{~s}}, \mathrm{O}_{1 \mathrm{~s}}$ $, \mathrm{Al}_{2 \mathrm{~s}}, \mathrm{La}_{3 \mathrm{~d}}, \mathrm{Ce}_{3 \mathrm{~d}}$.

\begin{tabular}{|l|l|l|l|l|}
\hline Amostra & $\mathrm{Mg}_{2 \mathrm{~s}}$ & $\mathrm{O}_{1 \mathrm{~s}}$ & $\mathrm{Al}_{2 \mathrm{~s}}$ & Promotor $3 \mathrm{~d} 5 / 2$ \\
\hline Tr-Co-oxi & $87,2-88,2$ & $529,6-530,2$ & 117,50 & - \\
\hline $\mathrm{Cp-Co-oxi}$ & 87 & $528,8-530$ & 117,37 & - \\
\hline Ae-Co-oxi & $87,5-88,5$ & $529,5-530,9$ & 118,27 & - \\
\hline $\mathrm{Ae-Co-La-oxi}$ & $87-87,9$ & $529,2-530,5$ & 117,71 & 834,63 \\
\hline $\mathrm{Ae-Ce-Co-oxi}$ & $87,4-88,3$ & $529,3-530,6$ & 118,01 & $882,4 / 885,1$ \\
\hline $\mathrm{CoAl}_{2} \mathrm{O}_{4}{ }^{*}$ & - & 531 & 119,2 & - \\
\hline $\mathrm{MgO}^{*}$ & 88,1 & 530 & - & - \\
\hline $\mathrm{MgAl}_{2} \mathrm{O}_{4}{ }^{*}$ & 89,3 & 531 & 119,4 & - \\
\hline $\mathrm{Al}_{2} \mathrm{O}_{3}{ }^{*}$ & - & 531 & 119 & - \\
\hline $\mathrm{La}_{2} \mathrm{O}_{3}{ }^{*}$ & - & 529 & - & 834,7 \\
\hline $\mathrm{Ce}_{2} \mathrm{O}_{3}{ }^{*}$ & - & 530 & - & 885 \\
\hline $\mathrm{CeO}_{2}{ }^{*}$ & - & 529,2 & - & 882,1 \\
\hline
\end{tabular}

* (NIST X-ray Photoelectron Spectroscopy Database, 2002) 


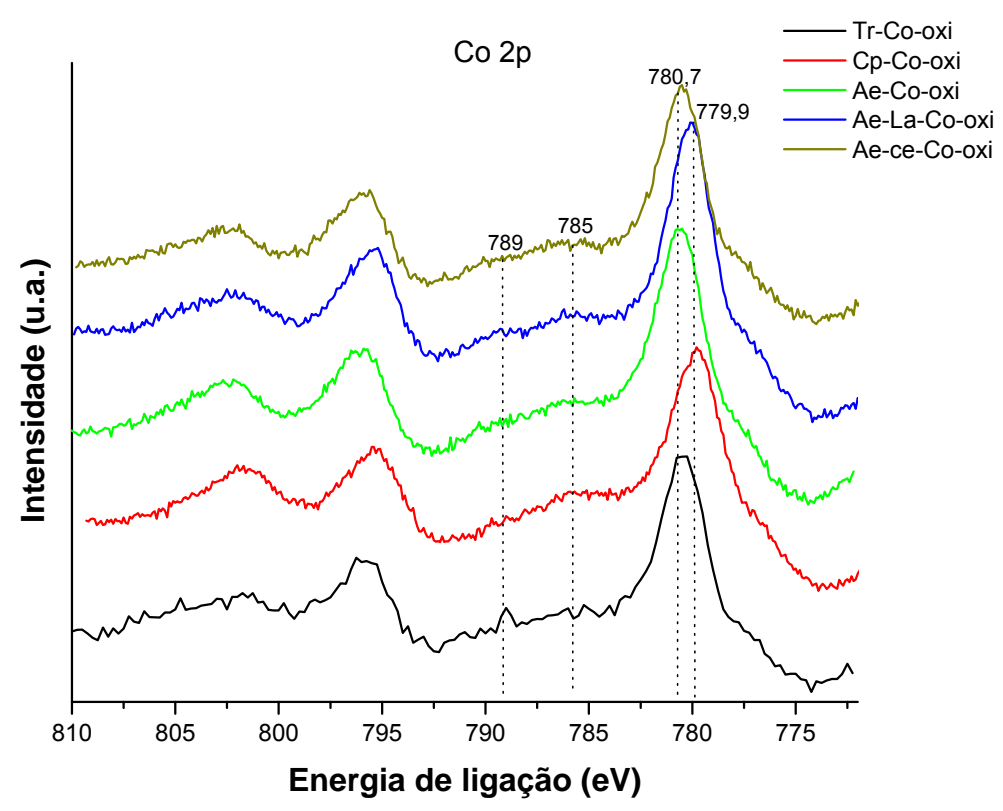

Figura 31. Espectros de XPS na região Co2p das amostras óxidas.

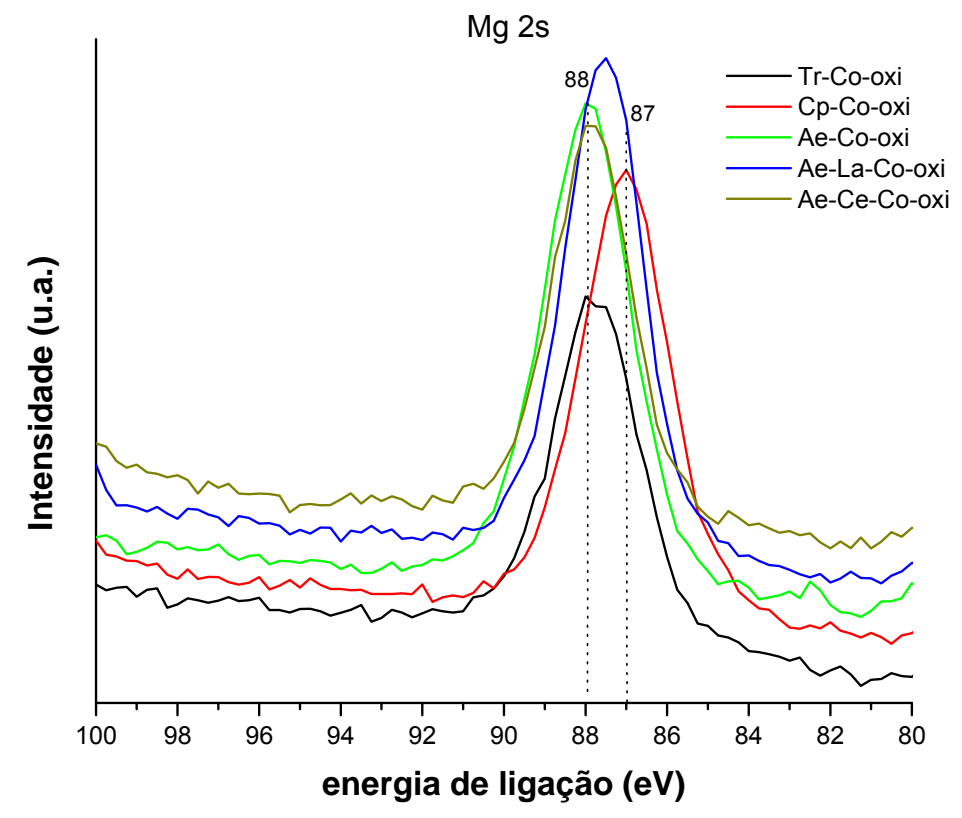

Figura 32. Espectros de XPS na região $M g$ 2s das amostras óxidas. 


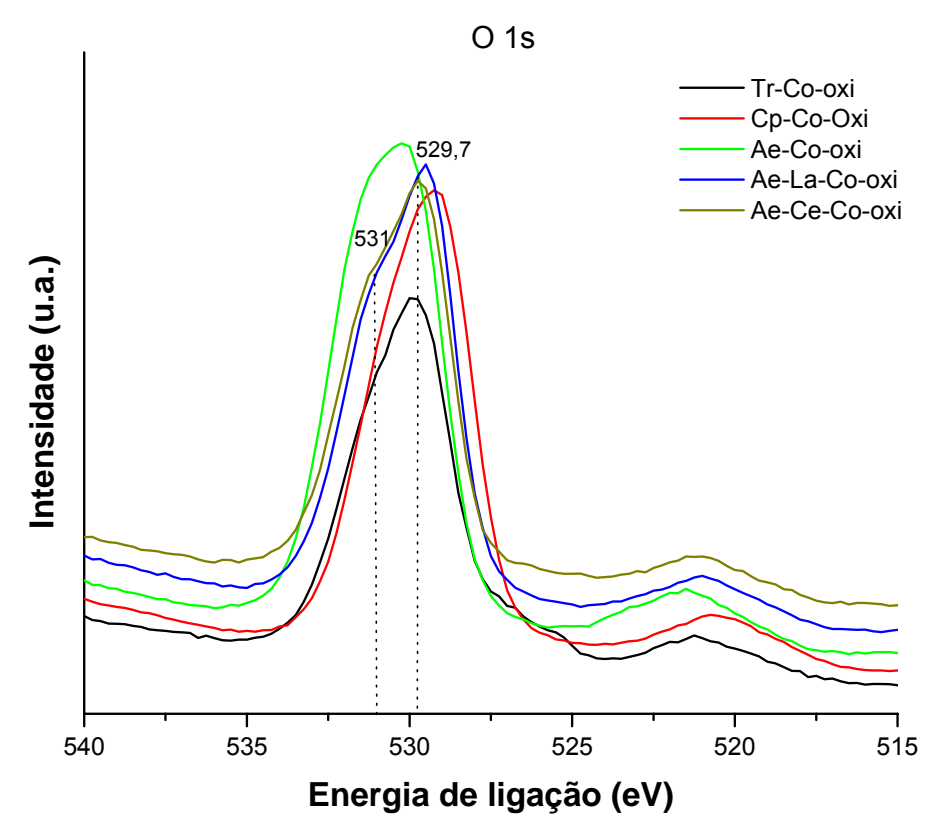

Figura 33. Espectros de XPS na região O1s das amostras óxidas.

Compostos de $\mathrm{Co}^{+2}$ exibem intensas linhas satélites localizadas a 5-6 eV, enquanto que compostos de $\mathrm{Co}^{+3}$ exibem linhas satélites fracas localizadas à 10$11 \mathrm{eV}$ do pico principal. $\mathrm{O} \mathrm{Co}^{0}$ não apresenta linhas satélites (KHASSIN et al., 2001).

Todas amostras de cobalto apresentaram picos para o $\mathrm{Co}_{2 p 3 / 2}$, Figura 31 , que basicamente podem ser decompostos em duas regiões, 779,9 e 780,7 eV, sendo estes valores característicos de compostos do tipo $\mathrm{Co}_{3} \mathrm{O}_{4}$ e $\mathrm{CoO}$ ou $\mathrm{Co}_{2} \mathrm{O}_{3}$, respectivamente. Para todos os compostos as linhas satélites do tipo shake up estão localizadas a 5- $6 \mathrm{eV}$ acima destes valores, sendo este um indicativo da presença de compostos do tipo $\mathrm{Co}^{+2}$. A separação spin-órbita dos picos $2 \mathrm{p}_{3 / 2}$ e $2 \mathrm{p}_{1 / 2}$ apresenta valores da ordem de $15,5 \mathrm{eV}$ o que mais uma vez indica a presença de compostos de $\mathrm{Co}^{+2}$, que possivelmente estão interagidos com as espécies de magnésio e alumínio.

Os espectros do $\mathrm{Mg}_{2 \mathrm{~s}}$, Figura 32, também apresentam um amplo pico o qual pode ser decomposto em dois picos em 87 e $88 \mathrm{eV}$. O primeiro pico na região de 
$87 \mathrm{eV}$ pode ser relacionado a uma interação do magnésio com o cobalto, que assim como o níquel, devido à transferência de elétrons do cobalto para o magnésio aparece em menor energia de ligação do que o $\mathrm{MgO}$ puro $(88,1$ eV). Já o pico em 88 eV apresenta um valor próximo ao $\mathrm{MgO}$ puro indicando uma fraca interação com o alumínio.

Na região do $\mathrm{O}_{1 \mathrm{~s}}$, Figura 33, observam-se dois picos, um na região de 529,5 eV e outro na região de $531 \mathrm{eV}$. O primeiro pico pode ser relacionado a oxigênio da fase $(\mathrm{Co}, \mathrm{Mg}) \mathrm{O}$, onde a interação leva a valores intermediários entre os reportados para os óxidos puros $(\mathrm{CoO}=529,5 \mathrm{eV}$ e $\mathrm{MgO}=53 \mathrm{OeV})$. O pico em maiores valores se deve a oxigênio da fase (Co.Mg)O interagida com alumínio, que normalmente apresenta picos em maiores energias de ligação, da ordem 531 eV.

Os valores de energia de ligação encontrados para os promotores cério e lantânio são muito próximos aos da referência para o $\mathrm{La}_{2} \mathrm{O}_{3}, \mathrm{CeO}_{2}$ e $\mathrm{Ce}_{2} \mathrm{O}_{3}$, mostrando uma fraca interação dos mesmos com a fase (Co,Mg)O.

Os resultados obtidos por XPS estão de acordo com os obtidos por DRX, onde se pode observar uma alta interação entre as espécies de níquel e cobalto com o suporte de magnésio e alumínio, indicando desta forma que catalisadores preparados por precursores do tipo hidrotalcita levam a uma alta dispersão dos óxidos mistos.

\section{8 - Espectroscopia de Absorção de Raios -X}

O espectro de XANES (X-ray Absorption Near Edge Spectroscopy) na borda K para os metais de transição $3 d$ envolve a promoção sucessiva de elétrons 1s para as camadas de valência. Normalmente em coordenação octaédrica, a transição de mais baixa energia envolvendo a excitação $1 \mathrm{~s} \rightarrow 3 \mathrm{~d}$ é proibida, porém esta transição torna-se permitida quando o metal está em coordenação tetraédrica, a qual confere 
um caráter $p$ ao orbital $d$ (híbrido $p-d$ ), tornando a transição $1 s \rightarrow 3 d$ parcialmente permitida e levando ao surgimento de uma pré-borda de absorção em 0,0eV. Em energias acima da excitação $1 \mathrm{~s} \rightarrow 3 \mathrm{~d}$, ocorre a principal absorção, a qual inclui transições para maiores energias como 1s $\rightarrow 4 p$ e 1s $\rightarrow$ np (SOUZA, 2006; VRÅLSTAD et al., 2006).

Na Figura 34 estão apresentados os espectros normalizados da região XANES da borda $\mathrm{K}$ do níquel das amostras de níquel calcinadas, da folha de níquel metálico, do $\mathrm{NiO}$ e $\mathrm{Ni}(\mathrm{OH})_{2}$. Para todas as amostras oxidas, verifica-se que a absorção na região da pré-borda é muito pouco expressiva, indicando desta forma uma coordenação octaédrica para o átomo de níquel. Este dado juntamente com a semelhança entre os espectros das amostras e do padrão de $\mathrm{NiO}$ sugere o níquel na forma de $\mathrm{NiO}$.

Níquel

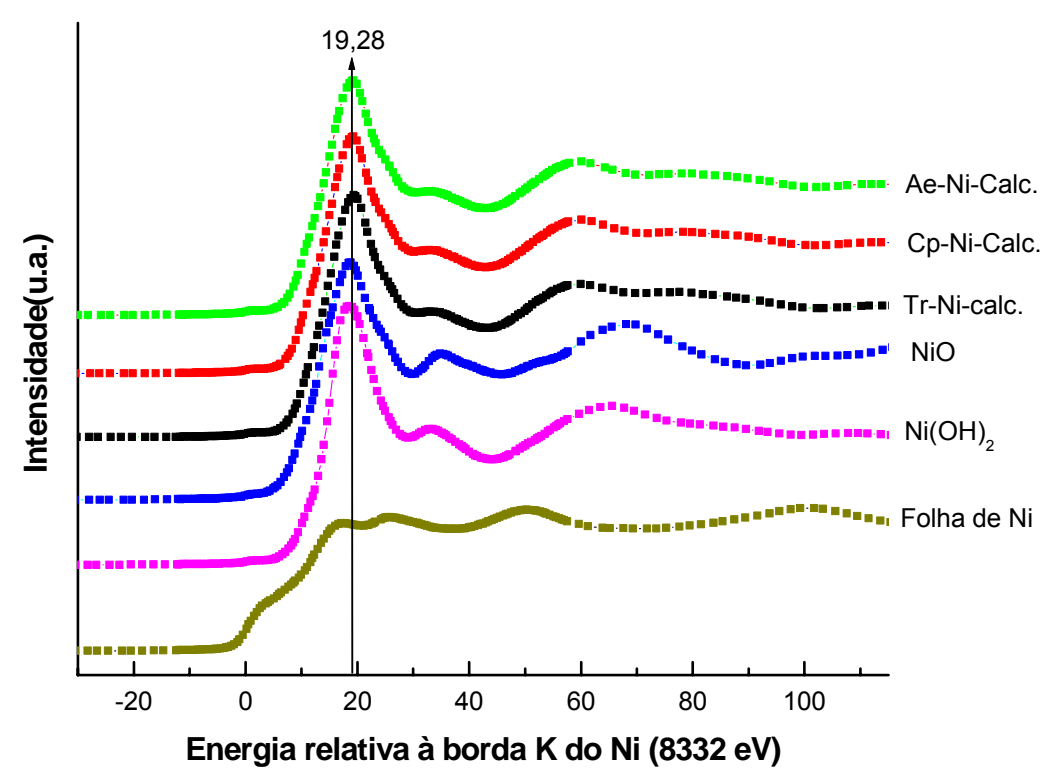

Figura 34. Espectros de XANES normalizados dos padrões e dos catalisadores de níquel. 
A Figura 35 apresenta as curvas das transformadas de Fourier do sinal de EXAFS (Extended X-Ray Absorption Fine Structure) da borda $\mathrm{K}$ do níquel das amostras de níquel calcinadas e do padrão de $\mathrm{NiO}$. O padrão $\mathrm{NiO}$ apresenta 3 picos, que de acordo com Hattori et al. (2002) são atribuídos às distâncias $\mathrm{Ni}-\mathrm{O}(\mathrm{A}), \mathrm{Ni}-\mathrm{Ni}$ (B), Ni-O (C), Ni-Ni (D), e Ni-O (E). As amostras apresentaram um intenso pico na região de 1,6 $\AA$ e picos menos intensos na região de 2,6 $\AA$. Os valores das distâncias encontrados são muito próximos ao do padrão de $\mathrm{NiO}$ para os picos $\mathrm{A}$ e $\mathrm{B}$ (Tabela 14). Estes resultados, juntamente com os de XANES sugerem que o níquel encontra-se na forma de $\mathrm{NiO}$, provavelmente dissolvido na matriz de $\mathrm{MgO}$ dopada com alumínio, como sugerido por DRX, RTP e XPS.

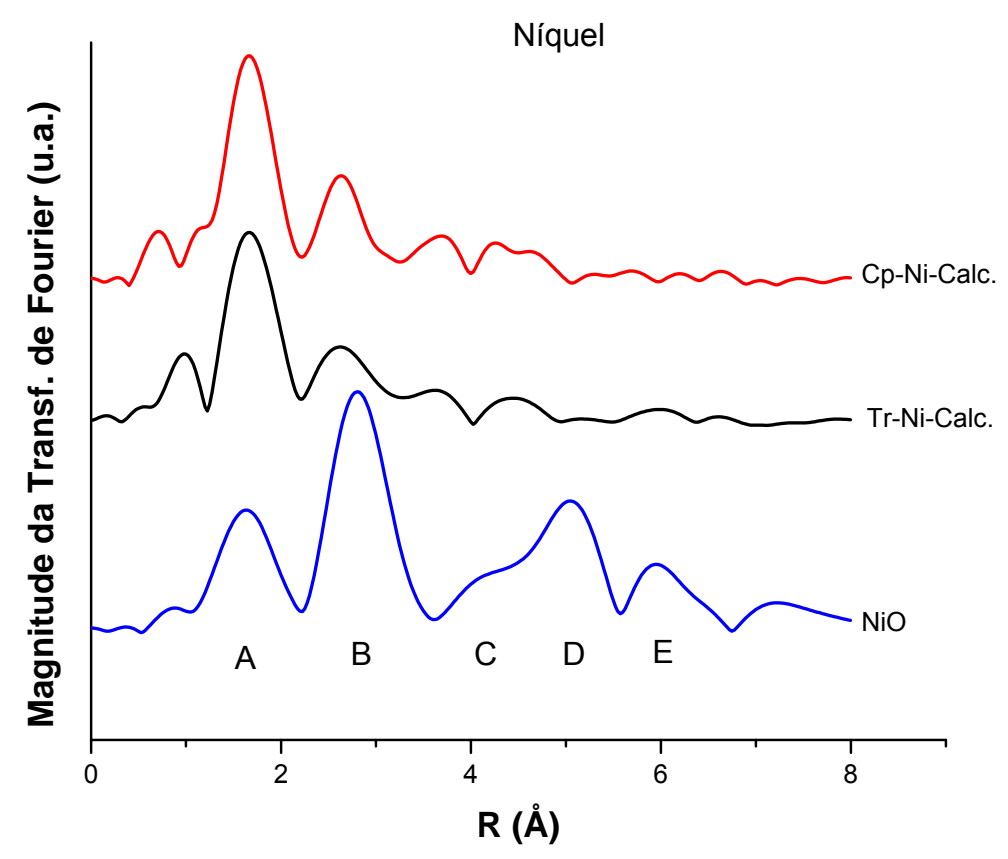

Figura 35. Magnitude da Transformada de Fourier do sinal de EXAFS da borda $\mathrm{K}$ do níquel para o padrão e os catalisadores. 
Tabela 14. Distâncias interatômicas obtidas por EXAFS

\begin{tabular}{|l|l|l|}
\hline Amostra & Distância Ni - O $(\AA)$ & Distância Ni - Ni $(\AA)$ \\
\hline $\mathrm{NiO}$ & 1,63 & 2,60 \\
\hline $\mathrm{Tr}-\mathrm{Ni}$ & 1,68 & 2,65 \\
\hline $\mathrm{Cp}-\mathrm{Ni}$ & 1,66 & 2,63 \\
\hline
\end{tabular}

Na Figura 36 estão apresentados os espectros normalizados da região XANES da borda $\mathrm{K}$ do cobalto das amostras de cobalto calcinadas, da folha de cobalto metálico e do óxido do $\mathrm{Co}_{2} \mathrm{O}_{3}$.

Para todas as amostras observa-se um pequeno pico na energia de $7710 \mathrm{eV}$ o qual é referente a uma pré-borda de absorção, atribuída à transição $1 \mathrm{~s} \rightarrow 3 d$ do cobalto em coordenação tetraédrica (VRÅLSTAD et al., 2006; LELIS et al., 2004), a qual pode ser observada em estruturas do tipo espinélio $\mathrm{AB}_{2} \mathrm{O}_{4}$, sugerindo, portanto, a presença do óxido $\mathrm{Co}_{3} \mathrm{O}_{4}$ ou $\mathrm{CoAl}_{2} \mathrm{O}_{4}$. Nas amostras também se pode observar o pico da borda $\mathrm{K}$ do cobalto em menor energia do que o padrão $\mathrm{Co}_{2} \mathrm{O}_{3}$, sugerindo a presença de espécies de cobalto divalentes.

A Figura 37 apresenta as curvas das transformadas de Fourier do sinal de EXAFS da borda $\mathrm{K}$ do cobalto das amostras de cobalto calcinadas e do padrão de $\mathrm{Co}_{2} \mathrm{O}_{3}$. De acordo com a literatura, o cobalto metálico apresenta um forte pico de

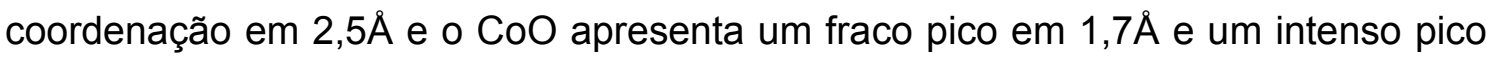
em 2,6 $\mathrm{A}$. O $\mathrm{Co}_{3} \mathrm{O}_{4}$ possui uma curva semelhante ao padrão $\mathrm{Co}_{2} \mathrm{O}_{3}$, sendo o pico em $1,5 \AA$ correspondente a $\mathrm{Co}^{+2 /+3}$ coordenados ao oxigênio (LELIS et al., 2004).

$\mathrm{O} \mathrm{Co}_{2} \mathrm{O}_{3}$ utilizado como padrão apresentou 3 picos, $\mathrm{A}$, B e $\mathrm{C}$ os quais podem

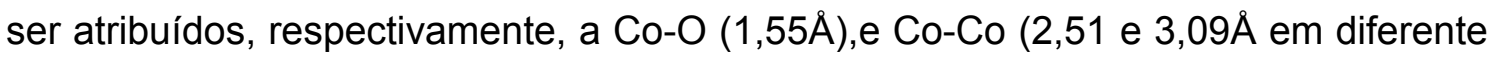
coordenação). As amostras apresentaram um intenso pico na região de $1,5 \AA$, valor próximo ao $\mathrm{CoO}$ e ao padrão $\mathrm{Co}_{2} \mathrm{O}_{3}$ e picos menos intensos na região de $2,8 \AA$ ( $\mathrm{Tr}$ Co-Calc.) e 2,3Å (Cp-Co-Calc.) referentes à coordenação Co-Me (onde $\mathrm{Me}=\mathrm{Mg}$ ou 
Al), como pode ser visto na Tabela 15. Estes valores sugerem a presença de espécies de cobalto de espécies divalente e trivalente nas amostras.

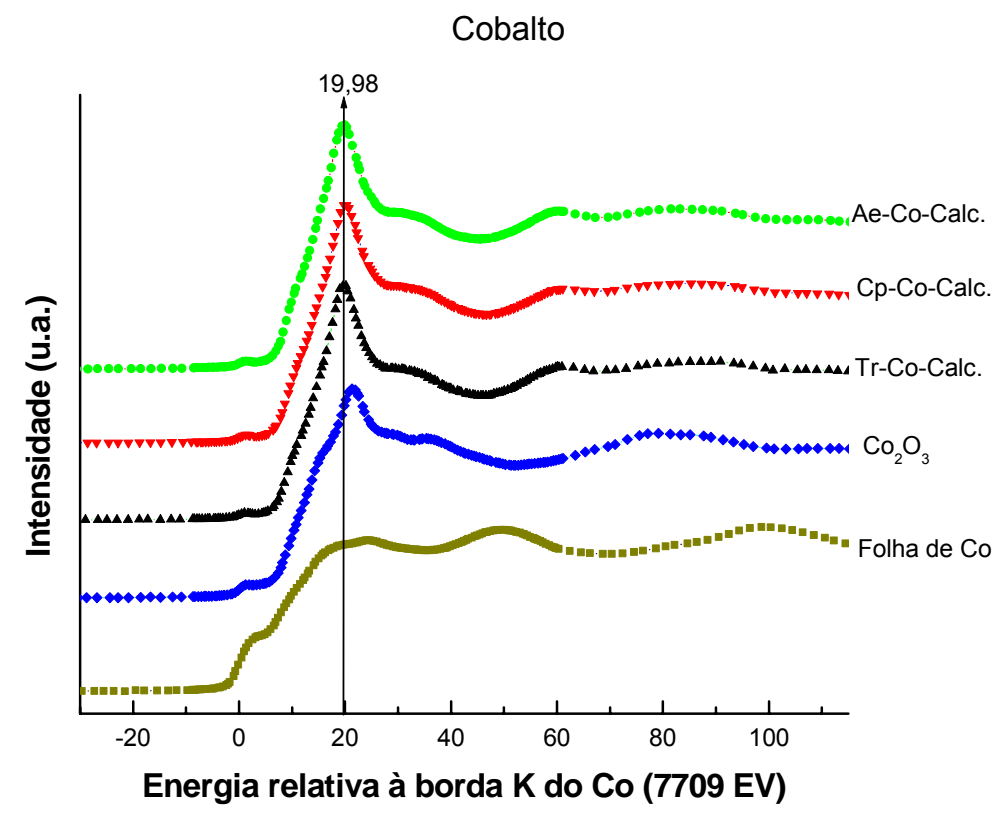

Figura 36. Espectros de XANES normalizados dos padrões e dos catalisadores.

Cobalto

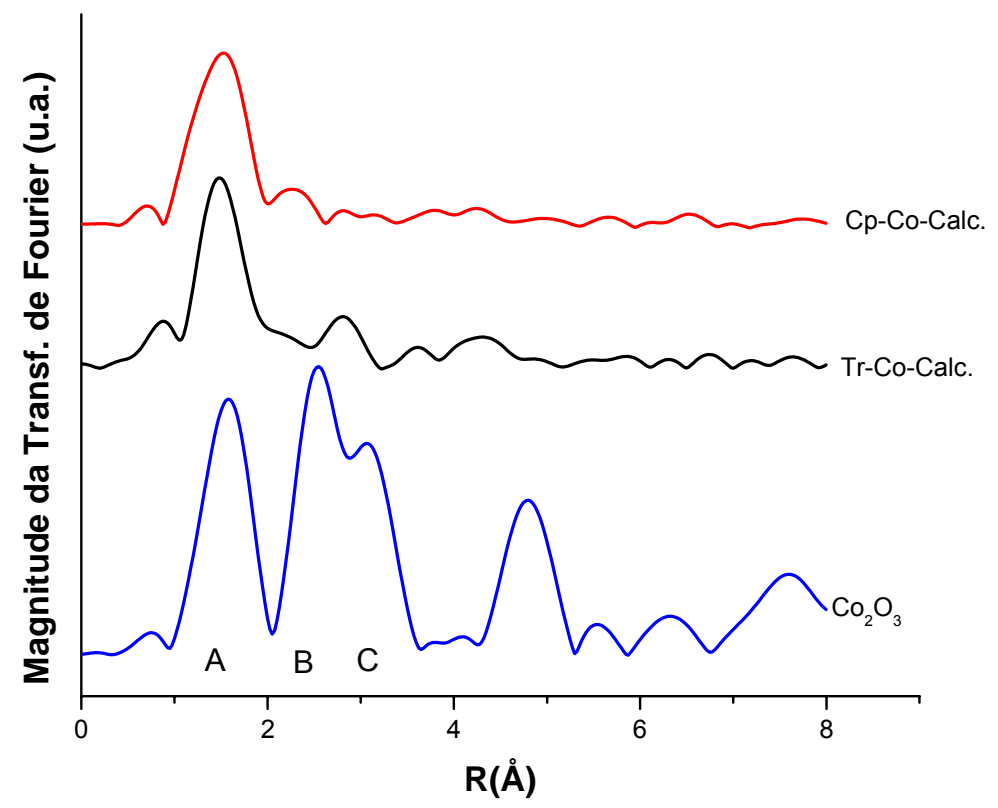

Figura 37. Magnitude da Transformada de Fourier do sinal de EXAFS da borda $\mathrm{K}$ do cobalto para o padrão e os catalisadores. 
Tabela 15. Distâncias interatômicas obtidas por EXAFS

\begin{tabular}{|l|l|l|}
\hline Amostra & Distância Co - O $(\AA)$ & Distância Co - Co R $(\AA)$ \\
\hline $\mathrm{Co}_{2} \mathrm{O}_{3}$ & 1,55 & 2,51 \\
& & 3,09 \\
\hline $\mathrm{Tr}-\mathrm{Co}$ & 1,48 & 2,82 \\
\hline $\mathrm{Cp}-\mathrm{Co}$ & 1,58 & 2,29 \\
\hline
\end{tabular}

\section{9 - Ensaios Catalíticos}

\subsection{1 - Reforma a vapor do metano (RVM)}

\section{Razão de alimentação $\mathrm{H}_{2} \mathrm{O}: \mathrm{CH}_{4}=4: 1$}

Nas Figuras 38 e 39 estão apresentados os resultados de Reforma a vapor do metano com razão molar de alimentação $\mathrm{H}_{2} \mathrm{O}: \mathrm{CH}_{4}=4: 1$ para os catalisadores de níquel. Na Tabela 16 estão apresentados os valores médios de conversão do metano e o rendimento em produtos, bem como a velocidade média de formação de carbono para os catalisadores de níquel.

Os catalisadores de cobalto não foram ativos para RVM com razão de alimentação $\mathrm{H}_{2} \mathrm{O}: \mathrm{CH}_{4}=4: 1$, apresentando imediata desativação devido à oxidação dos sítios ativos. Os catalisadores utilizados apresentaram uma coloração violeta característica da forma óxida do cobalto. A Figura 40 apresenta o difratograma de Raios-X do catalisador $\mathrm{Cp}$-Co após a desativação na RVM com razão de alimentação $\mathrm{H}_{2} \mathrm{O}: \mathrm{CH}_{4}=4: 1$, mostrando a re-oxidação dos sítios ativos.

De acordo com os resultados obtidos pode-se observar que os catalisadores de níquel não favoreceram a formação de carbono, indicando que a alta razão de água na alimentação pode ter aumentado a velocidade de gaseificação de depósitos carbonáceos (reação 25). Os catalisadores $\mathrm{Ae}-\mathrm{Ni}$ e $\mathrm{Cp}-\mathrm{Ni}$ apresentaram maiores 
conversões do que os catalisadores $\mathrm{Tr}-\mathrm{Ni}$ e do que os catalisadores promovidos. $\mathrm{O}$ catalisador Ae-La-Ni apresentou desativação com o tempo de reação. Pode-se observar também que os catalisadores preparados por quelatos apresentaram maior formação de $\mathrm{CO}_{2}$, mostrando assim um favorecimento da reação de deslocamento gás-água (reação 2), sendo que o efeito foi mais pronunciado nos catalisadores promovidos, onde a quantidade de $\mathrm{CO}_{2}$ foi maior do que a de $\mathrm{CO}$. A adição de promotores favoreceu a reação de deslocamento gás-água, provavelmente devido a uma maior velocidade de decomposição da água (reações 11 - 14) e conseqüente reação do oxigênio adsorvido com CO (reação 8).

Tabela 16. Valores médios de conversão do Metano (\%); mol produzido de $\mathrm{H}_{2} ; \mathrm{CO}$ e $\mathrm{CO}_{2} ; \mathrm{H}_{2}$ estequiométrico; Velocidade de formação de carbono $\left(\mathrm{mmolmin}^{-1}\right)$.

\begin{tabular}{|c|c|c|c|c|c|c|}
\hline Catalisador & $\begin{array}{c}\mathrm{XCH}_{4} \\
(\%)\end{array}$ & $\begin{array}{c}\mathrm{H}_{2} \\
(\mathrm{~mol})\end{array}$ & $\begin{array}{c}\mathrm{CO} \\
(\mathrm{mol})\end{array}$ & $\begin{array}{c}\mathrm{CO}_{2} \\
(\mathrm{~mol})\end{array}$ & $\begin{array}{c}\mathrm{H}_{2} \text { est. } \\
(\mathrm{mol})\end{array}$ & $\begin{array}{c}\mathrm{C} \\
\left(\mathrm{mmolmin}^{-1}\right)\end{array}$ \\
\hline $\mathrm{Tr}-\mathrm{Ni}$ & 90 & 3,3 & 0,8 & 0,2 & 3,2 & 0 \\
\hline $\mathrm{Cp}-\mathrm{Ni}$ & 100 & 3,3 & 0,6 & 0,4 & 3,4 & 0 \\
\hline $\mathrm{Ae}-\mathrm{Ni}$ & 100 & 3,3 & 0,6 & 0,4 & 3,4 & 0 \\
\hline Ae-La-Ni & 76 & 3,3 & 0,4 & 0,6 & 3,6 & 0 \\
\hline Ae-Ce-Ni & 87 & 3,1 & 0,5 & 0,5 & 3,5 & 0 \\
\hline
\end{tabular}

$\mathrm{H}_{2}$ estequiométrico $=$ mol CO${ }^{*} 3+\mathrm{molCO}_{2}{ }^{*} 4$ ( com base nas reações 1 e 2) [4] 

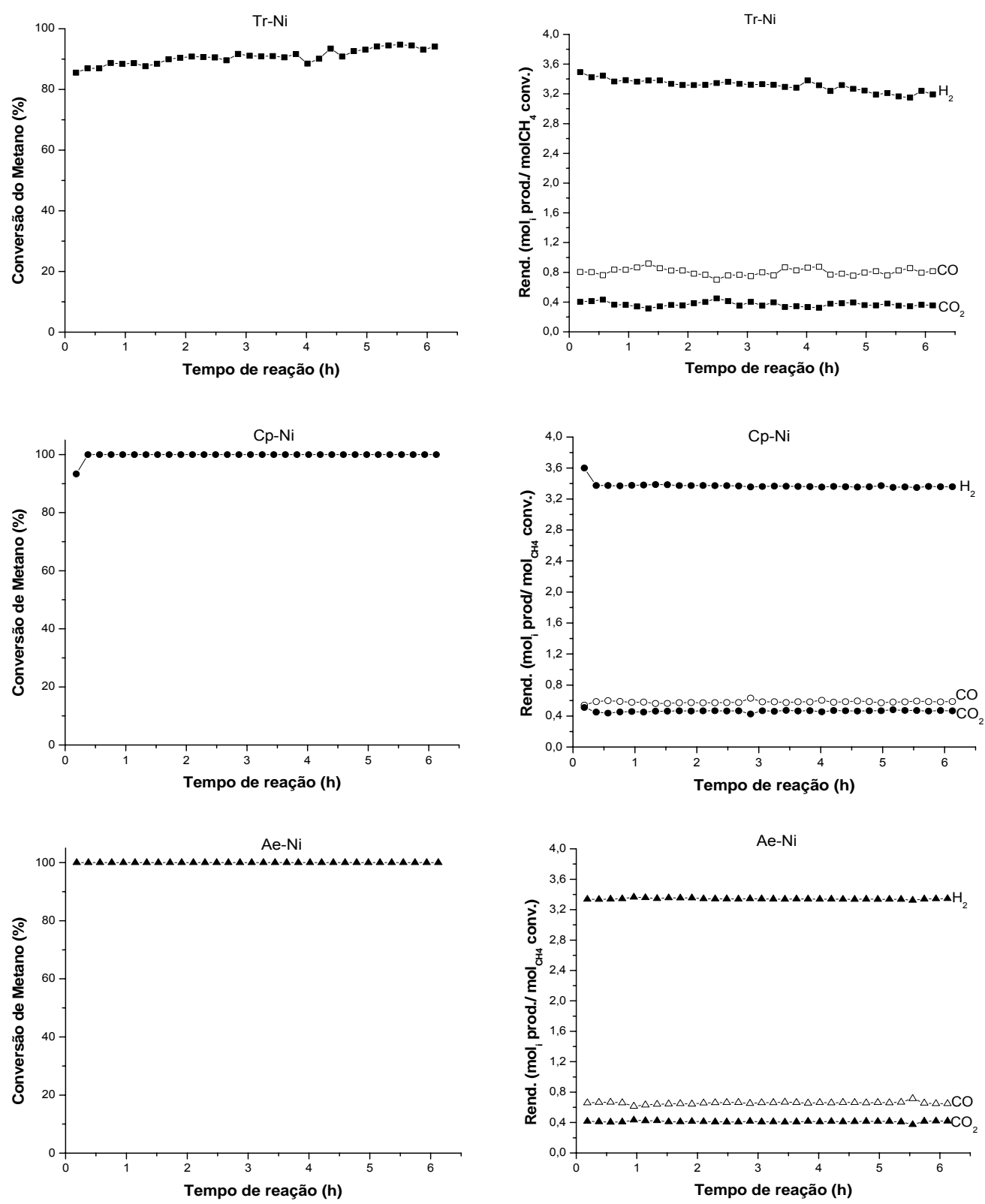

Figura 38. Conversão do Metano e Rendimento em Produtos para os catalisadores de níquel nãopromovidos na RVM com razão de alimentação $\mathrm{H}_{2} \mathrm{O}: \mathrm{CH}_{4}=4: 1$. 

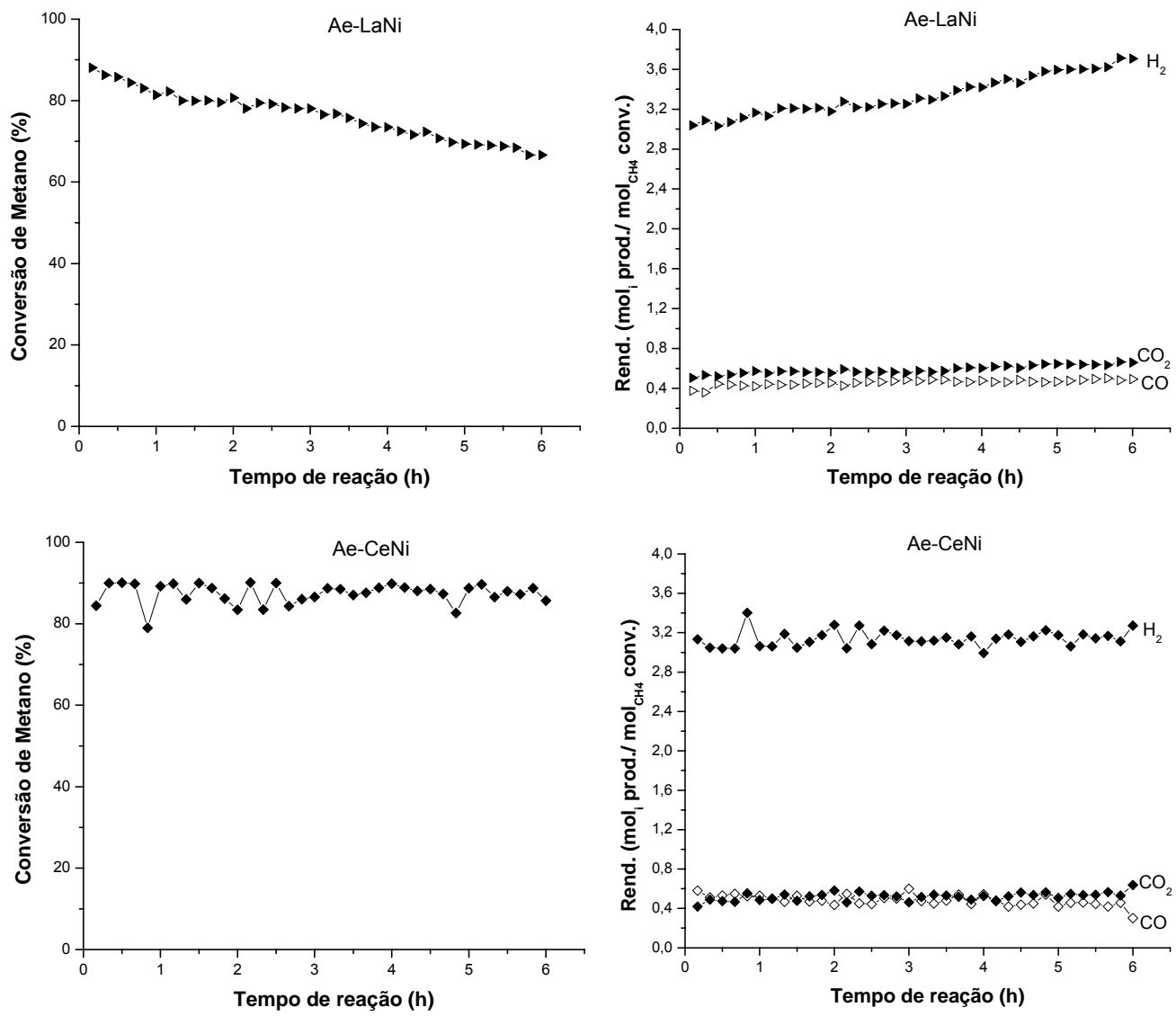

Figura 39. Conversão do Metano e Rendimento em Produtos para os catalisadores de níquel promovidos com Lantânio ou Cério na RVM com razão de alimentação $\mathrm{H}_{2} \mathrm{O}: \mathrm{CH}_{4}=4: 1$. 


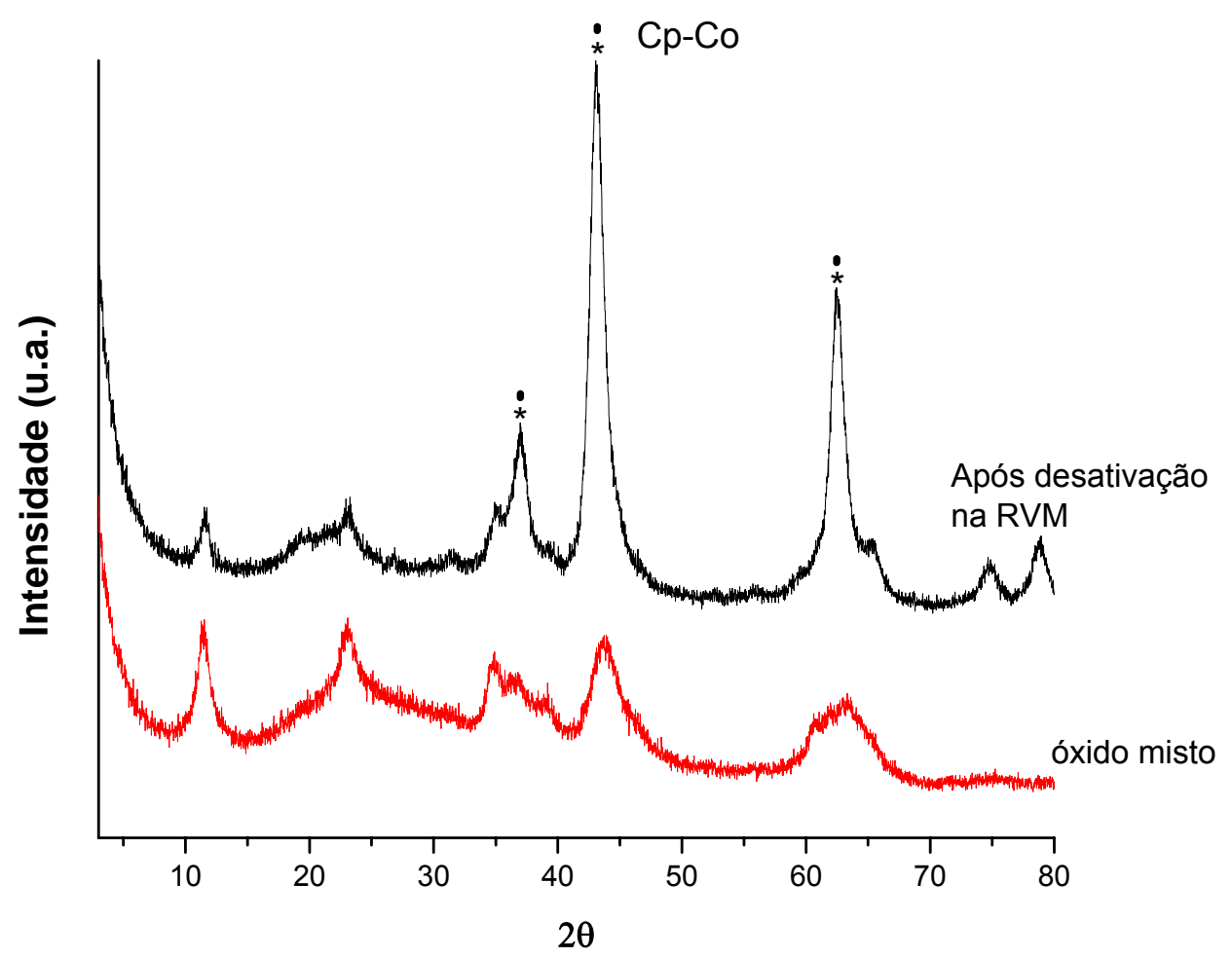

Figura 40. Difratogramas de Raios- $X$ do catalisador $\mathrm{Cp}$-Co após tratamento térmico e após a imediata desativação na RVM $\left(\left(^{*}=\mathrm{MgO}, \mathrm{CoO} ; \bullet=\mathrm{Co}_{3} \mathrm{O}_{4}\right.\right.$ e/ou $\mathrm{MgAl}_{2} \mathrm{O}_{4}$ e/ou $\mathrm{Co}_{2} \mathrm{AlO}_{4}$ e/ou CoAl $\mathrm{O}_{4}$ e/ou $\mathrm{MgCO}_{2} \mathrm{O}_{4}$ ).

\section{Razão de alimentação $\mathrm{H}_{2} \mathrm{O}: \mathrm{CH}_{4}=2: 1$}

Nas Figuras 41 a 44 estão apresentados os resultados de reforma a vapor do metano com razão de alimentação $\mathrm{H}_{2} \mathrm{O}: \mathrm{CH}_{4}=2: 1$ para os catalisadores de níquel e cobalto.

Na Tabela 17 estão apresentados os valores médios de conversão do metano e o rendimento em produtos, bem como a velocidade média de formação de carbono para os catalisadores de níquel e cobalto.

De acordo com os resultados, os catalisadores de níquel (Figura 41 e 42) apresentaram conversões próximas, sem desativação no tempo de reação, inclusive 
para o catalisador Ae-La-Ni, que apresentou desativação na razão de alimentação $\mathrm{H}_{2} \mathrm{O}: \mathrm{CH}_{4}=4: 1$, indicando uma possível oxidação dos sítios ativos devido ao excesso de água utilizado na alimentação.

$\mathrm{Na}$ razão estequiométrica de alimentação, os catalisadores apresentaram uma baixa velocidade de formação de carbono, sendo menor nos catalisadores AeLa-Ni; Ae-Ce-Ni; Tr-Ni; Ae-Ni e Cp-Ni, respectivamente. Assim como na razão $\mathrm{H}_{2} \mathrm{O}: \mathrm{CH}_{4}=4: 1$, os catalisadores promovidos apresentaram maior formação de $\mathrm{CO}_{2}$, indicando um favorecimento da reação de deslocamento gás-água e fortalecendo a hipótese de os promotores terem aumentado a velocidade de decomposição da água. 

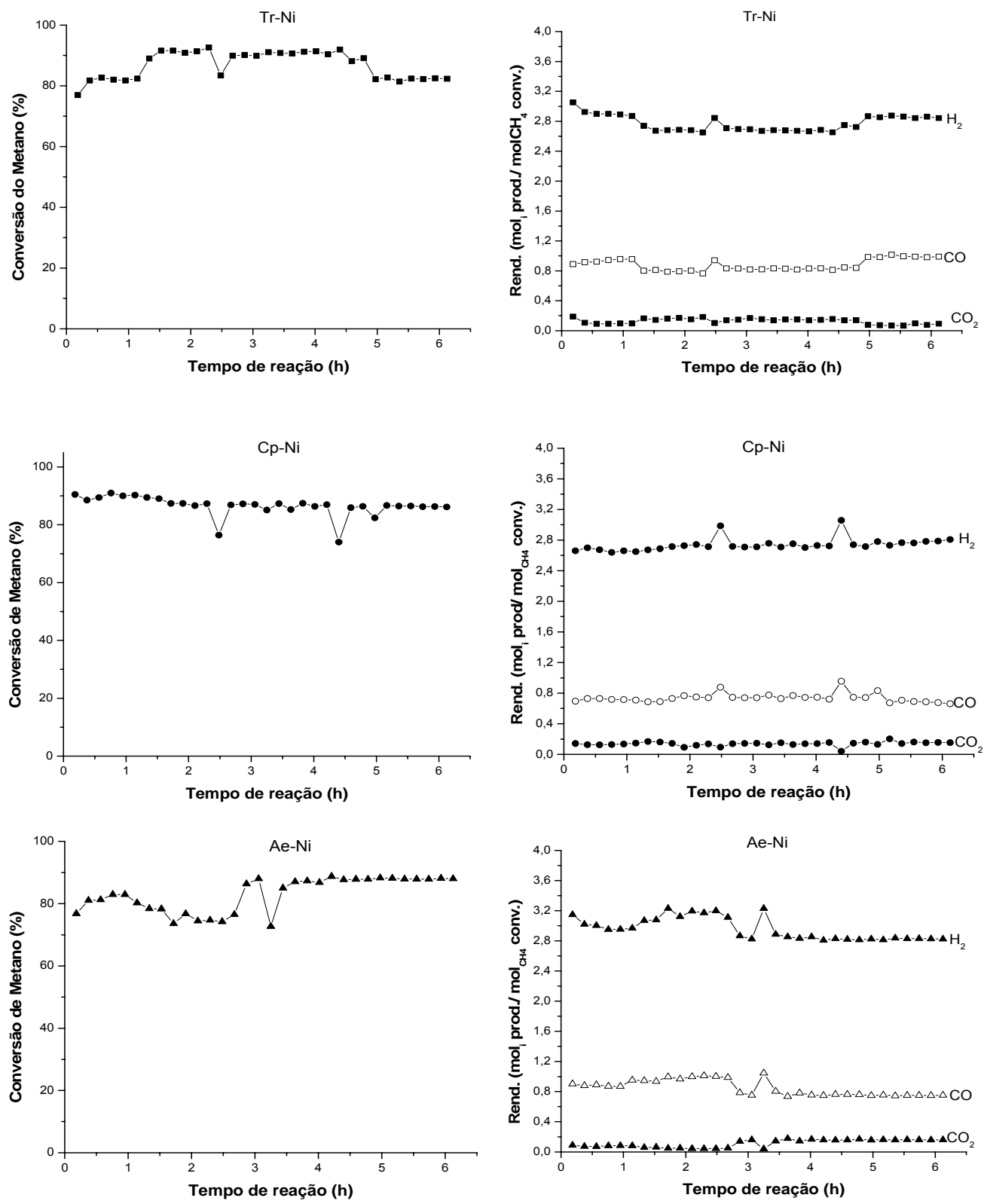

Figura 41. Conversão do Metano e Rendimento em Produtos para os catalisadores de níquel nãopromovidos na RVM com razão de alimentação $\mathrm{H}_{2} \mathrm{O}: \mathrm{CH}_{4}=2: 1$. 

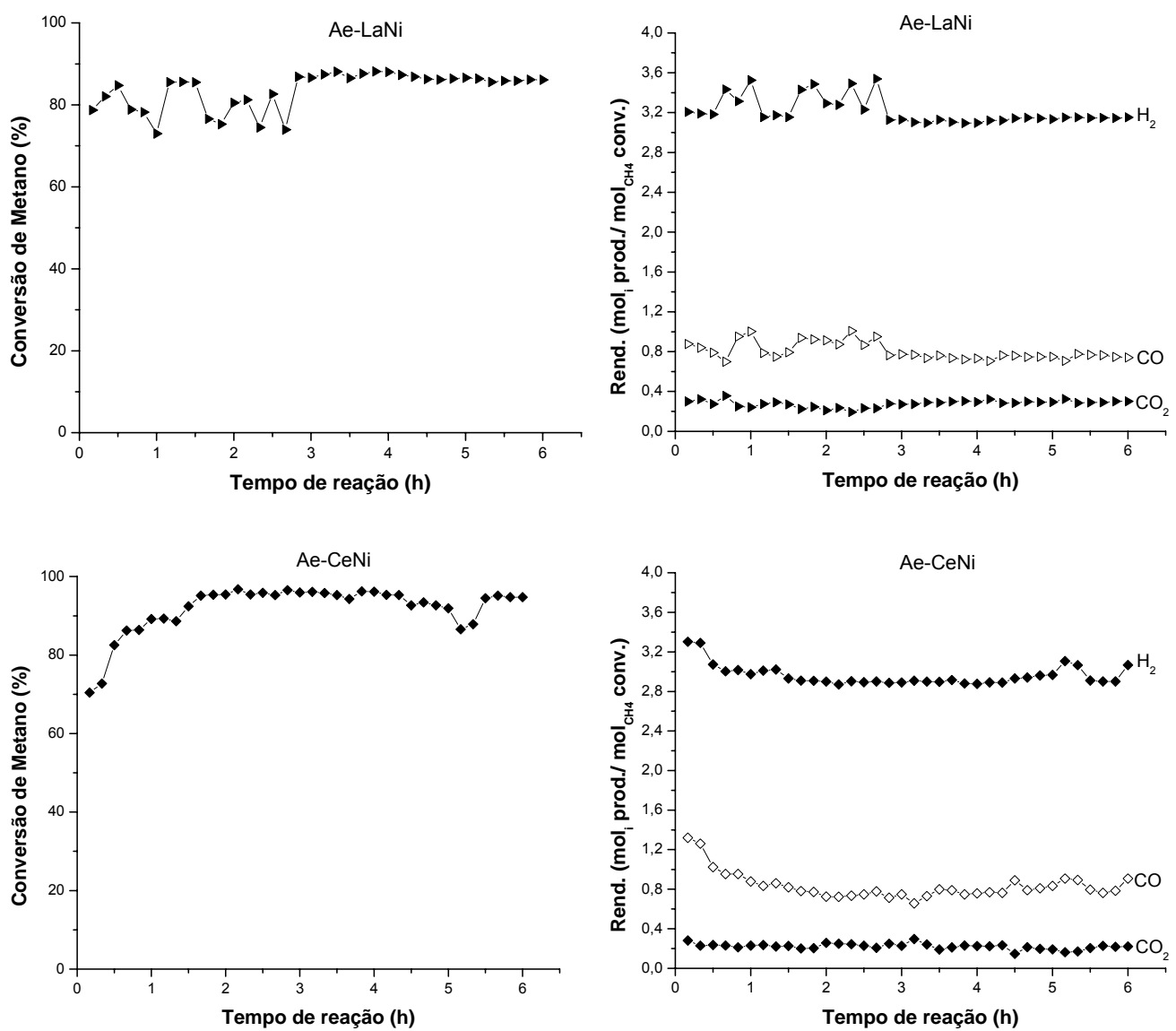

Figura 42. Conversão do Metano e Rendimento em Produtos para os catalisadores de níquel promovidos com Lantânio ou cério na RVM com razão de alimentação $\mathrm{H}_{2} \mathrm{O}: \mathrm{CH}_{4}=2: 1$.

Os catalisadores de cobalto (Figuras 43 e 44) apresentaram conversões iniciais próximas a $80 \%$, com exceção do catalisador $\mathrm{Cp}-\mathrm{Co}$, que apresentou conversão inicial próxima a $60 \%$, diminuindo para $45 \%$ após a primeira hora de reação. Os catalisadores promovidos apresentaram desativação com o tempo de reação. Este comportamento ocorre principalmente devido à oxidação de sítios ativos de cobalto pela água, visto que os catalisadores apresentaram menor formação de carbono. Os ensaios na razão de alimentação $\mathrm{H}_{2} \mathrm{O}: \mathrm{CH}_{4}=4: 1$ mostraram a alta afinidade dos sítios ativos de cobalto com a água. 

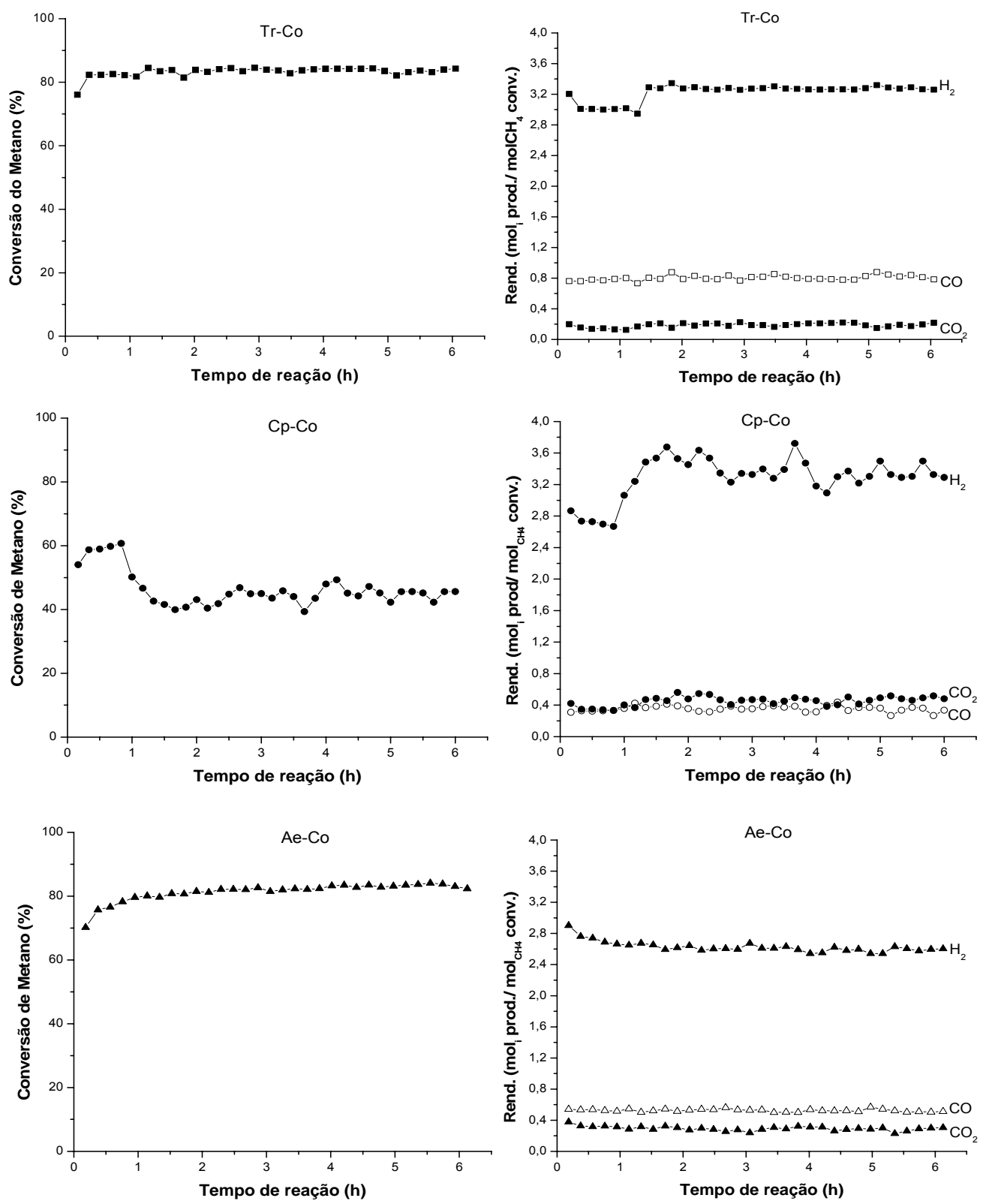

Figura 43. Conversão do Metano e Rendimento em Produtos para os catalisadores de cobalto nãopromovidos na RVM com razão de alimentação $\mathrm{H}_{2} \mathrm{O}: \mathrm{CH}_{4}=2: 1$. 

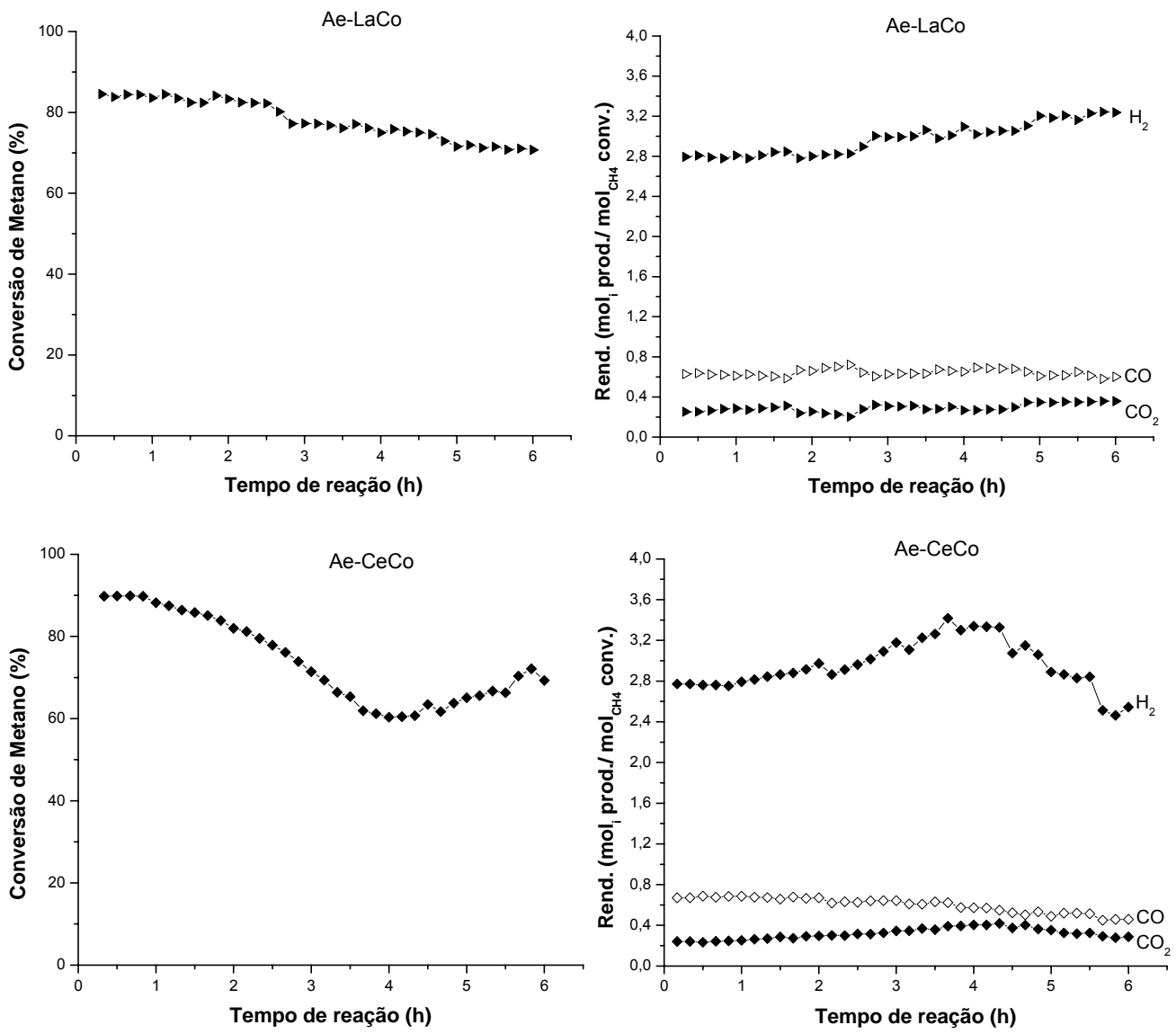

Figura 44. Conversão do Metano e Rendimento em Produtos para os catalisadores de cobalto promovidos com Lantânio ou cério na RVM com razão de alimentação $\mathrm{H}_{2} \mathrm{O}: \mathrm{CH}_{4}=2: 1$.

Com relação à formação de carbono, os catalisadores Tr-Co; Ae-Ce-Co e AeLa-Co apresentaram baixa formação de carbono quando comparados aos catalisadores $\mathrm{Cp}$-Co e Ae-Co. Este comportamento pode ser relacionado à redutibilidade do cobalto no catalisador, apresentada nos ensaios de RTP. Catalisadores com maior redutibilidade apresentam o metal menos disperso o que pode favorecer a formação de depósitos carbonáceos. Os catalisadores de cobalto foram mais seletivos para a formação de $\mathrm{CO}_{2}$ do que os catalisadores de níquel, mostrando um favorecimento da decomposição de água nestes catalisadores. Este resultado está de acordo com o comportamento na razão de alimentação 
$\mathrm{H}_{2} \mathrm{O}: \mathrm{CH}_{4}=4: 1$, onde os catalisadores desativaram completamente logo no início da reação, indicando uma competição entre a reação de decomposição da água (reações 11-14) e a decomposição do metano (reações 4 -7), onde provavelmente o excesso de água na alimentação favoreceu a decomposição da água e conseqüentemente levou à oxidação dos sítios ativos.

Tabela 17. Valores médios de conversão do Metano (\%); mol produzido de $\mathrm{H}_{2} ; \mathrm{CO}$ e $\mathrm{CO}_{2} ; \mathrm{H}_{2}$ estequiométrico; Velocidade de formação de carbono $\left(\mathrm{mmolmin}^{-1}\right)$.

\begin{tabular}{|c|c|c|c|c|c|c|}
\hline Catalisador & $\begin{array}{c}\mathrm{XCH}_{4} \\
(\%)\end{array}$ & $\begin{array}{c}\mathrm{H}_{2} \\
(\mathrm{~mol})\end{array}$ & $\begin{array}{c}\mathrm{CO} \\
(\mathrm{mol})\end{array}$ & $\begin{array}{c}\mathrm{CO}_{2} \\
(\mathrm{~mol})\end{array}$ & $\begin{array}{c}\mathrm{H}_{2} \text { est. } \\
(\mathrm{mol})\end{array}$ & $\begin{array}{c}\mathrm{C} \\
\left(\mathrm{mmolmin}^{-1}\right)\end{array}$ \\
\hline $\mathrm{Tr}-\mathrm{Ni}$ & 87 & 2,8 & 0,9 & 0,1 & 3,0 & 0,04 \\
\hline $\mathrm{Cp}-\mathrm{Ni}$ & 87 & 2,7 & 0,7 & 0,1 & 2,7 & 0,18 \\
\hline $\mathrm{Ae}-\mathrm{Ni}$ & 83 & 2,9 & 0,9 & 0,1 & 3,0 & 0,06 \\
\hline $\mathrm{Ae}-\mathrm{La}-\mathrm{Ni}$ & 84 & 3,2 & 0,8 & 0,2 & 3,5 & 0,02 \\
\hline $\mathrm{Ae-Ce-Ni}$ & 90 & 3,1 & 0,8 & 0,2 & 3,2 & 0,03 \\
\hline Tr-Co & 83 & 3,2 & 0,8 & 0,2 & 3,1 & 0,04 \\
\hline $\mathrm{Cp}-\mathrm{Co}$ & 46 & 3,3 & 0,4 & 0,5 & 2,9 & 0,15 \\
\hline Ae-Co & 81 & 2,6 & 0,5 & 0,3 & 2,7 & 0,24 \\
\hline Ae-La-Co & 77 & 3,0 & 0,6 & 0,3 & 3,0 & 0,08 \\
\hline Ae-Ce-Co & 72 & 3,0 & 0,6 & 0,3 & 3,1 & 0,05 \\
\hline
\end{tabular}

\section{Razão de alimentação $\mathrm{H}_{2} \mathrm{O}: \mathrm{CH}_{4}=0,5: 1$}

Os testes com baixa razão molar de alimentação foram feitos a fim de se analisar a estabilidade dos catalisadores frente à decomposição do metano.

Nas Figuras 45 e 46 estão apresentados os resultados de reforma a vapor do metano com razão de alimentação $\mathrm{H}_{2} \mathrm{O}: \mathrm{CH}_{4}=0,5: 1$ para os catalisadores de níquel. 
Na Tabela 18 estão apresentados os valores médios de conversão do metano e o rendimento em produtos, bem como a velocidade média de formação de carbono para os catalisadores de níquel e cobalto.

Nos testes de estabilidade, os catalisadores de níquel apresentaram conversões médias de 50\%, mostrando serem estáveis frente às reações de decomposição do metano (reações 4 -7), com exceção do catalisador Ae-La-Ni que sofreu uma rápida desativação. 

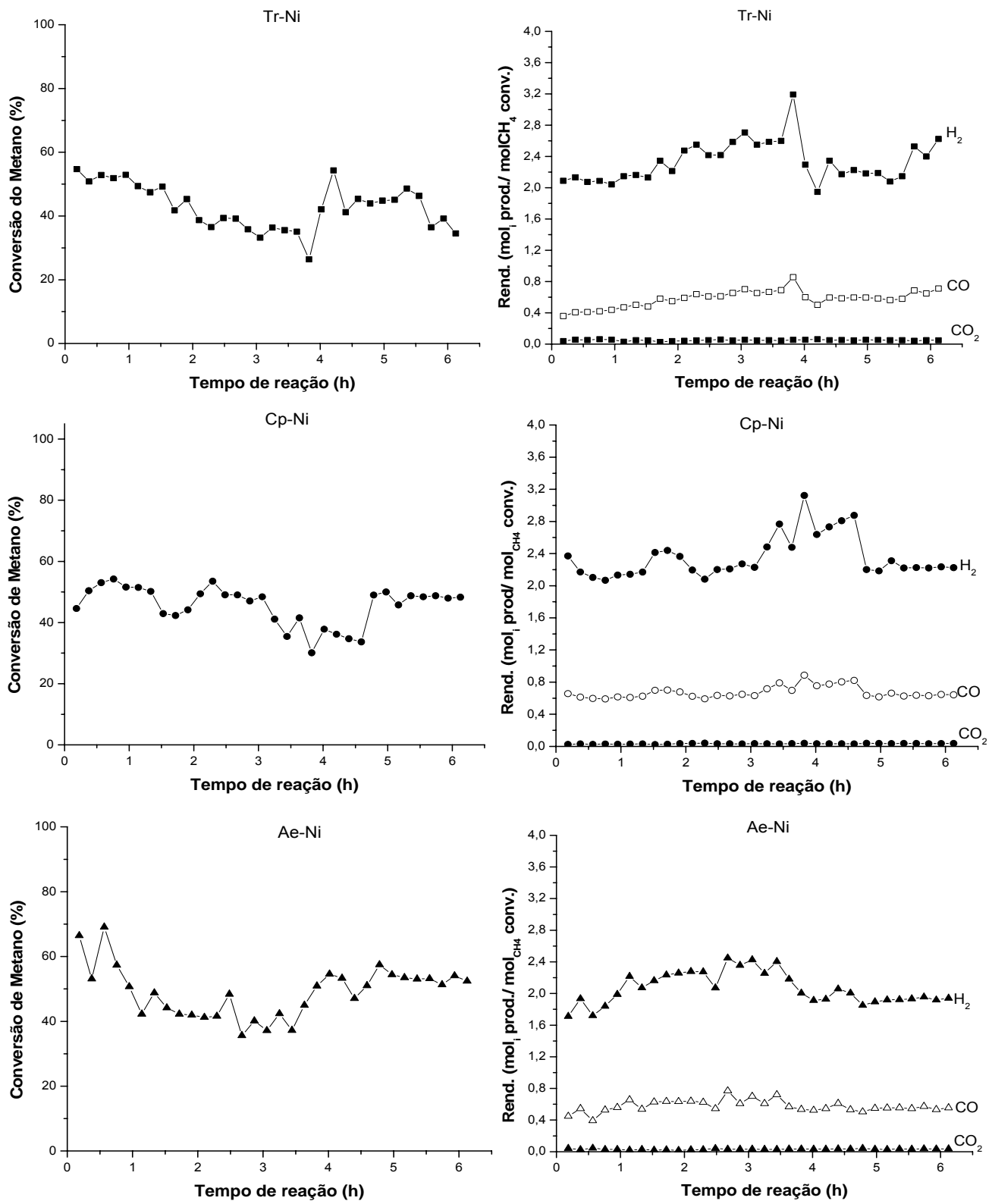

Figura 45. Conversão do Metano e Rendimento em Produtos para os catalisadores de níquel nãopromovidos na RVM com razão de alimentação $\mathrm{H}_{2} \mathrm{O}: \mathrm{CH}_{4}=0,5: 1$. 

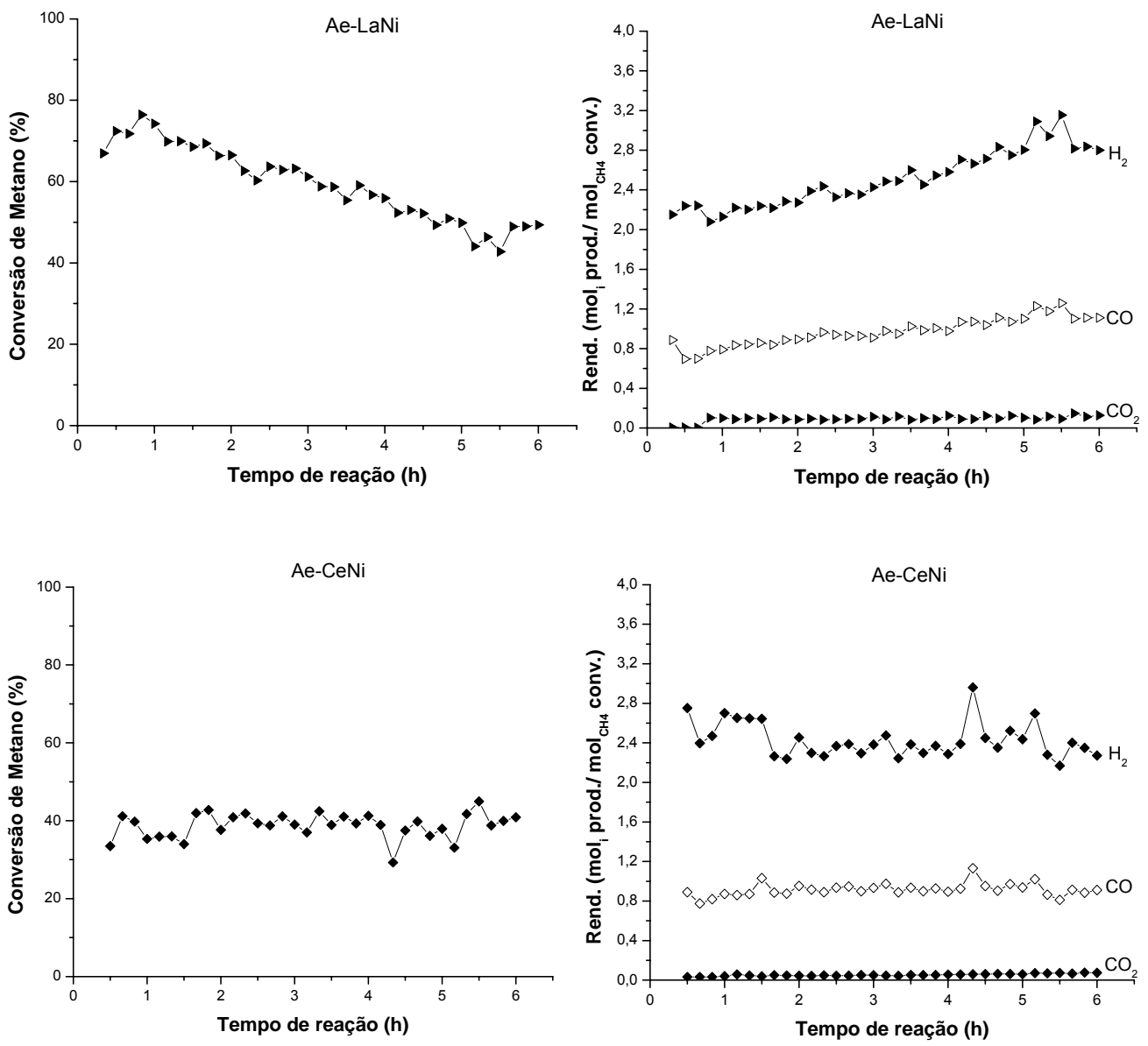

Figura 46. Conversão do Metano e Rendimento dos Produtos para os catalisadores de níquel promovidos na RVM com razão de alimentação $\mathrm{H}_{2} \mathrm{O}: \mathrm{CH}_{4}=0,5: 1$.

Nas Figuras 47 e 48 estão apresentados os resultados de reforma a vapor do metano com razão de alimentação $\mathrm{H}_{2} \mathrm{O}: \mathrm{CH}_{4}=0,5: 1$ para os catalisadores de cobalto. 

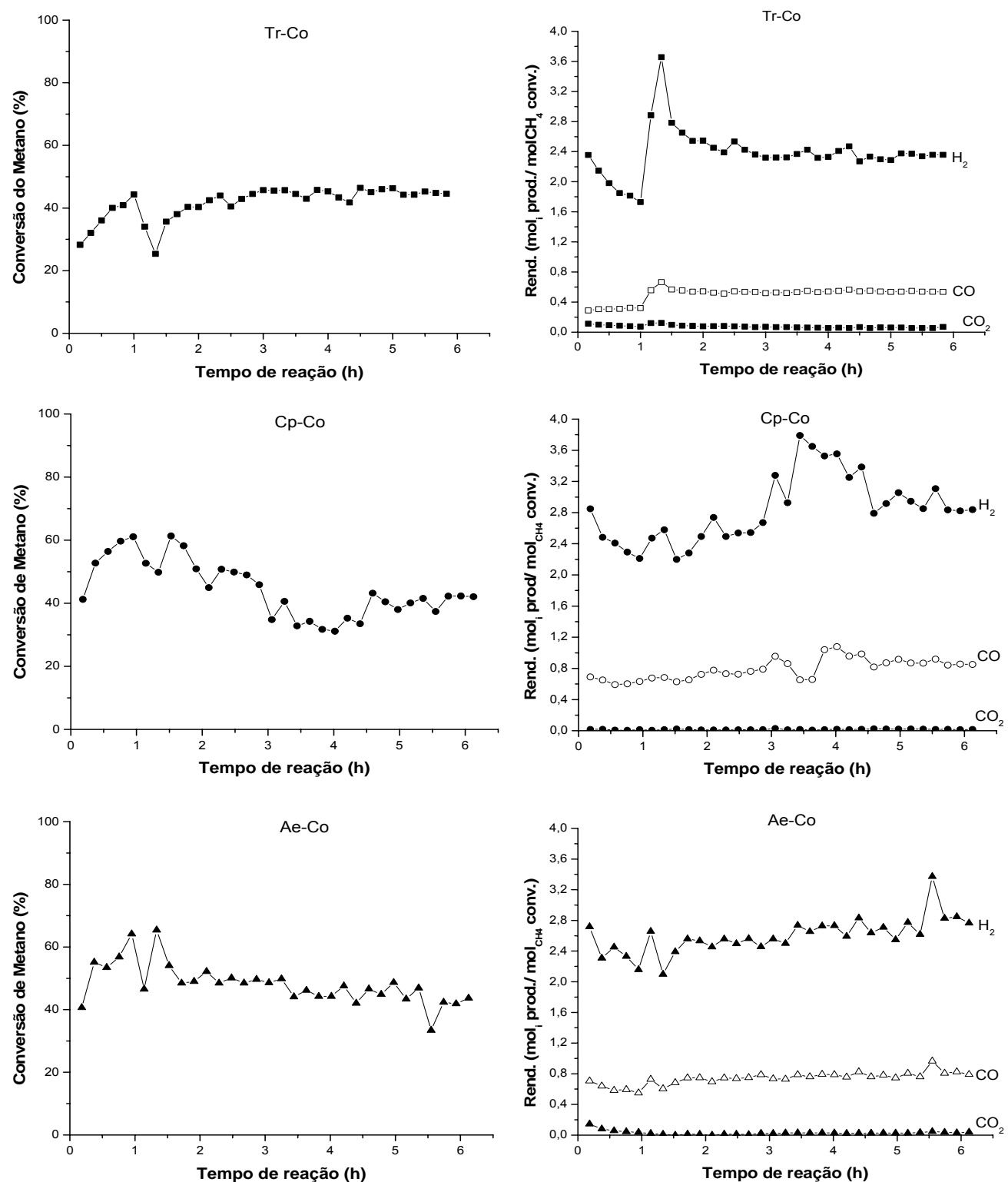

Figura 47. Conversão do Metano e Rendimento em Produtos para os catalisadores de cobalto nãopromovidos na RVM com razão de alimentação $\mathrm{H}_{2} \mathrm{O}: \mathrm{CH}_{4}=0,5: 1$. 

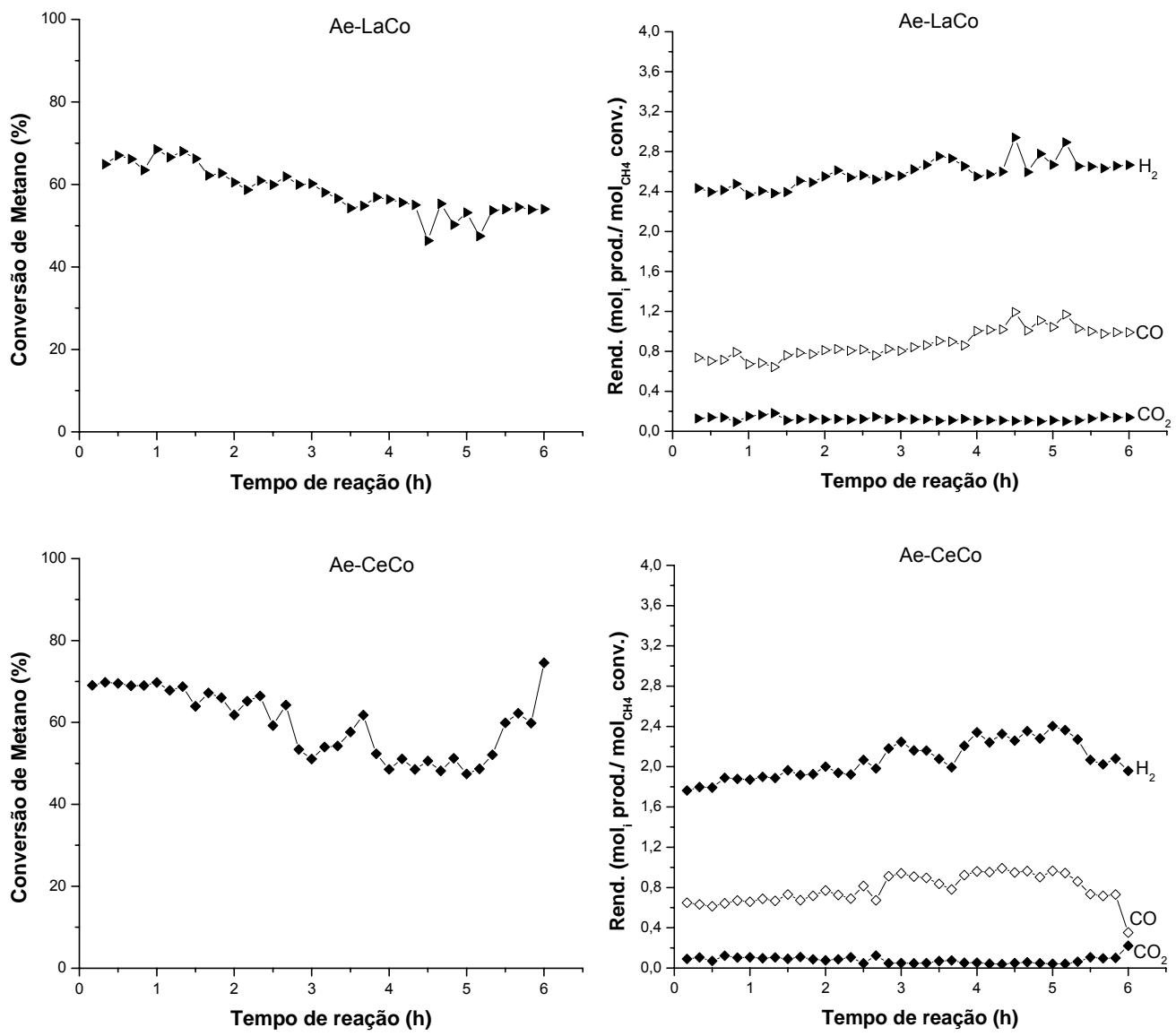

Figura 48. Conversão do Metano e Rendimento em Produtos para os catalisadores de cobalto promovidos na RVM com razão de alimentação $\mathrm{H}_{2} \mathrm{O}: \mathrm{CH}_{4}=0,5: 1$.

Os catalisadores de cobalto apresentaram comportamento semelhante aos catalisadores de níquel, porém o catalisador Ae-La-Co sofreu uma desativação mais lenta.

Os catalisadores promovidos, de níquel e de cobalto, apresentaram considerável redução na formação de carbono, como pode ser visto pela Tabela 18. 
Tabela 18. Valores médios de conversão do Metano (\%); mol produzido de $\mathrm{H}_{2} ; \mathrm{CO}$ e $\mathrm{CO}_{2} ; \mathrm{H}_{2}$ estequiométrico; Velocidade de formação de carbono $\left(\mathrm{mmolmin}^{-1}\right)$.

\begin{tabular}{|c|c|c|c|c|c|c|}
\hline Catalisador & $\begin{array}{c}\mathrm{XCH}_{4} \\
(\%)\end{array}$ & $\begin{array}{c}\mathrm{H}_{2} \\
(\mathrm{~mol})\end{array}$ & $\begin{array}{c}\mathrm{CO} \\
(\mathrm{mol})\end{array}$ & $\begin{array}{c}\mathrm{CO}_{2} \\
(\mathrm{~mol})\end{array}$ & $\begin{array}{c}\mathrm{H}_{2} \text { est. } \\
(\mathrm{mol})\end{array}$ & $\begin{array}{c}\mathrm{C} \\
\left(\mathrm{mmolmin}^{-1}\right)\end{array}$ \\
\hline $\mathrm{Tr}-\mathrm{Ni}$ & 43 & 2,3 & 0,58 & 0,05 & 1,9 & 0,273 \\
\hline $\mathrm{Cp}-\mathrm{Ni}$ & 46 & 2,3 & 0,67 & 0,04 & 2,1 & 0,228 \\
\hline $\mathrm{Ae}-\mathrm{Ni}$ & 49 & 2,1 & 0,58 & 0,03 & 1,9 & 0,322 \\
\hline $\mathrm{Ae}-\mathrm{La}-\mathrm{Ni}$ & 59 & 2,5 & 0,91 & 0,09 & 3,1 & 0,129 \\
\hline $\mathrm{Ae}-\mathrm{Ce}-\mathrm{Ni}$ & 37 & 2,7 & 0,95 & 0,05 & 3,1 & 0,035 \\
\hline Tr-Co & 42 & 2,4 & 0,50 & 0,07 & 1,8 & 0,284 \\
\hline Cp-Co & 44 & 2,8 & 0,79 & 0,02 & 2,4 & 0,174 \\
\hline Ae-Co & 48 & 2,6 & 0,79 & 0,03 & 2,5 & 0,188 \\
\hline Ae-La-Co & 54 & 2,6 & 0,87 & 0,12 & 3,0 & 0,108 \\
\hline Ae-Ce-Co & 60 & 2,1 & 0,80 & 0,08 & 2,7 & 0,167 \\
\hline
\end{tabular}

\subsection{2 - Oxidação Parcial do Metano (OPM)}

Os catalisadores tanto de níquel, quanto cobalto, não foram ativos para a oxidação parcial do metano com razão de alimentação $\mathrm{CH}_{4}: \mathrm{O}_{2}=2: 1$ (razão estequiométrica) mostrando rápida desativação por oxidação dos sítios ativos , possivelmente, devido à uma maior velocidade de adsorção dissociativa do oxigênio (reação 21) frente a do metano (reações de 4 - 7) (Zhang et al., 2005).

Nas Figuras 49 e 50 estão apresentados os resultados da oxidação parcial do metano com razão de alimentação $\mathrm{CH}_{4}: \mathrm{O}_{2}=4: 1$ para os catalisadores de níquel. $\mathrm{Na}$ Tabela 19 estão apresentados os valores médios de conversão do metano e o rendimento em produtos, bem como a velocidade média de formação de carbono para os catalisadores de níquel e cobalto.

Os resultados para os catalisadores de níquel mostram que os catalisadores não-promovidos $\mathrm{Tr}-\mathrm{Ni}$; $\mathrm{Cp}-\mathrm{Ni}$ e Ae-Ni favoreceram uma maior velocidade de formação de carbono do que os catalisadores promovidos, que apresentaram considerável redução nesta velocidade. 
Fazendo-se uma comparação entre $\mathrm{o} \mathrm{H}_{2}$ formado e o esperado a partir da formação de $\mathrm{CO}$ e $\mathrm{CO}_{2}\left(1 \mathrm{C}=2 \mathrm{H}_{2}\right.$, reações de 4 a 7$)$, tem-se que os catalisadores não promovidos apresentaram valores acima do previsto estequiometricamente. Isto pode estar relacionado à alta velocidade de formação de carbono de acordo com as reações de decomposição do metano (reações 4 a 7) frente a uma menor velocidade de gaseificação de C (reação 25).

Tabela 19. Valores médios de conversão do Metano (\%); mol produzido de $\mathrm{H}_{2} ; \mathrm{CO}$ e $\mathrm{CO}_{2} ; \mathrm{H}_{2}$ estequiométrico; Velocidade de formação de carbono $\left(\mathrm{mmolmin}^{-1}\right)$.

\begin{tabular}{|c|c|c|c|c|c|c|}
\hline Catalisador & $\begin{array}{c}\mathrm{XCH}_{4} \\
(\%)\end{array}$ & $\begin{array}{c}\mathrm{H}_{2} \\
(\mathrm{~mol})\end{array}$ & $\begin{array}{c}\mathrm{CO} \\
(\mathrm{mol})\end{array}$ & $\begin{array}{c}\mathrm{CO}_{2} \\
(\mathrm{~mol})\end{array}$ & $\begin{array}{c}\mathrm{H}_{2} \text { est. } \\
(\mathrm{mol})\end{array}$ & $\begin{array}{c}\mathrm{C} \\
\left(\mathrm{mmolmin}^{-1}\right)\end{array}$ \\
\hline $\mathrm{Tr}-\mathrm{Ni}$ & 53 & 1,5 & 0,61 & 0,01 & 1,2 & 0,332 \\
\hline $\mathrm{Cp}-\mathrm{Ni}$ & 64 & 1,3 & 0,62 & 0,02 & 1,2 & 0,380 \\
\hline $\mathrm{Ae}-\mathrm{Ni}$ & 61 & 1,4 & 0,66 & 0,02 & 1,3 & 0,330 \\
\hline $\mathrm{Ae}-\mathrm{La}-\mathrm{Ni}$ & 51 & 1,5 & 0,88 & 0,01 & 1,8 & 0,099 \\
\hline Ae-Ce-Ni & 50 & 1,5 & 0,92 & 0,01 & 1,9 & 0,062 \\
\hline Tr-Co & 50 & 1,7 & 0,70 & 0,01 & 1,4 & 0,239 \\
\hline $\mathrm{Cp}-\mathrm{Co}$ & 51 & 1,6 & 0,62 & 0,01 & 1,6 & 0,308 \\
\hline Ae-Co & 52 & 1,6 & 0,65 & 0,01 & 1,6 & 0,296 \\
\hline Ae-La-Co & 44 & 1,7 & 0,93 & 0,01 & 1,9 & 0,045 \\
\hline Ae-Ce-Co & 46 & 1,6 & 0,90 & 0,01 & 1,8 & 0,090 \\
\hline
\end{tabular}



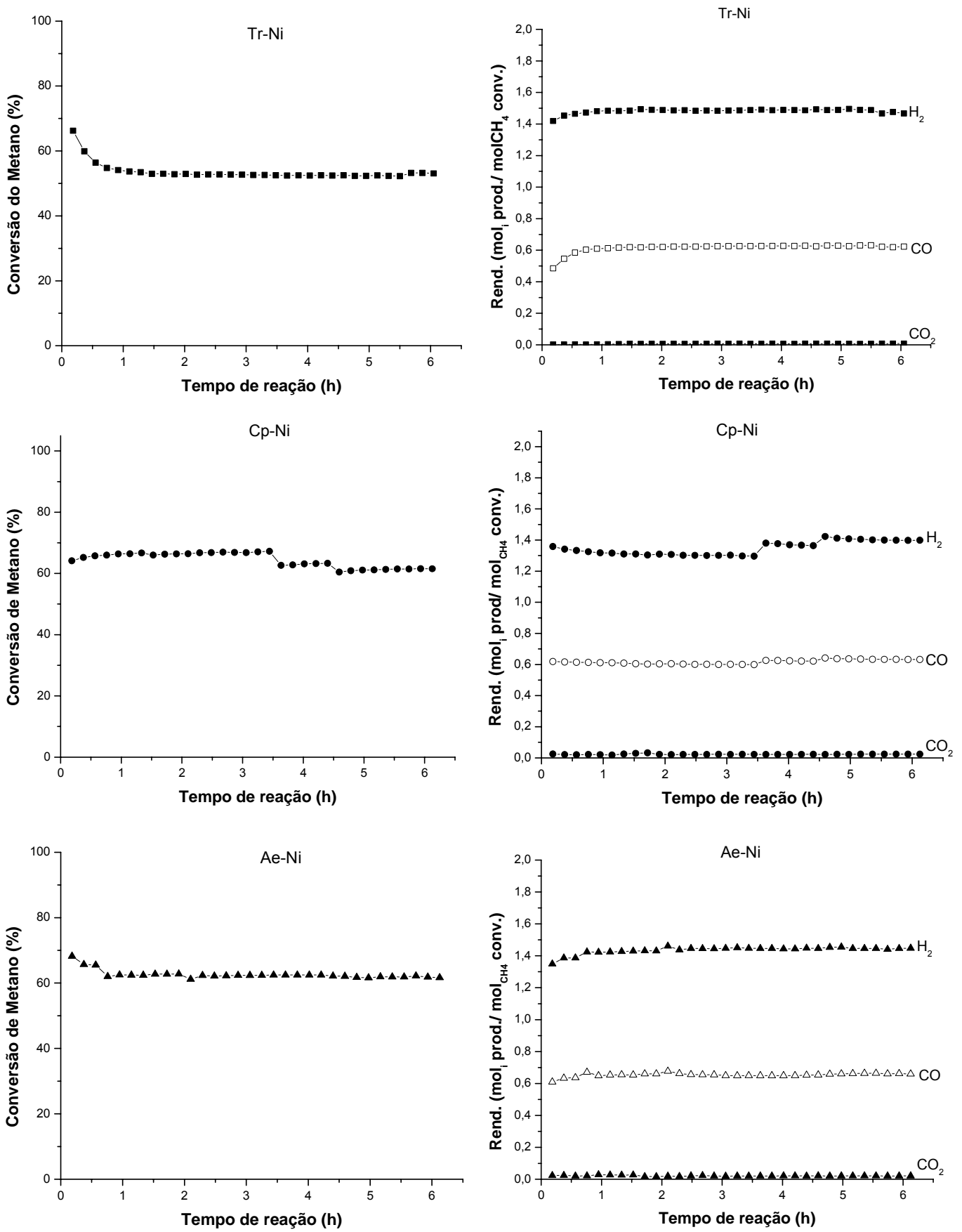

Figura 49. Conversão do Metano e Rendimento em Produtos para os catalisadores de níquel nãopromovidos na OPM com razão de alimentação $\mathrm{CH}_{4}: \mathrm{O}_{2}=4: 1$. 

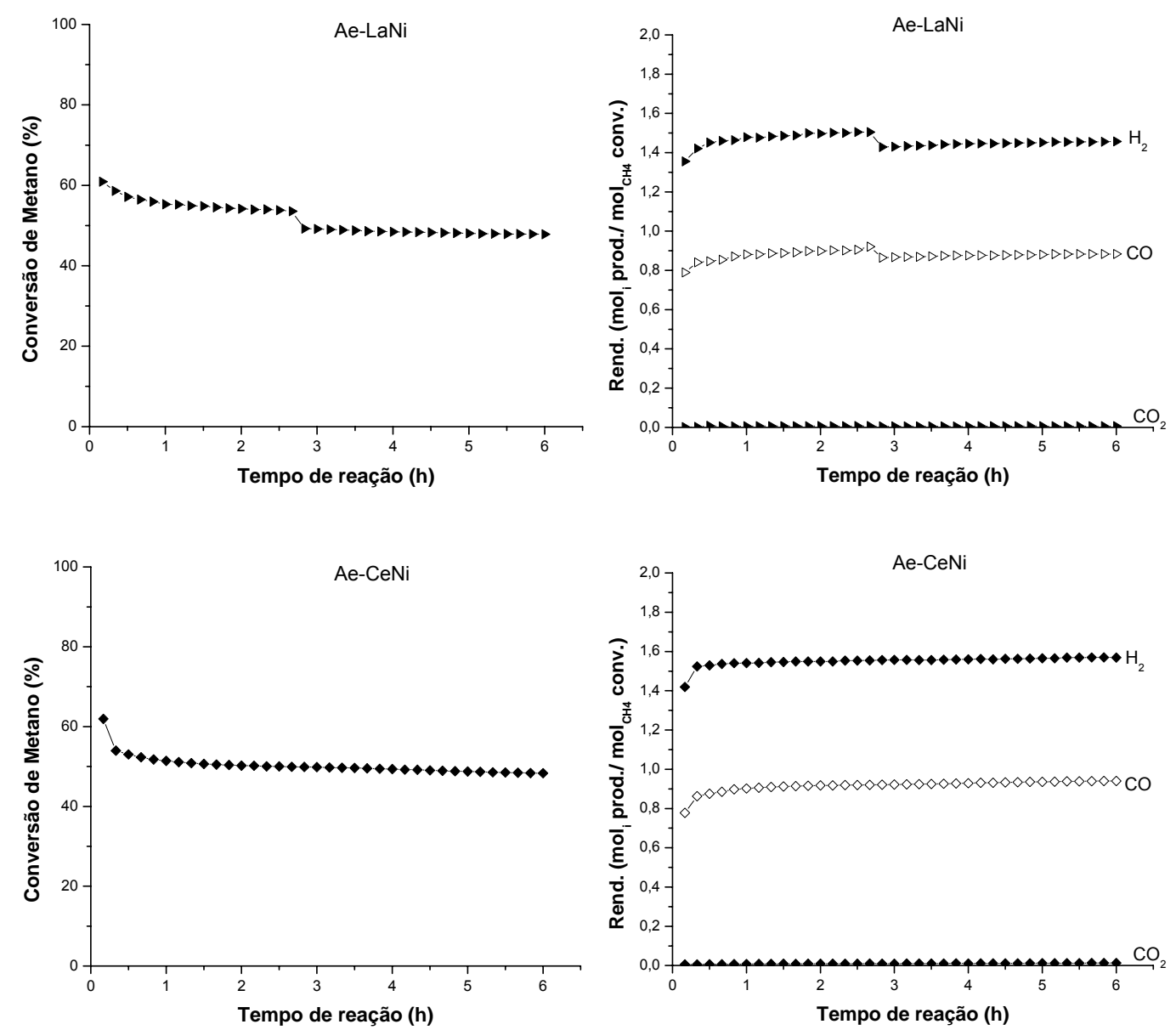

Figura 50. Conversão do Metano e Rendimento em Produtos para os catalisadores de níquel promovidos na OPM com razão de alimentação $\mathrm{CH}_{4}: \mathrm{O}_{2}=4: 1$.

A adição de promotores levou a uma maior seletividade para a formação de CO frente aos catalisadores não promovidos, esta maior seletividade está associada à redução na velocidade de formação de depósitos carbonáceos, o que indica que, mais uma vez, a adição de promotores favoreceu a reação entre carbono e oxigênio adsorvidos na superfície (reação 9), sendo um indicativo que os promotores aumentarem a velocidade de adsorção dissociativa do oxigênio (reação 21).

Paralelamente ao aumento na produção de CO, também se pode observar que o hidrogênio produzido é menor do que o esperado estequiometricamente pela formação de $\mathrm{CO}$ e $\mathrm{CO}_{2}$, para os catalisadores promovidos. Esta diferença pode estar 
ocorrendo devido a uma pequena parte de metano estar sofrendo uma reação de oxidação total (reação 16). Isto poderia ocorrer devido à alta velocidade de decomposição do oxigênio nestes catalisadores.

Na Figura 51 são apresentados os difratograma de Raios -X do precursor do catalisador Ae-La-Ni, do óxido misto obtido por tratamento térmico e do catalisador Ae-La-Ni após 6h de reação de oxidação parcial do metano.

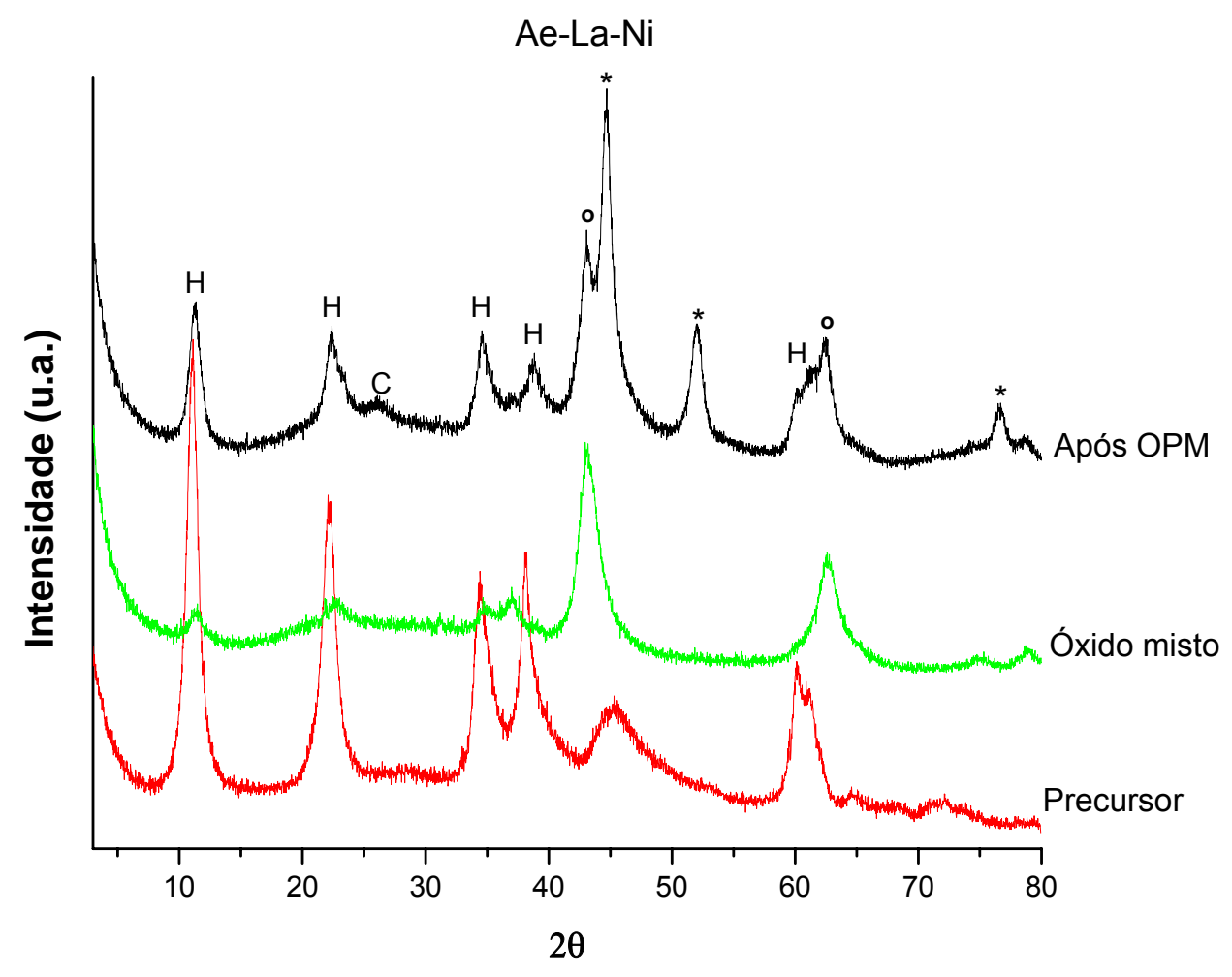

Figura 51. Difratograma de Raios- $X$ do catalisador Ae-La-Ni na forma de precursor, óxido misto e após 6 horas de OPM ( $\mathrm{H}=$ hidrotalcita; $\mathrm{O}=\mathrm{NiO}$ e/ou $\mathrm{MgO} ;{ }^{*}=\mathrm{Ni}^{0} ; \mathrm{C}=$ grafite).

De acordo com a Figura 51 o catalisador após as OPM apresenta a reconstrução de parte da estrutura da hidrotalcita, bem como a mistura das fases $\mathrm{NiO}$ e $\mathrm{MgO}$, observada no óxido misto e ainda o surgimento de novos picos que podem estar relacionados, à fase $\mathrm{Ni}^{0}$, mostrando que o catalisador se mantém ativo 
após 6h de reação (Apêndice A, Figura A9) e a fase grafite do carbono, que ocorre devido a um acúmulo de carbono durante o tempo de reação (SHISHIDO et al.; 2001; JCPDS, 1994).

Nas Figuras 52 e 53 estão apresentados os resultados da oxidação parcial do metano com razão de alimentação $\mathrm{CH}_{4}: \mathrm{O}_{2}=4: 1$ para os catalisadores de Cobalto.

Os catalisadores de cobalto apresentaram comportamento semelhante aos catalisadores de níquel, onde a adição de promotores diminuiu consideravelmente a velocidade de formação de carbono e favoreceu a formação de CO devido a uma maior gaseificação de espécies de carbono. 

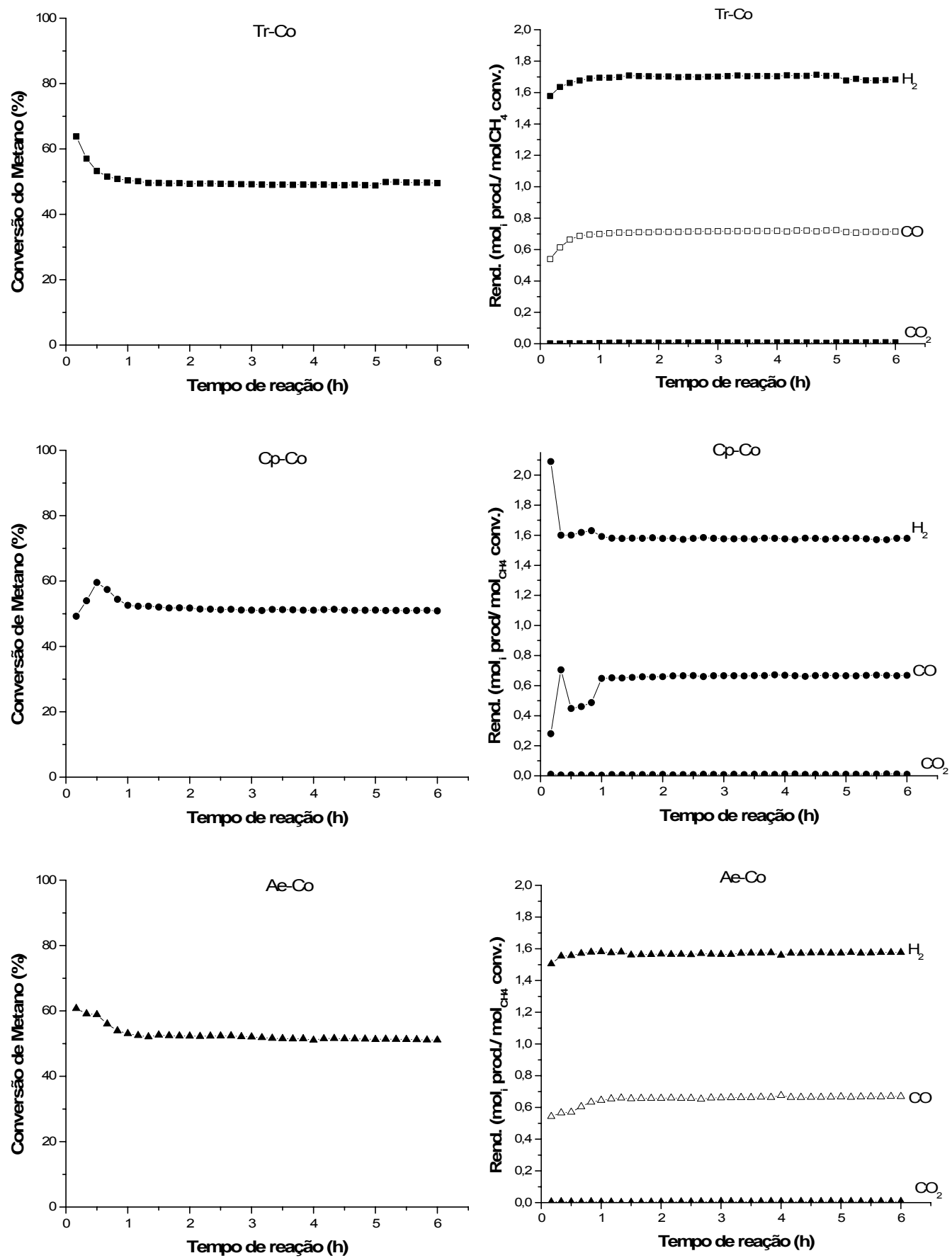

Figura 52. Conversão do Metano e Rendimento em Produtos para os catalisadores de cobalto nãopromovidos na OPM com razão de alimentação $\mathrm{CH}_{4}: \mathrm{O}_{2}=4: 1$. 

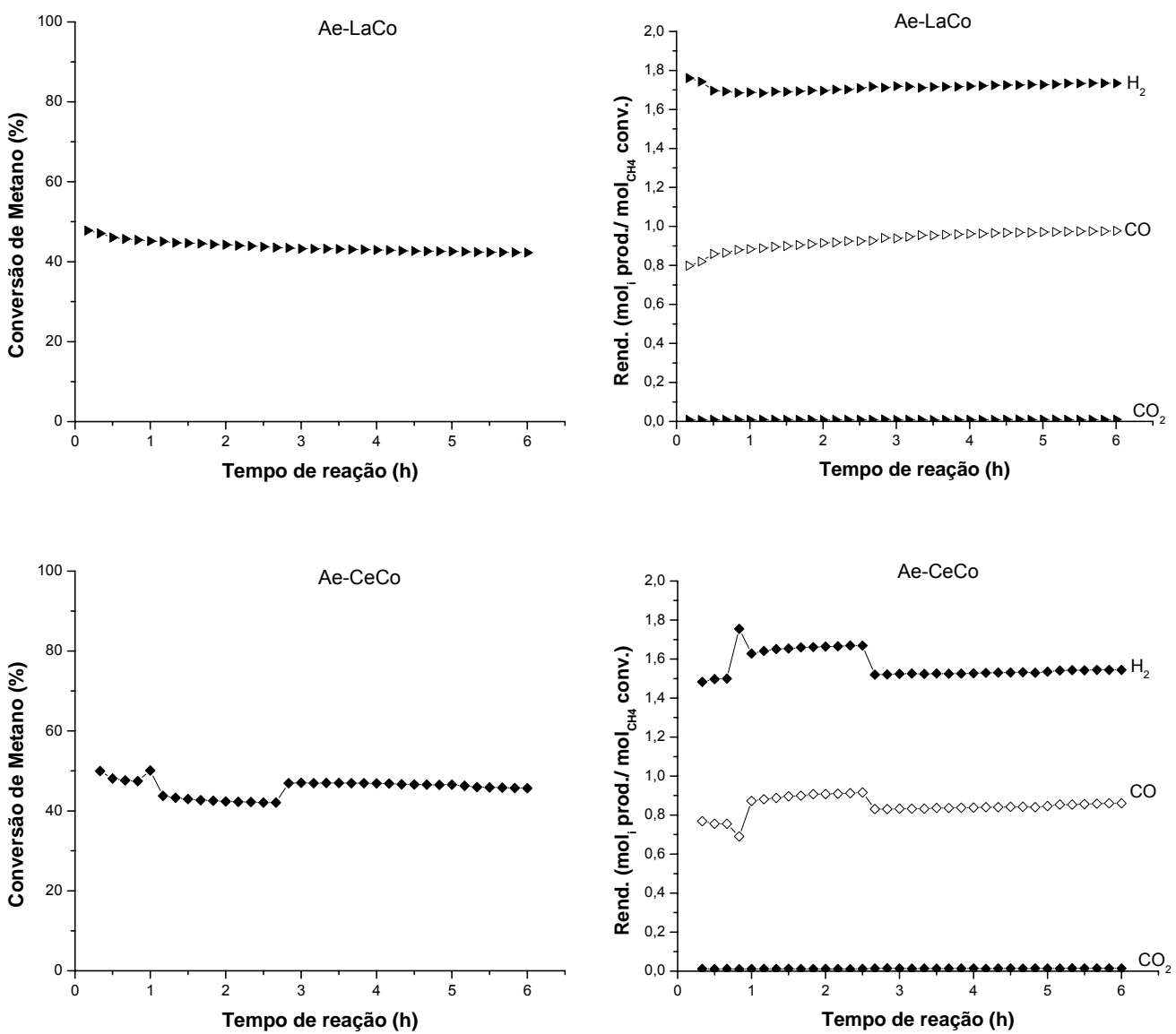

Figura 53. Conversão do Metano e Rendimento em Produtos para os catalisadores de cobalto promovidos na OPM com razão de alimentação $\mathrm{CH}_{4}: \mathrm{O}_{2}=4: 1$.

\subsection{3 - Reforma Oxidativa do Metano (ROM)}

Nas Figuras 54 e 55 estão apresentados os resultados da reforma oxidativa do metano com razão molar de alimentação $\mathrm{CH}_{4}: \mathrm{H}_{2} \mathrm{O}: \mathrm{O}_{2}=4: 4: 1$ para os catalisadores de Níquel.

Na Tabela 20 estão apresentados os valores médios de conversão do metano e o rendimento em produtos, bem como a velocidade média de formação de carbono para os catalisadores de níquel e cobalto. 

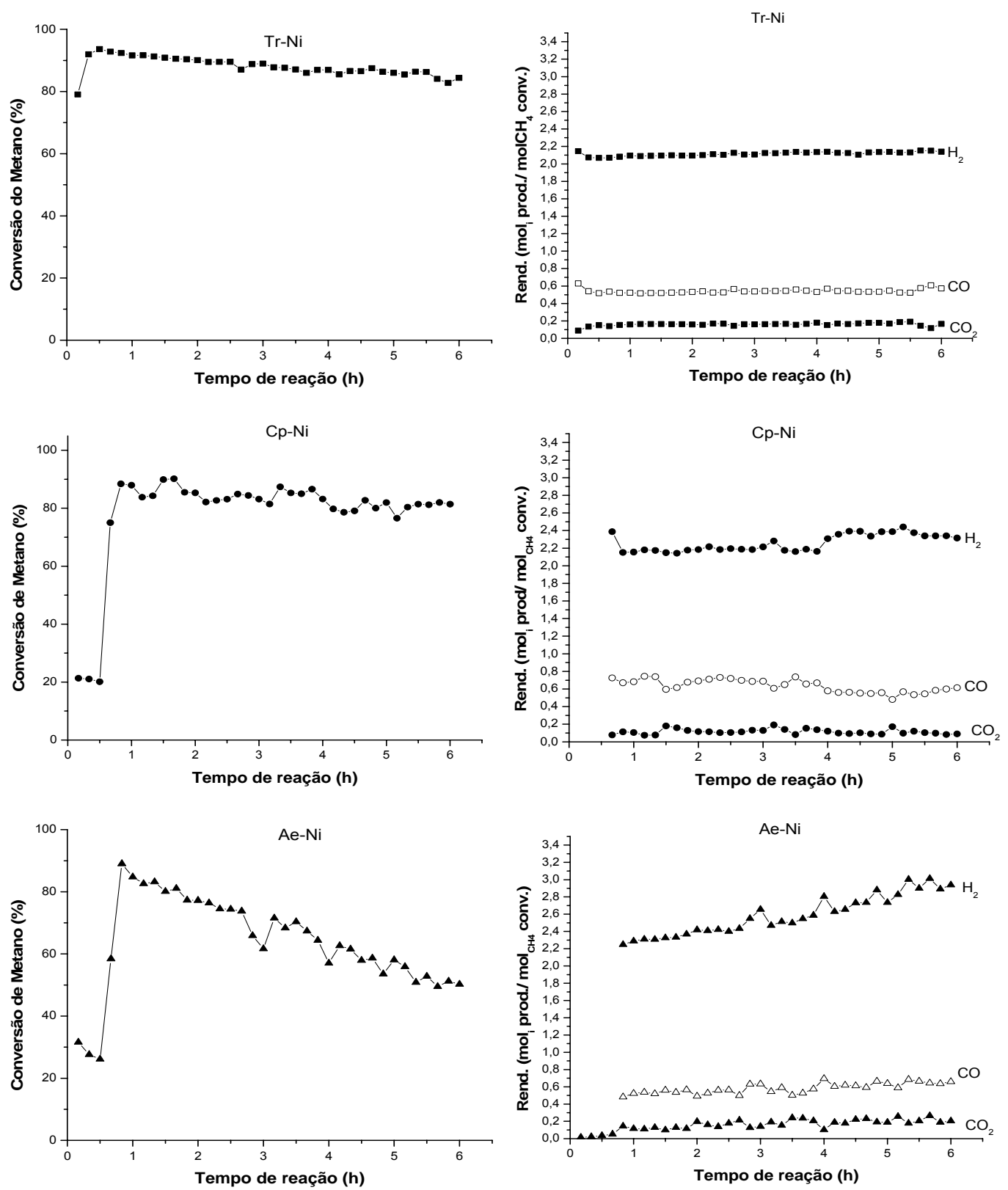

Figura 54. Conversão do Metano e Rendimento em Produtos para os catalisadores de níquel nãopromovidos na ROM com razão de alimentação $\mathrm{CH}_{4}: \mathrm{H}_{2} \mathrm{O}: \mathrm{O}_{2}=4:$ 4:1. 

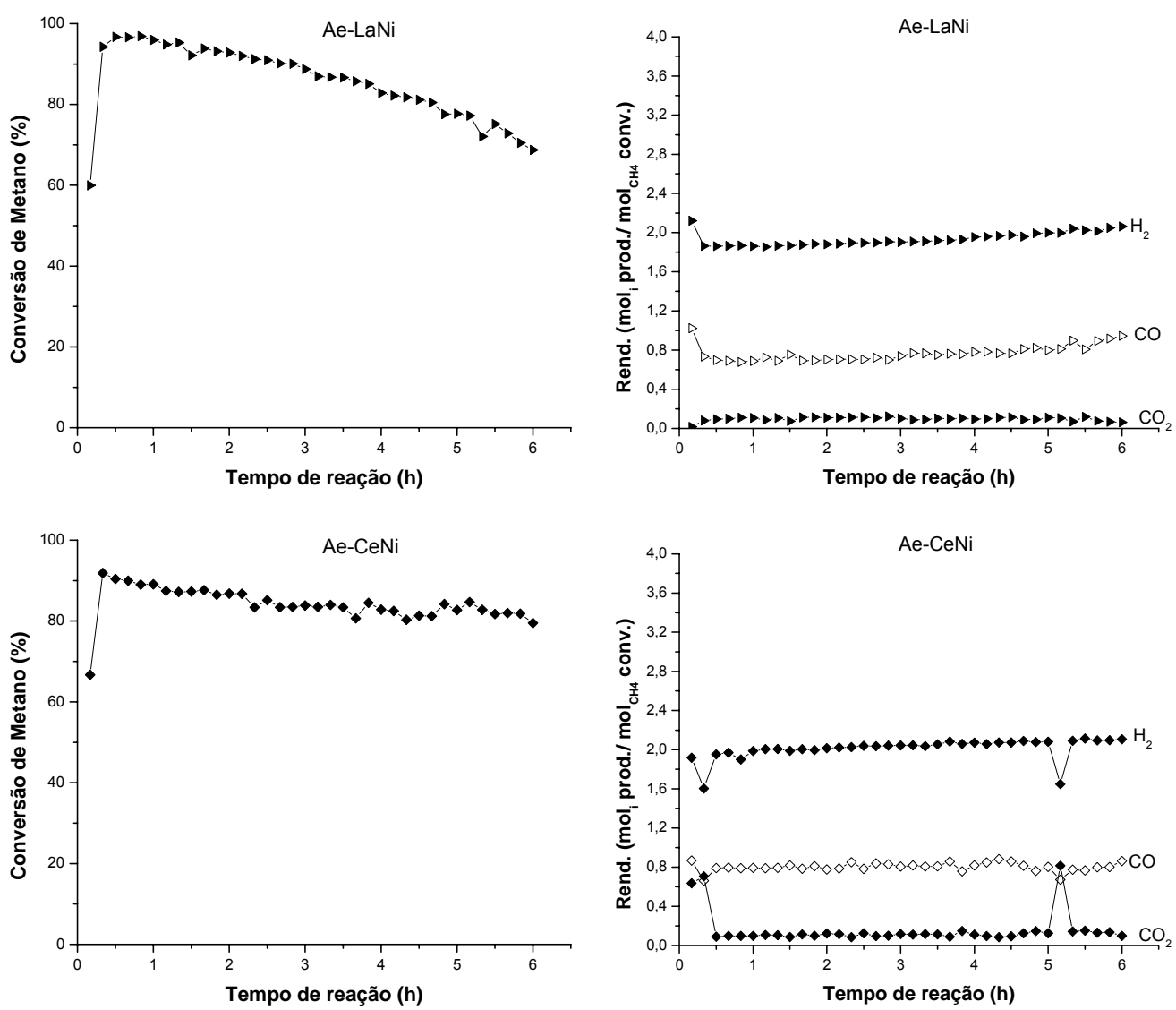

Figura 55. Conversão do Metano e Rendimento em Produtos para os catalisadores de níquel promovidos na ROM com razão de alimentação $\mathrm{CH}_{4}: \mathrm{H}_{2} \mathrm{O}: \mathrm{O}_{2}=4: 4: 1$.

Os catalisadores de níquel apresentaram conversões de metano inicialmente baixas, com aumento para $90 \%$ após um período de reação, diferentemente do observado na RVM e OPM. O acoplamento da oxidação parcial do metano, com a reforma a vapor do metano não favoreceu a redução na velocidade de formação de depósitos carbonáceos e para os catalisadores promovidos ainda apresentou uma maior velocidade de formação de carbono do que na oxidação parcial do metano.

Para o acoplamento foi considerada a seguinte reação global:

$\mathrm{CH}_{4}+1 / 4 \mathrm{O}_{2}+\mathrm{H}_{2} \mathrm{O} \rightleftarrows 1 / 2 \mathrm{CO}+1 / 2 \mathrm{CO}_{2}+3 \mathrm{H}_{2}$

$\mathrm{O}$ acoplamento aumentou a seletividade para a formação de $\mathrm{CO}_{2}$. 
Nas Figuras 56 e 57 estão apresentados os resultados da reforma oxidativa do metano com razão de alimentação $\mathrm{CH}_{4}: \mathrm{H}_{2} \mathrm{O}: \mathrm{O}_{2}=4: 4: 1$ para os catalisadores de cobalto.
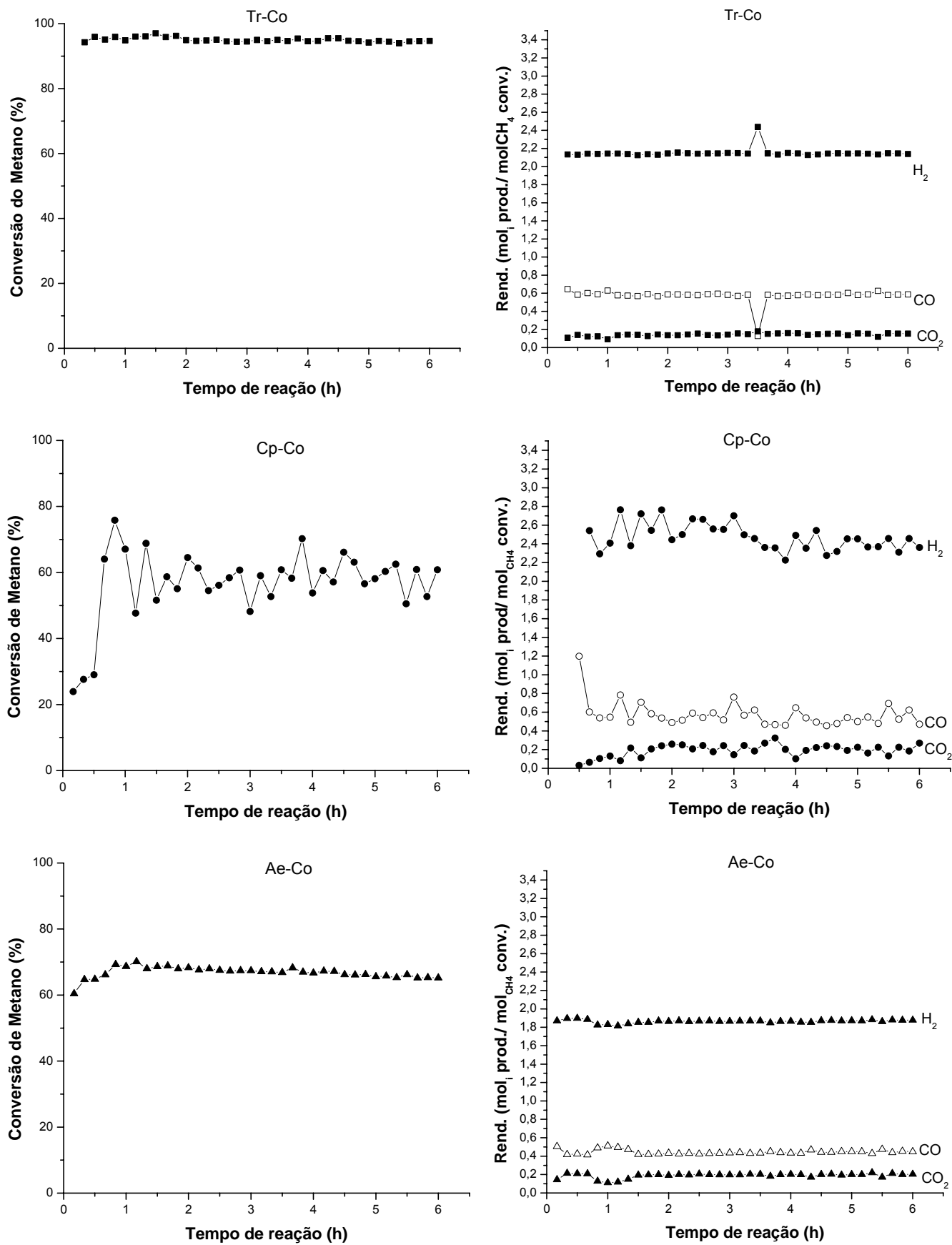

Figura 56. Conversão do Metano e Rendimento em Produtos para os catalisadores de cobalto nãopromovidos na ROM com razão de alimentação $\mathrm{CH}_{4}: \mathrm{H}_{2} \mathrm{O}: \mathrm{O}_{2}=4: 4: 1$. 

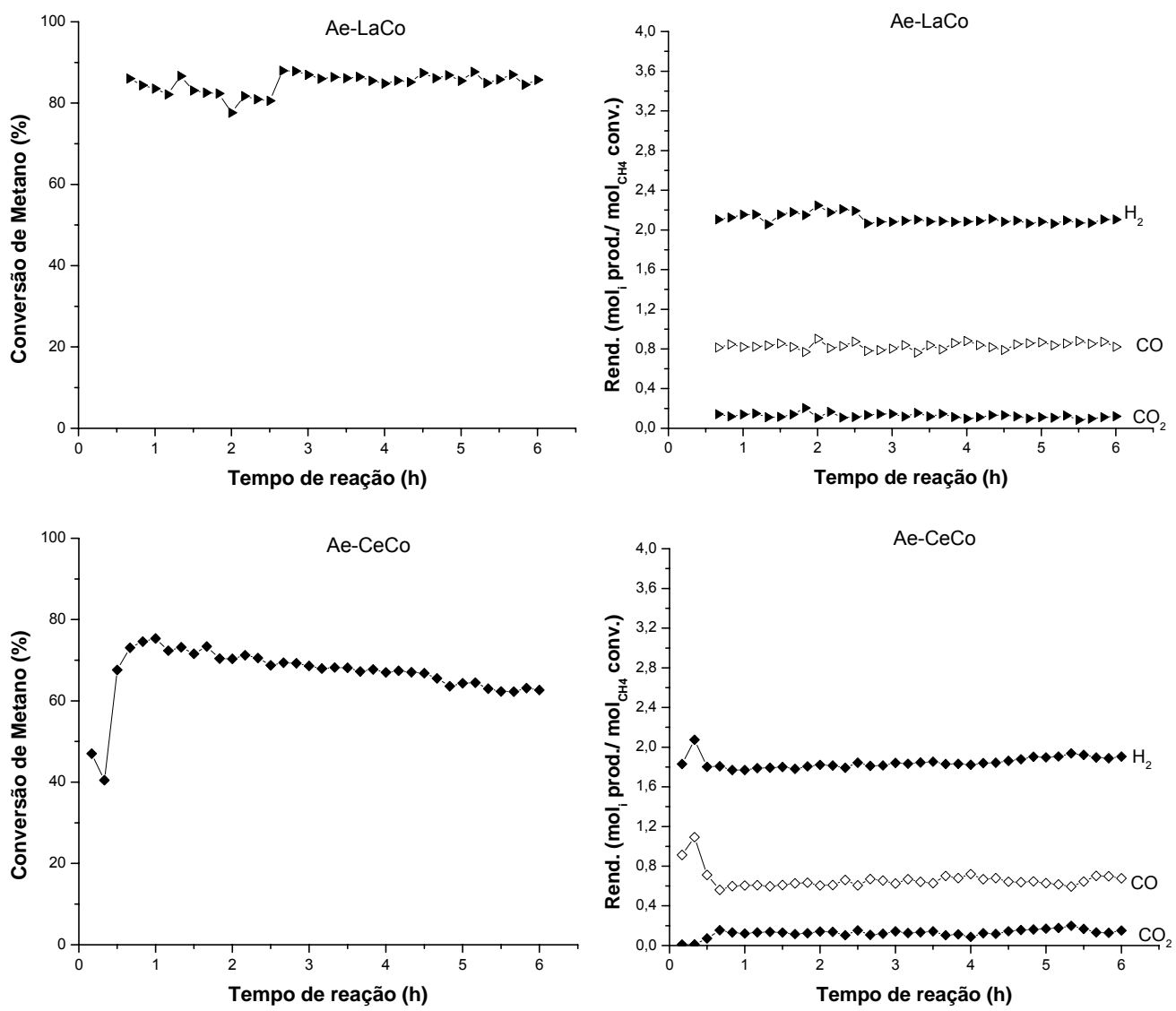

Figura 57. Conversão do Metano e Rendimento em Produtos para os catalisadores de cobalto promovidos na ROM com razão de alimentação $\mathrm{CH}_{4}: \mathrm{H}_{2} \mathrm{O}: \mathrm{O}_{2}=4: 4: 1$.

Os catalisadores de cobalto apresentaram comportamento semelhante aos catalisadores de níquel, onde o acoplamento levou a um favorecimento na seletividade para a formação de $\mathrm{CO}_{2}$ e a uma maior velocidade de formação de carbono. 
Tabela 20. Valores médios de conversão do Metano (\%); mol produzido de $\mathrm{H}_{2} ; \mathrm{CO}$ e $\mathrm{CO}_{2} ; \mathrm{H}_{2}$ estequiométrico; Velocidade de formação de carbono $\left(\mathrm{mmolmin}^{-1}\right)$.

\begin{tabular}{|c|c|c|c|c|c|c|}
\hline Catalisador & $\begin{array}{c}\mathrm{XCH}_{4} \\
(\%)\end{array}$ & $\begin{array}{c}\mathrm{H}_{2} \\
(\mathrm{~mol})\end{array}$ & $\begin{array}{c}\mathrm{CO} \\
(\mathrm{mol})\end{array}$ & $\begin{array}{c}\mathrm{CO}_{2} \\
(\mathrm{~mol})\end{array}$ & $\begin{array}{c}\mathrm{H}_{2} \text { est. } \\
(\mathrm{mol})\end{array}$ & $\begin{array}{c}\mathrm{C} \\
\left(\mathrm{mmolmin}^{-1}\right)\end{array}$ \\
\hline $\mathrm{Tr}-\mathrm{Ni}$ & 88 & 2,1 & 0,54 & 0,16 & 1,9 & 0,430 \\
\hline $\mathrm{Cp}-\mathrm{Ni}$ & 78 & 2,6 & 0,63 & 0,11 & 2,0 & 0,339 \\
\hline $\mathrm{Ae}-\mathrm{Ni}$ & 63 & 2,7 & 0,65 & 0,16 & 2,2 & 0,276 \\
\hline $\mathrm{Ae}-\mathrm{La}-\mathrm{Ni}$ & 85 & 1,9 & 0,77 & 0,10 & 2,3 & 0,197 \\
\hline Ae-Ce-Ni & 82 & 2,1 & 0,84 & 0,17 & 2,7 & 0,108 \\
\hline Tr-Co & 94 & 2,1 & 0,58 & 0,14 & 1,9 & 0,440 \\
\hline $\mathrm{Cp}-\mathrm{Co}$ & 56 & 2,6 & 0,62 & 0,18 & 2,2 & 0,221 \\
\hline Ae-Co & 66 & 1,9 & 0,44 & 0,20 & 1,8 & 0,400 \\
\hline Ae-La-Co & 86 & 2,2 & 0,76 & 0,11 & 2,3 & 0,191 \\
\hline Ae-Ce-Co & 66 & 1,8 & 0,66 & 0,13 & 2,1 & 0,247 \\
\hline
\end{tabular}




\section{6 - Conclusões}

A partir dos resultados obtidos pode-se concluir que:

- Por análise química elementar que as amostras não promovidas apresentaram uma perda de níquel e cobalto, mostrando que a incorporação dos metais não foi completa. Ainda, para as amostras de cobalto, e de níquel promovidas, a comparação dos resultados do bulk e da superfície apresentou uma considerável diferença entre os valores de lantânio e cério, sugerindo que parte dos complexos foi introduzida entre as camadas da hidrotalcita e que parte destes complexos depositou-se na superfície do precursor, ou ainda que o tratamento térmico favoreceu a migração dos promotores para a superfície.

- As análises texturais revelaram que as amostras preparadas por meio de complexos do tipo quelatos apresentaram maiores áreas, raio médio de poros e volume de poros do que as preparadas pelo método tradicional, sugerindo a introdução de complexos do tipo quelatos na estrutura da hidrotalcita.

- Os resultados de ATG apresentaram perfis típicos para as hidrotalcitas, sendo que os precursores obtidos a partir de quelatos apresentaram uma perda de massa total maior do que a apresentada para as amostras preparadas pelo método tradicional devido a presença das espécies do tipo quelato.

- Os resultados de DRX confirmaram a formação da estrutura do tipo hidrotalcita para os precursores, porém para as amostras promovidas com cério observou-se picos adicionais referentes ao $\mathrm{Ce}(\mathrm{OH})_{3}$, indicando que parte do cério não foi incorporada na estrutura. Também observou-se que o tratamento térmico levou à destruição da estrutura de camadas e a novos valores dos parâmetros de rede que sugerem, para as amostras de níquel, a formação do periclásio $\mathrm{Mg}(\mathrm{Al}) \mathrm{O}$ contendo 
níquel, e para as amostras de cobalto, o periclásio $\mathrm{Mg}(\mathrm{Al}) \mathrm{O}$ contendo cobalto juntamente com a presença do espinélio $\mathrm{Co}_{3} \mathrm{O}_{4}$.

- Os resultados de FTIR apresentaram diferenças entre os precursores preparados pelo método tradicional e por meio de quelatos, com o aparecimento de novas bandas referentes ao metal coordenado ao quelato, sugerindo a introdução do mesmo na estrutura.

- Os resultados de RTP das amostras de níquel indicaram a presença fase NiO livre e interagida de forma não estequiométrica com o suporte. Os perfis ainda sugerem que a maior concentração de níquel está presente na estrutura do tipo espinélio $(\mathrm{Ni}, \mathrm{Mg}) \mathrm{Al}_{2} \mathrm{O}_{4}$ e/ou a estrutura do tipo periclásio (Ni,Al)MgO. A adição dos promotores levou a uma melhor dispersão das espécies de níquel. Os ensaios para as amostras de cobalto indicaram a presença de $\mathrm{Co}_{3} \mathrm{O}_{4}$ e $\mathrm{Co}^{+2 /+3}$ interagidos de forma não estequiométrica com o suporte de magnésio e alumínio e que parte do metal está presente em fases termicamente estáveis, como a estrutura do tipo espinélio $(\mathrm{Co}, \mathrm{Mg}) \mathrm{Al}_{2} \mathrm{O}_{4}$ e/ou a estrutura do tipo periclásio (Co, $\left.\mathrm{Al}\right) \mathrm{MgO}$. A adição de promotores nos catalisadores de cobalto provocou uma diminuição na redutibilidade dos catalisadores, indicando uma maior dispersão do cobalto.

- Os resultados de XPS sugerem a presença da fase NiO fortemente interagida com o suporte de magnésio e alumínio. Os resultados obtidos para o cobalto indicam a presença de compostos de $\mathrm{Co}^{+2}$, que possivelmente estão interagidos com as espécies de magnésio e alumínio. Os valores de energia de ligação encontrados para os promotores cério e lantânio são muito próximos aos da referência para o $\mathrm{La}_{2} \mathrm{O}_{3}, \mathrm{CeO}_{2}$ e $\mathrm{Ce}_{2} \mathrm{O}_{3}$, mostrando uma fraca interação dos mesmos com as amostras. 
- Os resultados de XAS sugerem para os catalisadores de níquel a presença da fase $\mathrm{NiO}$, sendo um indicativo da formação da fase $\mathrm{Mg}(\mathrm{Ni}, \mathrm{Al}) \mathrm{O}$. Para as amostras de cobalto as análises sugerem que a presença de espécies de cobalto divalentes e trivalentes.

- RVM com razão de alimentação $\mathrm{H}_{2} \mathrm{O}: \mathrm{CH}_{4}=4: 1$ : os catalisadores de cobalto não foram ativos devido à re-oxidação dos sítios ativos pelo excesso de água. Os catalisadores de níquel não favoreceram a formação de carbono, indicando que a alta razão de água na alimentação pode ter aumentado a velocidade de gaseificação de depósitos carbonáceos A adição de promotores favoreceu a reação de deslocamento gás-água.

- RVM Razão de alimentação $\mathrm{H}_{2} \mathrm{O}: \mathrm{CH}_{4}=2: 1$ : os catalisadores apresentaram uma baixa velocidade de formação de carbono, sendo menor nos catalisadores Ae-La-Ni; Ae-Ce-Ni; Tr-Ni; Ae-Ni e Cp-Ni, respectivamente. Assim como na razão $\mathrm{H}_{2} \mathrm{O}: \mathrm{CH}_{4}=4: 1$, os catalisadores promovidos apresentaram maior formação de $\mathrm{CO}_{2}$, sugerindo que os promotores aumentaram a velocidade de decomposição da água. Os catalisadores de cobalto promovidos apresentaram desativação com o tempo de reação. Este comportamento ocorre principalmente devido à oxidação de sítios ativos de cobalto pela água, visto que os catalisadores apresentaram menor formação de carbono. Os catalisadores de cobalto foram mais seletivos para a formação de $\mathrm{CO}_{2}$ do que os catalisadores de níquel, mostrando um favorecimento da decomposição de água nestes catalisadores.

- RVM com razão de alimentação $\mathrm{H}_{2} \mathrm{O}: \mathrm{CH}_{4}=0,5: 1$ : os catalisadores de níquel e cobalto foram ativos no tempo de reação, sem desativação, com exceção dos catalisadores promovidos com La, mostrando serem estáveis frente às reações de decomposição do metano. 
- OPM: os catalisadores, tanto de níquel como cobalto, não foram ativos para a oxidação parcial do metano com razão de alimentação $\mathrm{CH}_{4}: \mathrm{O}_{2}=2: 1$, devido a uma rápida desativação por oxidação dos sítios ativos. Os catalisadores de níquel e cobalto promovidos apresentaram considerável redução na velocidade de formação de carbono.

- ROM: Os catalisadores de níquel e cobalto apresentaram comportamento semelhante, sendo que o acoplamento levou a um favorecimento na seletividade da formação de $\mathrm{CO}_{2}$, porém com uma maior velocidade de formação de carbono. 


\section{7 - Sugestões}

Para uma maior compreensão do comportamento dos catalisadores nas reações do metano sugere-se:

a. Verificar o desempenho dos catalisadores na Reforma Oxidativa do Metano, com diferentes razões de alimentação $\mathrm{CH}_{4}: \mathrm{H}_{2} \mathrm{O}: \mathrm{O}_{2}$, a fim de avaliar o efeito da variação da razão dos componentes alimentados na distribuição dos produtos;

b. Testar os catalisadores na Reforma do metano $\mathrm{com} \mathrm{CO}_{2}$ (reforma seca);

c. Preparar hidrotalcitas com diferentes concentrações de níquel e de cobalto para se verificar possíveis variações no desempenho dos catalisadores; e

d. Adicionar os promotores Cálcio e Ítrio e avaliar o desempenho dos mesmos com relação à velocidade de formação de depósitos carbonáceos e distribuição dos produtos, nas reações do metano. 


\section{8 - Referências Bibliográficas}

ANGELESCU, E.; PAVEL, O.D.; CHE.; M.; BIRJEGA, R.; CONSTENTIN, G. Cyanoethylation of ethanol on Mg-Al hydrotalcites promoted by $\mathrm{Y}^{3+}$ and $\mathrm{La}^{3+}$ Catalysis Communications, v. 5, p. 647-651, 2004.

ARAÚJO, M.C. Utilização de hidrotalcitas Mg/Co/Al na conversão de etanol. 2004. 115f. Dissertação ( Mestrado) - Faculdade de Engenharia Química, Universidade Estadual de Campinas, Campinas, 2004.

BASILE, F.; BASINI, L.; AMORE, M. D.; FORNASARI, G.; GUARINONI, A.; MATTEUZZI, D.; DEL PIERO, G.; TRIFIRÒ, F.; VACCARI, A. Ni/Mg/Al Anionic Clay Derived Catalysts for the Catalytic Partial Oxidation of Methane: Residence Time Dependence of the Reactivity Features. Journal of Catalysis, v. 173, p. 247-256, 1998.

BOROWIECKI, T.; GOLEBIOWSKI, A.; STASINSKA, B. Effects of small $\mathrm{MoO}_{3}$ additions on the properties of nickel catalysts for the steam reforming of hydrocarbons. Applied Catalysis A: General, v. 153, p. 141-15, 1997.

CANTRELL, D.G.; GILLIE, L.J.; LEE, A.F.; WILSON, K. Structure-reactivity correlations in MgAl hydrotalcite catalysts for biodiesel synthesis. Applied Catalysis A: General, v. 287, p. 183-190, 2005.

CARDOSO, D. Introdução à Catálise Heterogênea. São Carlos: Editora da Universidade Federal de São Carlos, 1987. 226p.

CASENAVE, S.; MARTINEZ, H.; GUIMON, C.; AUROX, A.; HULEA, V.; CORDONEANU, A.; DUMITRIU, E. Acid - base properties of Mg-Ni-Al mixed oxides using LDH as precursors. Thermochimica Acta, v. 379, p. 85-93, 2001.

CHEN, Y.G.; YAMAZAKI, O.; TOMISHIGE, K.; FUJIMOTO, K. Noble metal promoted $\mathrm{Ni}_{0.03} \mathrm{Mg}_{0,97} \mathrm{O}$ solid solution catalysts for the reforming of $\mathrm{CH}_{4}$ with $\mathrm{CO} 2$. Catalysis Letters, v. 39, p. 91-95, 1996.

CHEN, Y.G.; TOMISHIGE, K.; YOKOYAMA, K; FUJIMOTO, K. Catalytic performance and catalyst structure of nickel-magnesia catalysts for $\mathrm{CO}_{2}$ reforming of methane.

Journal of Catalysis, v. 184, p. 479-490, 1999.

CHMIELARZ, L; KUSTROWSKI; P; RAFALKA-ŁASOCHA, A; DZIEMBAJ, R. Influence of $\mathrm{Cu}, \mathrm{Co}$ and $\mathrm{Ni}$ cations incorporated in brucite-type layers on thermal behaviour of hydrotalcites and reducibility of the derived mixed oxide systemsThermchimica Acta, v. 395, p. 225-236, 2003.

CHOUDHARY, V.R.; UPHADE, B.S.; MAMMAN, A.S. Simultaneous steam and $\mathrm{CO}_{2}$ reforming to syngas over $\mathrm{NiO} / \mathrm{MgO} / \mathrm{SA}-5205$ in presence and absence of oxygen. Applied Catalysis A: General, v. 168, p. 33-46, 1998a. 
CHOUDHARY, V.R.; MAMMAN, A.S. Simultaneous oxidative conversion and $\mathrm{CO}_{2}$ or steam reforming to syngas over $\mathrm{CoO}-\mathrm{NiO}-\mathrm{MgO}$ catalyst. J. Chem. Technol.

Biotechnol., v. 73, p. 345-350,1998b.

CHOUDHARY, V.R.; MAMMAN, A.S. Oxidative conversion of methane to syngas over $\mathrm{NiO} / \mathrm{MgO}$ solid solution supported on low surface area catalyst carrier. Fuel Processing Technology, v. 60, p. 203-211, 1999.

CHOUDHARY, V.R. and MAMMAN, A.S. Energy efficient conversion of methane to syngas over NiO-MgO solid solution. Applied Energy, v. 66, p. 161-175, 2000.

CIOLA, R. Fundamentos de Catálise. São Paulo: Editora da Universidade de São Paulo, 1981, 337p.

CREPALDI, E. L.; VALIN, J. B. Hidróxidos duplos lamelares: síntese, estrutura, propriedades a aplicações. Química Nova, v. 21, p. 300-311, 1998.

DIAS, J.A.C.; ASSAF, J.M. Autothermal reforming of methane over $\mathrm{Ni} / \mathrm{Y}-\mathrm{Al}_{2} \mathrm{O}_{3}$ catalysts: the enhancement effect of small quantities of noble metals. Journal of Power Sources, v. 130, p. 106-110, 2004.

FIGUEIREDO, J. L.; RIBEIRO, F.R. Catalise heterogênea. Lisboa: Fundação Calouste Gulbenkian, 1989. 352p.

GAZZANO, M.; KAGUNYA, W.; MATTEUZZI, D. VACCARI, A. Neutron diffraction studies of polycrystalline Ni/Mg/Al mixed oxides obtained from hydrotalcite-like precursors. Journal of Physical Chemistry B, v. 101, p. 4514-4519, 1997.

GIACOVAZZO, C.; MONACO, H.L.; VITERBO, D.; SCORDARI, F.; GILLI, G.; ZANOTTI G.; CATTI, M. Fundamentals of Crystallography. Oxford: International Union of Crystallography, 1992. 654p.

GOTTE, A.; HERMANSSON, K.; BAUDIN, M. Molecular dynamics simulations of reduced $\mathrm{CeO}_{2}$ : bulk and surfaces. Surface Science, v. 552, p. 273-280, 2004.

HATTORI, Y.; KONISHI, T.; KANEKO, K. XAFS and XPS studies on the enhancement of methane adsorption by NiO dispersed ACF with the relevance to structural change of NiO. Chemical Physics Letters, v. 355, p. 37-42, 2002.

JOINT COMMITTEE ON POWDER DIFFRACTION STANDARDT (JCPDS). Pensilvânia: International Center of Diffraction Data, 1994. 1 CD-ROM.

KHASSIN, A.A.; YURIEVA, T.M.; KAICHEV, V.V.; BURKHTIYAROV, V.I.; BUDNEVA, A.A.; PAUKSHTIS, E.A.; PARMON, V.N. Metal-support interactions in cobalt-aluminum co-precipitated catalysts: XPS and $\mathrm{CO}$ adsorption studies. Journal of Molecular Catalysis A: Chemical, v. 175, p. 189-204, 2001.

KLOPROGGE, J.T.; FROST. L. Fourier Transform Infrared and Raman Spectroscopic Study of the Local Structure of Mg-, Ni-, and Co-Hydrotalcites. Journal of Solid State Chemistry, v. 146, p. 506-515, 1999. 
LELIS, M.F.F.; Porto,A.O.; GONÇALVES, C.M.; Fabris, J.D. Cation occupancy sites in synthetic Co-doped magnetites as determined withX-ray absorption (XAS) and Mossbauer spectroscopies. Journal of Magnetism and Magnetic Materials, v. 278 p. 263-269, 2004.

LI, C.; WANG, G.; EVANS, D.G; DUAN, X. Incorporation of rare-earth ions in Mg-Al layered double hydroxides: intercalation with an [Eu(EDTA)] chelate. Journal of Solid State Chemistry, v. 177, p. 4569-4575, 2004.

MAKOA, M.P.; COVILLE, N.J.; SOKOLOVSKII, V.D. Characterisation of $\mathrm{Co} / \mathrm{Mg} / \mathrm{Al}_{2} \mathrm{O}_{3}$ high pressure partial oxidation catalysts. Catalysis Today, v. 49, p. 11-16, 1999.

MALUF, S.S. Reforma a vapor do metano: preparação de catalisador níquel/alumina com promotor e ensaios catalíticos. 2001. 112f. Tese (Mestrado em físico-química)- Instituto de Química de São Carlos, Universidade de São Paulo, São Paulo, 2001.

NAVARRO, R.M.; ÁLVAREZ-GALVÁN, M.C.; ROSA, F.; FIERRO, J.L.G. Hydrogen production by oxidative reforming of hexadecane over $\mathrm{Ni}$ and $\mathrm{Pt}$ catalysts supported on Ce/La-doped $\mathrm{Al}_{2} \mathrm{O}_{3}$. Applied Catalysis A: General, v. 297, p. 60-72, 2006.

NIST X-ray Photoelectron Spectroscopy Database: Version 3.4 (Web Version) Gaithersburg :National Institute of Standards and Technology, 2002. Disponível em: <http://srdata.nist.gov/xps/>. Acesso em: 14 nov. 2006.

PÉREZ-RAMIREZ, J.; MUL, G.; MOULIJIN, A. In situ Fourier transform infrared and laser Raman spectroscopic study of the thermal decomposition of $\mathrm{Co}-\mathrm{Al}$ and $\mathrm{Ni}-\mathrm{Al}$ hydrotalcites. Vibrational Spectroscopy, v. 27, p. 75-88, 2001.

REBOURS, B.; CAILLERIE, J.E.; CLAUSE, O. Decoration of nickel and magnesium oxide crystallites with spinel-type phases. Journal of American Chemical Society, v. 116, p. 1707-1717, 1994.

RESSLER T. WinXAS: A new software package not only for the analysis of energy dispersive XAS data. Part 1. J. de Physique IV., Les Ulis Cedex, v. 7, p. 269-270, 1997.

RIBEIRO, E. S; FRANCISCO, M.S.P.; GUSHIKEM, Y.; GONÇALVES, J.E. Princípios Básicos de XAS e XPS. 2003. 37 f. Monografia - Instituto de Química, Universidade Estadual de Campinas, Campinas, 2003. Disponível em: < http://www.chemkeys.com/bra/md/ede_5/edrxex_1/edrxex_1.htm>. Acesso em: 14 nov. 2006.

RIVES, V.; ULIBARRI, M. A. Layered double hydroxides (LDH) intercalated with metal coordination compounds and oxometalates. Coordination Chemistry Reviews, v. 181, p. 61-120, 1999.

RUCKENSTEIN, E.; HU, Y.H. Carbon dioxide reforming of methane over nickel/alkaline earth metal oxide catalysts. Applied Catalysis A: General, v. 133, p. 149-161, 1995. 
RUCKENSTEIN, E.; HU, Y.H. The effect of precursor and preparation conditions of $\mathrm{MgO}$ on the $\mathrm{CO}_{2}$ reforming of $\mathrm{CH}_{4}$ over $\mathrm{NiO} / \mathrm{MgO}$ catalysts. Applied Catalysis A: General, v. 154, p. 185-205, 1997.

RUCKENSTEIN, E.; HU, Y.H. Combination of $\mathrm{CO}_{2}$ reforming and partial oxidation of methane over $\mathrm{NiO} / \mathrm{MgO}$ solid solution catalysts. Industry Engineering Chemical Research, v. 37, p. 1744-1747, 1998.

RUCKENSTEIN, E.; HU, Y.H. Methane partial oxidation over NiO/MgO solid solution catalysts. Applied Catalysis A: General, v. 183, p. 85-92, 1999.

RUCKENSTEIN, E.; WANG, H. Y. Combined catalytic partial oxidation and CO2 reforming of methane over supported cobalt catalysts. Catalysis Letters, v. 73, p. 99- 105, 2001.

SATTERFIELD, C.N. Heterogeneous Catalysis in industrial Practice. 2.ed. New York: McGraw-Hill, 1993. 554p.

SERRA, M.; SALAGRE, P.; CESTEROS, Y.; MEDINA, F.; SUEIRAS, J.E. Study of preparation conditions of NiO-MgO systems to control the morphology and particle size of the NiO phase. Solid State Ionics, v. 134, p. 229-239, 2000.

SHISHIDO, T.; SUKENOBU, M.; HIROYUKI, M.; FURUKAWA, R.; SHIRAHASE H.; TAEKEHIRA, K. $\mathrm{CO}_{2}$ reforming of $\mathrm{CH}_{4}$ over $\mathrm{Ni} / \mathrm{Mg}$-Al oxide catalysts prepared by solid phase crystallization method from Mg-Al hydrotalcite like precursors. Catalysis Letters, v. 73, p. 21-26, 2001.

SKOOG, D. A.; HOLLER, F.J.; NIEMAN, T.A. Princípios de análise instrumental. 5.ed. Porto Alegre: Bookman, 2002, 836p.

SONG, X.; GUO, Z. A new process for synthesis gas by co-gasifying coal and natural gas. Fuel, v. 84, p. 525-531, 2005.

SOUZA, E. C. Propriedades estruturais e eletroquímicas de ligas de hidreto metálico processadas para moagem de alta energia. 2006. 114f. Tese

(Doutorado em físico-química)- Instituto de Química de São Carlos, Universidade de São Paulo.

SOUZA, M.V.M.; MACEDO-NETO, O.R.; SCHMAL, M. Synthesis Gas Production from Natural Gas on Supported Pt Catalysts. Journal of Natural Gas Chemistry, v. 15, p. 21-27, 2006.

TAKEHIRA, K.; KAWABATA, T.; SHISHIDO, T.; MURAKAMI, K. OHI, T.; SHORO, D.; HONDA, M.; TAKAKI, K. Mechanism of reconstitution of hydrotalcite leading to eggshell-type Ni loading on Mg-Al mixed oxide. Journal of Catalysis, v. 231, p. 92104, 2005.

TOMISHIGE, K.; CHEN, Y.G.; FUJIMOTO, K. Studies on carbon deposition in CO2 reforming of $\mathrm{CH}_{4}$ over nickel-magnesia solid solution catalysts. Journal of Catalysis, v. 181, p. $91-103,1999$. 
TRIMM, D.L. Catalysts for the control of coking during steam reforming. Catalysis Today, v. 49, p. 3-10, 1999.

TSYGANOK, A.I; SUZUKI, K; HAMAKAWA, S; TAKERIRA, K; HAYAKAWA, T. MgAl layered double hydroxide intercalated with $\left[\mathrm{Ni}(\text { edta) }]^{-2}\right.$ chelate as a precursor for an efficient catalyst of methane reforming with carbon dioxide.- Catalysis Letters, v. 77, p. 75-86, 2001.

TSYGANOK, A.; SAYARI, A. Incorporation of transition metals into Mg-Al layered double hydroxides: Coprecipitation of cations vs. their pre-complexation with an anionic chelator. Journal of Solid State Chemistry, v. 179, p. 1830-1841, 2006.

TWIGG, M. V. Catalyst Handbook. 2.ed. London: Manson Publishing, 1996. 608p.

VACCARI, A. Preparation and catalytic properties of cationic and anionic clays. Catalysis Today, v. 41, p. 53-71, 1998.

VOGEL, A.I. Química analítica qualitativa. 5.ed. São Paulo: Mestre Jou, 1981. $665 p$.

VRÅLSTAD, T; GLOMM, W. R.; RØNNING,M.; DATHE, H.; JENTYS, A.; LERCHER, J.A.; ØYE, G.; STÖCKER, M.; SJÖBLOM J. Spectroscopic Characterization of Cobalt-Containing Mesoporous Materials. Journal of Physical Chemistry B, v. 110, p. 5386-5394, 2006.

WANG, H.Y.; RUCKENSTEIN, E. Partial Oxidation of Methane to Synthesis Gas over Alkaline Earth Metal Oxide Supported Cobalt Catalysts. Journal of Catalysis, v. 199, p. 309-317, 2001a.

WANG, H.Y.; RUCKENSTEIN, E. $\mathrm{CO}_{2}$ reforming of $\mathrm{CH}_{4}$ over $\mathrm{Co} / \mathrm{MgO}$ solid solution catalysts - effect of calcination temperature and Co loading. Applied Catalysis A: General, v .209, p. 207-215, 2001b.

WATTS, J.F. Microscopy Handbooks 22: An Introduction to surface analysis by electron spectroscopy. Oxford: Oxford Science Publications, 1990. 85p.

WEI, J.; IGLESIA, E. Isotopic and kinetic assessment of the mechanism of reactions of $\mathrm{CH}_{4}$ with $\mathrm{CO}_{2}$ or $\mathrm{H}_{2} \mathrm{O}$ to form synthesis gas and carbon on nickel catalysts. Journal of Catalysis, v. 224, p. 370-383, 2004a.

WEI, J.; IGLESIA, E. Structural requirements and reaction pathways in methane activation and chemical conversion catalyzed by rhodium. Journal of Catalysis, v. 225, p. 116-127, 2004b.

WEST A.R. Solid State Chemistry and its Applications. New York: John Wiley, 1984. 734p.

YAMAZAKI, O.; TOMISHIGE, K. and FUJIMOTO, K. Development of highly stable nickel catalyst for methane-steam reaction under low steam to carbon ratio. Applied Catalysis A: General, v. 136, p. 49-56, 1996. 
ZNAK, L.; STOLECKI, K.; ZIELINSKI, J. The effect of cerium, lanthanum and zirconium on nickel/alumina catalysts for the hydrogenation of carbon oxides. Catalysis Today, v. 101, p. 65-71, 2005.

ZHANG, X.; LEE, C. S.-M.; HAYWARD, D. O.; MINGOS, D. M. P. Oscillatory behaviour observed in the rate of oxidation of methane over metal catalysts.

Catalysis Today, v. 105, p. 283-294, 2005. 


\section{Apêndice A}

\section{Difração de Raios-X}

Cáculo parâmetros de rede:

Para o cálculo dos parâmetros de rede $a$ e $c$, da estrutura da hidrotalcita e parâmetro $c$ dos óxidos mistos, foram considerados os seguintes conceitos (GIACOVAZZO et al., 1992).

Tabela A1: Sistemas de cristalização, eixos e ângulos entre os eixos.

\begin{tabular}{|l|l|l|}
\hline Sistema de Cristalização & Eixos $^{*}$ & Ângulos entre os eixos \\
\hline Cúbico & $a=b=c$ & $\alpha=\beta=\gamma=90^{\circ}$ \\
\hline Tetragonal & $a=b \# c$ & $\alpha=\beta=\gamma=90^{\circ}$ \\
\hline Ortorrômbico & $a \# b \# c \# a$ & $\alpha=\beta=\gamma=90^{\circ}$ \\
\hline Hexagonal & $a=b \# c$ & $\alpha=\beta=90^{\circ} \gamma=120^{\circ}$ \\
\hline Romboédrico ou Trigonal & $a=b=c$ & $\alpha=\beta=\gamma \# 90^{\circ}$ \\
\hline Monoclínico & $a \# b \# c$ & $\alpha=\beta=90^{\circ} \gamma \# 90^{\circ}$ \\
\hline Triclínico & $a \# b \# c \# a$ & $\alpha \# \beta \# \gamma$ (todos \#90 $)$ \\
\hline
\end{tabular}

$a, b$ e $c$ : parâmetros de rede, ou seja, comprimento dos lados das células.

Tabela A2: Expressões algébricas de $d_{h}$ para vários sistemas cristalinos.

\begin{tabular}{|l|l|}
\hline Sistema & $1 / d^{2}{ }_{h k l}$ \\
\hline Cúbico & $\left(h^{2}+k^{2}+l^{2}\right) / a^{2}$ \\
\hline Tetragonal & $\left(h^{2}+k^{2}\right) / a^{2}+l^{2} / c^{2}$ \\
\hline Ortorrômbico & $h^{2} / a^{2}+k^{2} / b^{2}+l^{2} / c^{2}$ \\
\hline Hexagonal e Romboédrico & $4 / 3\left(h^{2}+k^{2}+k h\right) / a^{2}+l^{2} / c^{2}$ \\
\hline
\end{tabular}

\section{Estruturas}

A figura A1 apresenta um modelo da estrutura cúbica compacta, a qual pertence o $\mathrm{MgO}, \mathrm{NiO}$ e $\mathrm{CoO}$. A estrutura possui os íons de $\mathrm{O}^{-2}$ coordenados octaedricamente ao átomo metálico. 


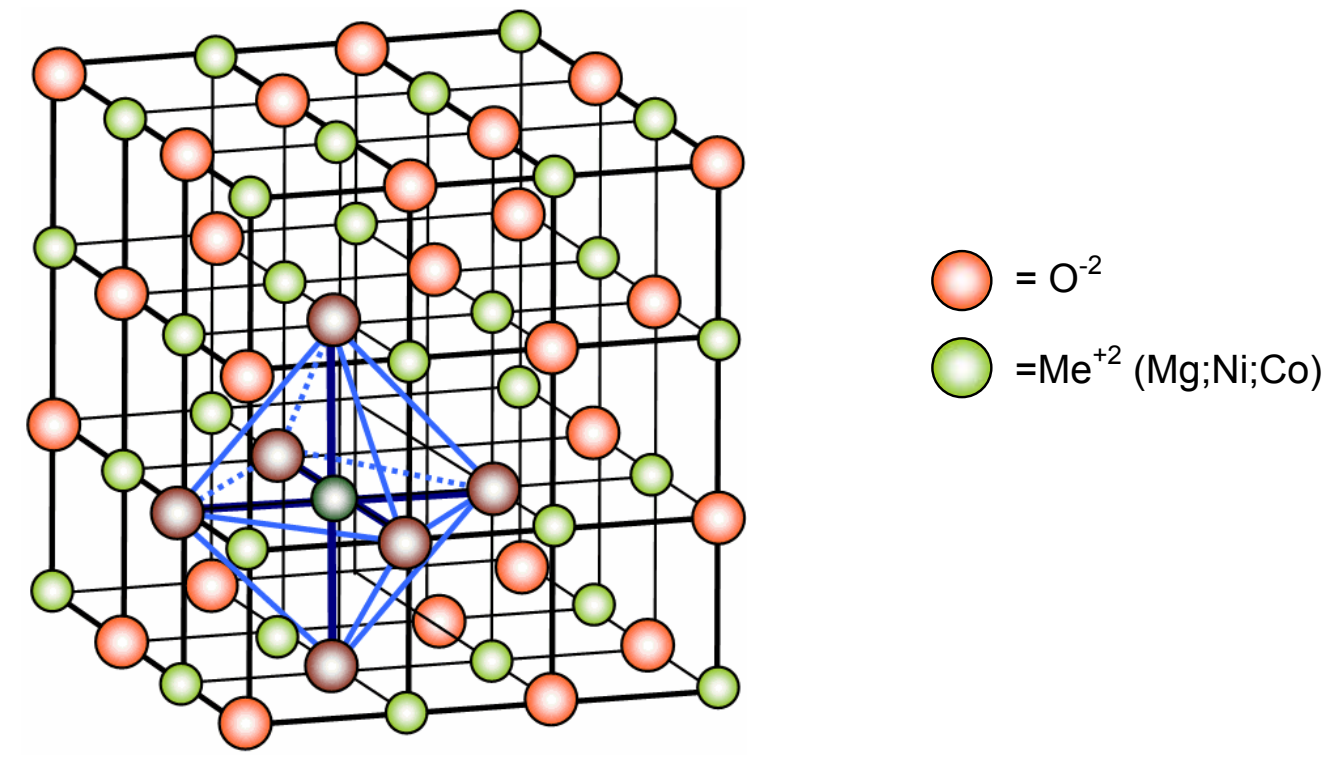

Figura A1. Estrutura cúbica compacta do MeO.

A figura A2 apresenta o modelo da estrutura do espinélio $\mathrm{MgAl}_{2} \mathrm{O}_{4}$. O termo espinélio é utilizado para indicar um considerável grupo de compostos com estrutura similar, tendo a fórmula geral $\mathrm{AB}_{2} \mathrm{X}_{4}$, sendo uma extensão ao grupo de nome espinélio $\mathrm{MgAl}_{2} \mathrm{O}_{4}$, que possui uma estrutura cúbica compacta levemente distorcida, onde o cátion marcado como $\mathrm{A}(\mathrm{Mg} ; \mathrm{Ni} ; \mathrm{Co})$ ocupa sítios tetraédricos enquanto que os B (Al) ocupam sítios octaédricos. 


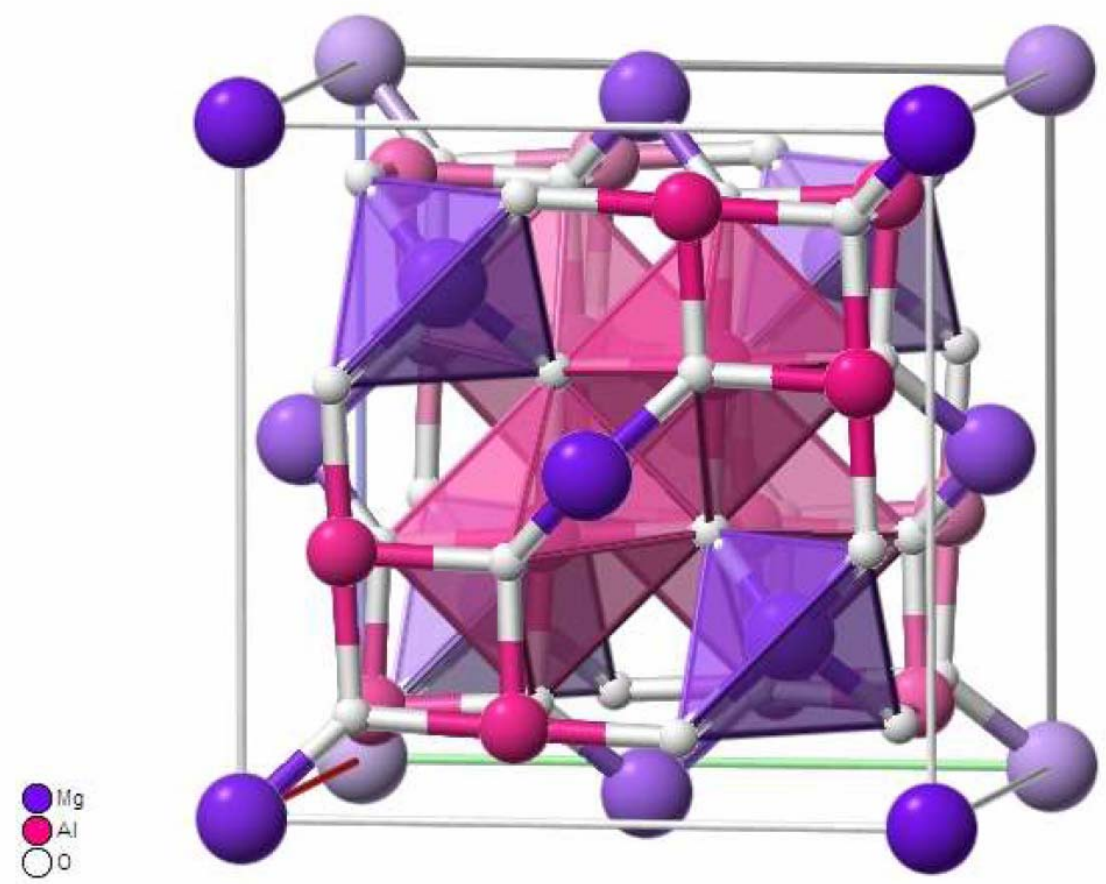

Figura A2. Estrutura do espinélio $\mathrm{MgAl}_{2} \mathrm{O}_{4}$.

Padrões de Raios- $X$

Difratogramas de Raios-X dos óxidos mistos sobrepostos com os padrões do JCPDS (1994).

\section{Catalisadores de Níquel}

Tabela A3 : Padrões do JCPDS* para os óxidos

\begin{tabular}{|c|c|c|c|c|c|}
\hline \multicolumn{2}{|c|}{$\mathrm{MgO}$} & \multicolumn{2}{c|}{$\mathrm{Al}_{2} \mathrm{O}_{3}$} & \multicolumn{2}{c|}{$\mathrm{NiO}$} \\
\hline $2 \theta$ & $(\mathrm{hkl})$ & $2 \theta$ & $(\mathrm{hkl})$ & $2 \theta$ & $(\mathrm{hkl})$ \\
\hline 36,95 & $(111)$ & 25,58 & $(012)$ & 37,28 & $(111)$ \\
\hline 42,91 & $(200)$ & 35,15 & $(104)$ & 43,30 & $(200)$ \\
\hline 62,31 & $(220)$ & 43,36 & $(113)$ & 62,92 & $(220)$ \\
\hline 74,68 & $(311)$ & 57,50 & $(116)$ & 75,44 & $(311)$ \\
\hline 78,61 & $(222)$ & 68,20 & $(300)$ & 79,39 & $(222)$ \\
\hline
\end{tabular}


Tabela A4: Padrão do JCPDS* para os espinélios

\begin{tabular}{|c|c|c|c|}
\hline \multicolumn{2}{|c|}{$\mathrm{MgAl}_{2} \mathrm{O}_{4}$} & \multicolumn{2}{c|}{$\mathrm{NiAl}_{2} \mathrm{O}_{4}$} \\
\hline $2 \theta$ & $(\mathrm{hkl})$ & $2 \theta$ & $(\mathrm{hkl})$ \\
\hline 31,27 & $(200)$ & 31,41 & $(200)$ \\
\hline 36,85 & $(311)$ & 37,01 & $(311)$ \\
\hline 44,83 & $(400)$ & 44,99 & $(400)$ \\
\hline 65,24 & $(440)$ & 65,53 & $(440)$ \\
\hline 59,24 & $(511)$ & 59,66 & $(511)$ \\
\hline
\end{tabular}

*(JCPDS, 1994)

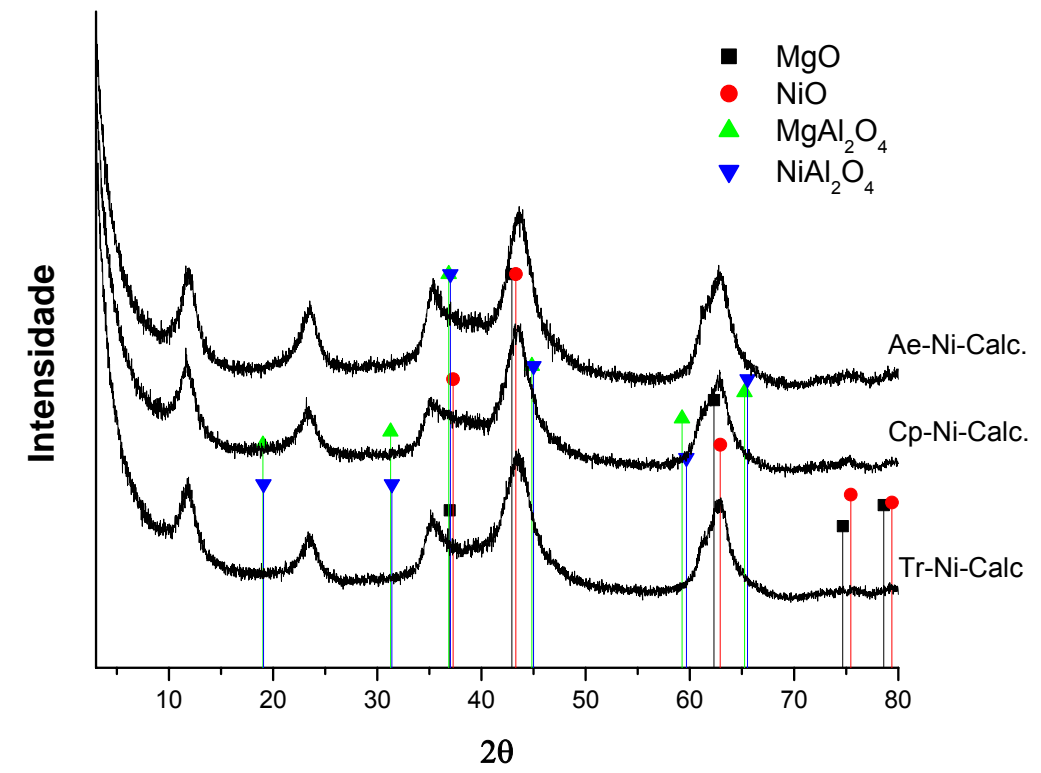

Figura A3: Difratogramas da misturas de óxidos sobrepostas com padrões do JCPDS. 


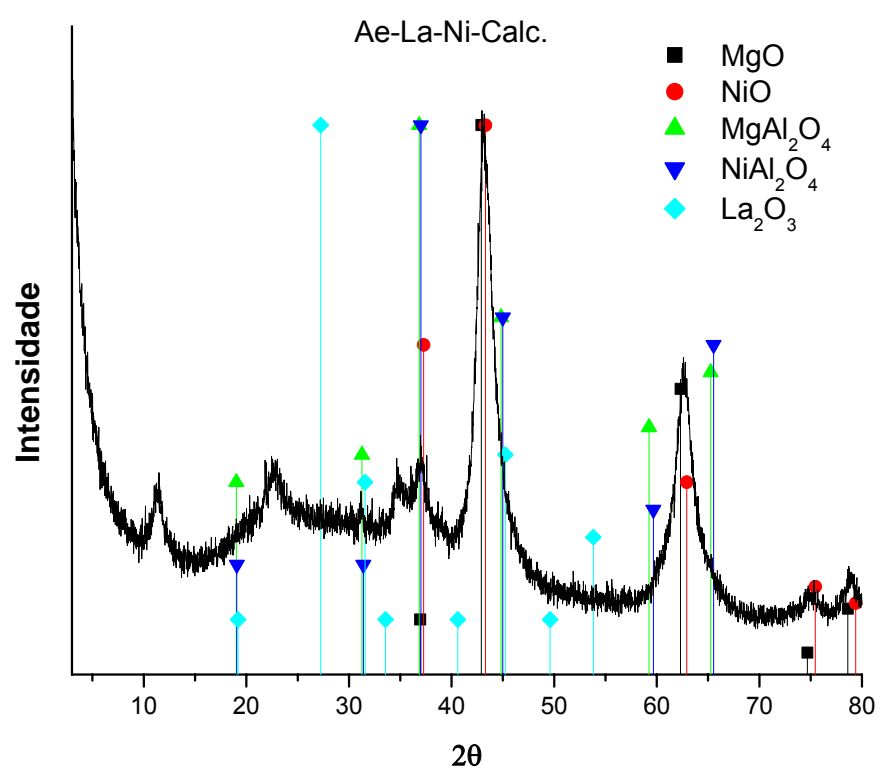

Figura A4: Difratogramas da mistura de óxido, promovida com lantânio, sobreposta com padrões do JCPDS.

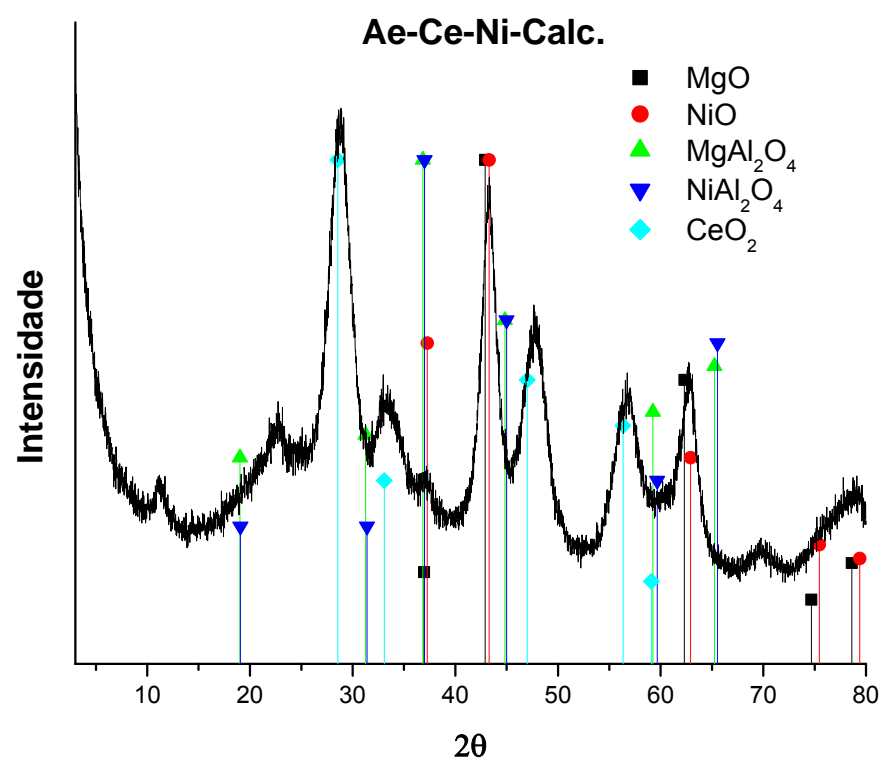

Figura A5: Difratogramas da mistura de óxido, promovida com cério, sobreposta com padrões do JCPDS. 


\section{Catalisadores de Cobalto}

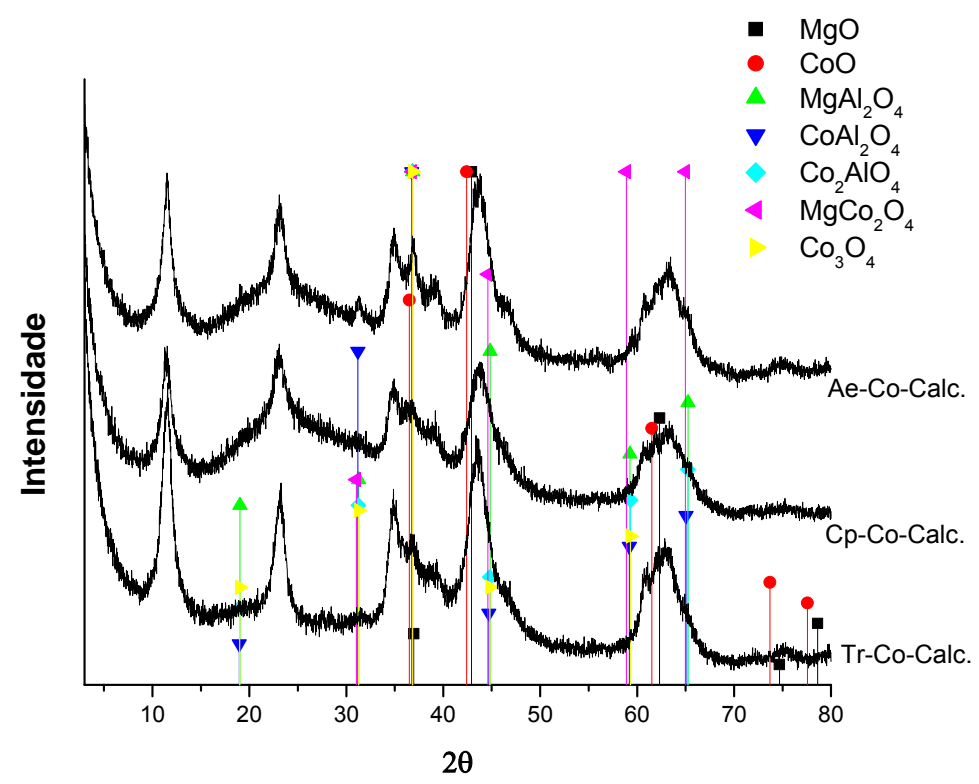

Figura A6: Difratogramas da misturas de óxidos sobrepostas com padrões do JCPDS.

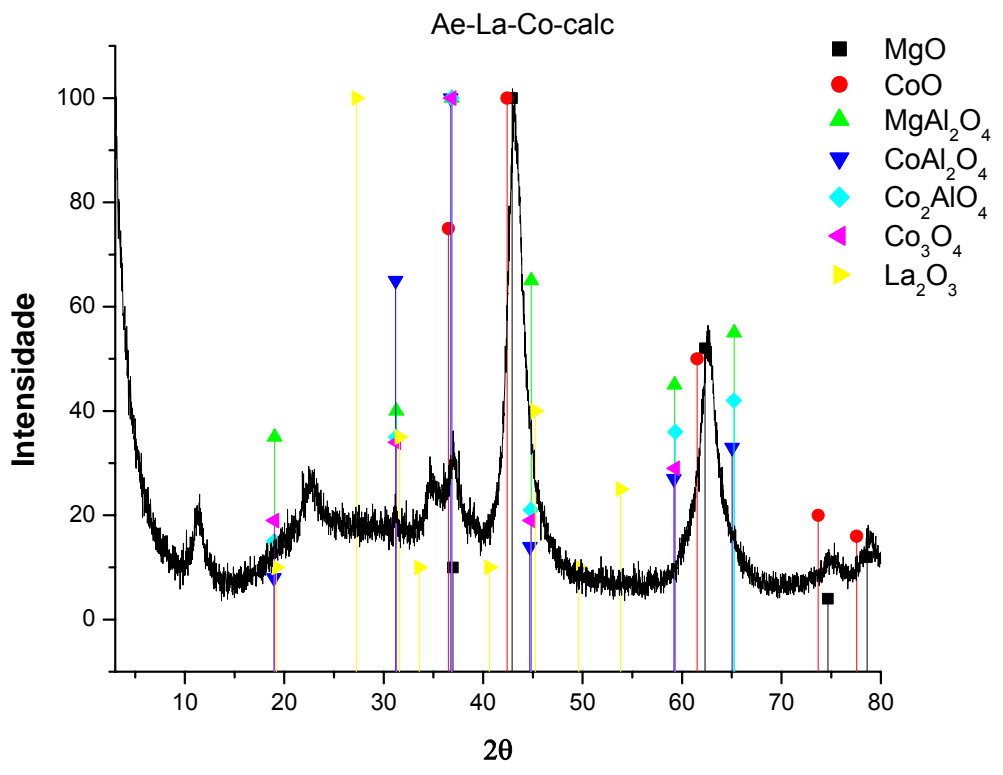

Figura A7: Difratogramas da mistura de óxido, promovida com lantânio, sobreposta com padrões do JCPDS. 


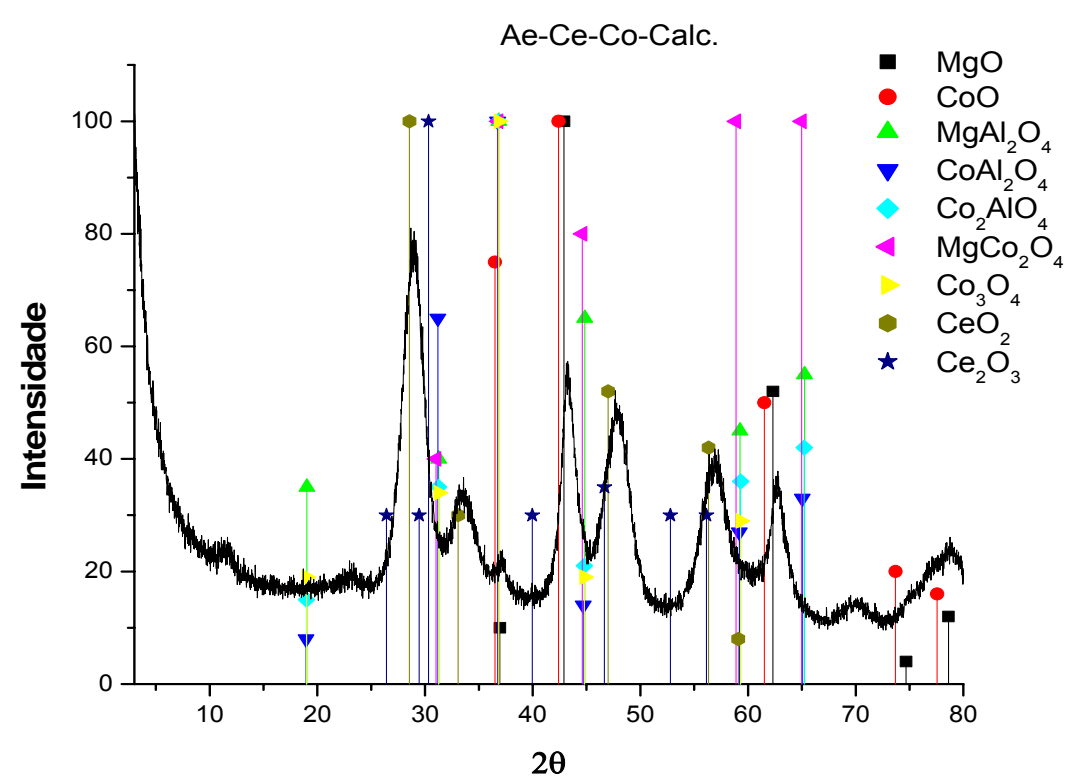

Figura A8: Difratogramas da mistura de óxido, promovida com cério, sobreposta com padrões do JCPDS.

Tabela A5 : Padrões do JCPDS para os óxidos e espinélios

\begin{tabular}{|c|r|r|r|r|r|r|r|}
\hline \multicolumn{2}{|c|}{$\mathrm{CoO}$} & \multicolumn{2}{c|}{$\mathrm{Co}_{3} \mathrm{O}_{4}$} & \multicolumn{2}{c|}{$\mathrm{CoAl}_{2} \mathrm{O}_{4}$} & \multicolumn{2}{c|}{$\mathrm{Co}_{2} \mathrm{AlO}_{4}$} \\
\hline $2 \theta$ & $(\mathrm{hkl})$ & $2 \theta$ & $(\mathrm{hkl})$ & $2 \theta$ & $(\mathrm{hkl})$ & $2 \theta$ & $(\mathrm{hkl})$ \\
\hline 36,49 & $(111)$ & 31,27 & $(220)$ & 31,19 & $(200)$ & 31,26 & $(200)$ \\
\hline 42,40 & $(200)$ & 36,85 & $(311)$ & 36,74 & $(311)$ & 36,82 & $(311)$ \\
\hline 61,52 & $(220)$ & 44,81 & $(400)$ & 44,69 & $(400)$ & 44,80 & $(400)$ \\
\hline 73,69 & $(311)$ & 59,30 & $(511)$ & 59,19 & $(511)$ & 59,31 & $(511)$ \\
\hline 77,56 & $(222)$ & 65,24 & $(440)$ & 65,04 & $(440)$ & 65,21 & $(440)$ \\
\hline
\end{tabular}

Tabela A6 : Padrões do JCPDS para os óxidos de lantânio e cério

\begin{tabular}{|c|c|c|c|c|c|}
\hline \multicolumn{2}{|c|}{$\mathrm{La}_{2} \mathrm{O}_{3}$} & \multicolumn{2}{c|}{$\mathrm{CeO}_{2}$} & \multicolumn{2}{c|}{$\mathrm{Ce}_{2} \mathrm{O}_{3}$} \\
\hline $2 \theta$ & $(\mathrm{hkl})$ & $2 \theta$ & $(\mathrm{hkl})$ & $2 \theta$ & $(\mathrm{hkl})$ \\
\hline 27,25 & $(222)$ & 28,55 & $(111)$ & 26,43 & $(100)$ \\
\hline 31,57 & $(400)$ & 33,08 & $(200)$ & 29,46 & $(002)$ \\
\hline 33,56 & $(411)$ & 47,01 & $(220)$ & 30,33 & $(101)$ \\
\hline 40,60 & $(431)$ & 56,33 & $(311)$ & 39,97 & $(102)$ \\
\hline 45,23 & $(440)$ & 59,09 & $(222)$ & 46,66 & $(110)$ \\
\hline 49,61 & $(611)$ & - & - & 52,78 & $(103)$ \\
\hline 53,82 & $(622)$ & - & - & 56,14 & $(112)$ \\
\hline
\end{tabular}


Difratogramas do catalisador Ae-La-Ni após 6 horas de OPM sobreposto com padrões do JCPDS (1994).

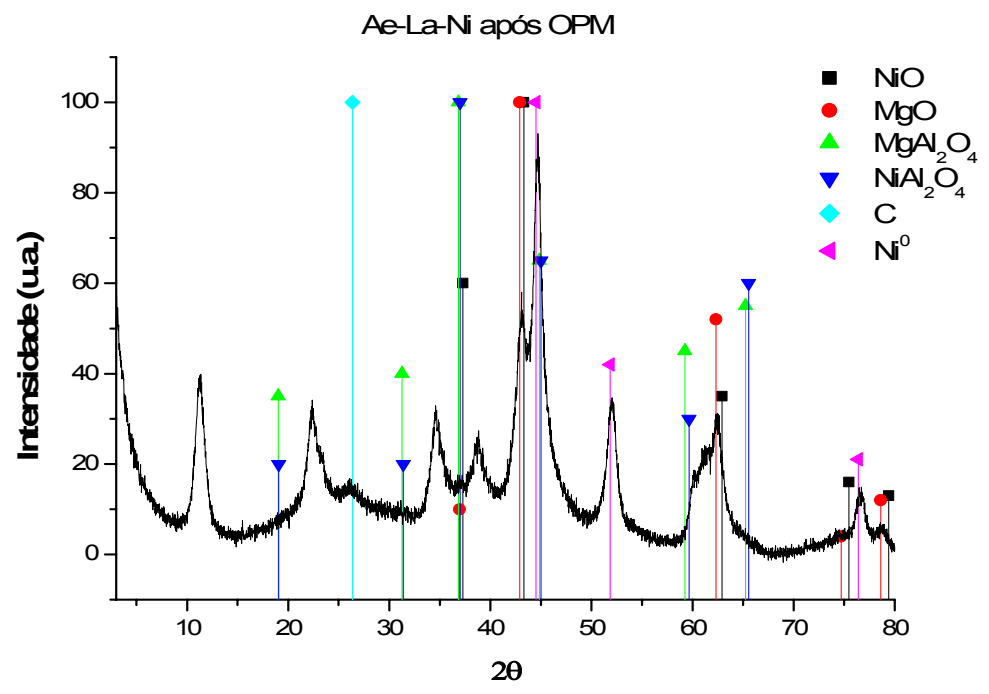

Figura A9: Difratograma do catalisador Ae-LaNi após 6 horas de reação de oxidação parcial do metano, sobreposto com padrões do JCPDS.

Tabela A7 : Padrões do JCPDS* para o níquel metálico e carbono (grafite).

\begin{tabular}{|c|c|r|r|}
\hline \multicolumn{2}{|c|}{$\mathrm{Ni}^{0}$} & \multicolumn{2}{c|}{ C (grafite) } \\
\hline $2 \theta$ & $(\mathrm{hkl})$ & $2 \theta$ & $(\mathrm{hkl})$ \\
\hline 44,51 & $(111)$ & 26,60 & $(002)$ \\
\hline 51,84 & $(200)$ & 42,21 & $(100)$ \\
\hline 76,37 & $(220)$ & 44,39 & $(101)$ \\
\hline
\end{tabular}




\section{Apêndice $B$}

\section{Cálculo da redutibilidade dos catalisadores por RTP.}

Para o cálculo da redutibilidade dos catalisadores foi considerado a seguinte equação para o consumo de $\mathrm{H}_{2}$ com base no padrão de $\mathrm{CuO}$.

Análise com fator 1 :

Área de $5125=2,137 \times 10^{-5} \mathrm{~mol}$ de $\mathrm{H}_{2}$

Análise com fator 10:

Área de $46506=1,63 \times 10^{-5} \mathrm{~mol}$ de $\mathrm{H}_{2}$

Os cálculos foram feitos utilizando a composição elementar de bulk obtida por EDX e $\mathrm{O}_{2}$ estequiométrico.

\section{- Catalisadores de níquel}

$\operatorname{Tr}-\mathrm{Ni}_{1} \mathrm{Mg}_{9} \mathrm{Al}_{3,6} \mathrm{O}_{15,4}$

$\mathrm{Cp}-\mathrm{Ni}_{1} \mathrm{Mg}_{10} \mathrm{Al}_{3,5} \mathrm{O}_{16,2}$

$\mathrm{Ae}-\mathrm{Ni}_{1} \mathrm{Mg}_{12,5} \mathrm{Al}_{4,2} \mathrm{O}_{19,9}$

$\mathrm{Ae}-\mathrm{La}_{0,1} \mathrm{Ni}_{1} \mathrm{Mg}_{9,1} \mathrm{Al}_{1,8} \mathrm{O}_{12,9}$

$\mathrm{Ae}-\mathrm{Ce}_{0,2} \mathrm{Ni}_{1} \mathrm{Mg}_{10} \mathrm{Al}_{2,3} \mathrm{O}_{14,8}$

\section{- Catalisadores de cobalto}

Tr- $\mathrm{Co}_{1} \mathrm{Mg}_{10} \mathrm{Al}_{4} \mathrm{O}_{17}$

$\mathrm{Cp}-\mathrm{Co}_{1} \mathrm{Mg}_{7,7} \mathrm{Al}_{3,1} \mathrm{O}_{13,3}$

$\mathrm{Ae}-\mathrm{Co}_{1} \mathrm{Mg}_{7,7} \mathrm{Al}_{3,1} \mathrm{O}_{13,3}$

Ae-La ${ }_{0,1} \mathrm{Co}_{1} \mathrm{Mg}_{9,1} \mathrm{Al}_{1,5} \mathrm{O}_{12,5}$

$\mathrm{Ae}-\mathrm{Ce}_{0,3} \mathrm{Co}_{1} \mathrm{Mg}_{9,1} \mathrm{Al}_{1,5} \mathrm{O}_{12,9}$ 